Portland State University

PDXScholar

$1-1-1974$

\title{
Strategies and the management of a portfolio of business units
}

Donald Leland Pope

Portland State University

Follow this and additional works at: https://pdxscholar.library.pdx.edu/open_access_etds Let us know how access to this document benefits you.

Recommended Citation

Pope, Donald Leland, "Strategies and the management of a portfolio of business units" (1974).

Dissertations and Theses. Paper 566.

https://doi.org/10.15760/etd.566

This Dissertation is brought to you for free and open access. It has been accepted for inclusion in Dissertations and Theses by an authorized administrator of PDXScholar. Please contact us if we can make this document more accessible: pdxscholar@pdx.edu. 
STRATEGIES AND THE MANAGEMENT

OF A PORTFOLIO OF BUSINESS UNITS

by

DONALD LELAND POPE

A thesis submitted in partial fulfillment of the requirements for the degree of

\author{
DOCTOR OF PHILOSOPHY \\ in \\ SYSTEMS SCIENCE
}

Portland State University

1974

Reproduced with permission of the copyright owner. Further reproduction prohibited without permission. 
TO THE OFFICE OF GRADUATE STUDIES AND RESEARCH:

The members of the Committee approve the thesis of

Donald Leland Pope presented August 5, 1974.

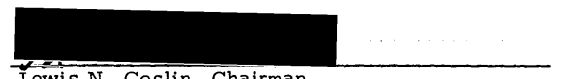

Lewis N. Goslin, Chairman

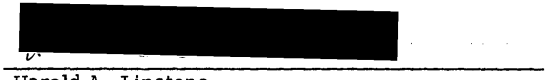

Harold A. Linstone
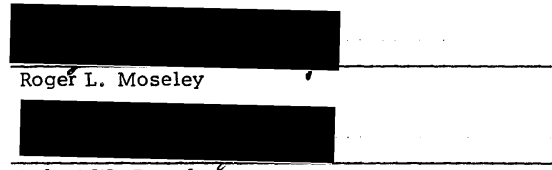

Robert W. Rempfer

APPROVED:

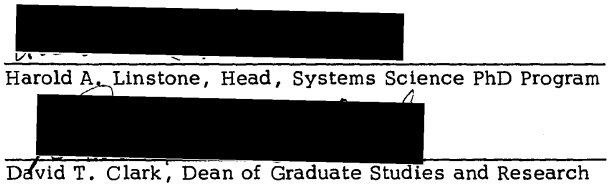

August 5, 1974

Reproduced with permission of the copyright owner. Further reproduction prohibited without permission. 
AN ABSTRACT OF THE THESIS OF Donald Leland Pope for the Doctor of Philosophy in Systems Science presented August 5, 1974.

Title: Strategies and the Management of a Portfolio of Business Units.

APPROVED BY MEMBERS OF THE THESIS COMMITTEE:

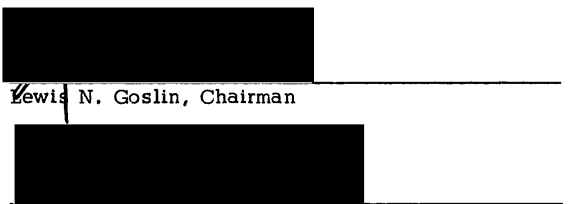

Harold A. Linstone

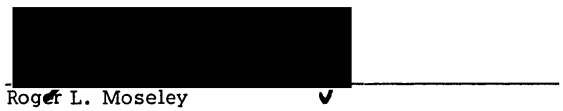

Robert W. Rempfer'/

The dissertation deals with the allocation of resources, among profit producing elements within a company, to achieve satisfactory results over a planning horizon. The company is viewed as a confederation of profit making elements called Strategic Business Units (SBU) which are independent of each other and held together by a central authority. The dissertation uses a computerized simulation model of the deterministic type in a time- 
sharing mode. The model is deterministic with some limited probabilistic effects. It is used to develop projected balance sheets and profit and loss statements for each period in a predetermined planning horizon and to evaluate the success of a set of alternative futures of the SBU. The set of SBU alternatives to be evaluated as the "company" may be arbitrarily chosen by the operator or chosen through the use of a near-optimal, integer programming algorithm for a variety of measurement criteria and subject to various restraints on the balance sheet.

The research uses data generated by the long-range planning process at an intermediate sized, multinational corporation listed on the New York Stock Exchange. The data consist of assets, liabilities, and profit and loss statement items for each period in a planning horizon and for each of three alternatives of each SBU in the study. In addition, a beginning corporate balance sheet is required as are planned corporate expense items and the specification of operating restrictions.

Research into the effect of several strategic policies, including dividend rate and debt to equity ratio, on the future prospects of the company in accordance with the optimal value of five different measurement criteria, is reported. The five measurement criteria are present value of shareholder equity, growth in earnings per share, growth in total assets, total assets and growth in sales.

The appendix material contains listings of computer programs used in the model (written in the Basic computer language), the research data 
used, numerous computer printouts, and technical discussions on the model.

Several tentative conclusions are listed, many areas for further research are suggested, and strengths and constraints of the model are discussed. It is concluded that the techniques developed have good potential for increasing cash generation and the efficiency of the investment process in a company; the dividend rate has a significant effect on how fast a company can grow; and the model is flexible and can be used for a number of investigative purposes to support company decision-makers . An interesting area for further research is the tentative conclusion that return on assets, when used as an optimization criterion, produces a significantly different set of SBU alternatives from the one which results from using the other measurement criteria.

Reproduced with permission of the copyright owner. Further reproduction prohibited without permission. 


\section{PREFACE}

This preface presents an overview of the research, the concept of Strategic Business Units (SBU), the methodology employed and the organization of the dissertation.

\section{$\underline{\text { Research }}$}

This dissertation deals with the allocation of resources among profit producing elements, within a business enterprise, to achieve satisfactory results over a planning horizon. There is a great deal of material generally available on the subject, and it is very broad; however, the methods which are developed in the dissertation were chosen for use in a specifi: business enterprise. In particular, the company is viewed as a confederation of profit-making elements (SBU) which are independent of each other and held together by the power exercised over them by a central authority.

The central authority has a decision-making responsibility and the job of orchestrating the combined efforts of the profit-making elements toward a specified goal. In other words, the management of a company has the responsibility for administering the whole company to achieve a result desired by their "stakeholders". In most multi-divisional companies, as well as many others, this is a complicated task. Certain mechanical techniques can be used, however, to gain insight into the results of 
management actions or, alternately, clues can be discovered as to which management actions should be considered, using mechanical aids. The dissertation is an investigation of one such resource allocation approach to aiding management planning and evaluation of the enterprise.

\section{Strategic Business Units (SBU)}

In the dissertation the profit-making elements of the company are called SBU, and a typical, large company can be thought of as being composed of 15 to $40 \mathrm{SBU}$, plus a central decision-making body. During the planning phase of the company's year, several alternative plans (market share options), represented by profit and loss statements and abbreviated balance sheets, are produced for each SBU. The result is a wealth of information composed by planners in each SBU, working in consort with their operating people and central management. Using the planning data and the power of a modern high speed computer to manipulate such specific data, the central decision-making group can greatly enhance their ability to forecast, evaluate, and choose excellent coursesof action.

In examining the dissertatior, it will become apparent a vast amount of data is involved, but it should also be noted in a company using longrange planning, this data is generated by that process and need only be organized to be used in the procedures discussed.

The problem of this dissertation is difficult enough because of the many combinations of alternatives to be investigated, but it is inherently more difficult because SBU must be considered as whole entities. In

Reproduced with permission of the copyright owner. Further reproduction prohibited without permission. 
other words, a planner/decision-maker cannot choose to use only a fraction of an SBU in his desired company makeup. However, the work presented here provides a method for how excellent combinations of alternatives can be chosen in spite of the integer nature of the problem.

Methodology

It also should be noted the methods used are designed for investigation using a computer terminal so results are immediately available to the planning analyst and decision-makers. A computer simulation model was developed using a corporate balance sheet as the key scorekeeping device, and the model was structured so as to either select a quasi-optimal set of SBU or simply to evaluate the prospects of an operator selected set. The selection of the near-optimum (qua si-optimum) set of SBU is an integer programming problem, and an algorithm for the solution of this problem was devised as part of the interactive model.

The simulation is of the deterministic (evaluation) type, as compared to the probabilistic type, and as such each run is the complete evaluation of one set of SBU options, unless the model is being used in the optimal mode. If it is, several iterations may be required before a satisfactory set of options is found.

Six strategic policies were evaluated using the model which were: 1) the dividend policy, 2) the debt to equity ratio policy, 3) the policy on pricing to obtain market share, 4) the effect of a growth, stability, or Iiquidation poiicy, 5) the policy of limiting SBU assets, and 6) a policy 
of acquiring SBU with specific characteristics. These policies were investigated relative to the present value of the shareholder equity as a measurement criterion.

Five measurement criteria were used for evaluation, they were:

1) the present value of shareholder equity, 2) growth in earnings per share, 3) growth in total assets, 4) total assets, and 5) growth in sales.

The research was performed by running the model, with a number of assumed values, and analyzing the results by comparing how the several measures reacted. Although much of the analysis was done by analyzing the independent effects of the policies, the joint effect of the dividend policy and the debt to equity policy was investigated by "mapping" the measurement criteria over a suitable region of interest.

The simulation is restricted by a number of criteria some of which could also be used to carry out investigations into the effects of policies. Some of these are 1) the discount factor used to state future dollar amounts in present values, 2) the minimum acceptable ratio between current assets and current liabilities, 3) the minimum amount of cash as a fraction of other assets, 4) the interest rate on borrowed money, 5) forecasted return on surplus cash which is invested, 6) the maximum acceptable dilution from equity sales and 7) the price at which new equity can be raised.

It was the :nitial intent of the research to explore the effects which occur when a probability distribution is associated with the contribution of each SBU market share opti on as well as with the market share each

Reproduced with permission of the copyright owner. Further reproduction prohibited without permission. 
option achieved. However, as the work progressed it became apparent the computer program for the non-probability case would reach the maximum acceptable size for the computer, and the time to execute an evaluation of a given set of SBU was at least five minutes of "terminal-connect" time. Thus it was determined to carry out a reduced effort in the probability case, but one which would provide a base for further research. To do this, probability distributions were associated with SBU assets, liabilities and profits and the model was used to generate probable outcomes of cash flow and profit for a given set of SBU.

\section{Organization}

The examination of this research effort is contained in five chapters and four appendices. Chapter I discusses some aspects of business strategy related to the allocation of resources to large segments of a corporation and mentions some of the concepts for measuring success. Chapter II discusses the research approach in detail, including the simulation modei, and the five different optimization criteria, and the policy questions which were investigated.

Chapter III discusses validation of the model and the specific data used in the investigation. As pointed out earlier, the model is of the evaluation type and as a result it has heen easter to validate, but to do this both test data and real data were used. Sensitivity of the model to input errors and initial conditions is also mentioned.

Reproduced with permission of the copyright owner. Further reproduction prohibited without permission. 
Chapter IV discusses the results using the model and contains a number of tables which compare various output results. Chapter V contains the summary and conclusions of the research along with the advantages and disadvantages of the model. A section on suppositions, which contains a number of indicative results which need further investigation, is also included in Chapter $\mathrm{V}$ as is a subsection on other investigations which could prove to be interesting and of value.

Appendix A contains the detail techniques for capturing the input data, the application of restrictions, and the computer techniques for finding the quasi-optimal solution to the integer programming problem. Appendix B contains a listing of the principal computer programs used in the research.

Appendix $\mathrm{C}$ is a collection of specific run results along with information on interpreting the computer printouts. Appendix D is a collection of the data which was used as input to the research.

I gratefully acknowledge the help of Professors L.N. Goslin, H.A. Linstone, R. L. Moseley, and R. W. Rempfer, for their encouragement over the extended period of academic preparation, research, and composition of this document.

The author is also greatly indebted to Omark Industries for its support and to Mrs. Marguerite Wunder for many hours of dedication and hard work in typing and retyping the manuscript.

I am particularly grateful to my wife, Jane, and to my children, Dan, Scott, and Tim for their forbearance, support, and encouragement without which this work could never have been completed.

Donald L. Pope

Reproduced with permission of the copyright owner. Further reproduction prohibited without permission. 


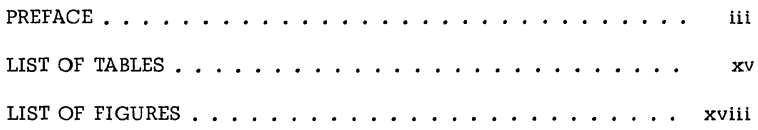

CHAPTER

I BUSINESS STRATEGY . . . . . . . . . . 1

Overview.................... 1

The Problem ................ 1

strategy ................... 2

Strategic Problems Facing a Large Corporation Corporate Planning

The Concept of Strategic Business Units

The Criteria for Defining an SBU

Some of the Difficulties in Using SBU

Concepts for Measuring Success .......

The Generation of Cash

The Present Value of Shareholder Equity

Growth in Earnings Per Share

Total Assets and Growth in Total Assets

Growth in Sales

Other Mea sures of Success

Managing a Portfolio of Strategic Business Units

Relationship Between Growth and Cash

Other Factors which Influence Growth

Summary . . . . . . . . . . .

Reproduced with permission of the copyright owner. Further reproduction prohibited without permission. 
Objective of the Research ..........

The Simulation Model ...........

The Calculation Section of the Model

The Corporation Balance Sheet

Input to the Simulation

Restrictions

The Output of the Simulation

The Optimization Routine

The Computer

The Research Program ...........

The Dividend Policy

The Debt to Equity Ratio Policy

The Pollicy on Pricing to Obtain Market Share

Effect of Managing the SBU for Growth, Stability, Liquidation

The Effect of Limiting SBU Assets

The Effect of Acquiring SBU with Specific

Characteristics

Joint Effects

Probabilistic Assumptions ..........

The Research

The Mean and Variance

The Total Probabilistic Program

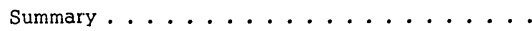

Class of Model .............. 50

Reproduced with permission of the copyright owner. Further reproduction prohibited without permission. 


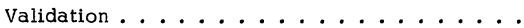

Computational Validation

Validation of Assumptions

Description of the Set of SBU ........ 55

Results of the Model Using the Base Case . . . 58

Run Time

Results

Validation

Sensitivity ..................... 60

Initial Conditions

Errors in Input

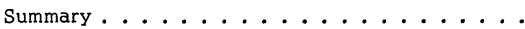

IV DISCUSSION OF RESULTS . . . . . . . . . . 64

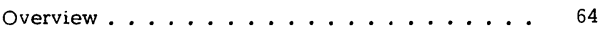

The Cases Examined .......... 65

The Dividend Policy. .......... 69

The Debt to Equity Ratio Policy ......... 71

The Policy on Pricing to Obtain Market Share . . 74

The Effect of Managing for Growth, Stability or

Liquidation ............ 74

The Effect of Limiting SBU Assets . . . . . . 77

The Effect of Acquiring SBU with Specific

Characteristics......... 80

A Consideration of Joint Effects ........ 81

Reproduced with permission of the copyright owner. Further reproduction prohibited without permission. 
CHAPTER

PAGE

The Probabilistic Case ......... 86

Results for Assigned Three-Point Probability Distributions

Results for Randomly Assigned Three-Point Probability Distributions

Results for a Reduced Set of SBU Options

Other Results ..............

Comparison of Measurement Criteria

The Present Value of Shareholder Equity/Assets Employed

The Company-Selected Set of SBU

Results with Restricted Optima . . . . . . 97

Summary ................... 100

V SUMMARY AND CONCLUSIONS ......... 101

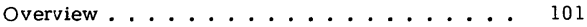

Advantages and Constraints ......... 102

Advantages of the Model

Constraints in the Model and Approach

Suppositions and Other Investigations . . . 106

Suppositions

Other Investigations of Interest

Conclusions ........................ 110

Summary ........................... 113

A SELECTED BIBLIOGRAPHY ................ 114

Reproduced with permission of the copyright owner. Further reproduction prohibited without permission. 
A SUPPLEMENTARY MATERIAL TO CHAPTER II . . . . . 117

Overview ......................... 117

Input Data ..................... 117

SBU Profit and Loss Statement

SBU Assets and Liabilities

Abbreviated Corporation Profit and Loss Statement

Corporate Balance Sheet

Corporate Operating Criteria

Balance Sheet During Simulation ....... 127

The Measurement Criteria and Optimization . . . 129

Case I Present Value of Shareholder Equity

Case II Growth in Earnings Per Share

Case III Growth in Total Assets

Case IV Total Assets

Case V Growth in Sales

B COMPUTER PROGRAMS ............ 141

List of Computer Programs Found in Appendix B . . 141

Discussion ....................... 141

Program ER2

Program ER6

Program ERP

Program PR3

Program PR4

Program PR6

Program PR9

C COLLECTION OF SPECIFIC RUN RESULTS . . . . 161

List of Computer Runs Found in Appendix C . . . 161

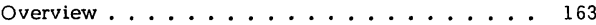

Reproduced with permission of the copyright owner. Further reproduction prohibited without permission. 
Discussion .............

Computer Runs for the Investigation of Joint

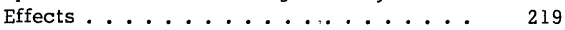

Computer Runs for Probability Investigation . . . 240

Computer Run for Restricted Optima . . . . . 244

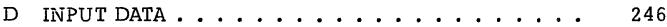

List of Tables Found in Appendix D . . . . . 246

Discussion..................... 246 
LIST OF TABLES

TABLE

PAGE

I The Set of SBU Used in the Research ........... 56

II Continuation of Table I $\ldots \ldots \ldots \ldots \ldots \ldots \ldots \ldots \ldots \ldots \ldots$

III Optimum Values of the Mea surement Criteria as Influenced by the Dividend Policy $\ldots \ldots \ldots \ldots \ldots \ldots \ldots \ldots \ldots \ldots$

IV Optimum Values of the Measurement Criteria as Influenced by the Debt to Equity Ratio............... 72

$\mathrm{V}$ Comparison of Mea surement Criteria for a Wide Range of Market Share Penetration................ 75

VI Comparison of Key Operating Criteria for a Wide Range of Market Share Penetration ................ 76

VII Comparison of Mea surement Criteria for a Wide Range of Market Share Penetration .............. 78

VIII Comparison of Key Operating Criteria for a Wide Range of Market Share Penetration .............. 79

IX Comparison of Key Operating Results when an SBU with Specific Characteristics is Acquired...........

$\mathrm{X}$ The Present Value of Shareholders Equity Corresponding to Joint Values of Debt to Equity Ratio and Dividend

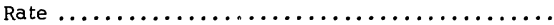

XI Research Results of the Probability Investigation Using Twenty Âssigned Tinree-Point Probability Distributions. 88

Reproduced with permission of the copyright owner. Further reproduction prohibited without permission. 
XII Research Results of the Probability Investigation Using

Randomly Generated Numbers to Choose One of

Twenty Three-Point Probability Distributions ....

XIII Research Results of the Probability Investigation with

SBU Number 18 Liquidated in Year One of the Study

and with Assigned Three Point Probability Distri-

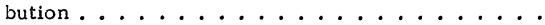

XIV Comparison of Measurement Criteria in the Analysis of

Dividend Poli cy .............

XV Comparison of Key Operating Results for Two Widely

Varying Measurement Criteria ..........

XVI Comparison of Key Operating Results for the Company

Selected Case and an Optimal Case .......

XVII The Amount by which the Present Value of Shareholder

Equity will be Reduced if a Given SBU is Liquidated

XVIII Summary of Computer Runs ............. 164

XIX Continuation of Table XVIII ........... 165

XX Summary of Computer Runs in Joint Effects Study . . . . 166

XXI The Market Share Options which are in the Optimum Set

for Each Case........................... 170

XXII Corporate Balance Sheet Data . . . . . . . . . 247

XXIII SBU Profit and Loss Data , , , , . . . . . . . 248

Reproduced with permission of the copyright owner. Further reproduction prohibited without permission. 
XXIV SBU Assets and Liabilities Data . . . . . . . . . 254

XXV Corporate Profit and Loss Data . . . ..... 260

XXVI Corporate Specifications Data .......... 261

XXVII Arbitrarily Assumed Three-Point Probability Distributions

Used with the Probabilistic Investigations . . . . 262

Reproduced with permission of the copyright owner. Further reproduction prohibited without permission. 


\section{LIST OF FIGURES}

\section{FIGURE}

1 Criteria for Defining an SBU as a Separate Entity ....... 10

2 The Relation of Cash Flows between Corporate and the

Strategic Business Units ............... 17

3 The Cash Flows within a Strategic Business Unit ....... 18

4 Section I of Model $\ldots \ldots \ldots \ldots \ldots \ldots \ldots \ldots \ldots \ldots \ldots \ldots \ldots \ldots \ldots$

5 Section II of Model $\ldots \ldots \ldots \ldots \ldots \ldots \ldots \ldots \ldots \ldots \ldots \ldots \ldots \ldots$

6 Simplified Corporation Balance Sheet ............. 34

7 Policies and Measurements Investigated in the Research ... 68

8 The Present Value of Shareholders Equity as a Function of the Debt to Equity Ratio and Dividend Rate....... 85

9 Data Input Sheet SBU Profit and Loss Statement ....... $\quad 119$

10 Data Input Sheet Abbreviated Corporation Profit and Loss

Statement ............................ 121

11 Data Input Sheet SBU Assets and Liabilities ......... 122

12 Data Input Sheet Corporate Balance Sheet ............ 124

13 Data Input Sheet Corporate Specifications ........... 126

14 Guide to Layout of Balance Sheet Printouts .......... 167

15 Guide to Layout of Probability Run Printouts .......... 169

Reproduced with permission of the copyright owner. Further reproduction prohibited without permission. 
CHAPTER I

\section{BUSINESS STRATEGY}

\section{OVERVIEW}

This chapter discusses the general nature of business strategy as a base for developing the specific research problems of the dissertation. The principal problem under investigation has to do with the allocation of company resources to large operating segments of the company in such a way as to satisfactorily achieve company objectives. The concept of Strategic Business Units (SBU) is introduced as a structure and as the set of decision variables to be used for the allocation of resources .

Concepts for measuring success are discussed, and the paiticular importance of generating sufficient cash is examined as is the role cash generation plays in limiting the growth rate of a business. The concept of managing the set of SBU which constitute a company, as an investment portfolio, is discussed.

\section{THE PROBLEM}

The principal problem is the allocation of company resources (cash) to large operating segments of the company in such a way as to satis-

Reproduced with permission of the copyright owner. Further reproduction prohibited without permission. 
factorily achieve company objectives. This dissertation is also concerned with a discussion of some of the strategic problems facing the firm, some of the measurements of success, some techniques for choosing strategies, an examination of the concept of Strategic Business Units (SBU) introduced by the Boston Consulting Group (BCG) (5), and some techniques for managing by SBU. The research deals to a large extent with systematic techniques for selecting those SBU which meet selected criteria and a discussion of the implications of doing so. Thus, this work deals with an area of strategic business planning and brings some of the techniques and tools of system analysis including a computerized simulation model to bear on the problems.

The typical firm must manage many resources and is faced with the generation and investment of large amounts of cash each year. Because the techniques explored in this paper have the potential for significantly increasing the effectiveness of the cash generation and investment process, it is believed to be of substantial value.

\section{STRATEGY}

The large business corporation today is a complex system of interconnected parts which is managed to achieve a complex set of interrelated goals. The management discipline frequently described for handling the long range portion of this task is variously named Long Range Planning, Strategic Planning, Corporate Planning, Top Management Plan-

Reproduced with permission of the copyright owner. Further reproduction prohibited without permission. 
ning, Corporate Strategy, and Business Strategy $(1,2,5,7,15,37)$. Authors writing under these titles cover many of the same subjects, and the name ascribed to the process seems to be more one of personal taste than close definition.

During the late 1950's and early 1960's, comprehensive (or longrange planning) expanded rapidly (15). This rapid expansion seems to have been in response to the recognition that strategic planning can provide a very important advantage to the company that employs it successfully. Steiner (15)' states:

One of the great advantages of such planning is that it simulates the future - on paper. If the simulation does not result in the desired picture, the exercise can be erased and started all over again --- planning prepares a business to cope better with the environmental changes of the future.

Cannon (7) points out that, "Business strategles are not the ends, but rather the means of initiating the actions needed to achieve the ends or purposes of the company". For these reasons it is important to understand how the various strategies and resulting plans employed by a company affect its long-run prospects.

Many of the problems facing a corporation are not strategic in nature, and a good definition of what is strategic and what is non-strategic (or tactical, or operational) is required. Steiner makes a good case that plans should be integrated with operations and plans are more effective when this is done (15, pp 132-136). On a continuum strategic planning is at one end and tactics or operations are at the other. Steiner gives

Reproduced with permission of the copyright owner. Further reproduction prohibited without permission. 
fifteen characteristics for differentiating between strategies and tactical planning showing the complexity of the subject. (15, pp 37-38). In a simplistic sense, tactical planning is the detalled deployment of resources to achieve the strategic plans. Ackoff states "The more functions of an organization's activities that are affected by a plan, the more strategic it is". (1)

\section{Strategic Problems Facing a Large Corporation}

The modern business corporation, where the techniques discussed in this paper will be of most value, is complex in the sense of dealing in many products and frequently across many national borders. Most, if not all, will be classified as multinational, although being multinational is not in itself a requirement for using these techniques. Rather it is complexity, and most particularly, complexity in the number and outcomes of investment opportunities, facing the corporate decision-makers, which is important. The typical large company is composed of many organizational units reporting through structure to a corporate headquarters. Some employ centralized management and some decentralized management, but in all, the key allocation decisions are made at the top and frequently require approval by the board of directors.

A key allocation decision is taken to mean such things as the acquisition of another company, the development of goals and objectives of significant operating units of the company, and development of policies relating to such things as spending for research and development,

Reproduced with permission of the copyright owner. Further reproduction prohibited without permission. 
new products, advertising, plant and equipment, inventory levels, etc. They are allocation decisions because all imply something about the use of resources, usually, cash, and they are key because they frequently have a large bearing on the outcome of the company. The discussion focuses mainly on the allocation of cash. The management of other resources are important, but in Iong-range planning, many can be liquidated into cash or acquired by the expenditures of cash.

There are a host of restrictions on the corporation some of which are well-defined, and some of which are "fuzzy" in the sense of not being formally defined or are subject to interpretation, as the case arises. Among these restrictions are external forces such as national laws, taxes and policies; physical factors of the business environment such as transportation, weather, and 1 abor availability and quality; and those imposed on or by the corporation balance sheet. The balance sheet is a subject of particular interest in this paper. Some of the constraints on the balance sheet are the ratio of debt to equity, of short-term assets to short-term liabilities, of cash to short-term assets, of short-term to long term debt, and ultimately the amount of new equity (if any) the enterprise can obtain.

Some of the variables which serve to complicate the planning process either implicitly or explicitly are the dividend policy of the company, the profit from operations of the company, the action of competitors, the cash generation to be expected, the cash consumption expected, cost and

Reproduced with permission of the copyright owner. Further reproduction prohibited without permission. 
availability of borrowed capital, and the return on invested funds. All of these factors must be considered and decisions rendered on the allocation of present and future cash to competing components of a company. How to do this is surely one of the most important questions facing the strategic decision-making body of the corporation.

\section{Corporate Planning}

As corporate planning grew, more factors were recognized and many articles were written on the subject, and some successes and many fallures were noted (15). Many schemes of organization and techniques for planning were tried, modified, and tried again, and the field has been in a state of rapid evolution from the time of its recognized beginning (15). Of course, in some sense strategic planning is as old as business itself, but the modern era started with the advent of the large scale digital computer which allowed planners to build simplified models of the firm and evaluate future results of current policy actions.

There has been a large element of qualitative thinking in most good strategic plans, and in some sense, thinking through the problem and putting the thoughts on paper may be a major value of strategic planning. However, introduction of quantitative methods has made it possible to judge the feasibility of a set of strategies. As an example, the results of the disastrous reduction in security values in 1969-1974 could have been modeled and evaluated for those companies which employed a heavy debt stratte gy to determine what effect the reduction in security prices

Reproduced with permission of the copyright owner. Further reproduction prohibited without permission. 
would have had on their ability to maintain their strategy.

There are a number of strengths associated with planning versus non planning, but perhaps the most apparent is the value received from formalizing thoughts about the future. Another is composing alternative strategies, a third is depicting likely future scenarios, and a fourth is building a normative future. Weaknesses:or shortcomings in planning seem to include 1) the amount of work required, 2) scenarios built on inaccurate information, 3) bad organization, and 4) failure to take into account the right variables $(3,15)$.

There are a number of problems facing the planner/decision-maker, but those dealt with in this paper are selecting a management entity, selecting variables for measuring success of the total corporation, selecting which entities should be included in the corporation, which should be liquidated (or not purchased), and of those included, what should be expected of them with regard to their key variables. It appears some of the key decisions for corporate management are 1) into which management entity should capital be invested, 2) how much growth should be encouraged, 3) how much cash should be produced or consumed, and 4) which entities should be liquidated and 5) which should be acquired.

\section{The Concept of Strategic Business Units}

A concept introduced by the Boston Consulting Group (BCG) is particularly interesting, and although there does not seem to be much written about it they have applied it to a considerable degree in their consulting

Reproduced with permission of the copyright owner. Further reproduction prohibited without permission. 
work $(5,6)$. The BCG is an international management consulting organization specializing in policy issues related to Corporate strategy development and has written numerous working papers and a number of pamphlets and books which deal with various aspects of Corporate strategy $(5,34$, $35,36,37,38)$. In addition, they have worked closely with companies, and the techniques they develop for a specific company may not be made public and hence may not be widely used. The BCG has brought a certain amount of consistency and order to the investment decisions mentioned above by formulating the problem in terms of the management of a portfolio of SBU. Ansoff (2) suggests a similar concept in terms of a portfolio of markets, but BCG assumes the units are independent businesses from the point of view of strategic decisions; whereas Ansoff uses the concept in connection with desirable markets to enter. The SBU is very important to the concepts developed further in this paper and should be carefully considered before proceeding.

Many major companies can be characterized as composed of a number of relatively independent sub organizations and are structured around familiar ways of organizing such as job function, product line, and profit centers. In a private communcation BCG has indicated that an SBU may be thought of as a business which can be managed in a strategic sense, reasonably independently of the rest of the company, so that a decision could be made to either expand the business rapidly to a position of competitive dominance or to sell it off entirely without worrying about

Reproduced with permission of the copyright owner. Further reproduction prohibited without permission. 
the effect of that decision on the other businesses in the company. An $\mathrm{SBU}$ is the smallest component which allows this range of decision, and thus a company may be thought of as a set of SBU which are independent, operational entities to be managed in such a way as to optimize company objectives in the long run and hence as a portfolio of investments to be managed.

The SBU is a new way of structuring thinking about the management task, and like other approaches it has strengths and weaknesses. Its main weakness is in the assumption that one business unit is independent of all other business units in the company. This is only approximately true for most entities; however, the degree to which it is true enters into the decision whether to formulate an entity as an SBU or to combine it with entities with which it is interdependent to formulate a larger SBU. The strength of the SBU concept is similar to, but greater than, those associated with product line management concepts. It is more powerful than management by product line; however, because once a business unit is defined, the usuai financial and accounting data can be matntained, and business units can be described and measured in terms of profitability, growth rate, market share, growth in industry, competitors' size, cash generation, assets employed, capital retention percentage, and so on. Of course, many of these same measures can be developed for other management structures; but seemingly with more difficulty and inaccuracy than with SBU.

Reproduced with permission of the copyright owner. Further reproduction prohibited without permission. 
The Criteria for Defining an SBU

The criteria for defining an SBU seem to be those given in Figure 1 .

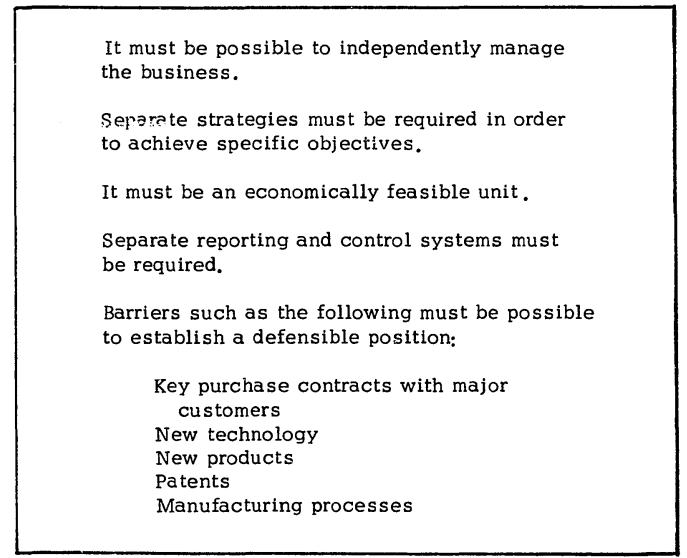

Figure 1. Criteria for defining an SBU as a separate entity.

There is very little written on the use of SBU, but the BCG has stated privately a number of their clients have used the SBU concept. Probably the most important of the criteria for defining an SBU is the requirement the SBU can be managed independently, which means the results of taking a range of management actions in one SBU have a negligible effect on all other SBU. The obvious problem with the independence assumption comes when products or markets of one SBU are affected by actions taken in another. If the effect is material, it seems the two affected parts should be combined, or if they cannot be without changing 
parts of the original, perhaps they should be combined in total. It is also possible the SBU concept does not fit every situation.

A less obvious problem with the independence assumption, but one which is probably more important, occurs when allocations of shared assets are altered by acquisition or divestiture. Perhaps this problem is handled best by carefully attributing the full share of allocated expenses to each $\mathrm{SBU}$. In the case an SBU is managed for its "marginal" contribution to the corporation (because it uses otherwise under-employed assets), management must recognize it may not be profitable on a "stand alone" basis and be willing to establish reduced profit objectives.

Another of the criteria which seems to be particularly important is the SBU must be large enough to be an economical unit. This means, although the size will vary with each company situation, that the extra cost of applying management to the unit is economically justified. If an SBU is too small, the information gathering, controlling, reporting, planning, and other management functions may cost more than can be gained through any better management decisions which might result. Also, too many SBU in a corporation may produce too high a level of complication. What constitutes too high a level complication depends on the particular company, its organization structure, expertise, informating-handling capacity, management training, markets and products among others.

Another criterion requires a "defensible barrier" be erected around the SBU. Thus geography, technology, transportation costs, patents,

Reproduced with permission of the copyright owner. Further reproduction prohibited without permission. 
contracts, tariffs, new technology, and secret processes help serve this purpose.

\section{Some of the Difficulties in using SBU}

Most companies probably have not had a long history of being managed by SBU and thus are likely to be presently managed in units which when examined are mixtures of SBU. As examples, it is likely a large plant would be found to produce products for several SBU, sales managers may be selling the prod ucts of several SBU, and similarly for other company functions. This is not necessarily bad, and the degree to which assets and people should be physically separated is dictated by the economies involved. However, those resources which are not physically assigned to one SBU or another must be allocated on some rational basis. There are some expenses, and perhaps some assets, which are strictly corporate in nature and need not be allocated to any SBU, but if relatively small it is not likely the allocation of such corporate items materially changes the quantitative aspects of the management decision process; although it is possible it affects the "psychological" aspects of the managerial process.

Thus far it seems a number of the problems and difficulties of managing by SBU have been raised, and it is appropriate to mention some of the advantages of using the SFiU concept. On the positive side, there seems to be one major advantage which is that much of the theory, built over the years for managing investments and for making micro-economic decisions

Reproduced with permission of the copyright owner. Further reproduction prohibited without permission. 
in a firm, is available for making decisions about SBU. Thus, a company can be thought of as a portfolio of independent investments, some of which are owned and some of which are oniy potentially members, and the principal problem is to find the best (or, at least, a satisfactory) set of possible SBU to comprise the company portfolio, given the projected operating results and characteristicsdata of each.

Most companies generate and invest millions of dollars each year, and it seems a systematic approach to such investment problems could produce a significant economic advantage to a company which utilizes them. It is hypothesized a more systematic and rigorous approach, to the investment problem using the concept of SBU in conjunction with appropriate factors for measuring success over the planning horizon, will provide techniques for significantly increasing the effectiveness of the cash generation and cash investment process.

\section{CONCEPTS FOR MEASURING SUCCESS}

There are a number of methods, and combination of methods, availabie for measuring and predicting success of part of a company and a company as a whole. There are a number of "older" quantitative measures (15) which are used by the top management of an enterprise to determine its present, and the likelihood of its continuing success. Traditional accounting and balance sheet data such as after tax earnings per share, dividend rates, number of continuous periods for which dividends have

Reproduced with permission of the copyright owner. Further reproduction prohibited without permission. 
been paid, growth in earnings per share and growth in sales are examples of such measures (15). Another older method is to consider the number of years required to "pay back" the cost of the initial investment of a specific project and to accept the project if the number of years is less than the established criteria of the company (6). These older methods are currently in wide use, and although they may be faulted for measuring the wrong factors, or not considering all factors, they are in use and "understood" by people who are currently top decision-makers in industry.

Among "newer" techniques, currently employed for evaluating alternative investments for cash, is Return on Investment (ROI) which is a simple calculation of a ratio of income to investment cost (15). It is similar in use to Discounted Cash Flow (DCF), where the present value of the cash flow of a project is compared to a cutting score established by management. If the ratio is equal to or greater than the cutting score, the project is accepted $(15,21)$. Although these methods and the method of pay back period mentioned above are frequently applied to smaller units than the SBU, they can be applied to much larger units as well. On large scale decisions such measures as profit growth, replacement of depreciation and the set of all projects justi fied by ROI have been used (34). These methods, as well as the "older" methods, suffer from frequently being uncoordinated, and their affect on overall company success is not well understood.

The BCG has suggested that from the point of view of a shareholder in

Reproduced with permission of the copyright owner. Further reproduction prohibited without permission. 
a company, for an investment to be of value, it must pay dividends to the investor at some point (34). This implies that the appreciation in stock price, which seems to be at tractive to many investors, is promulgated on the expectation that at some time (however far into the future) the company will return cash to the owner of company stock. This does not mean a company must pay dividends in the short range or that a dividendpaying company is a good one. In fact, it is quite possible dividends are a poor strategy (36). Rather, it means there must be a reasonable expectation the company could pay dividends (or that the realistic liquidation value of the company is significant). If accepted accounting principles are used, the ability to pay dividends is measured in part by size of shareholder equity.

If a company wishes to grow it must generate sufficient cash to invest in enough profitable opportunities to meet its growth objective. If a company cannot find better opportunities than bank interest rates (to pay off loans or to keep it from borrowing money), perhaps it should pass the money on to shareholders for they probably can do as well. The point of this statement is that a company's earnings per share may not be an adequate measure of success, and the increase in shareholder equity per share may be a better measure for the purpose of the shareholder. It may be the decision-maker should examine several measures before making an investment decision.

Reproduced with permission of the copyright owner. Further reproduction prohibited without permission. 
The Generation of Cash

Another important variable and measurement factor is the amount of cash generated. Cash is generated and consumed in a number of ways in a company (See Figure 2 and 3 ).

Figure 2 shows the relation of cash flows between the corporate decision node and the SBU, while Figure 3 shows the cash flows within an SBU. The charts are simplified and do not show the time delays which need to be considered to make them realistic.

If a significant amount of cash is generated, beyond cash consumption needs, so that a positive cash flow results, the company is in a position to reinvest this cash or to declare it as dividends to its shareholders. Thus the amount of positive cash flow is an important measurement criterion of company success. It is then incumbent upon management to put this cash to the best possible usa, and one mea sure of management success is how well they invest this cash.

This point also has a subtler implication as well, which is that if a company does not have a positive cash flow, and further if it has no real prospect of a positive cash flow, then no matter how profitable it may be, it will eventually reach a point where it can no longer borrow money, equity will be diluted, and it will never be able to pay a dividend. It then appears the company's stock price will suffer, and it will be judged to have been a poor investment for the shareholders involved. This factor is embodied in the present value of the shareholder equity, and

Reproduced with permission of the copyright owner. Further reproduction prohibited without permission. 


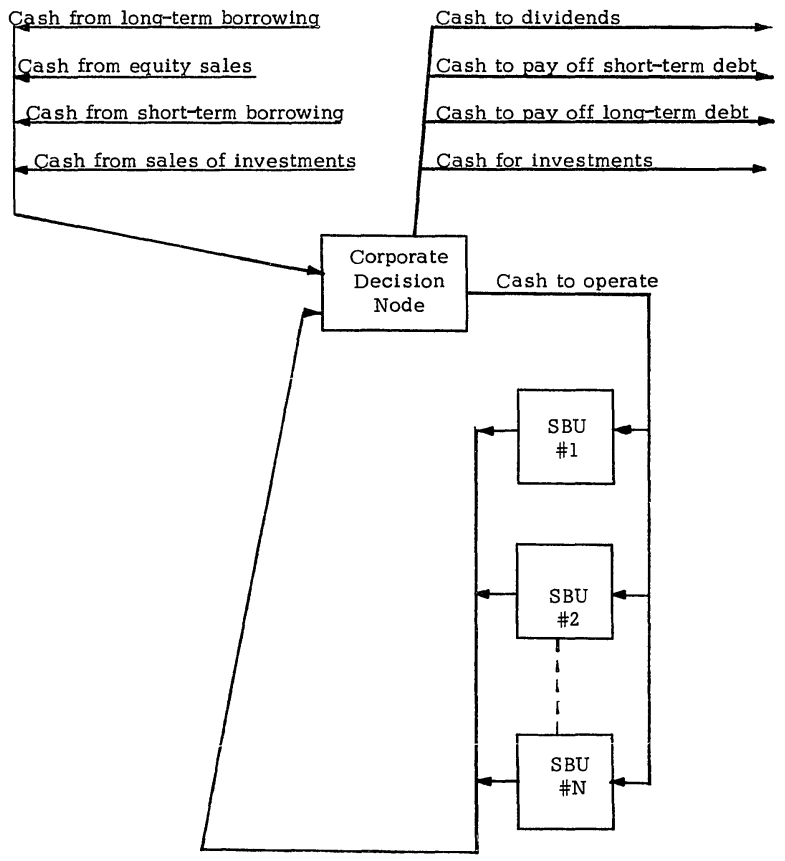

Cash generated by operations

Figure 2. The relation of cash flows between corporate and the strategic business units.

Reproduced with permission of the copyright owner. Further reproduction prohibited without permission. 


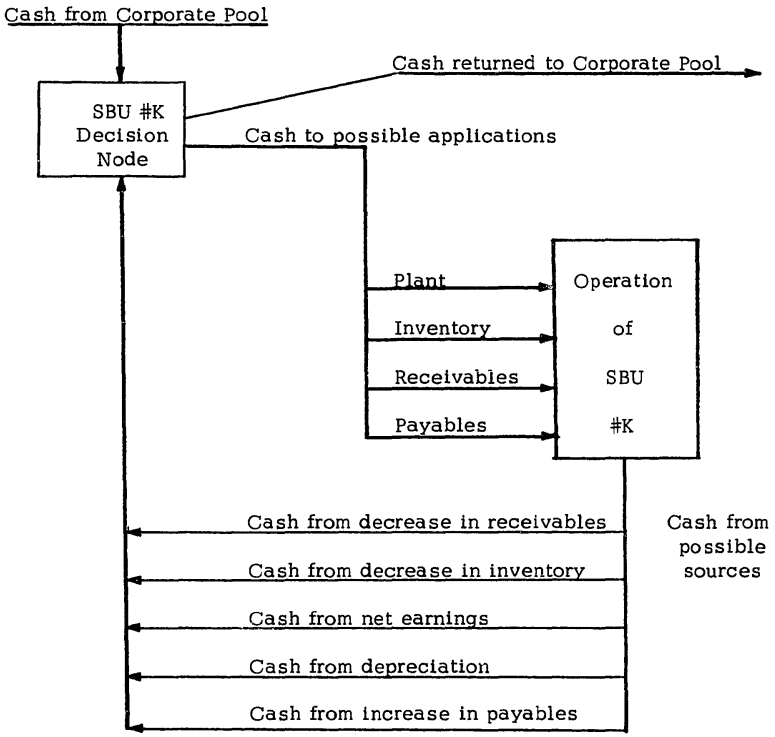

Figure 3. The cash flows within a strategic business unit.

Reproduced with permission of the copyright owner. Further reproduction prohibited without permission. 
hence the present value of shareholder equity is proposed as a good measure of corporate success.

There a re other pertinent measurement factors at work in a corporation. It is not uncommon for each operating manager of each unit to be judged on performance on a year-to-year basis and to have a significant amount of his pay depend on the annual results obtained rather than the results obtained over his career (6). This influences him to produce as much profit growth as possible in the short run, and such a strategy seems to leave to chance how well the long-run objectives of the company are met. As will be discussed later, there is a relationship between growth of an SBU and the amount of cash consumed or generated (38). The current methods for selecting which element of a company should generate cash, and which should be managed for growth by investment of cash, seems to be judgmental. Further, because of the short-term pressure mentioned above, the decision may not be made in a rational, concise manner but may follow by default.

In light of the above discussion, it appears several measures of company success should be utilized to aid strategic decision making and several of these are used in the research reported here. One of the most inclusive is the present value of long-run shareholder equity. Others are growth in earnings per share, total assets, growth in total assets and growth in sales.

Reproduced with permission of the copyright owner. Further reproduction prohibited without permission. 
The Present Value of Shareholder Equity

Shareholder equity is a standard balance sheet item which is used to measure at one point in time (generally at year end, but conceptually at any time a balance sheet is prepared) the value which will accrue to shareholders if the company is liquidated. Thus, it is the excess of assets over other liabilities. It does not generally reflect the actual value of a corporation's stock on an established market as shares may sell at substantial amounts over this figure at times for some companies, and at less than this yalue at other times. It is, however, a well-known measure which is available for all publicly held companies, and it seems to be a better measure for long-run purposes than stock price which is subject to the vagaries of a highly unpredictable market place.

In general, shareholder equity is increased by earnings and equity sales and decreased by dividends paid out or losses sustained. There can be other accounting transactions which affect equity for a complicated company, but these are generally relatively small and need not be considered for the purpose of this discussion. If it ever is necessary to consider them, they can be treated as one of the three types of classifications mentioned above without loss of generality. As mentioned in the previous paragraph, a balance sheet records the assets and liabilities at a point in time. All publicly held companies are required by governmental regulations to publish an audited balance sheet at the cluse of each year.

Reproduced with permission of the copyright owner. Further reproduction prohibited without permission. 
For the purpose of decision-making, the present value of the shareholder equity is desirable because it puts on a comparable basis the value of alternative futures. The mathematical formula for the present value of the shareholder equity of a set of SBU is discussed in Appendix A.

\section{Growth in Earnings $\mathrm{Pe}_{\mathrm{i}}$ Share}

Probably the most commonly used measure of success is growth in earnings per share. There seems to be a substantial premium placed on the value of companies, which maintain a steady growth rate in earnings per share, by the investment community. This figure is normally the after tax rate, but the before tax rate can be of interest in special situations where non-uniform tax rates apply. High earnings per share, although desirable, are not as important as a demonstrable growth in earnings per share, and a consistent growth pattern seems to be more desirable yet. By a consistent growth pattern is meant that a regression line for earnings per share versus time will have a positive slope and a "high" coefficient of correlation.

\section{Total Assets and Growth in Total Assets}

Two other measures of success are total assets and the growth in total assets of the corporation. Total assets are taken from the balance sheet of the corporation and are customarily thought of as the sum of cash, inventory, recelvables, investments, real estate, and buildings and e quipment, less depreciation. In addition, many balance sheets contain intangible assets which represent the value of patents, licenses,

Reproduced with permission of the copyright owner. Further reproduction prohibited without permission. 
trademarks, and corporate goodwill. Total assets are equal to the total liabilities of the corporation, and hence from year to year may be subject to variations not truly reflecting any particular change in the business health. As an example, if payables are increased through a failure to pay bills, cash will be increased and assets will be larger, but the value of the business may not be judged to be higher. Further, if the growth in total assets has been in buildings or intangibles, the true value of the business may not have been increased proportionately. Thus the size of assets or the growth of assets, particularly over a few years, may not be a good measure, but over a longer period of time it is indicative, and if the balance sheet values remain in the same ratio to one another at the end of a study horizon as at the start, either total assets or growth in total assets can be useful measures.

\section{Growth in Sales}

Probably the second most watched measure of business success is growth in saies. Sales are aiso frequentiy used in the denominator of ratios which express such things as profit, margin, and expenses as a fraction of sales so they may be compared from period to period. As an example, Fortune magazine (39) ranks the 500 largest manufacturing companies in the United States in terms of dollars of sales, but to maintain its rank on the list, a company must grow as fast in sales as its nearest competitors in rank and to gain higher rank must grow faster in sales. There seems to be a certain degree of status attached to being ranked in

Reproduced with permission of the copyright owner. Further reproduction prohibited without permission. 
this select group and hence, at least in ssome quarters, growth in sales is watched as an important measure of business success.

\section{Other Mea sures of Success}

There are a number of other measures of success which could be mentioned, but because they are not emphasized in the research reported in this work, they will not be discussed; however, one of particular importance which will be mentioned is return on assets employed. For large-scale evaluation, this factor can be taken as the ratio of after tax profit to total assets. Alternately, a sub set of assets may be chosen, such as plant and equipment, inventory and receivables, or plant and equipment before or after depreciation. In any case, consistency in the manner in which the measure is applied in comparison among entities is probably more important than any one choice of the denominator in the measure.

\section{MANAGING A POR TFOLIO OF STRATEGIC BUSINESS UNITS}

This work is most certainly not intended to be a discussion of management generally, but two points, which may be peculiar to managing or thinking about a company in the context of SBU need to be mentioned. These are used in other systems also, but they are emphasized as being of particular importance here, because the system using SBU focuses on them. One of these is how much cash is avallable for relnvestment and the other, closely related to the first, is how fast the portfolio can grow

Reproduced with permission of the copyright owner. Further reproduction prohibited without permission. 
in terms of earnings (or other acceptable measures).

\section{Relationship between Growth and Cash}

Cash flow and how it is calculated has been discussed, but the relationship between growth and cash generation is very important and is given by BCG (36) in the following form. First, growth rate is used by BCG to be the firm's return on equity if no dividends are paid and is given by them as:

$$
\begin{aligned}
& \text { Growth rate }=\left(\frac{\mathrm{D}}{\mathrm{E}}(\mathrm{r}-\mathrm{i})+\mathrm{r}\right) \\
& \mathrm{D}=\text { debt } \\
& \mathrm{E}=\text { equity } \\
& \mathrm{r}=\text { rate of return on total assets before } \\
& \quad \text { interest on debt } \\
& \mathrm{i}=\text { rate of interest paid on debt }
\end{aligned}
$$

"Since dividend payments reduce this rate of growth in assets, the effect of dividends may be introduced by multiplying the expression by (p) , the percent of earnings retained." (36; Page 10)

Then, $p$ multiplied by growth rate $=p\left(\frac{D}{E}(r-i)+r\right)=g$

If the effect after tax is to be considered each side of the equation must be multiplied by ( $t$ ), as one minus the effective tax rate, to give the fraction of earnings retained after tax; thus,

$$
\mathrm{tg}=\mathrm{pt}\left(\frac{\mathrm{D}}{\mathrm{E}}(\mathrm{r}-\mathrm{i})+\mathrm{r}\right)
$$

Cash enters the formulation through the debt coefficient, and if there is a positive cash flow during a given period, debt may be reduced as seen 
by examining balance sheet arithmetic. Because if excess cash is available, a given amoute may be subtracted from both the cash and debt account, leaving the balance sheet with total assets equal to total liabilities. On the other hand, if cash is consumed by the company (and other accounts remain equal), debt must be increased. In both instances, equity could have been changed, had the decision-maker so desired, by buying the company's shares. The equity section of the balance sheet would thas be reduced, by selling shares to raise further cash and increasing the size of the equity section. It should also be noted that expansion in the business enterprise generally requires an investment in cash because increased sales frequently mean increased receivables, inventories and/or production facilities.

In the above equation, growth is a function of debt and equity, which in turn is a function of the amount of cash generated, but the ratio of debt to equity is limited by management's willingness to accept risk. A maximum figure for the debt to equity ratio seems to be about $(0.60)$, as found in (9). Thus, for whatever level of debt to equity chosen, the growth rate of the corporation is limited by the amount of cash it generates. Other factors enter the formula, particularly profit and the cost control mechanisms, which can be employed to increase profit, but after cost control steps are taken and everything has been done with price to maximize return, growth is still seen to be limited by the amount of cash generated.

Reproduced with permission of the copyright owner. Further reproduction prohibited without permission. 


\section{Other Factors which influence Growth}

Other factors which influence growth rate are dividends and taxes, and it is fairly obvious reduced taxes are desirable. Tax reductions are possible through certain types of tax havens, and other considerations available to multinational corporations $(40)$, and should be taken into account in strategic decision-making. On the other hand, dividends enter the growth formula in exactly the same way as taxes, but are presumed to have a positive effect on the value at which new equity can be raised. There is substantial literature on the advisability and reason for paying dividends (9) which need not be discussed here, but it is one of the strategic decisions which must be rendered, and because the dividend rate has a material effect on the rate at which a company can grow, it should be carefully considered.

Another reason why the portfolio of SBU is an important concept in strategy is because each member of the set of SBU can be examined not only in light of usual management criteria, but for what it can contribute in terms of cash (or the consumption of cash) so as to balance the cash needs of the corporation with its growth objectives. Further, growth objectives over time can be examined in light of the potentials of the portfolio, and strategic actions can be taken to acquire or liquidate holdings to balance cash-generating and consuming units to meet corporate growth objectives.

Reproduced with permission of the copyright owner. Further reproduction prohibited without permission. 


\section{SUMMARY}

This chapter has discussed the problem undertaken in the dissertation, along with the nature of business strategy. The concept of the Strategic Business Unit (SBU) was introduced,as were several measures of success. The importance of cash generation was mentioned, and how cash generation limits the growth rate of a business was explored. The concept of a portfolio of business units was introduced, and it was mentioned that one purpose of this research was to develop and test a methodology for improving on the current methods of selecting those SBU which should be included in a company portfolio.

In the next chapter the structure of the simulation model and the details of the research are explored in depth. The specific technique, for evaluating and selecting optimal sets of SBU according to certain optimization criteria, is discussed. The research program covers such topics as the dividend policy, the debt to equity ratio policy, the policy on pricing to obtain market share, and the effect of managing an SBU for growth, stability, or liquidation. Also examined in the research program is the effect of limiting SBU assets, the effect of acquiring SBU with specific characteristics, joint effects of some strategic policies, the difficulty of working with probabilistic assumptions, and the research technique used to obtain some probabilistic results.

Reproduced with permission of the copyright owner. Further reproduction prohibited without permission. 


\section{CHAPTER II}

\section{THE RESEARCH}

\section{OVERVIEW}

This chapter discusses the objectives of the research, the nature of the simulation model used and the research program undertaken. The optimization routines are discussed here and found in more detail in Appendix A for each of the five measures of success explored. In a like manner, the necessary but complicated detail associated with the input to the model is found in Appendix A, although the essentials are discussed in this chapter. The restrictions on the model are very important in testing actual situations, and these are explored, along with ways they might be altered to give insight into a problem being researched.

Research is called for on six different policies, and at first each of these is examined independently of the others while later the joint effect between two of the more important ones is investigated. The number of computer runs to carry out the indicated research is shown to be substantial. Finally, the difficulty in carrying through the research under probabilistic assumptions is discussed, as is the specific research for the probabilistic work which was accomplished.

Reproduced with permission of the copyright owner. Further reproduction prohibited without permission. 


\section{OBJECTIVE OF THE RESEARCH}

One objective of the research was to develop and test a methodology for selecting those SBU which should be included in a company portfolio and to determine the investment strategy which should be used ivith each. In doing this, a simulation model of a company composed of a number of SBU was designed, and a decision procedure for selecting a "best" set of SBU was included as an integral part of the simulation model.

Another objective of the research was to use the simulation model to test various strategies applicable to the management of a portfolio of SBU. The simulation model was used to investigate the effect of 1 ) the dividend policy, and 2) the debt to equity ratio policy, on the five measures of success mentioned in Chapter I. Other policies investigated include 1) the policy on pricing to obtain market share; 2) the effect of managing SBU for growth, stability, or liquidation of market share; 3) the effect of limiting SBU assets; and 4) the effect on the overall results of the corporation of acquiring SBU with specific characteristics.

Chapter I described the concept of SBU and the various measurement factors which can be applied to them for determining success. Once this is done, it seems likely some SBU will present a better investment opportunity for the corporation than will others, and if resources are severely limited, it may be necessary to liquidate some SBU or not invest in all of the acquisition prospects presented. Thus the set of SBU to be considered may not all be a part of the corporation, but sorne can be included as prospective acquisition candidates; of course, their liquid-

Reproduced with permission of the copyright owner. Further reproduction prohibited without permission. 
ation will not generate cash to the corporation, but it is seen as a signal not to buy.

\section{THE SIMULATION MODEL}

The simulation model is composed of an output section, an input section and a calculation section. This portion of the chapter describes with frequent reference to Appendix A, the calculation section, the input to the simulation, the restrictions on the model, the output of the simulation, the optimization routine, and the computer used to operate the model. The corporation balance sheet is used as the score-keeping device of the simulation, and because it is an evaluation class of simulation the results are deterministic. In other words, the model does not use the technique of making a number of runs with data drawn from probability distribution to obtain a distribution of results. Except for some limited probabilistic investigations, the model uses the input data as completely deterministic and calculates the resulting output using fixed arithmetical relationships.

From the point of view of building, design and operation of the model, the input and output are most time-consuming, but do not present any particularly difficult concepts. They are, of course, necessary to understand, and the coding and systemization techniques are particularly important to the simulation efficiency.

Reproduced with permission of the copyright owner. Further reproduction prohibited without permission. 


\section{The Calculation Section of the Model}

It is the calculation section of the model which is particularly important and some of the techniques used there are not conceptually obvious. Figures 4 and 5 are the flow charts of the overall simulation model. Because of limitations of the computer (or the size of the simulation program), it was necessary to partition the simulation model into three sections. Sections I and II of the model are depicted in Figures 4 and 5 respectively, but Section III is not shown in flow chart form because it only manipulates data, prints output results, and is so conceptually simple that it need not be displayed. The computer programs referenced in the figures are found in Appendix B.

There are two modes of operation considered in the simulation. The first is the evaluation of a set of SBU as given without the possibility of selecting an "improved" subset. The second mode is that which selects an "improved" subset subject to given restrictions and evaluates the results, as in the first mode. There are references made to several factors and operations in the flow charts relative to the optimization mode which are not obvious, and these are discussed in the optimization portion of Appendix A.

\section{The Corporation Balance Sheet}

The simplified corporation balance sheet shown in Figure 6 is the basic device for keeping score in the simulation, and because it is also

Reproduced with permission of the copyright owner. Further reproduction prohibited without permission. 


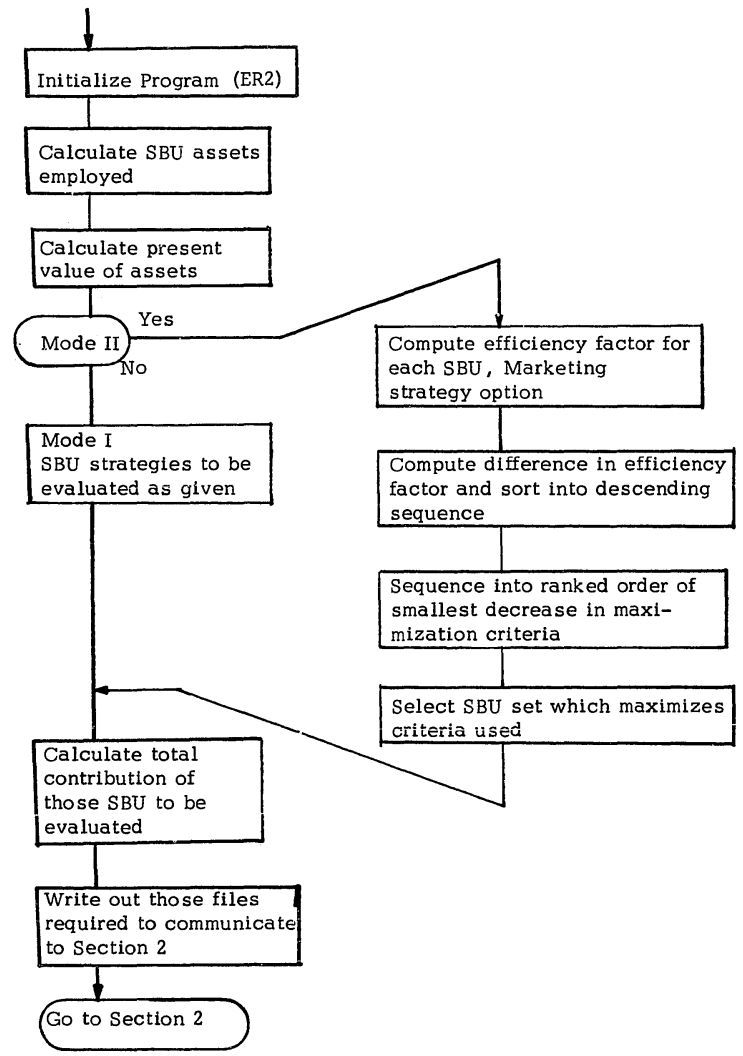

Figure 4. Section I of model

Reproduced with permission of the copyright owner. Further reproduction prohibited without permission. 


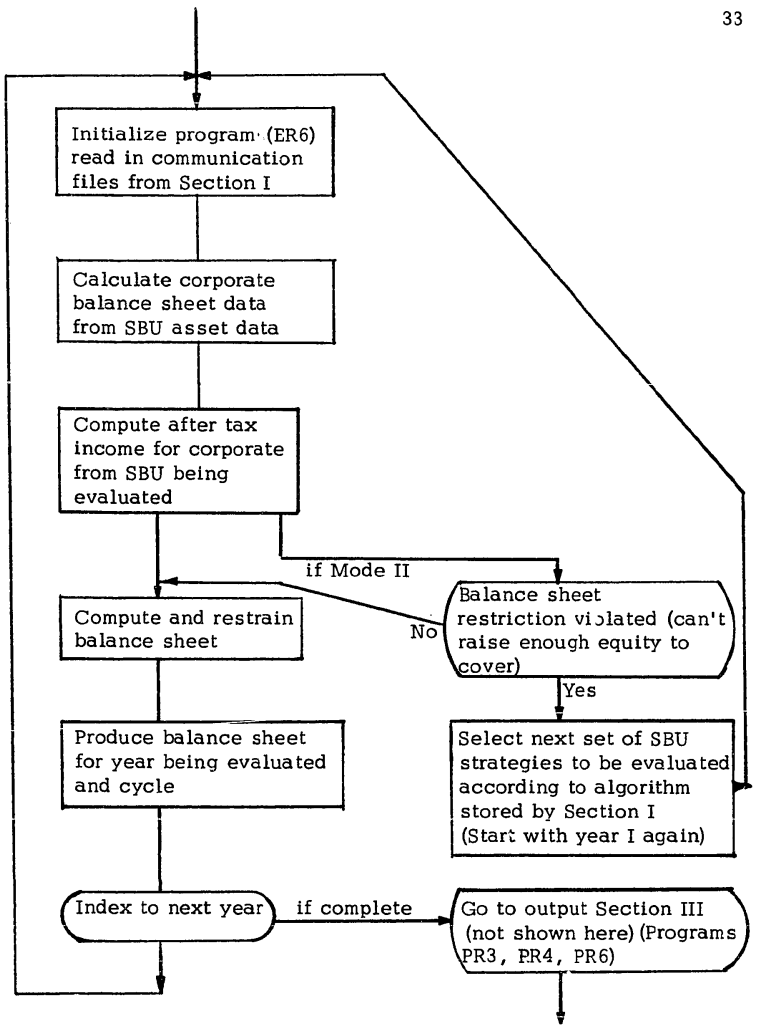

Figure 5. Section II of model

Reproduced with permission of the copyright owner. Further reproduction prohibited without permission. 
the device for recording the state of the corporation at a given time, it is the principal object of the simulation. Its roie is described in more detail in Appendix A, but using the balance sheet, the simulation proceeds from year to year, starting with the beginning year data, and cycles through the data one year at a time until it has completed a new balarice sheet for each year. The restrictions on the balance sheet, along with the input data, determine the beginning balance sheet for the next year's cycle. If the balance sheet restrictions are violated, the simulation is started again with less aggressive market share strategies and the process is repeated until an acceptable balance sheet is computed for all years.

Assets

Cash

Inventories

Receivables

Total Current Assets

Plant

Depreciation

Sub Total

Investments

Total Assets
$\mathrm{XXX}$

$\mathrm{XXX}$

$\mathrm{XXX}$

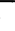

$\mathrm{XXXX}$

Total Current Liab.

$(\mathrm{XXX})$

$\mathrm{xXX}$

$\mathrm{XXX}$

Figure 6. Simplified corporation balance sheet.
Long Term Debt

Shareholder Equity

\section{Liabilities}

Payables $\quad \mathrm{XXX}$

Short Term Debt XXX

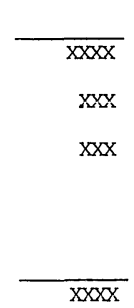

Reproduced with permission of the copyright owner. Further reproduction prohibited without permission. 
Input to the Si mulation

The input to the simulation, along with the computer programs which perform the calculations, is a very important portion of the process, and thus it is particularly desirable to understand the data required to specify a major corporation. The data input sheet $\mathrm{S}_{H}$ as displayed and discussed in Appendix $\bar{A}_{t}$ depict the information required, But because an explanation of the input requirements is involved, it is also found in Appendix A. It is necessary to go through the discussion there, if a detailed understanding of the simulation process of the corporation is to be obtained.

The SBU profit and loss statement and the SBU assets and liabilities must be pre-calculated for each market share option of each SBU for each year in the planning horizon. Because a medium to large company can easily have 20 SBU, three market share options per SBU, and a planning horizon of five years, this set of data can be 300 pages in length and contain 4,500 separate entries. This gives the reader some appreciation of the size of the task facing the would-be model user, and it would be very difficult to collect and organize this mass of data for the research, had it not been calculated as part of the long-range planning process of the company being modeled.

Appendix A should be consulted in any case to get an overview of the forms used and nature of the data required. In particular, the sub section on corporate operating criteria should be examined to understand specific assumptions and restrictions called out for input, and although these data

Reproduced with permission of the copyright owner. Further reproduction prohibited without permission. 
are for input, it is through changes in them that the effect of policy changes in such things as debt to equity ratio and dividend rate are entered into the simulation model.

\section{Restrictions}

The restrictions which are used as described below are part of the computer programs found in Appendix B,and are described in some detail in Appendix A. Only one market share assumption for each SBU is to be used in the totals reaching the balance sheet, and the model is constrained so not more than one market share option for an SBU will be in the final set chosen. The market share options are not designed to be changed during the course of a simulation run; although it is assumed an SBU can be liquidated if necessary during the planning horizon. If it appears a mixed strategy of market share options is desirable, the system as depicted is sufficiently general to accomplish this if the user will formulate such a combination of input data.

There are many other restrictions, some of which are implicit in the assumptions of the computer program and others which are explicit in the computer input mentioned in the previous sub section. The most important ones are debt to equity ratio, the value at which new equity can be raised, the maximum dilutions from equity sales which will be allowed, the minimum ratio of short term assets to short term liabilities (current ratio), and the minimum amount of cash which must be maintained as a fraction of other beginning current assets.

Reproduced with permission of the copyright owner. Further reproduction prohibited without permission. 
The Output of the Simulation

The output and results of the simulation are discussed in more detail in Chapter IV. In general, there are two classes of output; one aids the researcher in determining if the simulation is functioning as designed, and a second helps the researcher (or manager) explore the effects of various possible strategic actions. Only the second class is discussed in this chapter, the other deemed a part of computer programming and model validation, and is discussed in Chapter III.

The output is used for gaining insight for strategic decision-making and is generalized as follows, but the specific cases used and the research results obtained are found in Chapter IV. The output is: 1) The SBU and the related market share strategies selected in each study (as mentioned previously, these are either specified by the operator or alternately are selected by a quasi-optimization routine); 2) the resulting balance sheet and income statement for each year; 3) the present value of shareholder equity; 4) earnings per share by year; 5) growth in earnings per share per year; 6) growth in total assets; 7) total assets; 8) growth in sales; 9) return on shareholder equity by year; 10) return on assets employed by year; 11) debt to equity ratio by year; 12) required borrowings and/or equity sales by year; and 13) net cash generated each year.

\section{The Optimization Routine}

Às mentioned previousiy, the simulation is carried out in one of two

Reproduced with permission of the copyright owner. Further reproduction prohibited without permission. 
ways -- either as an evaluation of a given set of SBU market share options, or if so desired, by the operator, the model will select the best set of SBU market share options which satisfy the restraints mentioned above, Best is defined in terms of one of the five measurement criteria used in the research. They are treated as being totally independent, with no attempt made to obtain a global optimum because of both the complexity of the task, and the questionable value which could come from such an attempt when the surface is not smooth and the input data, being management estimates and frequently subject to error.

The five criteria used subject to the restrictions on the balance sheet were: 1) the present value of long run shareholder equity; 2) the growth in earnings per share; 3) growth in total assets; 4) total assets; and 5) growth in sales. The optimization algorithm for each measurement factor is described in Appendix A; the measurement criteria and the derivation of the technique to solve the integer programming problem involved should be noted in particular. If it happens a restricted optimum must be obtained, the routine requires an interactive input from the operator.

\section{The Computer}

The computer used in the research was an IBM 370 Model 135. The computer program was operated in a time share mode using IBM's ITF time share package (10) with 65,000 Bytes of Core storage. The programs were written in the IBM subset of the Basic language and are described in

Reproduced with permission of the copyright owner. Further reproduction prohibited without permission. 
Appendix B. They were operated from a teletype TT33 with a punched paper tape input device, but other such terminals could have been used equally well. Other time-sharing services are available which provide much larger memories and more efficient software, and if they had been used, they would have made the computer programming simpler, because there would not have been as many small programs required, and disk files to store the input data could have been avoided.

\section{THE RESEARCH PROGRAM}

The results of the research program are discussed with much detail in Chapter IV, but the strategic policies to be tested and the techniques used are discussed in what follows. First, these policies were investigated independently from each other, and later the joint effect between the dividend policy and the debt to equity ratio policy was investigated. Probabilistic assumptions are discussed separately in Section V of this chapter.

\section{The Dividend Policy}

The fact that paying dividends reduces cash avallable for growth, as well as the rate at which a company can grow, has already been discussed. This effect was examined by varying the dividend rate by steps of 0.10 and analyzing the change in the five measurement criteria already mentioned. The optimal set of SBU options for each of the measurement criteria, with an assumed dividend rate, was used as a base line and deviations were

Reproduced with permission of the copyright owner. Further reproduction prohibited without permission. 
measured from it.

\section{The Debt to Equity Ratio Policy}

The meaning of this ratio has been presented in Chapter I. The maximum allowable debt to equity ratio was changed in incremental steps and the resulting changes in the measurement criteria of the five cases were analyzed. The optimal set of SBU market share options was found for a specific assumption of the ratio and deviations were measured from it by using that set as the control set.

\section{The Policy on Pricing to Obtain Market Share}

The policy was examined by pre-selecting those SBU market share options which resulted in maximum market share and evaluating this set as a base line. The effect then was compared against the optimal set and against two significantly less aggressive options. The results are analyzed and conclusions drawn about effect of aggressiveness toward market share in Chapter IV.

\section{Effect of Managing the SBU for Growth, Stability, Liquidation}

This refers to growth, stability and liquidation of market share. The effect of aggressive growth was examined in the previous paragraph, but in this section comparisons were made among the three policies by selecting and evaluating those SBU market share options which were characterized as being stable in the one case and those which would liquidate market share in the other. The results and conclusions are dis-

Reproduced with permission of the copyright owner. Further reproduction prohibited without permission. 
cussed in Chapter IV.

\section{The Effect of Limiting SBU Assets}

The assets of the corporation were limited by selecting one particularly large and profitable option which had much lower assets, comparing the results obtained with this $\mathrm{SBU}$ with the results for other important sets of SBU. The analysis of results is reported in Chapter IV.

\section{The Effect of Acguiring SBU with Specific Characteristics}

The effect was investigated by using the optimal set of SBU options without the particularly large and profitable SBU, and by augmenting the set of SBU options with the large SBU which had, a large cash generation, a medium cash generation, and a small cash generation. The changes in the prospects of the combined company are analyzed and discussed in Chapter IV.

\section{Joint Effects}

Up to this point only the effect of each policy acting independently has been examined. To examine the joint effects requires investigating the response surface, but if this is done for all policies, the number of combinations to be examined makes the computer task completely impractical. However, two of the policies are particularly well suited for investigating the effect on a measure of success when they are allowed to vary jointly. Therefore, a more modest effort was undertaken which allowed a more thorough explorati on of the joint effect between the dividend policy 
and the debt to equity ratio policy for the present value of shareholder equity.

To accomplish this task a "map" was made of the optimal surface in the region bounded by $0.1 \leqslant$ dividend rate $\leqslant 0.3$ and $0.3 \leqslant$ debt to equity ratio $\leq 0.7$. This region includes a segment where the optimum solution is restricted, as well as a portion where it is not restricted. Generally a grid size of 0.1 was used, except an intermediate point on the debt to equity line at 0.45 was evaluated. Chapter IV analyzes the results.

\section{PROBABILISTIC ASSUMPTIONS}

It was the initial intent of the research to explore the probabilistic effects which occur when a probability distribution is associated with the contribution of each SBU market s hare option, as well as with the market share each option achieved. It was also hoped a distribution could be associated with the assets and liabilities of each SBU market share option, and the optimal set of SBU could be obtained under such conditions. However, as the work progressed it became apparent the computer program for the non-probability case would reach the maximum acceptable size for the computer, and in addition the time to execute an evaluation of a given set of SBU was at least five minutes, near the acceptable limit for interactive programs. Thus it was determined programming the total probability case was impractical.

The literature seems to indicate problems in handiling probabilistic

Reproduced with permission of the copyright owner. Further reproduction prohibited without permission. 
assumptions. For instance, Wagner (17, p 659) states about stochastic linear programming,

... you will see that such a formulation magnifies the size of the problem. You will be justified in concluding that the more general situations modeled in Section 16.7 is likely to be beyond practicality for most real linear programming applications.

Such a conclusion is certainly true for interactive time sharing programs with problems the size of the model in this research.

The above notwithstanding, a probability distribution was associated with each asset account, the payables account, and the contribution of each SBU market share option. Instead of carrying the probabilities through either the optimization section or the evaluation option of the model, it was determined to obtain a probability distribution of the after tax profit attributable to a given set of SBU market s hare options and a probability distribution of the cash flows generated by this given set. As an intermediate step, a probability distribution of each asset account, the payables account, and the liquidation value (a total of six distributions for each year for each market share option) was obtained. These outputs should be quite valuable to the business planner, even though the model is not run to completion, because a great deal of the uncertainty in the model is generated from the sources which were assigned distributions rather than from the corporate items which were not. The planner can choose values from the output distributions at some satisfactory level of confidence and determine by further computation the effects on the balance

Reproduced with permission of the copyright owner. Further reproduction prohibited without permission. 
sheet. Thus the approach is intermediate between ideal and the deterministic one discussed in earlier sections, but it is judged to be valuable.

The research was carried out by using an arbitrary three-point probability distribution for each account involved. See Table XXVII of Appendix D for the assumed distributions.: There are aix values requiring a distribution for each SBU market share option for each year in the study, and thus for the fiveyear study horizon, with the twenty SBU and three market share options each, there are a total of 1,800 distributions required. Rather than assign a distribution for each of these values, which conceptually could be done, twenty different distributions were formulated. The three points chosen for the distribution were; 1) the deterministic value given in the planning input; 2) a percentage below this value; and 3) a percentage above the given value. The probabilities associated with these points were chosen arbitrarily, in such a way that the given value was not necessarily the mean of the distribution. The given values may be somewhat optimistic in general, and the mean of the three-point distributions chosen turned out to be somewhat less than the given value.

\section{The Research}

The research was carried out by using the optimal set of market share options found in the deterministic case for present value of shareholder equity. First, one of the twenty distributions was used for each of the 30 values requiring a distribution for each SBU market share option and the indicated output distributions were obtained. Second, a random

Reproduced with permission of the copyright owner. Further reproduction prohibited without permission. 
number generator, which is available in the Basic computer language (10), was used to choose one of the twenty distributions for each of the values requiring a distribution and again the indicated output distributions were assigned a probability of one, the other two points were assigned probability zero, and the program was rerun. Finally, the largest SBU, Number 18, market share option 1 was assumed to have been liquidated in the first year of the first procedure above and the program was rerun.

The purpose of the research steps was to establish the model as a means of 1) demonstrating that this limited probabilistic output can be obtained in a real problem, 2) examining some of the differences which result when different probability assumptions are made, 3) demonstrating the validity of the program through the degenerate case where the probability of the deterministic values are one, and 4) comparing results when the large SBU was not present.

\section{The Mean and Variance}

Weil known probability theorems indicate that the mean of the probability distribution (which is the sum of a number of probability distributions which meet certain conditions) is the sum of the means of the distributions in question. In a like manner, the variance is the sum of the variances (8). Additionally the distribution, which is the sum of the distributions, approaches a normal distribution, as the number of individua! distributions in the sum becomes large. The principal condition to be met for these

Reproduced with permission of the copyright owner. Further reproduction prohibited without permission. 
results to hold is for the individual distributions to be mutually independent. For other more technical conditions see Feller (8). For the purpose of this research, it is assumed the distributions are mutually independent. In practice, however, they are very likely only independent to an unknown degree; the variance in asset size, for instance, could have some effect on the probable profit. This effect is ignored in the approach taken, for to do otherwise requires taking the covariance into account, the problem being too big for the computer for such a large number of distributions.

\section{The Total Probabilistic Program}

The total probabilistic program could have been attacked in one of two ways. The first way would be as a simulation problem, where the specified input is drawn from probability distribution and the resulting value of the pertinent measurement criteria recorded. The sequence would have been continued until sufficient validity appeared in the output to terminate the simulation. But because this only would ha ve yielded an evaluation of one set of SBU options for an extensive number of runs, it could not serve as an optimizing procedure. After enough runs it could give valid information on the probable outcomes of the one set of SBU options.

The second way would be to assume a relationship between the mean and the variance of the distribution of each input function and attempt to carry the parameters through the computations. The initial step of this

Reproduced with permission of the copyright owner. Further reproduction prohibited without permission. 
was done as discussed above, but it becomes difficult if the distribution parameters are carried through the restrictions imposed by the balance sheet.

Some further insight into the problem can be obtained by assigning different values to some of the key numbers in the SBU market share options and running the model to assess the effect. There is a good reason why this approach in conjunction with the limited exploration of probabilities carried out above may be adequate, and that is because in most cases very little is known about the nature of the probabilities associated with the numbers submitted by the SBU managers. These numbers tend to become self-fulfilling forecasts if accepted for implementation, and as such their distributions are hard to measure. Thus, if some idea of the nature of the distribution of profit and cash flow is known, much of the information possible will have been obtained.

\section{SUMMARY}

The objectives of the research were discussed along with the details of the simulation used and the research programs undertaken. Much of the supporting detail was found in Appendix A. Five different measures of success were described in Appendix A, as were the appropriate techniques for optimizing the selection of SBU for each. The input, the output, and the restrictions on the computer program were discussed. Six different strategic policies were called out for research, and the research to invest-

Reproduced with permission of the copyright owner. Further reproduction prohibited without permission. 
igate these independently and in a limited case jointly was discussed. The problems associated with trying to devise a model under probabilistic assumptions were mentioned, as were the techniques for the limited investigation of probabilities which were carried out.

The next chapter discusses validation of the model, and because the model is deterministic and an "evaluation" type of model validation is easier than it would be for a probabilistic simulation type. The test program is described and the input data which were chosen from a specific company are discussed. The output of the model is described, and the results from the test of real data are discussed, as is the sensitivity of the results to the initial conditions. Specific research results, however, are left for Chapter IV.

Reproduced with permission of the copyright owner. Further reproduction prohibited without permission. 


\section{CHAPTER III}

\section{MODEL VALIDATION}

\section{OVERVIEW}

Because the mode is an "evaluation" type rather than the probabilistic type (which uses random data drawn from distributions), it is much easier to validate. The tests used to verify the accuracy of the compuater programs are described, and a description of the real data used in the research is presented. The case to be modeled uses actual planning data supplied by a large international company headquartered in Portland, Oregon, and in addition utilizes the input of company personnel routinely involved in the planning process.

The output of the model is described, and the results for the specific cholce of market share options the company chose are discussed. The sensitivity of the model to errors in data and differences in assumptions is examined, and conclusions are reached about the accuracy of the inudeling process. The model is found to be accurate and a useful tool for pre-evaluating the results of specific planning actions which could be taken.

The model utilized in the research is fully described in Chapter II and Appendix A. The programs are detailed in Appendix B, and listings 
of each conputer program used are found there as well. Appendix $\mathrm{C}$ is a collection of specific run results and supports both this chapter and Chapter IV. Appendix D provides the input data used in the research study.

\section{CLASS OF MODEL}

The evaluation type of model is easy to validate because it is easy to prove the accuracy of output results for given input data used. In simulations using data drawn from probability distributions, it is necessary to determine if the results truly represent the output function of the system; probabilistic work and verification thus must be undertaken $(12,13,14)$.

In the evaluation model, there are a large number of variables influencing the results of the simulation, but these variables nevertheless enter the computation in rather straightforward ways. Difficulty and complexity relate instead to the size of the problem involved. In this research, an added complexity involves restrictions on the output results and the integer nature of the decision variables.

There are twenty different SBU with three market share options each, and, with the possibility of liquidation of each SBU, there are eighty possible SBU market share options from which to choose the best twenty. The best market share options must be chosen for each SBU according to the measurement criteria and within the restrictions. The problem is computationally difficult if there are more than three of four such SBU .

Reproduced with permission of the copyright owner. Further reproduction prohibited without permission. 
It is easily seen that the computational capability of the evaluation model is a great aid for the size of the problem being investigated.

The calculation job is substantial even in the case where optimization is not required, and it simply is desired to compute the resulting balance sheet over a several period time horizon subject to appropriate restrictions. With the usual desire to try several alternative policy decisions for evaluation, the simulator becomes a very useful tool of the planning process. Hence, even though the model is deterministic, rather than probabilistic, it is comprehensive in nature and potentially quite useful.

\section{VALIDATION}

Two classes of validations which must be performed: The model must be computationally accurate, and the model must truly represent the realworld phenomenon it is supposed to represent. Meier (12) lists several procedures for validating both classes in complex programs.

\section{Computational validation}

The programs found in Appendix B are sufficiently complex to be tested in segments, and the technique of putting in "windows" to print out intermediate results was used, with these results then checked by hand calculations. Because the full set of input data is too complex to use for model validation, a set of input data was contrived to test the computational aspects of the model. Each principal branch of the model was verified by hand computation and by modifying the input assumptions

Reproduced with permission of the copyright owner. Further reproduction prohibited without permission. 
of Table XXVI of Appendix D. In a similar manner, the integer programming assumptions of the model were verified by greatly reducing the debt to equity ratio restriction of the model, until the program was forced to find a restricted solution using the integer programming algorithm, and comparing the model results with hand-computed values.

The probability research program outlined in Chapter II was completed after the rest of the research was finished, and the results of the model using deterministic data were thus available for comparison. The probability program was found to be arithmetically accurate by hand computation, further verified by assigning probability equal to one to the given planning input data and probably equal to zero to the other two points in the threepoint distribution used in the investigation. The results matched those obtained using the deterministic programs.

Because the three-point distributions were chosen quite arbitrarily by the author it was not possible to check their validity; however, it is possible to establish their plausibility. There are twenty such distributions in total, and assuming the deterministic input value is a value of unity, the average of the means of the distributions is 0.9435 , thus tending to compensate for the assumed optimism in the input data. The average of the variance of the distributions is 0.025 and the standard distribution is 0.158 . It can be shown the sum of the distributions approaches a normal distribution as the number of distributions becomes large, using well known probability theory. If the sum is normally

Reproduced with permission of the copyright owner. Further reproduction prohibited without permission. 
distributed, the case represented by the total distribution indicates that 95.5\% of the time the profit of an SBU market share option, with a planned profit of one dollar, would be expected to lie in the range $\$ 0.6275<$ profit $<\$ 1,2595$. Alternately, for an SBU with $\$ 10,000$ of planned profit, there is a $95.5 \%$ chance that the profit will be in the range $\$ 6,275<$ profit < $\$ 12,595$. This is at least a plausible value for the likely range of profits in such an operating SBU. Of course, some of the three-point distributions would be more or less dispersed than the "typical" one described.

\section{Validation of Assumptions}

There are a number of assumptions implicit in the computational procedures of the model. One important one is how the planned results of each SBU combine to represent the entire corporation. This has been done at the end of each time period by "generally accepted" accounting rules for consolidation. However, the assumption that these entities can be consolidated must be recognized. In an actual international company facing currency exchange regulations, dollar devaluations, and restrictions on the use of funds, these assumptions may not hold, but the effect was regarded as not materia 1 to the purpose of the research. If restrictions of this general type are significant in a given situation, they could be programmed as restrictions in the section of the program doing the consolidation.

The assumptions in Table XXVI of Appendix D (parallel to Figure 13 of Appendix A) are those in use at the company providing input data, and to

Reproduced with permission of the copyright owner. Further reproduction prohibited without permission. 
this extent thus reflect reality. Most of the factors called for in Figure 13 have an acceptable range which depends on the risk orientation of company management and the industry in which the company is engaged (9).

It is assumed that each of the input data resulting from each market share option of each SBU is a completely accurate forecast of the results which will be obtained by operating with that strategy. This, of course, is not absolutely true; each item of input data is in reality only a point in some probability distribution. But as pointed out in Chapter II, with the probabilistic nature of the whole problem computationally too difficult, the probable cash flow and probable profit of the set of SBU market share options were instead investigated as described. In a sense, the market share options of the SBU are self-fulfilling forecasts, because in practice they become budgets for the people managing the SBU, and management pressure is applied to try to achieve the indicated results. This influences the variance of the distribution of the input data, acting to limit the natural dispersion of data.

There is an assumption the SBU are independent of each other and of the non-company environment in which they operate, and although this is approximately true for many SBU, there certainly exist examples where they are independent neither of one another nor of the business environment. One example is where one SBU has sales to another SBU in the same company. Although the planning was done with the effect of such sales eliminated in the data used in this investigation, it is a problem in

Reproduced with permission of the copyright owner. Further reproduction prohibited without permission. 
general. It can sometimes be handled by eliminating the effect from the data as it was in the cases here or by restructuring the SBU (such as combining two which have large transactions with each other into one). As a second example, the success of the SBU might so change the business environment that the anti-trust division of the government would restrict the SBU because it has become too large a factor in the market place. Another example is where the stock market, recognizing its success or failure, has changed the extent to which the company can borrow money. Such effects are ignored in the model because the basic assumptions are that the results developed for each SBU are independent and feasible.

Because it is based on the real planning information upon the accuracy of which people's livelihood depended, the model is believe to be reasonably representative. Further, the model follows the same accouriting rules for combining the data as does the manual system employed by the planners who routinely use the data. The information has a historical base, and the alternative market share assumptions chosen by the company are available for critique. Some aspects of the real data are described in the next section.

\section{DESCRIPTION OF THE SET OF SBU}

Table I and Table II (which continues Table I) characterize the nature of the set of SBU used in the research, and the complete input data files

Reproduced with permission of the copyright owner. Further reproduction prohibited without permission. 
TABLE I

THE SET OF SBU USED IN THE RESEARCH

\begin{tabular}{|c|c|c|c|}
\hline $\begin{array}{l}\text { SBU } \\
\text { No. }\end{array}$ & $\begin{array}{c}\text { Market Share } \\
\text { Strategy } \\
\text { (Company Strategies } \\
\text { are marked } * \text { ) }\end{array}$ & $\begin{array}{l}\text { Range of } \\
\text { Market Share } \\
\text { over } 5 \text { years } \\
(\%)\end{array}$ & $\begin{array}{l}\text { Aggressiveness } \\
\text { Toward Growth }\end{array}$ \\
\hline 1 & $\begin{array}{l}i * \\
2 \\
3\end{array}$ & $\begin{array}{l}27.9-36.0 \\
27.7-27.7 \\
27.7-20.0\end{array}$ & $\begin{array}{l}\text { High } \\
\text { Even } \\
\text { L ow }\end{array}$ \\
\hline 2 & $\begin{array}{l}1 * \\
2 \\
3\end{array}$ & $\begin{array}{l}35.1-44.0 \\
34.1-32.7 \\
35.1-20.0\end{array}$ & $\begin{array}{l}\text { High } \\
\text { Even } \\
\text { Low }\end{array}$ \\
\hline 3 & $\begin{array}{l}1 * \\
2 \\
3\end{array}$ & $\begin{array}{r}9.3-20.8 \\
10.7-9.7 \\
9.3-6.0\end{array}$ & $\begin{array}{l}\text { High } \\
\text { Even } \\
\text { Low }\end{array}$ \\
\hline 4 & $\begin{array}{l}1 * \\
2 \\
3\end{array}$ & $\begin{array}{l}0.8-3.8 \\
0.9-0.9 \\
0.9-0\end{array}$ & $\begin{array}{l}\text { High } \\
\text { Evene } \\
\text { Low }\end{array}$ \\
\hline 5 & $\begin{array}{l}1 * \\
2 \\
3\end{array}$ & $\begin{array}{l}35.8-42.3 \\
35.0-35.0 \\
35.8-20.0\end{array}$ & $\begin{array}{l}\text { High } \\
\text { Even } \\
\text { Low }\end{array}$ \\
\hline 6 & $\begin{array}{l}1 * \\
2 \\
3\end{array}$ & $\begin{array}{l}46.4-50.5 \\
40.0-40.0 \\
46.4-30.0\end{array}$ & $\begin{array}{l}\text { High } \\
\text { Even: } \\
\text { Low }\end{array}$ \\
\hline 7 & $\begin{array}{l}1 * \\
2 \\
3\end{array}$ & $\begin{array}{l}12.8-21.7 \\
11.0-11.5 \\
12.8-8.8\end{array}$ & $\begin{array}{l}\text { High } \\
\text { Even } \\
\text { Low }\end{array}$ \\
\hline 8 & $\begin{array}{l}1 * \\
2 \\
3\end{array}$ & $\begin{array}{l}79.9-81.8 \\
79.9-79.9 \\
79.9-54.0\end{array}$ & $\begin{array}{l}\text { High } \\
\text { Even } \\
\text { Low }\end{array}$ \\
\hline 9 & $\begin{array}{l}1 * \\
2 \\
3\end{array}$ & $\begin{array}{l}10.3-21.7 \\
10.3-10.0 \\
11.0-0.5\end{array}$ & $\begin{array}{l}\text { High } \\
\text { Even } \\
\text { Low }\end{array}$ \\
\hline
\end{tabular}

Reproduced with permission of the copyright owner. Further reproduction prohibited without permission. 
TABLE II

CONTINUATION OF TABLE I

\begin{tabular}{|c|c|c|c|}
\hline 10 & $\begin{array}{l}1 \\
2 \\
3 *\end{array}$ & $\begin{array}{r}10.0-16.0 \\
10.5-10.5 \\
10.5-5.9\end{array}$ & $\begin{array}{l}\text { High } \\
\text { Even } \\
\text { Low }\end{array}$ \\
\hline 11 & $\begin{array}{l}1 * \\
2 \\
3\end{array}$ & $\begin{array}{r}13.5-29.2 \\
14.7-11.7 \\
13.5-8.0\end{array}$ & $\begin{array}{l}\text { High } \\
\text { Even } \\
\text { Low }\end{array}$ \\
\hline 12 & $\begin{array}{l}1 \\
2 * \\
3\end{array}$ & $\begin{array}{l}33.5-37.5 \\
33.5-23.3 \\
33.5-17.7\end{array}$ & $\begin{array}{l}\text { High } \\
\text { Even } \\
\text { Low }\end{array}$ \\
\hline 13 & $\begin{array}{l}1^{*} \\
2 \\
3\end{array}$ & $\begin{array}{l}25.0-27.8 \\
25.0-25.0 \\
28.3-17.3\end{array}$ & $\begin{array}{l}\text { High } \\
\text { Even } \\
\text { Low }\end{array}$ \\
\hline 14 & $\begin{array}{l}1 \\
2 \\
3 *\end{array}$ & $\begin{array}{l}15.4-20.0 \\
15.4-10.4 \\
23.1-16.1\end{array}$ & $\begin{array}{l}\text { High } \\
\text { Even } \\
\text { Low }\end{array}$ \\
\hline 15 & $\begin{array}{l}1 \\
2 * \\
3\end{array}$ & $\begin{array}{r}7.7-8.2 \\
10.5-10.7 \\
6.6-5.2\end{array}$ & $\begin{array}{l}\text { High } \\
\text { Even } \\
\text { Low }\end{array}$ \\
\hline 16 & $\begin{array}{l}1 * \\
2 \\
3\end{array}$ & $\begin{array}{l}17.7-22.4 \\
15.7-16.5 \\
15.7-11.0\end{array}$ & $\begin{array}{l}\text { High } \\
\text { Even } \\
\text { Low }\end{array}$ \\
\hline 17 & $\begin{array}{l}1 \\
2 * \\
3\end{array}$ & $\begin{array}{l}42.7-50.0 \\
42.1-42.7 \\
41.3-36.8\end{array}$ & $\begin{array}{l}\text { High } \\
\text { Even } \\
\text { Low }\end{array}$ \\
\hline 18 & $\begin{array}{l}1 \\
2 * \\
3\end{array}$ & $\begin{array}{l}61.0-70.0 \\
61.0-64.0 \\
49.0-29.4\end{array}$ & $\begin{array}{l}\text { High } \\
\text { Even } \\
\text { Low }\end{array}$ \\
\hline 19 & $\begin{array}{l}1 * \\
2 \\
3\end{array}$ & $\begin{array}{l}22.1-33.5 \\
18.2-21.6 \\
22.1-14.0\end{array}$ & $\begin{array}{l}\text { High } \\
\text { Even } \\
\text { Low }\end{array}$ \\
\hline 20 & $\begin{array}{l}1 * \\
2 \\
3\end{array}$ & $\begin{array}{l}0-31.4 \\
8.0-13.0 \\
0-9.5\end{array}$ & $\begin{array}{l}\text { High } \\
\text { Even } \\
\text { Low }\end{array}$ \\
\hline
\end{tabular}

Reproduced with permission of the copyright owner. Further reproduction prohibited without permission. 
for all SBU are found in Table XXII through XXVI of Appendix D. The descriptive titles of the SBU are not shown in order to disguise the nature of the business. Table I and II show the data has a wide range of values possible with regard to probable market share. There is a range in aggressiveness toward market share from highly aggressive, to passive, to liquidation of the business.

In the research, only twenty SBU out of a possible thirty were used, the other ten were withheld to limit the size of the problem. The company has since seen fit to reduce the number to sixteen by liquidating and combining. The beginning balance sheet data in Table XXII of Appendix D was scaled to take into account the actual reduced nature of the company. The balance sheet was kept in approximately the same proportion as it was in the company's published balance sheet.

\section{RESULTS OF THE MODEL USING THE BASE CASE}

The output of the model is discussed in Chapter II and Chapter IV with specific computer output found in Appendix C. The purpose of this section is to discuss the results which were obtained by using the model on the real input data and evaluating the results for the same SBU market share options which were chosen by the company. The resulting output is found in computer run $\mathrm{AO}$ of Appendix $\mathrm{C}$, and this case is also used in some of the analysis of results found in Chapter IV. It is advisable to read the explanation of the data formats contained in Appendix $\mathrm{C}$ for a

Reproduced with permission of the copyright owner. Further reproduction prohibited without permission. 
complete understanding of the output results .

\section{Run Time}

The initialization phase of program ER2 (See Appendix B) runs about seven minutes for the pure evaluation case. The optimum case runs an additional 25 ininutes if all files must be processed; although these programs need not be rerun unless results for new measurement criteria are desired. The balance sheet building phase of program ER6 runs about five minutes, or one minute per year in the planning horizon, and as such is near the upper limit of acceptability for interactive timesharing. Because the model was competing for time with regular batch process jobs which were running concurrently, the particular computer software chosen for this research (IBM Basic ITF) (10), and the computer used were slower than a commercially available software program. A given case requires about ten minutes of terminal connect time once the initialization phase is complete when running in the environment described. However, the probability case requires about 30 minutes of terminal connect time to complete.

\section{$\underline{\text { Results }}$}

The output found in computer run $\mathrm{AO}$ indicates seemingly acceptable financial results. The company is expected to experience a growth in earnings per share of $46.6 \%$ over the five year period; an increase in dividends from $\$ 0.37$ to $\$ 0.54$ per share; growth in sales of $46.3 \%$; growth in assets $61.8 \%$; and total cash generation of $\$ 9,422$ million. 
The company could do better, as we will discuss in Chapter IV.

\section{Validation}

Validation of the computations was achieved using test data. Running the real data resulted in further validation, because combinations of effects existed which had not been apparent with only test, data. Hand computation proved that the many restrictive calculations applied against the balance sheet were being properly met, with a few subtle program "bugs" uncovered before the program satisfactorily met all of the criteria.

One validation test on real data, once the program is known to compute as it should, is the test of reasonableness, wherein the balance sheet entries must appear to be in the correct proportion to each other and must stay in good proportion throughout the study horizon. The results portrayed in computer Run $\mathrm{AO}$ seem to meet this criterion.

How well does the simulation actually forecast the results achieved in practice? At first it was thought it would be possible to measure this. More likely what would be measured is how well the people preparing the planning input data for the SBU, did their job not how well the model computed the given input data. A "field" comparison of projected results to actual does not test the validity of the model.

\section{SENSITIVITY}

\section{Initial Conditions}

One of the important factors which must be checked is the sensitivity

Reproduced with permission of the copyright owner. Further reproduction prohibited without permission. 
of the model to initial conditions (12). Had the company been short of cash rather than in a "strong" cash position, the results would have been different. First, it may not have been possible to meet all of the boundary conditions and some conditions probably would have been relaxed (for instance the debt to equity ratio or dividend rate). In the way assets or profits from SBU operations reach the company profit and loss statement and balance sheet, the model is linear, with the changes resulting from modifications of the input easily estimated without running the model. For instance, if the profit of an SBU is increased by $\$ 1,000$ after taxes, this will result in an $\$ 800$ increase in equity, a $\$ 200$ increase in dividends, and an $\$ 800$ change in some combination of an increase in investment or decrease in debt - - depending on what restrictions are in force. Whether such a change is significant or not is judgmental; the important thing is that the linearity of the computational portion of the model makes sensitivity analysis easier. Such sensitivity analysis can of course be carried on by making an incremental change in the input and examining the resulting change by operating the model. But because of the way input variables enter the computation, this is unnecessary. Thus it is relatively easy to establish the effect of a change in any one variable on the final output.

\section{Errors in Input}

The other sensitivity condition which normally should be explored is output changes which result if there are recording or transcribing errors in the input data. The remarks under the iast sub-section are appropriate

Reproduced with permission of the copyright owner. Further reproduction prohibited without permission. 
here as well, and because the input variables enter in a linear fashion, their effect can be easily computed by hand or by simple investigation using the model.

\section{SUMMARY}

The validation of the model was described using test data as well as real company data, the latter evaluated for the set of SBU market share options the company had chosen for itself. Although tests of reasonableness and computational accuracy were applied, it was not useful to compare actual results obtained in the field with the prediction of the model, because the variations in field results came from differences in SBU planning data, not from differences in the model. The validation of the model for the limited probability research was described in some detail.

It was pointed out the model is deterministic in nature (an evaluation model) and not a probabilistic model using data drawn from distributions; however, some abbreviated probabilistic investigations were performed.

A description of the SBU input data was presented and the results of the model using the "base case" data was presented as a base for discussing sensitivity to initial conditions and errors in input. It was noted, because the variables entered the model in linear ways, it was relatively easy to establish the effect any one would have on the final results, and this could be done either by hand computations or by running test cases through the model. It also was noted different assumptions of initial

Reproduced with permission of the copyright owner. Further reproduction prohibited without permission. 
balance sheet conditions, particularly cash, car have a significant effect on company results in the ensuing years.

The next chapter discusses the results of the research program described in Chapter II and analyzes the large number of situations which were investigated.

Reproduced with permission of the copyright owner. Further reproduction prohibited without permission. 
CHAPTER IV

\section{DISCUSSION OF RESULTS}

\section{OVERVIEW}

This chapter discusses the results of the research program described in Chapter II and presents a summary of the cases run on the computer . Analysis of results obtained for each of the six policies and five measurement criteria investigated is presented, assuming each policy is independent. Later there is a short explo ration of the joint effects between the debt to equity ratio and the dividend policy, using the present value of shareholder equity as a measurement criterion. Results from the limited investigation into probabilistic effects are also presented.

There are a number of results and conclusions examined in detail in the chapter, some of which follow. Dividends decrease the rate at which a company can grow, because dividends consume cash which then cannot be used for funding new opportunities. The limit on debt to equity ratio has a predictable and extensive influence on the rate at which a company can grow if the optimum set of SBU are restricted, but if there is sufficient cash available to fund the best set of SBU options, the ratio does not have such an effect. Aggressive growth in market share requires considerably more cash than does a strategy of managing for stability. However, over

Reproduced with permission of the copyright owner. Further reproduction prohibited without permission. 
the long run aggressive growth may generate more cash than does a policy of maintaining a stable market share. A particularly good use of the model would be in the evaluation of candidates for acquisition. The model is a great arithmetical aid because many of the computations, although simple in form, are complicated by their large number and the restrictions placed on the balance sheet.

Other results are mentioned, most importantly the effect of using return on assets employed as a measurement criterion; it seems this may unduly restrict the future earnings of the corporation. Some results of using the algorithm for finding the restricted optimum set of SBU market share options are mentioned, including the technique employed with the interactive computer program.

A great deal more data is available in computer outputs found in Appendix $\mathrm{C}$ than can be presented in the written discussion in this chapter -- in fact, a complete analysis of each attempted case could be a complete chapter. Hopefully, essential aspects of each case are presented in sufficient depth to emphasize important differences.

\section{THE CASES EXAMINED}

Developed to handle cases where all values of the input data are assumed to be deterministic, the model does not handle situations where certain variables are assumed to be drawn from probability distributions. While a limited investigation into the probabilistic effects is presented,

Reproduced with permission of the copyright owner. Further reproduction prohibited without permission. 
it is carried neither to an optimal solution nor a complete evaluation. This chapter discusses two complete types of cases. In the simplest case, the market share strategies to be evaluated are given, with the resulting corporate balance sheet calculated, the restraints applied, and the SBU market share options assumed to meet the imposed restraints. If the restraints cannot be met, it is assumed sufficient equity can be raised. This option is economical to run, giving indicative values while seeking information about the effects of using specific strategies.

The second type of case is more complex, using the optimization routine to obtain the set of $\mathrm{SBU}$ and their market share strategies which maximize a specific measurement criterion within given restraints. This case does use much more computer time, however, and hence is more costly to use. The run time is a function of the number of SBU, the time horizon, and how many cycles must be completed before the solution meets the restraints. In the case that the maximum solution does not violate the restraints, it takes about the same amount of computer time as the first type of case.

The computer programs composing the computer model are found in Appendix B, and the listings may be used to duplicate or extend the results reported on here. It probably would be desirable, however, to reprogram them if a different computer is to be used.

The real data and most aspects of the model have been discussed in previous chapters, and the computer printouts resulting from carrying

Reproduced with permission of the copyright owner. Further reproduction prohibited without permission. 
through the research program described in Chapter II and Appendix A are found in Appendix C.

The several computer runs made to examine the five measurement criteria called for in the research program are summarized in Tables XVIII through XX of Appendix C, and are discussed in the appropriate sections of this chapter. As can be seen from Tables XVIII through XX and Figure 7, it was possible to reduce the number of runs significantly, using one optimal run as a comparison base. Because the company generated sufficient cash, it did not need to seek a restricted optimum in a large number of cases.

Investigation of all policies with all measurement criteria was unnecessary. Using the present value of shareholder equity as a measurement criterion, Policies III through VI were investigated. The analysis would not have been changed appreciably by selecting the optimum SBU market share option resulting from other measurement criteria, because they gave very similar optimum sets. For the SBU market share options which resulted in the optimum for each measurement criterion, see Table XXI in Appendix C.

Three measurement criteria were found to have the same optimum set, further reducing the number of separate computer runs. As can be seen from Figure 7 and Tables XVIII through XX, these cases were I, III and IV -namely, the present value of shareholder equity, growth in total assets, and total assets. While there should be no reason for these to always

Reproduced with permission of the copyright owner. Further reproduction prohibited without permission. 


\section{$\underline{\text { Policies }}^{1}$}

I - The Dividend Policy

II - The Debt to Equity Ratio Policy

III - The Policy on Pricing to Obtain Market Share

IV - Effect of Managing the SBU for Growth; Stability; Liquidation

$\mathrm{V}$ - The Effect of Limiting SBU Assets

VI - The Effect of Acquiring SBU with Specific Characteristics

$\underline{\text { Measurement Criteria }}^{1}$

CASE I - Present Value of Shareholder Equity

CASE II - Growth in Earnings per Share

CASE III - Growth in Total Assets

CASE IV - Ending Total Assets

CASE V - Growth in Sales

${ }^{1}$ For a discussion of the policies and measurement criteria see Chapter II and Appendix A.

Figure 7. Polictes and measurements investigated in the research.

Reproduced with permission of the copyright owner. Further reproduction prohibited without permission. 
result in the same optimum set, they probably are highly correlated in many cases. For the specific data set being investigated they simply resulted in the same set of SBU options.

\section{THE DIVIDEND POLICY}

The evidence seems rather conclusive that the dividend policy has a significant effect on the long-run success of an enterprise. But this statement must be qualified -- as must most conclusions in this report -because the results are for the particular enterprise under investigation. Other company situations could show somewhat different findings.

The computer output for this investigation is labeled $\mathrm{Al}, \mathrm{A} 2, \mathrm{~B} 1, \mathrm{~B} 2$, E1, and E2 in Table XVIII. Using the five measurement criteria to investigate how the optimal values changed for different dividend rates, the dividend policy was explored. Table III records the results of the computer runs. Over the ranges investigated, the growth in sales was not affected by changes in dividend policy because the optimum set of SBU market share options was not restricted. Hence, the same market share options were being pursued.

Because the optimal set of SBU market share options was changed, the effects are those which are independent of the SBU operations. With the same operating units therefore producing the same profits, it is seen that company management can significantly influence the results by changes in the dividend policy.

Reproduced with permission of the copyright owner. Further reproduction prohibited without permission. 
TABLE III

OPTIMUM VALUES OF THE MEASUREMENT

CRITERIA AS INFLUENCED BY

THE DIVIDEND POLICY

Measurement

Criteria
Dividend Rate as a Percent of Earnings $10 \%$ $20 \%$ $30 \%$

Present Value of Shareholder Equity (millions of \$) 167.2 159.4 153.1

Growth in Earnings Per Share (\%) ${ }^{2}$ 67.9

64.2 59.7

Growth in Total Assets (\%) ${ }^{2}$ 73.0

65.8 57.9

Ending Total Assets (millions of \$) 103.6

98.1

93.3

Growth in Sales (\%) ${ }^{2}$

55.1

55.1

1 If the present value of equity is adjusted downwards for equity sales made and this effect is removed, the numbers are, 167.2, 158.1, 149.2.

2 See Appendix A for definition of growth.

Reproduced with permission of the copyright owner. Further reproduction prohibited without permission. 
Dividends are paid out of equity. This is why the present value of shareholder equity (as well as some of the other criteria) are affected to such a large extent. For the case using a $20 \%$ dividend rate and the shareholder equity as a criterion, the cash paid out in dividends totaled $\$ 10,716$ million for the five-year period. This is a significant amount of money to withhold from investment, when assets at the beginning of the first year total only $\$ 59$ million.

\section{THE DEBT TO EQUITY RATIO POLICY}

The effect of debt to equity ratio policy on the present value of shareholder equity is minimal, unless the market share options are changed. But as shown in Section IX of this chapter, such a change does materially reduce shareholder equity.

The computer output for this investigation is labeled $\mathrm{Al}, \mathrm{A} 3, \mathrm{Bl}, \mathrm{B} 3$, El, and E3 in Appendix C, and the debt to equity ratio policy was explored, using the five measurement criteria and investigating how the optimal values changed for different debt to equity ratios. Note in Table IV which records the results of the computer runs, that the present value of shareholder equity is given in both an adjusted and unadjusted form. The adjusted value is found by removing the present value of the new equity purchased from the unadjusted value shown. While this is done to give a better comparison because equity could have, in other cases, been purchased, it was not necessary to meet the restrictions.

Reproduced with permission of the copyright owner. Further reproduction prohibited without permission. 
TABLE IV

\section{OPTIMUM VALUES OF THE MEASUREMENT CRITERIA AS INFLUENCED BY THE DEBT TO EQUITY RATIO}

Mea surement

Criteria
Debt to Equity Ratio

45

171.5

167.2

159.4

Equity ${ }^{1}$ (millions of \$)

$(\%)^{2} \quad 53.1$

56.8

64.2

Growth in Total Assets (\%) ${ }^{2}$

66.4

66.2

65.8

Ending Total Assets (millions of \$)

98.5

98.3

98.1

Growth in Sales (\%) ${ }^{2}$

55.1

55.1

55.1

1 If the present value of equity is adjusted downwards for equity sales made and this effect is removed, the numbers are, 158.7, 158.5, 158.1.

2 See Appendix A for definition of growth.

Reproduced with permission of the copyright owner. Further reproduction prohibited without permission. 
Again, growth in sales was not changed by changes in the debt to equity ratio over the range investigated. Had the optimal set of SBU market share options changed, because balance sheet restrictions could not be met by raising new equity, sales growth would also have been reduced by a reduction in the debt to equity ratio.

The present value of unadjusted shareholder equity is significantly larger for low debt to equity ratios than for large ratios, because in the model new equity is raised to meet the debt to equity restriction. After the present value of this new equity has been removed, there is very little difference apparent; almost all of the difference would be removed if the effect of the new equity is also reduced by the amount it increases earnings. Therefore, the increase in shareholder equity, for the reduced debt to equity ratio in Table IV, is viewed as a spurious result. But it must be recognized that shareholder equity would be significantly reduced if a restricted set of market share options were required.

Because a different number of shares are outstanding in each case, the growth in earnings per share is deceiving. If actual earnings are considered, earnings show very nearly the same pattern as do assets. The conclusion reached above holds that the effect of the debt to equity ratio depends on whether it restricts the optimum set of SBU options. Its effect on the balance sheet seems to be minimal for the company under investigation, since in the range shown the same set of SBU options are in use.

Reproduced with permission of the copyright owner. Further reproduction prohibited without permission. 


\section{THE POLICY ON PRICING TO OBTAIN MARKET SHARE}

The computer output results for this investigation are labeled Al, A4, and A5, in Appendix C, and the effect of pricing to obtain market share was investigated by evaluating the set of SBU market share options which gave the largest, medium, and minimum market share. While Table V compares results for the optimum values of the five measurement criteria used, Table VI provides a comparison for other important operating criteria. The data in Table VI is for the final year of operation in the planning period, and was chosen as a way of comparing alternatives, and as a way to answer questions about the long range results.

The comparison of profits in the final year among the market penetration cases is particularly significant. Another important effect is that under low market penetration, more cash is generated (\$13.7 million) than under high penetration (\$8.3 million). In the first instance, market position is being liquidated; in the second, cash is being invested into inventories, receivables and other assets to produce the growth.

It seems a policy to increase market share (frequently done through pricing) results in a significantly stronger company. This conclusion is justified by the fact that most of the measurement criteria are more favorable for maximum market share penetration case than for the minimum market share penetration case. It does, however, require significantly more cash.

VI. THE EFFECT OF MANAGING FOR GROWTH STABILITY OR LIQUIDATION The effect of managing the SBU for growth, stability, or liquidation

Reproduced with permission of the copyright owner. Further reproduction prohibited without permission. 
TABLE V

COMPARISON OF MEASUREMENT CRITERIA

FOR A WIDE RANGE OF MARKET

SHARE PENETRATION

Measurement $^{1} \quad$ Optimum Max.Mkt. Med.Mkt. Min.Mkt. Criteria Value Share Value Share Value Share Value

Present Value of Shareholder Equity (millions of \$) 159.4 158.4 152.3 118.5

Growth in Earnings per Share (\%) 64.2 63.0 31.4 $-13.7$

Growth in Total Assets (\%) 2 65.8 65.2 56.1 18.3

Ending Total Assets (millions of \$)

98.1

97.3

90.5

67.4

Growth in Sales (\%)

55.1

55.1

26.1

$-14.3$

${ }^{1}$ All of the runs were made with a dividend rate of $20 \%$ and a debt to equal ratio of 0.60 .

2 See Appendix A for definition of growth.

Reproduced with permission of the copyright owner. Further reproduction prohibited without permission. 


\author{
TABLE VI \\ COMPARISON OF KEY OPERATING \\ CRITERIA FOR A WIDE RANGE \\ OF MARKET SHARE \\ PENETRATION
}

Mea surement * Factor

Max.Mkt. Med.Mkt. Min.Mkt. Share Share Share

$\begin{array}{lccr}\begin{array}{l}\text { Sales in Final Year } \\ \text { (millions of \$) }\end{array} & 114.2 & 90.5 & 58.0 \\ \begin{array}{l}\text { Debt to Equity } \\ \text { Ratio in Final Year }\end{array} & .29 & .31 & .44 \\ \begin{array}{l}\text { Return on Equity in } \\ \text { Final Year (\%) }\end{array} & 19.6 & 16.7 & 14.5 \\ \begin{array}{l}\text { Dividends/share } \\ \text { in Final Year }\end{array} & .59 & .47 & .28 \\ \begin{array}{l}\text { Total Cash } \\ \text { Generated (in } \\ \text { millions of \$) }\end{array} & 8.3 & 14.6 & 13.7 \\ \begin{array}{l}\text { Cash Held as Invest- } \\ \text { ment in Final Year } \\ \text { (millions of \$) }\end{array} & 16.4 & 22.9 & 23.5 \\ \begin{array}{l}\text { Profit in Final Year } \\ \text { (millions of \$) }\end{array} & 13.5 & 10.7 & 6.3\end{array}$

* All of the runs were made with a dividend rate of $20 \%$ and a debt to equal ratio of 0.60 and the set of SBU options which are optional for measurement criteria 1 .

Reproduced with permission of the copyright owner. Further reproduction prohibited without permission. 
is very similar to the policy used in the investigation of market penetration. Tables V and VI should be considered for this case as well, and many of the same conclusions can be reached as found in the previous section. One significant difference in interpretation between the two sections is the amount of cash avallable for investment in the final year of the study period. If it is desirable to accumulate a large amount of cash for such purposes as acquisition or hedge against depression, a company might be less aggressive about obtaining increased market share. Although it seems almost trite, a stable strategy toward market share increases cash reserves.

\section{THE EFFECT OF LIMITING SBU ASSETS}

The computer output results for this section are labeled A1, A4, A5, and $A 6$, in Appendix C. While much of the information for the analysis of this section is also contained in Tables V and VI, more information was developed to help analyze this case, using the model to evaluate a set of SBU market share options which had greatly reduced assets. One SBU, Number 18, is significantly larger than the others and is very profitable with a large return on assets, as shown by the input data found in Appendix D. The model was run assuming all SBU, except Number 18 , were liquidated and the cash brought into the balance sheet. The aggressive market share option of Number 18 was used, however. Tables VII and VIII are the same as Tables V and VI, except that the results of run A6 have been added to the right-hand column.

Reproduced with permission of the copyright owner. Further reproduction prohibited without permission. 
TABLE VII

\section{COMPARISON OF MEASUREMENT \\ CRITERIA FOR A WIDE RANGE \\ OF MARKET SHARE \\ PENETRATION}

Mea surement ${ }^{1}$

1

Optimum Max.Mkt. Med.Mkt. Min.Mkt. Reduced Criteria Value Share Value Share Value Share Value Assets

\begin{tabular}{lccccc}
$\begin{array}{l}\text { Present Value of } \\
\text { Shareholder Equity } \\
\text { (millions of \$) }\end{array}$ & 159.4 & 158.4 & 152.3 & 118.5 & 142.2 \\
$\begin{array}{l}\text { Growth in Earnings } \\
\text { per Share (\%) }\end{array}$ & 64.2 & 63.0 & 31.4 & -13.7 & 24.8 \\
$\begin{array}{l}\text { Growth in Total } \\
\text { Assets (\%) }\end{array}$ & 65.8 & 65.2 & 56.1 & 18.3 & 50.2 \\
$\begin{array}{l}\text { Ending Total Assets } \\
\text { (millions of \$) }\end{array}$ & 98.1 & 97.3 & 90.5 & 67.4 & 79.5 \\
$\begin{array}{l}\text { Growth in Sales } \\
\text { (\%) }\end{array}$ & 55.1 & 55.1 & 26.1 & -14.3 & 26.1 \\
\hline
\end{tabular}

1 All of the runs were made with a dividend rate of $20 \%$ and a debt to equal ratio of 0.60 .

2 See Appendix A for definition of growth.

Reproduced with permission of the copyright owner. Further reproduction prohibited without permission. 
TABLE VIII

\section{COMPARISON OF KEY OPERATING \\ CRITERIA FOR A WIDE RANGE \\ OF MARKET SHARE \\ PENETRATION}

\begin{tabular}{|c|c|c|c|c|}
\hline & & & & \\
\hline $\begin{array}{l}\text { Measurement } 1 \\
\text { Factor }\end{array}$ & $\begin{array}{l}\text { Max. Mkt. } \\
\text { Share }\end{array}$ & $\begin{array}{l}\text { Med. Mkt. } \\
\text { Share }\end{array}$ & $\begin{array}{l}\text { Min. Mkt. } \\
\text { Share }\end{array}$ & $\begin{array}{l}\text { Reduced } \\
\text { Assets }\end{array}$ \\
\hline $\begin{array}{l}\text { Sales in Final Year } \\
\text { (millions of } \$ \text { ) }\end{array}$ & 114.2 & 90.5 & 58.0 & 38.2 \\
\hline Debt to Equity & & & & \\
\hline Ratio in Final Year & .29 & .31 & .44 & .33 \\
\hline $\begin{array}{l}\text { Return on Equity in } \\
\text { Final Year (\%) }\end{array}$ & 19.6 & 16.7 & 14.5 & 15.5 \\
\hline $\begin{array}{l}\text { Dividends/Share } \\
\text { in Final Year }\end{array}$ & .59 & .47 & .28 & .39 \\
\hline $\begin{array}{l}\text { Total Cash } \\
\text { Generated in } \\
\text { Millions of } \$\end{array}$ & 8.3 & 14.6 & 13.7 & 35.8 \\
\hline $\begin{array}{l}\text { Cash Held as Invest- } \\
\text { ment in Final Year } \\
\text { (millions of \$) }\end{array}$ & 16.4 & 22.9 & 23.5 & 44.5 \\
\hline $\begin{array}{l}\text { Profit in Final Year } \\
\text { (millions of } \$ \text { ) }\end{array}$ & 13.5 & 10.7 & 6.3 & 8.9 \\
\hline
\end{tabular}

1. All of the runs were made with a dividend rate of $20 \%$ and a debt to equal ratio of 0.60 and the set of SBU options which are optional for measurement criterion l.

Reproduced with permission of the copyright owner. Further reproduction prohibited without permission. 
The results reflect things expected to happen, were large amounts of assets changed into cash and the cash invested. But the earnings are modest by comparison, despite the fact a great deal of cash is invested, because the pretax return on invested cash is assumed to be only eight percent $(8 \%)$, while after-tax return on equity is found to be $15.5 \%$. The results, with just the aggressive option of SBU Number 18 present, are superior to the results of the entire set of SBU using the least aggressive option, and the results demonstrate how one superior SBU can contribute a great deal to the profitability of a company. The single SBU shows how a company, in divesting many of its less profitable assets, could make a very acceptable return $(\$ 8.9$ million in profit, which is only $\$ 4.6$ million less than with maximum market share), and have $\$ 28.1$ million more cash available for acquisition or other corporate purposes. This may or may not be desirable for any one company, but the possibility of obtaining such results may be of a great interest, showing as they do the flexibility of the model.

\section{THE EFFECT OF ACQUIRING SBU WITH SPECIFIC CHARACTERISTICS}

The computer output results for this investigation are labeled $\mathrm{Al}$ and A7, and the effect was investigated by again using the extraordinarily large results from SBU Number 18. Four runs in total are used to draw conclusions about this effect; these runs contain the four possible values of market share options for SBU Number 18 which are $0,1,2$, and 3

Reproduced with permission of the copyright owner. Further reproduction prohibited without permission. 
respectively. The run with market share option equal to zero is considered to be the case of a company which wants to acquire a new SBU, and each of the alternatives using market share options 1,2 , and 3 are then considered for the effect on the financial results of the company after the acquisition of one of the three "new" SBU. Table IX summarizes the results of the four computer runs, where some interesting statistics resulted. The runs were made using the present value of shareholder equity as the maximization criterion, and show that future aspects of the company could be greatly improved by option 1 or 2 and would be helped by option 3. It is beyond the scope of this research to speculate on the price at which the acquisition could be made, and the decision-making group of the company must determine the price they are willing to pay to become a company with the characteristics shown for the combined companies. Thus, although a great deal more analysis would be required to determine if the acquisition is practical, the technique demonstrated here could be of great value. The probabilistic techniques described in Section $\mathrm{X}$ of this chapter would also be of value, and although they do not go to sufficient depth to be comparable wi th the results shown in Table IX, they would be useful in an acquisition analysis.

\section{A CONSIDERATION OF JOINT EFFECTS}

The computer output results for this investigation are labeled $\mathrm{Jl}$ through I13 and A1, A2, and A3. As described in Chapter II, an investi-

Reproduced with permission of the copyright owner. Further reproduction prohibited without permission. 
TABLE IX

COMPARISON OF KEY OPERATING RESULTS WHEN AN SBU WITH SPECIFIC CHARACTERISTICS IS ACQUIRED

Measurement Criteria
Company Without SBU \# 18
Company With Company With Company With SBU \#18- 1 SBU \#18-2 SBU \#18- 3

\begin{tabular}{|c|c|c|c|c|}
\hline $\begin{array}{l}\text { Present Value of Shareholder } \\
\text { Equity (millions of \$) }\end{array}$ & 103.8 & 159.4 & 156.1 & 124.9 \\
\hline Growth in Earnings per Share (\%) & 444.2 & 61.2 & 45.7 & 31.5 \\
\hline Growth in Total Assets (\%) & 28.0 & 65.8 & 62.2 & 34.0 \\
\hline Ending Total Assets (millions of: \$) & 60.2 & 98.1 & 95.0 & 76.6 \\
\hline Growth in Sales (\%) & 73.5 & 54.2 & 49.8 & 43.0 \\
\hline Sales in Final Year (millions of \$) & 76.6 & 114.8 & 111.5 & 98.1 \\
\hline Debt to Equity Ratio in Final Year & .42 & .29 & .30 & .40 \\
\hline Return on Equity in Final Year (\%) & 12.8 & 19.6 & 18.3 & 19.6 \\
\hline Dividends/Share in Final Year (\$) & .21 & .60 & .54 & .43 \\
\hline Total Cash Generated (millions of \$) & -0.6 & 7.9 & 7.9 & -1.3 \\
\hline Cash Held in Final Year (millions of \$) & 9.3 & 16.0 & 16.1 & 8.2 \\
\hline Profit in Final Year (millions of \$) & 4.9 & 13.6 & 12.2 & 9.7 \\
\hline
\end{tabular}


gation of the joint effects between the two strategic policies, debt to equity ratio and dividend rate, were carried out, and Table $\mathrm{X}$ and Figure 8 summarize the results. The results were obtained using the present value of shareholder equity as a maximization criterion for the various combinations of dividend rate and debt to equity ratio limits shown in Table X. Some of the combinations were not possible within the restrictIons, and hence restricted optima were required for Runs J9 through J13, the five most restrictive combinations. For the combinations where restricted optima were required, there is an entry in Table X under the column labeled Present Value of Shareholder Equity of Liquidated SBU. The present value of shareholder equity was adjusted by removing the present value of new equity sales, because if required, new equity could also have been raised. To render the cases comparable, it was desirable to make such an adjustment.

Figure 8 demonstrates that the present value of shareholder equity (adjusted), is very nearly a plane in the three dimensions shown, except for the effect of incurring a restricted optimum. The restricted optimum is quite probably less than a true optimum, but it is obtained by the operator of the model, as explained elsewhere. The operator must exercise judgment about which SBU should be reduced or liquidated, basing such judgment on factors outside the model's assumptions. In any case, the restrictions force the true optimum to be less than the extended plane, which represents the present value of shareholder equity for the unrestricted optimum.

Reproduced with permission of the copyright owner. Further reproduction prohibited without permission. 
TABLE X

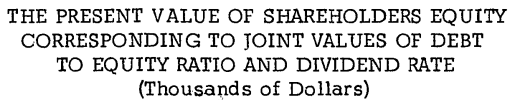

Debt to Equity Dividend Present Value Present Value Present Value of Ratio Rate of of Shareholder Shareholders Shareholders Equity Equity Equity of Liquidated SBU

Unadjusted Adjusted

\begin{tabular}{|c|c|c|c|c|}
\hline 0.3 & $\begin{array}{l}0.1 \\
0.2 \\
0.3\end{array}$ & $\begin{array}{l}179.5 \\
175.0 \\
162.7\end{array}$ & $\begin{array}{l}165.8 \\
157.3 \\
143.2\end{array}$ & $\begin{array}{l}4,431.1 \\
5,330.6 \\
8,203.2\end{array}$ \\
\hline 0.4 & $\begin{array}{l}0.1 \\
0.2 \\
0.3\end{array}$ & $\begin{array}{l}182.6 \\
174.2 \\
162.9\end{array}$ & $\begin{array}{l}168.1 \\
158.9 \\
146.1\end{array}$ & $\begin{array}{r}- \\
866.7 \\
4,339.3\end{array}$ \\
\hline 0.45 & $\begin{array}{l}0.1 \\
0.2 \\
0.3\end{array}$ & $\begin{array}{l}177.9 \\
171.5 \\
165.1\end{array}$ & $\begin{array}{l}167.8 \\
158.7 \\
169.7\end{array}$ & $\begin{array}{l}- \\
- \\
-\end{array}$ \\
\hline 0.5 & $\begin{array}{l}0.1 \\
0.2 \\
0.3\end{array}$ & $\begin{array}{l}173.6 \\
167.2 \\
160.8\end{array}$ & $\begin{array}{l}167.5 \\
158.3 \\
149.2\end{array}$ & $\begin{array}{l}- \\
-\end{array}$ \\
\hline 0.6 & $\begin{array}{l}0.1 \\
0.2 \\
0.3\end{array}$ & $\begin{array}{l}167.2 \\
159.4 \\
153.1\end{array}$ & $\begin{array}{l}167.2 \\
158.1 \\
149.2\end{array}$ & $\begin{array}{l}- \\
- \\
-\end{array}$ \\
\hline 0.7 & $\begin{array}{l}0.1 \\
0.2 \\
0.3\end{array}$ & $\begin{array}{l}167.3 \\
158.1 \\
149.0\end{array}$ & $\begin{array}{l}167.3 \\
158.1 \\
149.0\end{array}$ & $\begin{array}{l}- \\
-\end{array}$ \\
\hline
\end{tabular}

Reproduced with permission of the copyright owner. Further reproduction prohibited without permission. 


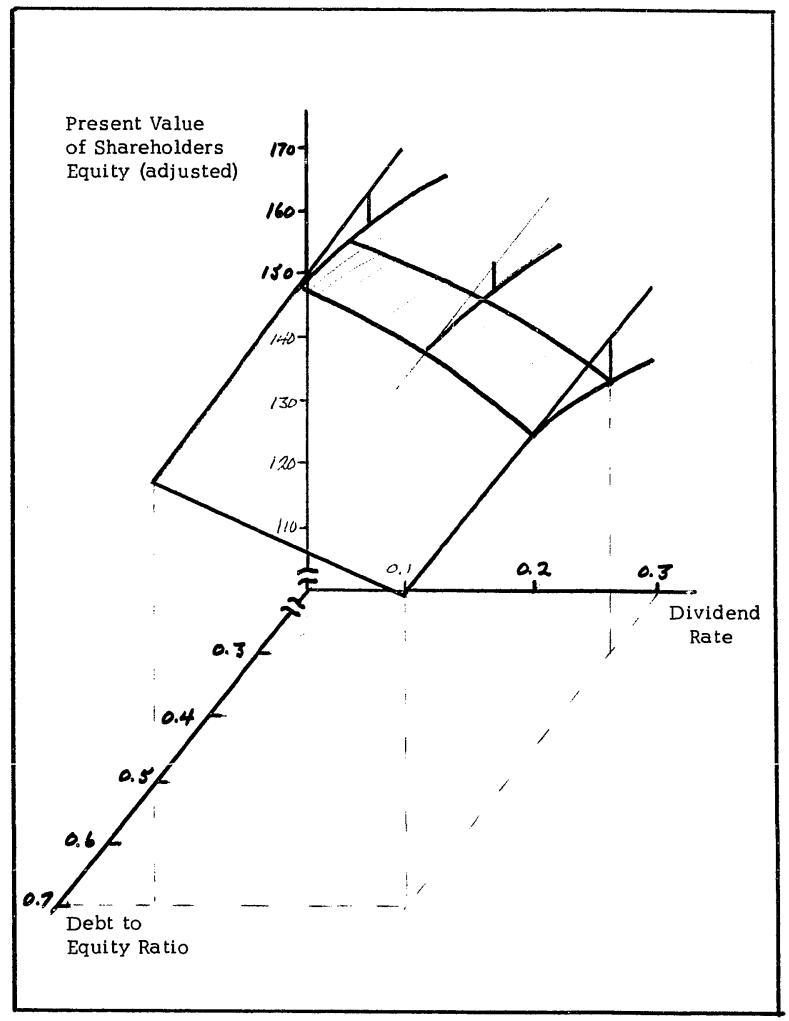

Figure 8 . The present value of shareholders equity as a function of the debt to equity ratio and dividend rate.

Reproduced with permission of the copyright owner. Further reproduction prohibited without permission. 
Using Figure 8, it is possible to forecast the results of any combination of dividend rate and debt to equity ratio in the region where the function is linear, and hence no further investigation in that region is warranted. Because the surface is not smooth, predicting the results of any given combination is difficult in the region where restricted optima are involved. Because of the integer nature of the problem, the surface is composed of a cluster of parallelepipeds subject to the choice of SBU options made by the operator of the model.

\section{THE PROBABILISTIC CASE}

As explained in Chapter II, the probabilistic research was confined to obtaining the mean and variance of the profit and of the cash flow distributions as computed for a given set of SBU market share options. For cases in which the central limit theorem holds, the distribution found will be approximately normally distributed. A begiming company balance sheet similar to Table XXII of Appendix D was used, in conjunction with the set of SBU market share options found when the present value of shareholder equity was optimized (Computer run Al, Table XXI). The beginning balance sheet had such large assets, compared with those required by the set of SBU used, that a large cash flow resulted in the first year. Because the input balance sheet represents given historical information, it was assumed to be a one-point probability distribution with variance zero, and therefore, the variance of the cash flows were less in the first year than in subsequent years. (Program ERP of Appendix B gives the precise definition of the tech-

Reproduced with permission of the copyright owner. Further reproduction prohibited without permission. 
nique used.)

The use of the output results in a real situation is rather obvious. The planner or decision-maker can gauge the likelihood of generating a certain level of profit and cash flow, and if this level is not sufficient, he may take steps to add other SBU, delete poorly performing SBU, or act to reduce the possible variances in critical SBU. Computer output such as found in Tables XI through XIII and in Appendix C would be a good aid in making such decisions.

\section{Results for Assigned Three-Point Probability Distributions}

Table XI and computer Run P1 record the results obtained for the arbitrarily assigned three-point probability distributions. Using the normal distribution and the results in the fifth year for the case in Table XI, it is found that $95.5 \%$ of the time (the mean plus or minus two standard deviatiuns), the cash generated will lie in the range $\$ 4,003<$ cash flow $<$ $\$ 15,903$. In a similar manner $95.5 \%$ of the time the profit in the fifth year can be expected to lie in the range of $\$ 12,360<$ profit $<\$ 15,946$. The dispersion is so much less in the case of profit than it is in the case of the cash flow because of the number of sums required to obtain the total distribution for the cash flow. For a given year, twenty random variables need to be summed to find profit, inventory, receivables, net value of plant, and payables. To find total assets plus profit for a given year, these must be combined algebraically. To determine the cash flow, the assets for a given year must be subtracted from the assets of the

Reproduced with permission of the copyright owner. Further reproduction prohibited without permission. 


\section{RESEARCH RESULTS OF THE PROBABILITY INVESTIGATION USING TWENTY ASSIGNED THREE-POINT \\ PROBABILITY DISTRIBUTIONS \\ ('Thousands of \$)}

$\begin{array}{crccc}\text { Year } & \begin{array}{c}\text { Expected } \\ \text { Cash Flow }\end{array} & \begin{array}{c}\text { Variance of } \\ \text { Cash Flow }\end{array} & \begin{array}{c}\text { Expected } \\ \text { Profit }\end{array} & \begin{array}{c}\text { Variance } \\ \text { in Profit }\end{array} \\ 1 & 32,901 & 3.20 \times 10^{6} & 9,456 & 5.51 \times 10^{5} \\ 2 & 6,187 & 6.08 \times 10^{6} & 10,171 & 5.59 \times 10^{5} \\ 3 & 6,339 & 6.80 \times 10^{6} & 11,222 & 6.20 \times 10^{5} \\ 4 & 8,363 & 7.83 \times 10^{6} & 12,841 & 7.49 \times 10^{5} \\ 5 & 9,953 & 8.83 \times 10^{6} & 14,153 & 8.08 \times 10^{5}\end{array}$

TABLE XII

RESEARCH RESULTS OF THE PROBABILITY INVESTIGATION USING RANDOMLY GENERATED NUMBERS TO CHOOSE ONE OF TWENTY THREE-POINT PROBABILITY DISTRIBUTIONS

(Thousands of \$)

$\begin{array}{crccc}\text { Year } & \begin{array}{c}\text { Expected } \\ \text { Cash Flow }\end{array} & \begin{array}{c}\text { Variance of } \\ \text { Cash Flow }\end{array} & \begin{array}{c}\text { Expected } \\ \text { Profit }\end{array} & \begin{array}{c}\text { Variance } \\ \text { in Profit }\end{array} \\ 1 & 32,718 & 8.92 \times 10^{6} & 8,565 & 2.73 \times 10^{6} \\ 2 & 4,233 & 11.51 \times 10^{6} & 9,604 & 1.58 \times 10^{6} \\ 3 & 7,711 & 12.72 \times 10^{6} & 10,965 & 0.80 \times 10^{6} \\ 4 & 8,532 & 21.41 \times 10^{6} & 12,862 & 3.69 \times 10^{6} \\ 5 & 9,809 & 19.87 \times 10^{6} & 13,724 & 2.00 \times 10^{6}\end{array}$

Reproduced with permission of the copyright owner. Further reproduction prohibited without permission. 
TABLE XIII

\section{RESEARCH RESULTS OF THE PROBABILITY INVESTIGATION WITH SBU NUMBER 18 LIQUIDATED IN YEAR ONE OF THE STUDY AND WITH ASSIGNED THREE- POINT PROBABILITY DISTRIBUTION}

(Thousands of \$)

$\begin{array}{crccc}\text { Year } & \begin{array}{c}\text { Expected } \\ \text { Cash Flow }\end{array} & \begin{array}{c}\text { Variance of } \\ \text { Cash Flow }\end{array} & \begin{array}{c}\text { Expected } \\ \text { Profit }\end{array} & \begin{array}{c}\text { Variance } \\ \text { in Profit }\end{array} \\ 1 & 68,978 & 5.40 \times 10^{6} & 2,140 & 16,389 \\ 2 & -466 & 1.49 \times 10^{6} & 2,853 & 23,687 \\ 3 & 114 & 1.76 \times 10^{6} & 3,544 & 31,157 \\ 5 & 1,222 & 2.13 \times 10^{6} & 4,427 & 41,561 \\ 5 & 2,285 & 2.60 \times 10^{6} & 5,505 & 60,174\end{array}$

previous year, with the profits of the given year added to this number. Thus, while the profit of any year is the sum of only 20 distributions, the cash flow is the algebraic sum of as many as 189 distributions. Because the variances are added, even when the means are subtracted, the dispersion of the resulting distribution has the opportunity to be much greater than the dispersion of the distribution for the profit value, even though the underlying probability distributions are assumed to be equal.

Results for Randomly Assigned Three-Point Probability Distributions

As discussed earlier there are 30 separate values requiring a probability distribution for each SBU market share option. Results in Table XI should be compared with those in Tabies XiI in order to understand the results

Reproduced with permission of the copyright owner. Further reproduction prohibited without permission. 
of the investigation when the probability distribution associated with each value was chosen at random. The main difference between the two results is the size of the variance of the cash flow distribution. For example, in the fifth year $95.5 \%$ of the time the cash flow can be expected to lie in the range $\$ 889<$ cash flow $<\$ 18,719$. In a similar manner $95.5 \%$ of the time the profit should lie in the range $\$ 10,896<$ profit $<\$ 16,552$, both of which have much larger ranges than found in the case of Table XI.

The difference is very likely because of the dispersion of the distribution assigned to SBU Number 18. As mentioned previously, SBU Number 18 is very large compared with any of the other SBU. And as can be seen from Table XXVII of Appendix D, the distribution which was assigned to it (also Number 18 in the first case) has a variance equal to 0.0096 , much smaller than the average of the variances of the entire set. When the distributions were chosen at random, it was thus likely some distributions with larger variances were assigned to some of the values of SBU Number 18 , resulting in the differences observed.

\section{Results for a Reduced Set of SBU Options}

Table XIII is the result of using the same procedures as those depicted in Table XI, except that SBU Number 18 is assumed to have been liquidated in the first year, with this liquidation producing the large cash flow seen in the first year results. There are substantially lower profits expected from the reduced set of SBU. Thus, $95.5 \%$ of the time in the fifth year the cash flow shouĩa iie in the range $-\$ 2,405<$ cash filow $<\$ 6,925$ and

Reproduced with permission of the copyright owner. Further reproduction prohibited without permission. 
profit in the range $\$ 5,010<$ profit $<\$ 6,000$. The range of the cash flow overlaps with the range for the cash flows for the other two cases, but this is not true for the likely range of profits.

\section{OTHER RESULTS}

A number of other results could be tabulated from the large number of runs performed, and the more important ones are discussed in the following subsections. Each balance sheet could be the subject of an extensive financial analysis, but such a detailed discussion is not warranted.

\section{Comparison of Measurement Criteria}

Table XIV compares not only the values of the measurement criteria where they are optimized, but the cases where other measurement criteria are optimized as well. While results shown are for the case where the dividend policy is being investigated, results for the debt to equity ratio policy would be very similar. As pointed out earlier, measurement criteria I, II, and IV resulted in the same optimal set, and the results are not duplicated in Table XIV.

As shown in Table XIV, the results are very similar, even though non optimal values are being compared. In a similar manner as discussed in regard to Table III, an adjustment of the present value of shareholder equity is shown in Table XIV. There was no change in Measurement Criterion V (growth in sales), because over the range of investigation the changes in dividenả poîicy did not resuit in a restricted optimum.

Reproduced with permission of the copyright owner. Further reproduction prohibited without permission. 
TABLE XIV

COMPARISON OF MEASUREMENT CRITERIA IN THE ANALYSIS OF DIVIDEND POLICY

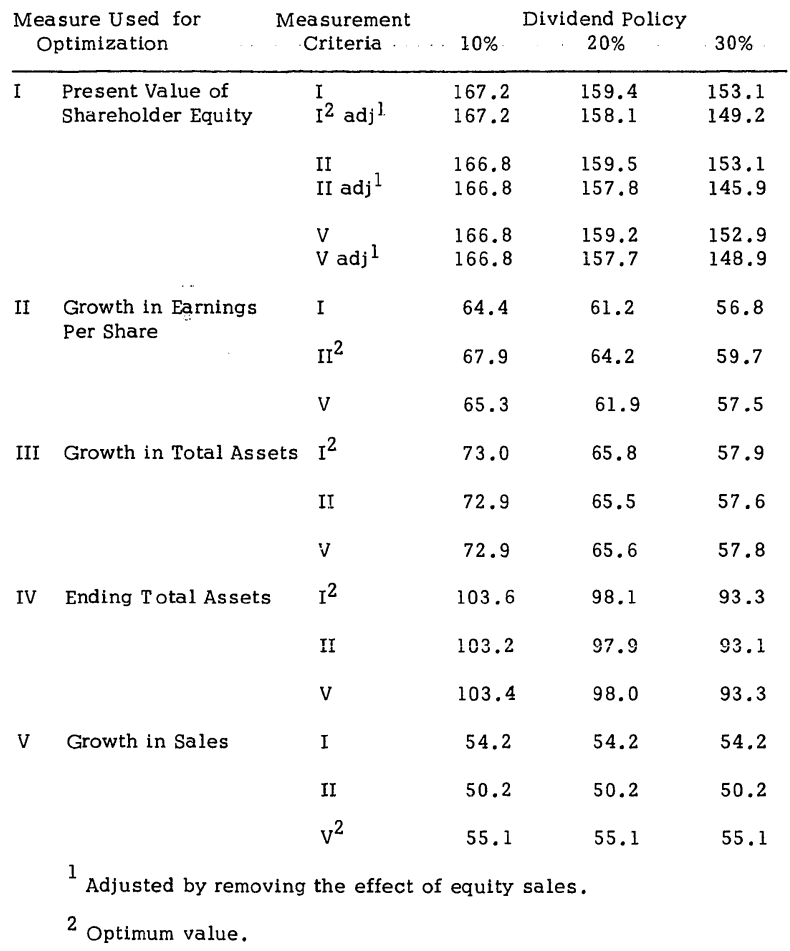

Reproduced with permission of the copyright owner. Further reproduction prohibited without permission. 
The observation that the measurement criteria seem to give highly correlated results could be unique to the company being considered, or it generally could be true. There are only a few differences in SBU market share options among the optimum sets of each measurement criterion in Table XXI of Appendix C, and it seems the measurement criteria may produce very similar optimum sets and similar measurement results over a wide range of companies. The result should be investigated further.

The Present Value of Shareholder Equity Divided by the Present Value of Net Assets Employed

One computer run (Fl) used as its measurement criterion for optimization the present value of shareholder equity divided by the present value of net assets employed. Table XXI shows that the optimal set under this criterion differs significantly from those of the other five criteria. This conclusion is made based on the type of SBU market share options and the number of different SBU options appearing in the optimal set.

A comparison of results for this measurement criterion with the results for the present value of shareholder equity is contained in Table XV. The comparison seems to indicate there could be a significant opportunity for investigation, as many companies today use some form of return on assets as a measurement factor $(5,15,2 \mathrm{I})$. Table XV demonstrates that equity divided by assets generates more cash over the study horizon, but that it generates only $85 \%$ as much profit in the final year. In addition, sales and growth in earnings per share grew more slowly. For the set of measures

Reproduced with permission of the copyright owner. Further reproduction prohibited without permission. 
TABLE XV

COMPARISON OF KEY OPERATING RESULTS FOR TWO WIDELY VARYING MEASUREMENT C RITERIA

Mea surement Criteria
Present Value of Present Value of ShareShareholder Equity holder Equity divided by the Present Value of Net Assets 1

\begin{tabular}{|c|c|c|}
\hline $\begin{array}{l}\text { Present Value of Shareholder } \\
\text { Equity (millions of \$) }\end{array}$ & 159.4 & 154.3 \\
\hline Growth in Earnings Per Share $(\%)^{2}$ & 61.2 & 40.4 \\
\hline Growth in Total Assets $(\%)^{2}$ & 65.8 & 60.5 \\
\hline Ending Total Assets (millions of \$) & 98.1 & 93.2 \\
\hline Growth in Sales $(\%)^{2}$ & 54.2 & 46.8 \\
\hline Sales in Final Year (millions of \$) & 114.8 & 105.3 \\
\hline Debt to Equity Ratio in Final Year (\%) & .29 & .30 \\
\hline Return on Equity in Final Year (\%) & 19.6 & 17.6 \\
\hline Dividends/Share in Final Year & .60 & .51 \\
\hline Total Cash Generated (millions of $\$$ ) & 7,9 & 9.2 \\
\hline $\begin{array}{l}\text { Cash Held as Investment in Final } \\
\text { Year (millions of \$) }\end{array}$ & 16.0 & 17.4 \\
\hline Profit in Final Year (millions of $\$$ ) & 13.6 & 11.5 \\
\hline
\end{tabular}

${ }^{1}$ A dividend rate of $20 \%$ and a debt to equity limit of 0.6 were used. 2 See Appendix I for a definition of growth.

Reproduced with permission of the copyright owner. Further reproduction prohibited without permission. 
compared in the company investigated, a significantly different company results from the use of the present value of shareholder equity divided by the present value of net assets as a measure of success. This result should be investigated in much more depth and for several other measurement criteria.

\section{The Company-Selected Set of SBU}

This subsection compares the results of using the company-selected market share options with an optimal set found for the present value of shareholder equity shown in Table XVI. The company-chosen set (computer Run AO) is discussed in Chapter III. As seen in Table XXI, there is not a large number of differences in the SBU market share options chosen. While the resulting values shown in Table XVI are not very different from optimum, the profit in the last year of the planning horizon is only $89 \%$ of the optimum profit. There seems to be a difference significant enough to warrant investigation by the company.

There may be perfectly good operating reasons beyond the ones considered in the model for using the market share options chosen. The optimal solution, however, does show that another set of options could be considered and that it is feasible within the restrictions specified. But the model would be of value even if such an evaluation were its only use.

Reproduced with permission of the copyright owner. Further reproduction prohibited without permission. 
TABLE XVI

\section{COMPARISON OF KEY OPERATING RESULTS FOR THE COMPANY SELECTED CASE AND AN OPTIMAL CASE}

\begin{abstract}
Measurement ${ }^{1}$ Criteria
\end{abstract}

Present Value of Company Selected Shareholder Equity Market Share Options Optimal Case
"Base Case"
Present Value of $\mathrm{S}$ hareholder

Equity (millions of \$)

Growth in Earnings Per Share (\%) ${ }^{2}$

Growth in Total Assets (\%) ${ }^{2}$

Ending Total Assets

(millions of \$)

Growth in Sales $(\%)^{2}$

Sales in Final Year

(millions of \$)

Debt to Equity Ratio

in Final Year

Return on Equity in

Final Year (\%)

Dividends/Share in Final Year

Total Cash Generated

(millions of \$)

Cash $\mathrm{H}$ eld as Investment

in Final Year (millions of \$)

Profit in Final Year

(millions of \$)
159.4

156.0

61.2

46.7

65.8

61.8

98.1

94.7

54.2

46.3

114.8

108.9

.29

.30

19.6

18.3

.60

.54

7.9

9.4

16.0

17.6

13.6

12.2

${ }^{1}$ A dividend policy of $20 \%$ and a debt to equity limit of 0.6 were used. 2 See Appendix I for a definition of growth.

Reproduced with permission of the copyright owner. Further reproduction prohibited without permission. 


\section{RESULTS WITH RESTRICTED OPTIMA}

The operation of the model when a restricted optimum is required uses program ER6 of Appendix B, and this function of the model has been discussed in Chapter II and Appendix A. The operator must decide which SBU market share options are to be changed or liquidated to meet the balance sheet restrictions. Computer runs J9 through J13 of Appendix C exemplify specific cases where it was necessary to obtain a restricted quasi-optimal solution for the conditions being tested. The sequence of events leading to a solution may be followed on the computer run sheets cited.

As indicated in Appendix A, the algorithm for obtaining the optimum requires moving from the unrestricted optimum to the restricted optimum, replacing the one set of SBU options with another set of SBU options which reduce the value of the measurement criterion by the least amount. Although this can probably be done mechanically in order to obtain a mechanical optimum, the modelidoes not encompass all of the factors influencing the measurement criterion. Hence, the mechanical solution is probabiy not as satisfactory as the operator-selected solution, since judgment in this process is very important. Liquidation generally is necessary and some SBU may be much easter to liquidate in practice than others, and it is therefore important for the operator to be able to designate which SBU are to be liquidated. The number of liquidations involved will be important in a practical application of the model, as it may be easier to liquidate one large SDU than to liquidate several small ones.

Reproduced with permission of the copyright owner. Further reproduction prohibited without permission. 
Table XVII (from computer run W1) is produced as an aid to the operator in choosing which SBU can be liquidated with the least effect on the measurement criterion. The entries in Table XVII are found by using program PR9 on the intermediate files produced by the first major section of the model (program ER2) for each measurement criterion to be considered. The table shows the amount the criterion will be reduced, for the present value of shareholder equity, if the SBU in question is liquidated from the optimum set of SBU. For example, the first SBU which should be considered for liquidation is Number 10, because it makes the smallest contribution $(\$ 386)$ to the measurement criterion. Number $3(\$ 449)$ should be second, but only after Number 10 has been restored to the evaluation set. Otherwise, the two would have been liquidated, and the total reduction would be the sum of the two values in question $(\$ 835)$-- more than SBU Number 14 (\$566), which should be the next step in order.

In the operation of Run $\mathrm{J} 9$ of Appendix $\mathrm{C}$ line 2 as an example, the computer prints a number -2621 , which is the dollars of equity still to be raised to meet the restrictions. It is possible to develop a computer program to print the amount by which the needed new equity will be reduced if certain SBU market share options in certain years are liquidated, but this was not done as part of the research. If it were, such a list could be used as a guide in conjunction with Table XVII to help the operator make reasonably efficient decisions about liquidation. More work needs to be done to develop such a program and table. However, because it depends

Reproduced with permission of the copyright owner. Further reproduction prohibited without permission. 
TABLE XVII

THE AMOUNT BY WHICH THE PRESENT

VAIUE OF SHAREHOLDER EQUITY

WILL BE REDUCED IF A GIVEN

SBU IS LIQUIDATED

\begin{tabular}{cccc}
$\begin{array}{l}\text { SBU } \\
\text { Number }\end{array}$ & $\begin{array}{c}\text { Amount of Reduction } \\
\text { (Thousands of \$) }\end{array}$ & $\begin{array}{l}\text { SBU } \\
\text { Number }\end{array}$ & $\begin{array}{c}\text { Amount of Reduction } \\
\text { (Thousands of \$) }\end{array}$ \\
\hline 1 & 4,431 & 11 & 2,931 \\
2 & 1,323 & 12 & 2,167 \\
3 & 449 & 13 & 931 \\
4 & 1,128 & 14 & 566 \\
5 & 3,164 & 15 & 2,904 \\
6 & 5,300 & 16 & 667 \\
7 & 763 & 17 & 575 \\
8 & 1,656 & 18 & 39,811 \\
9 & 867 & 19 & 1,598 \\
10 & 386 & 20 & 615
\end{tabular}

Reproduced with permission of the copyright owner. Further reproduction prohibited without permission. 
on which measurement criterion is being used, and on which restrictions are in effect, the reduction in required equity can be changed significantly.

\section{SUMMARY}

Each of six policies were analyzed in detail, as were the effect of five measurement criteria, and it was found the five measurement criteria gave very similar results. Some consideration was given to the results of joint effects between two of the policies. The substantially different results obtained using an optimization criterion, with assets in the denominator, was examined, as was the difference between the company-chosen set and an optimal set of SBU market share options.

A limited probability investigation was discussed, providing a probability distribution of profit and of cash flow for a set of SBU being evaluated. Although the model was not programmed to use these distributions to find the optimal solution set and the resulting probable balance sheet, the work is considered to be a valuable base for further research. Finally, the use of the model to find the quasi-optimum set of SBU market share options, when a restricted optimum was required, was explored, and some of possible aids to the operator in finding which market share options to liquidate were mentioned.

The next chapter contains the findings and conclusions of the research, along with suggestions for other investigations. The constraints of the model are discussed, along with some tentative conclusions.

Reproduced with permission of the copyright owner. Further reproduction prohibited without permission. 
CHAPTER V

SUMMARY AND CONCLUSIONS

\section{OVERVIEW}

This chapter summarizes the conclusions obtained and mentions the advantages and constraints of the model and the approach. Some points are more conclusive than others, and those which are not conclusive are contained in a section of suppositions. An important subsection of the chapter deals with problems which would seem to warrant further investigation.

The use of the model is explored, as is its value as a device for obtaining insight into the results of managing SBU in selected ways. The value of the several measurement criteria for optimization is highlighted, and the similarity of the results obtained using the criteria is mentioned.

The success of procedures developed in this research for i mproving the methods of selecting SBU to be included in a company portfolio is commented on. It is suggested that the simulation model should be used in a supporting role to company management, and the policies which seem to be best suited for simulation are indicated.

Reproduced with permission of the copyright owner. Further reproduction prohibited without permission. 


\section{ADVANTAGES AND CONSTRAINTS}

This section discusses the advantages and constraints of the model, but the suppositions or tentative results of the research and other investigations of interest are found in the next sections.

\section{Advantages of the Model}

The advantages of the model are made most apparent by the uses to which it can be put and its flexibility with a wide range of investigations. Perhaps the most important advantage of the model is to support the planning process by helping gain insight into the future through evaluating alternative scenarios and "playing what if games". Thus it can be used to investigate the effect of changing assumptions about the business environment.

The model is quite flexible, as can be seen from the very wide choice of input data, restrictions, and company specification which can be used. A particularly good use of the model would be in the evaluation of acquisition possibilities. This can be done with relative ease by considering an existing company as one SBU and the acquisition candidate as other SBU. The various market share options can be alternative assumptions about the acquisition candidate. Of course, if funding the new acquisition requires divestiture, the present company would have to be partitioned, though probably not into all of its component SBU.

Another use of the model is to help select the optimum set of SBU

Reproduced with permission of the copyright owner. Further reproduction prohibited without permission. 
market share options from those available. This is particularly useful when the company resources are not sufficient to fund all of the opportunities presented for consideration. The model is sufficiently flexible to do this for several measures of success, and hence the model can be used either to evaluate a selected set of SBU options or to find an optimal set.

The model is valuable in computing the mean and standard deviation of the distribution of after-tax profit and cash flow which result from a given set of SBU market share options. These are both useful numbers to the planner or decision-maker. With such numbers, actions can be taken to add or delete critical SBU, or to reduce the variation in certain key variables of an SBU, in order to help meet management objectives.

Another good use of the model is to evaluate the effect of such strategic policies as debt to equity ratio, dividend rate, and growth rate, and hence the model is an aid to financial planning.

The model is also a good arithmetical tool because many computations in financial planning can be performed by the model. Although simple in form, these computations are complicated by their large number and the restrictions placed on the final balance sheet. Thus it is useful when a number of outcomes are possible and numerous alternatives are to be evaluated. The model can also be used to evaluate the sensitivity of results to initial conditions or errors in the data, and with its capacity for rapid calculation, many changes can be made and the results computed.

The model should be used in a supporting role. It is mechanistic in

Reproduced with permission of the copyright owner. Further reproduction prohibited without permission. 
nature, and although it can be used to establish the apparent feasibility of a set of market share options, management must look further and examine other factors before making decisions, because the model cannot possibly consider all of the variables.

\section{Constraints in the Model and Approach}

There are a number of constraints or shortcomings in the model, some of which would also be constraints in other modeling efforts. One important constraint is the fact that the model is connected loosely with the outside business environment, and the optima found are less than global. Some of the factors which are ignored, and perhaps should be considered, are stock price, government actions, competitive actions, national laws, and the degree of any labor unrest. Some of these are taken into account when the elemental planning job for each SBU is performed, but the model has no means for taking these into account, once the consolidation of results has taken place. Of course, it is one of the jobs of management to review the Output of the model for just such things.

The SBU are assumed to be independent of each other. This generally is not wholly true, but can usually be taken into account, elther by combining SBU or by eliminating the effect of intercompany transactions. Further, the contribution of the SBU is assumed to be independent of corporate level expenses, which may not be totally true and must be compensated for by allocating such expenses .

While the fiexibiiity of the model is a definite audvantage, it is also

Reproduced with permission of the copyright owner. Further reproduction prohibited without permission. 
a disadvantage because of the cost and difficulty in obtaining the required volume of input data. The complexity is likewise an advantage and a problem because it makes the model slow to execute, and the training and start-up costs, resulting from complexity, are burdensome. The concept of SBU generally is new in industry, and a certain amount of care must be used to be sure the SBU are properly formed and are not too large or too small. Of course, this problem can be argued to be an advantage, forcing as it does a degree of planning which otherwise might not have taken place.

The choice of computer, and the computer language, could have been better, Although the choices were made for economical reasons, the performance of the model would have been better had the programming been done in the IBM language known as PL-1. Unfortunately, the more generally known language, Fortran, was not available for timesharing software used. The Basic language, although it makes the programs more easily understood, does not have the power for data handling required of such an extensive model, and required a great deal of core storage.

There are some other more detailed problems in the model approach. The model: 1) does not simulate operation within an SBU; 2) except to a limited degree assumes no probability distribution for the input data; 3) assumes the SBU are integer in nature; and 4) does not provide for the balance sheet restrictions or company specifications to vary with time. The optimization program was accomplished in two phases because of

Reproduced with permission of the copyright owner. Further reproduction prohibited without permission. 
a shortage of core storage, and this division of the programs caused several false starts. The computer run time was difficult to make acceptable for the restricted optima case, and a great deal of programming effort and time went into making the program operate in the space available.

\section{SUPPOSITIONS AND OTHER INVESTIGATIONS}

This section discusses some suppositions or tentative conclusions and indicates some of the areas where further investigation would be useful. Most of the suppositions are good areas for further research as well. The next section of this chapter discusses the conclusions which can be reached about the research.

\section{Suppositions}

There are a number of results which seem to be true, and there is indicative information which suggests certain others may be true, but which require further investigation. Such findings are contained in this subsection. Perhaps the most important of these is the possibility that return on assets may not be a desirable measure for the long-range success of a corporation. While the information was drawn from an example of only one company, for the company examined it was true.

Another important supposition is that the five measures of success (present value of shareholder equity, growth in earnings per share,etc.) are very highly correlated. Even though the measures gave slightly different

Reproduced with permission of the copyright owner. Further reproduction prohibited without permission. 
results in the research, the results were very similar for the case studied.

It seems aggressive growth will use more cash in the short run than will a less aggressive approach to growth, but the more aggressive approach will generate more profit and more cash in the long run. There are times when it may be appropriate to increase cash rather than attempt to grow more rapidly, and one of these times may be when an analysis of the risks involved shows that more rapid growth is not justified. Another may occur when it is the known policy of the company to accumulate cash for some purpose such as a hedge against depression, or for use in a possible acquisition.

When the optimal solutions were restricted, and less aggressive. market share options were required, the restricted optimal solution was not appreciably approached until an SBU was liquidated and the cash was entered into the balance sheet. There needs to be more study on the nature of the decision surface for problems of this type. Of course, it is a function of the particular case involved, but it is interesting that the less aggressive options made only small changes in the amount by which restrictions were violated until liquidation took place.

Company management can act independently of the SBU and materially change the success level of the corporation by changing the dividend policy. It seems this is stronger than a supposition, but other supporting work with other companies would help to verify the result.

It appears the debt to equity ratio does not particularly change the

Reproduced with permission of the copyright owner. Further reproduction prohibited without permission. 
success of the company until the optimum set of market share options are restricted.

The present value of shareholder equity weights the near term results more heavily than long-range results, and as valuable as this measure seems to be, this effect must be considered further to be sure it provides desirable results.

\section{Other Investigations of Interest}

The ideas presented in this subsection, along with those in the supposition subsection above, are areas where further research work could be useful.

An important area for further research would be an extension of the probability work started in this dissertation. It would be of particular value to complete the evaluation of a given set of SBU market share options, so that a balance sheet produced for the planning horizon would meet the restrictions at some stated level of confidence.

Perhaps the most important area for further research not already mentioned is the effect on company success of other restrictions on the balance sheet. Among these are price at which equity can be raised, cash as a percentage of short term assets, and short term assets as a multiple of short term liabilities.

Related to the point above is an investigation of the relationship between stock market results, dividend policy and company success. The model is related to the equity and stock market by the assumption that equity

Reproduced with permission of the copyright owner. Further reproduction prohibited without permission. 
can be raised at a certain value, but this needs further refinement before mechanically obtained restricted optima will be of great value.

The company investigated was cash "rich" and work needs to be done with companies which are cash "poor" (that is where there are many competing SBU options for the small amount of cash avallable). This may lead to a whole new range of suppositions and insight, for it seems reasonable that the concepts yresented in this research are of more value for such cases.

The effect of other factors such as tax rate, currency exchange limitations, and risk of expropriation should be investigated.

There could be more meaningful work done on devising guidelines for aiding the operator of the model in easily and accurately making good choices of SBU to remove from the optimal solution set when obtaining a restricted optimum. The amount of equity which must be raised is known, as is the amount which the balance sheet restrictions will allow. However, the amount of reduction in the unfulfilled requirement, which results from the liquidation of an SBU, is a function of the debt to equity ratio. Dividend rate measurement criteria and other corporate specifications could be computed in tabular form as a helpful aid to the decision-maker.

More useful work can be done on investigating the value of acquiring specific companies; particularly if it can be done with some of the SBU lumped into one "super" SBU to reduce complexity. This "reduced" model would be of value for its efficiency of operation, which in turn could make

Reproduced with permission of the copyright owner. Further reproduction prohibited without permission. 
it a better tool forplanners and decision-makers for this specific purpose. The effects on company success by the discount factor, cost of capital, and other possible corporate expense such as advertising and research and development are worth further investigation.

Another area for possible investigation is the question of the effect that liquidating one SBU may have on other SBU in the company. They are assumed to be independent, but if adjustments have been made for interSBU sales or if corporate expenses have been allocated, the independence assumption is not strictly true. The magnitude of the effects should be understood.

\section{CONCLUSIONS}

The principal problem of the research was to find a procedure to aid in the allocation of company resources to large operating segments of the company in such a way as to help satisfactorily achieve company objectives. The author believes the methods examined in this research accomplish that objective.

It is concluded that the methods presented have onod potential for significantly increasing the cash generation and the efficiency of the investment process in a company. The procedure seems to be particularly valuable where used in a supporting role. It should be noted that, at best, simulation and modeling only are supportive to decision-makers and should never take on a decision-making role, because there are many factors

Reproduced with permission of the copyright owner. Further reproduction prohibited without permission. 
(human and other) outside the assumptions of the model.

The present value of shareholder equity is a useful measurement criteria, although, as mentioned previously, more research needs to be done to be sure the measure does not have unfavorable side effects. It seems there may be a high degree of correlation between the five measures investigated, and all gave a similar optimal set. However, it seems several of the measures should be used together to aid in decision-making, focusing as they do on different aspects of the problem.

The model is very flexible and can be used for a number of purposes, such as to evaluate a given set of SBU options or to find the optimum set of options for specified measurement criteria. It can be used in an interactive mode as an aid to decision-making, and is valuable for evaluating alternatives, performing arithmetical calculations, and as an aid in finding feasible SBU option sets.

It is concluded that the dividend policy has a strong effect on the rate at which a company can grow. The debt to equity ratio policy has its major influence when a restricted optimum is required, and when such is the case, it has a significant effect on which SBU options are included in the optimum set.

The use of pricing to obtain market share indicates more aggressive options will generate more sales, use more cash in the short run, and make more profit. However, the higher risk associated with them may or may not be acceptable. Essentially, the same results are noted from an investigation of the policy of managing for growth stability, or liquidation except

Reproduced with permission of the copyright owner. Further reproduction prohibited without permission. 
that the less aggressive approaches accept a lower market share and profit in order to generate cash.

For the purpose of acquisition, it appears SBU with specific characteristics can be acquired to best meet the measurement criteria. The degree to which this is satisfied depends on the options available when the input data for the SBU are formulated.

The simulation model is a valuable tool for examining the effect of those strategic policies which can be quantified.

There are ranges of complexity where the procedures of this research are most applicable, as well as some very definite limitations. The first obvious limitation is the size, speed, and cost of the available computer hardware. For the computer and language used in this research, twenty SBU with three market shure options each are a practical li mit, and perhaps fifty such SBU are a practical limit for the largest interactive programs. In any case, the limit on management's ability to orchestrate a much larger set of SBU is questioned, although such corporate giants as ITT may be exceptions to the rule. Likewise, there is a lower limit on the number of SBU; even though the method is completely valid, the complexity is not sufficient to warrant the effort if there are too few SBU involved. Perhaps such a lower limit is approximately six SBU (a number which was chosen quite arbitrarily as a mater of the author's judgrient).

A further conclusion is the SBU are good decision variables. It may be possible to develop a very similar methodology as used in this research for other corporate structures, but the concept of SBU seems to present the 
variables in a way which can be useful for analysis and decision-making. In any case, if a company is not involved in this type of modeling, perhaps it should be; it seems to greatly enhance the ability to choose good combinations of SBU market share options.

\section{SUMMARY}

The strengths, constraints, suppositions, recommended investigations and conclusions which represent the results of this research were presented in this chapter. The work has been found useful by the author, and it is his belief the techniques presented here are a useful addition to knowledge of how the planning process in large corporations can be enhanced. The methodology presented here is but one tool, but it seems to be a powerful analytical device for evaluating alternatives and selecting those options which best meet company objectives.

Reproduced with permission of the copyright owner. Further reproduction prohibited without permission. 


\section{A SELECTED BIBLIOGRAPHY}

\section{BOOKS}

1. Ackoff, R.L.; A Concept of Corporate Planning; Wiley-Interscience: New York, 1970.

2. Ansoff, R.U.; Corporate S trategy, McGraw-Hill: New York, 1965.

3. Ayres, R.U.; Technological Forecasting and Long Range Planning, McGraw-Hill: New York, 1969.

4. Bogen, J.I., Shipman, S.S. (editors); Financial Handbook; The Ronald Group, Boston, Mass., 1968.

5. Boston Consulting Group; Prospectives on Growth, Boston Consulting Group, Boston, Mass., 1968.

6. Boston Consulting Group; Prospectives on Corporate Strategy, Boston Consulting Group, Boston, Mass., 1968.

7. Cannon, J.T.; Business Strategy and Policy; Harcourt, Brace \& World, Inc., New York, 1968.

8. Feller, W.; An Introduction to Probability Theory and its Applications, Volume I; john Wlley \& Sons, New York, 1950.

9. Hunt, P., Williams, C.M., Donaldson, G.; Basic Business F inance, Richard \& Irwin, Inc., Homewood, Illinois, 1965.

10. International Business Machines Corporation; IBM System $/ 360$ OS/DOS ITF; Basic Terminal Users Guide; International Business Machines, Inc., New York, 1970.

11. Markowitz, H.; Portfolio Selection: Efficient Diversification of Investments, John Wiley \& Son, Inc., New York, 1959.

12. Meier, R.C., Newell, W.T., Pazer, H.L.; Simulation in Business and Economics, Prentice-Hall, Englewood Cliffs, New Jersey, 1969 .

Reproduced with permission of the copyright owner. Further reproduction prohibited without permission. 
13. Naylor, T.H.; Balintfy, J.L.; Burdick, D.S., and Chu, K; Computer Simulation Techniques, John Wiley \& Son, Inc., New York, 1968.

14. Schreiber, A.N., Editor; Corporate Simulation Models, University of Washington Press, Seattle, Washington, 1970.

15. Steiner, G.A.; Top Management Planning, MacMillan Co., London, 1969.

16. Troy, Leo; Manual of Performance Ratios for Business Analysis and Profit Evaluation; Prentice-Hall, Inc., Englewood Cliffs, New Hersey, 1966.

17. Wagner, H.; Principles of Operation Research, Prentice-Hall, Inc., Englewood Cliffs, New Jersey, 1969.

\section{II . HARVARD BUSINESS REVIEW}

18. Christopher; Marketing Planning that Gets Things Done. Sep.- Oct., 1970 (PP 56-64).

19. Hillman; How to Redeploy A ssets. Nov. - Dec., 1971 (PP 95-103).

20. Kotler; Corporate Models: Better Marketing Plans. Jul. - Aug., 1970 (PP 135-149).

21. Welter; Put Policy First in DCF Analysis. Jan. - Feb., 1970. (PP 141-148).

22. Wittnekert; Bigñess versus Profitability. Jan. - Feb., 1970. (PP 158-166).

\section{MANAGEMENT SCIENCE JOURNAL}

23. Agnew, et al; Chance Constrained Programming to Portfolio Section. June 1969 (PP 512-520).

24. Bierman and Hausman; The Resolution of Investment Uncertainty through Time. August 1972 (PP 654-662).

25. Chen, Jen, Zionts; Portfolio Models with Stochastic Cash Demands. November 1972 (PP 319-332).

Reproduced with permission of the copyright owner. Further reproduction prohibited without permission. 
26. Eppen \& Fama; Three Asset Cash Balance and Dynamic P ortfolio Problems. J anuary 1971 (PP 311-319).

27. Fama; Portfolio Analysis in a Stable Paretian Market, January 1965 (PP 404-419).

28. Hastie; The Determination of Optimal Investment Policy, August 1967 (PP 757-774).

29. Krause; A Model for Aggregate Financial Planning. June 1972 (PP 555-566).

30. Levy; Portfolio Performance and the Investment Horizon. August 1972 (PP 645-653).

31. Pyle and Turnousky; Risk Aversion in Chance Constrained Portfolio Selection. November 1971 (PP 218-225).

32. Sharpe; A Linear Programming Algorithm for $M$ utual Fund Portfolio Selection. March 1967 (PP 499-510).

33. Sharpe; Mean - Absolute - Deviation Characteristic . Lines for Securities and Portfolios. October 1971 (PP 1-13).

IV. BOSTON CONSULTING GROUP PAMPHLETS AND WORKING PAPERS

34. Critical Strategy Decisions; August 1969.

35. Experience Curves as a Planning Tool (IEEE Spectrum, June 1970).

36. Growth and Financial Strategies, 1968.

37. The Impact of Strategic Planning on Executive Behavior, 1968.

38. Strategy Formulation and Evaluation; A Rigorous Approach, 1970.

\section{OTHER SOURCES}

39. Fortune Magazine; "The Fortune 500", Volume IXXXIX No.5, Time, Inc., New York, 1974.

40. Management Accounting; "Section 931 and the Puerto Rican Program", Vol. IV, No.9, March 1974, The National Association of Accountants, New York, 1974.

Reproduced with permission of the copyright owner. Further reproduction prohibited without permission. 
APPENDIX A

SUPPLEMENTARY MATERIAL TO CHAPTER II

\section{OVERVIEW}

This appendix contains material which augments the research material found in Chapter II, and it should be read by anyone who is interested in gaining a better understanding of the details of the simulation model. There are three major sections in this appendix, the first describes the input detail and data collection forms, the second discusses the balance sheet restrictions during simulation, and the third discusses the measurement criteria and the development of the optimization algorithm for each of the five measures used in the research. The material found here is best read in conjunction with the discussion in Chapter II.

\section{INPUT DATA}

The discussion which follows is organized around each of the five data input sheets which are required to specify a corporation composed of a number of SBU. Many of the items on the data sheets are self-explanatory and are not mentioned; however, some are not and these are described in more detail. Throughout the discussion, item number refers to the line number on the figure under discussion.

Reproduced with permission of the copyright owner. Further reproduction prohibited without permission. 


\section{$\underline{\text { SBU Profit and Loss Statement }}$}

Figure 9 (SBU Profit and Loss Statement) must be completed for each SBU market share option under investigation. Thus, in the case of the research reported, there were three market share options for each SBU and twenty SBU; the length of the study horizon was five years, and therefore, there were 150 data sheets to be completed. In abbreviated studies some of the items may not be needed, and if so the data collection phase can be somewhat simplified. While most of the data entries are standard business items and need no explanation, a few should be explained.

Item 9, equivalent fraction of contribution which is fully taxed, is used to account for the significant cash flows which occur when an SBU has tax-sheltered income. This can occur, for example, when income is derived from a Section 931 company, which has special tax treatment under the law (40). (It should be noted tax losses carried forward, or taxsheltered income derived from certain types of corporate investments, should be accounted for in the data sheet of Figure 10.) Thus, if none of the contribution is tax sheltered, 1.0 is enetered $(100 \%)$, but if some taxsheltered income is included, the fraction of line 8 which would be equivalent to no tax-sheltered income, is entered. For example, if line 8 equals $\$ 1$ million and includes $\$ 100,000$ which is taxed at one-half of the corporate rate, 0.95 should be entered.

Line 10, SBU market share at year end, and line 13, market share strategy, are used together. Line 10 is simply management's best guess for the percent of market obtained by the SBU using the strategy recorded

Reproduced with permission of the copyright owner. Further reproduction prohibited without permission. 


\begin{tabular}{|c|c|}
\hline Line \# & Description \\
\hline 1 & Net Sales \\
\hline 2 & Cost of Sales \\
\hline 3 & Gross Margin \\
\hline 4 & Selling Expense \\
\hline 5 & Engineering Expense \\
\hline 6 & Administrative Expense \\
\hline 7 & Other Income (Expense) \\
\hline 8 & SBU Contribution \\
\hline 9 & $\begin{array}{l}\text { Equivalent fraction of } \\
\text { contribution which is } \\
\text { fully taxed }\end{array}$ \\
\hline 10 & $\begin{array}{l}\text { SBU market share at } \\
\text { year end }\end{array}$ \\
\hline 11 & SBU \# \\
\hline 12 & End of Year \# \\
\hline 13 & $\begin{array}{l}\text { Market Share Strategy } \\
(1,2 \text { or } 3)\end{array}$ \\
\hline 14 & Blank \\
\hline 15 & $\begin{array}{l}\text { End of Record Signal } \\
999,777,555 \text {, or } 0\end{array}$ \\
\hline
\end{tabular}

Figure 9. Data input sheet SBU profit and loss statement (in thousands of dollars).

Reproduced with permission of the copyright owner. Further reproduction prohibited without permission. 
in this input sheet and labeled as 1,2 , or 3 in Item 13. Conceptually, any number of strategies can be employed, but for practical purposes the study in this paper is limited to three. The data designated on the input sheet should be management's best estimate of the SBU results expected from the market share stated in Item 10 and labeled in Item 13 . Item 14 is left blank for space for expansion if other factors are discovered which should be carried through the simulation. Item 15 is a data processing convenience to label the record as to end of file 999 , end of year 555 , end of SBU within the year 777 , or otherwise zero.

\section{$\underline{\text { SBU Assets and Liabilities }}$}

Figure 11 records the assets associat ed with each SBU market share option for each year and corresponds to the data described in Figure 9. Because of differences in use during computer processing, the data are contained in different files, but conceptually they need not have been. Again, much of the data is usual accounting information and needs no particuiar expianation.

Items $6,7,8$, and 9 are supplied by the $\mathrm{c}$ omputer and are the result of simple formulas. Item 6 , total assets employed, is defined as the sum of inventory plus receivables plus plant and equipment. (Line $1+2+3)$. This definition is arbitrary and other combinations of assets could be used. Item 7, total net assets employed, Is Item 6 less accumulated depreciation Line 4. Item 8 is another measure of assets employed which is computed by subtracting payables Item 5 from Item 7 . 


\begin{tabular}{|c|c|c|}
\hline Line \# & Description & \\
\hline 1 & Total SBU Contribution & Computer supplied \\
\hline 2 & Corporate Income (or expense) & $\begin{array}{l}\text { (excluding investme } \\
\text { of surplus cash) }\end{array}$ \\
\hline 3 & Interest to Service Debt & Computer supplied \\
\hline 4 & $\operatorname{Tax}$ & Computer supplied \\
\hline 5 & Net Profit after Tax & Computer supplied \\
\hline 6 & Tax Rate on Fully Taxed income & (fraction) \\
\hline 7 & $\begin{array}{l}\text { Equivalent Fully Taxed Income } \\
\text { from SBU }\end{array}$ & Computer supplied \\
\hline 8 & $\begin{array}{l}\text { Interest Income from Investment } \\
\text { Pre-tax }\end{array}$ & Computer supplied \\
\hline 9 & Equivalent Fully Taxed Income & Computer supplied \\
\hline 10 & End of Year \# & \\
\hline
\end{tabular}

Figure 10. Data input sheet abbreviated corporation profit and loss statement (in thousands of dollars).

Item 9 is the after tax liquidation value of the company, at the end of the year designated, if the SBU is company owned, and it is set equal to zero if it is not company owned; however, in the simulation it $w$ as arbitarily set equal to Item 8 , but other values could have been used.

Item 13 is identical to that in Figure 9 and connects the data in Figure 9 and Figure 11. For data processing convenience and to keep the record size exactly equal to 15 , Item 10 and 14 are blank. They do, however,

Reproduced with permission of the copyright owner. Further reproduction prohibited without permission. 


\begin{tabular}{|c|c|c|}
\hline Line \# & Description & \\
\hline 1 & Average Inventory & \\
\hline 2 & Average Receivables & \\
\hline 3 & $\begin{array}{l}\text { Average Plant, Equipment } \\
\text { and Land }\end{array}$ & \\
\hline 4 & $\begin{array}{l}\text { Accumulated Depreciation } \\
\text { for Line } 3\end{array}$ & \\
\hline 5 & Average Payables & \\
\hline 6 & Total Assets Employed & $\begin{array}{l}\text { Computer calcu } \\
\text { lated, need not } \\
\text { be supplied }\end{array}$ \\
\hline 7 & Total Net Assets Employed & $"$ \\
\hline 8 & $\begin{array}{l}\text { Total Net Assets Employed } \\
\text { after Payables }\end{array}$ & $"$ \\
\hline 9 & $\begin{array}{l}\text { After Tax Liquidation value } \\
\text { of the SBU (if currently owned } \\
\text { by corporation, otherwise zero) }\end{array}$ & 1 \\
\hline 10 & Blank & \\
\hline 11 & SBU \# & \\
\hline 12 & End of Year \# & \\
\hline 13 & $\begin{array}{l}\text { Market Share Strategy } \\
(1,2 \text { or } 3)\end{array}$ & \\
\hline 14 & Blank & \\
\hline 15 & $\begin{array}{l}\text { End of Record Signal } \\
(999,777,555 \text {, or } 0)\end{array}$ & \\
\hline
\end{tabular}

Figure 11. Data input sheet SBU assets and liabilities (in thousands of dollars).

Reproduced with permission of the copyright owner. Further reproduction prohibited without permission. 
allow for other data items if any are found necessary.

It must be noted that all inter SBU profit must be eliminated before entering data on forms of Figure 9 and 11 .

\section{Abbreviated Corporation Profit and Loss Statement}

Figure 10 records the corporation profit and loss information; however, all but two lines are calculated by the computer from information supplied in Figures 9 and 11 . Line 2 is the corporate income (negative if expense) which is derived from sources other than SBU. This type of entry occurs from corporate headquarter operations, royalty income, and other miscellaneous income or expense which is strictly related to corporate management. Income from the investment of surplus cash, however, is handled separately by the computer within the simulation and should not be entered here. Line 6 is the corporate tax rate on fully taxed income. In the United States this tax rate is $50 \%$, but it may vary from state to state depending on local taxes, and it is required for each year in the planning horizon.

The formulas for the calculation of the computer supplied numbers are simple financial relations which lead to the after tax income of the corporation, Line 5 .

\section{Corporate Balance Sheet}

Figure 12 provides the beginning balance sheet entries for the simulation, and this base data, along with the projected operating results

Reproduced with permission of the copyright owner. Further reproduction prohibited without permission. 
Beginning of Year I

\begin{tabular}{|c|c|c|c|c|}
\hline Line & & Assets & Line \# & \\
\hline 1 & Cash & & 7 & Payables \\
\hline 2 & Inventories & & 8 & Short Term Debt \\
\hline 3 & Receivables & & 9 & Long Term Debt \\
\hline 4 & Investments & & 10 & $\begin{array}{l}\text { Shareholder } \\
\text { Equity }\end{array}$ \\
\hline & $\begin{array}{l}\text { Plant, Equipment } \\
\text { and Land }\end{array}$ & & & \\
\hline 6 & $\begin{array}{l}\text { Accumulated } \\
\text { Depreciation }\end{array}$ & & & \\
\hline 11 & Total Assets & & 12 & Total Liabilities \\
\hline
\end{tabular}

13 Shares of common stock outstanding

14 Dividend declared on beginning number of shares (total \$)

Čomputer Supplied

15 Dividends per share

Computer Supplied

Figure 12. Data input sheet corporate balance sheet (in thousands of dollars).

already discussed, is used to compute the future balance sheets which are key to the simulation. Lines 11 and 12 , total assets and total liabilities respectively, must be equal by definition and lines 14 and 15 are computer supplied. Unllke the other input data sheets discussed, this form is required only once and need not be supplied for each succeeding year of the planning horizon.

Reproduced with permission of the copyright owner. Further reproduction prohibited without permission. 
The calculation of succeeding years of the balance sheet is described in the section on The Balance Sheet During Simulation, as found in this appendix.

\section{Corporate Operating Criteria}

Figure 13 is used to record corporate operating criteria which serve to limit the size of some of the balance sheet items in the simulation as well as establish a base for some of the strategic questions raised. Most of the factors are self-explanatory and are well defined in financial literature. However, a few require explanation.

Line 1, the discount factor, as established by management as the pretax value of the cost of capital to the firm. There are a number of articles relating to the definitions of this term (9), and it seems it can have a wide range of possible values. It is at least equal to the bank rate for borrowing money, but it is probably higher because excessive borrowing can "weaken" the balance sheet and increase the interest cost at which further borrowing can be done. If a company is making a specific pre-tax profit on its present assets, and wants to maintain this value as a minimum, then the value of the discount factor should be at least equal to this profit rate. Its effect on the simulation results could be investigated and would be an interesting undertaking. However, for the purpose of this research it was set at $15 \%$.

Line 2 is the rule for declaring dividends. This, of course, is only an approximation to reality for dividends, as declared by most boards of directors, seem to take into account other factors besides earnings;

Reproduced with permission of the copyright owner. Further reproduction prohibited without permission. 


\begin{tabular}{|c|c|}
\hline Line \# & Description \\
\hline 1 & $\begin{array}{l}\text { Discount factor s } \\
\text { (Management established value } \\
\text { equal to the pre-tax cost of } \\
\text { capital to the firm) }\end{array}$ \\
\hline 2 & $\begin{array}{l}\text { Dividends as a fraction of net } \\
\text { profit after tax }\end{array}$ \\
\hline 3 & Maximum debt to equity ratio \\
\hline 4 & $\begin{array}{l}\text { Minimum current ratio (must } \\
\text { be greater than } 1 \text { ) }\end{array}$ \\
\hline 5 & $\begin{array}{l}\text { Minimum cash as a fraction of } \\
\text { other beginning current assets }\end{array}$ \\
\hline 6 & $\begin{array}{l}\text { Effective interest rate pre-tax } \\
\text { on long and short term debt }\end{array}$ \\
\hline 7 & $\begin{array}{l}\text { Return on corporate investments } \\
\text { pre-tax }\end{array}$ \\
\hline 8 & $\begin{array}{l}\text { Maximum acceptable dilution } \\
\text { from equity sales (as a fraction } \\
\text { of the current year's earnings/share) }\end{array}$ \\
\hline 9 & $\begin{array}{l}\text { Number of times old earnings/share } \\
\text { for which new equity can be raised }\end{array}$ \\
\hline 10 & Blank \\
\hline
\end{tabular}

Figure 13. Da ia input sheet corporate specifications.

however, such a dividend rate is quite adequate to investigate the effect of changes in the dividend policy.

Line 8 , the maximum acceptable dilution from equity sales, limits the amount of new equity that $\mathrm{c}$ an be raised by selling stock. It is a management : judgment factor, but $\mathrm{i}$ s required to restrict the balance sheet during

Reproduced with permission of the copyright owner. Further reproduction prohibited without permission. 
simulation. Line 9, the number of times last year's earnings per share for which new equity can be raised, is a semi-automatic way of entering the sale price of a new issue of company stock. It has the same basis in practice however, as "earnings per share multiples" and is one way of judging probable stock selling prices, thus restricting the simulation.

It is assumed the specifications established in Figure 13 hold for the entire planning horizon, and as a result only one input form is required. It was judged to be unnecessary to make the data vary with time, although they could, of course, be assumed to have a different value for each year in the planning horizon. The data processing program could have been made with this flexibility. It was arbi trarily decided not to do so because of lack of information on how to meaningfully set such parameters, further complicated by the computing complexities it would have introduced.

\section{BALANCE SHEET DURING SIMULATION}

This section describes the restrictions imposed on the balance sheet during simulation as well as how some of the restrictions result in new balance sheet values.

During the simulation cash in Figure 12 , line 1 is adjusted to make assets balance liabilities. If the number is negative, investments line 4, Figure 12, will be liquidated. Or if insufficent investments are avallable, the debt or equity section will be increased to bring the cash value to an acceptable level as a fraction of other current assets if possible. Cash in

Reproduced with permission of the copyright owner. Further reproduction prohibited without permission. 
excess of a certain level is assumed to be invested at a specified rate of return at line 4, Figure 12, or by an alternate criterion to pay off debt, if any.

Debt line 8 and 9, Figure 12, either short or long term is assumed to be equal to the previous year's value until after cash on line 1 , Figure 12, is computed and investments liquidated: Then the short term debt (or as seen later, possibly long term debt or equity) is increased as above, to bring the cash level to a specified fraction of other current assets.

The amount of short term debt (Line 8 , Figure 12) depends upon the smallest allowable current ratio as specified on Line 4 of Figure 13. The remainder of debt required to meet the above criteria is long term debt (line 9, Figure 12). If in the meantime the debt to equity ratio exceeds line 3 of Figure 13, more equity is required, instead of increased debt, to raise cash to meet the above restrictions.

Shareholder equity line 10 , Figure 12 , equals beginning equity plus after tax profit line 5 , Figure 10, minus dividends resulting from the calculation required by line 2 , Figure 13 , plus equity sales, if any, resulting from the restriction on the debt to equity ratio. The dilution from equity sales is limited as a fraction of the current year's earnings per share by $\nexists$ management established criteria at line 8, Figure 13. The value of such equity sales is established at line 9, Figure 13. If the restrictions on equity sales cannot be met, a restricted optimal solution is required and the techniques described in the section on restrict ed optimal solutions 
must be employed.

The other balance sheet accounts are computed from input data and, as such, influence the extent to which the boundaries established by restrictions listed above are encountered.

The computation of the other balance sheet lines is as follows in Figure 12. Inventory line 2 of Figure 12 is the result of summing over all line I's of Figure 11, for the year in question for the SBU market share assumptions being evaluated. Accounts receivable line 3 of Figure 12 is the result of summing over all line 2's of Figure 11, for the year in question for the SBU market share assumptions being evaluated.

Investment line 4 is computed as the result of a beginning value from the previous years balance sheet and is added to, or subtracted from, as required by the restrictions noted above. Plant, Equipment and Land line 5 is line 3, Figure 11 , for the year in question and is summed over the SBU market share assumptions being evaluated. Depreciation line 6 is line 4, Figure 11, and is summed in the same manner. Payables line 7 is line 5 , Figure 11, and is summed in the same manner. For precise and detailed formulation of these calculations and restrictions refer to the computer program in Appendix B.

\section{THE MEASUREMENT CRITERIA AND OPTIMIZATION}

This section discusses the more technical aspects of each of the measurement criteria used in the research. The principal algorithm for obtaining the solution to the integer programming problem is presented

Reproduced with permission of the copyright owner. Further reproduction prohibited without permission. 
under Case I and is referenced when the other four cases are discussed.

\section{Case I - Present Value of Shareholder Equity}

The mathematical expression for the objective function is described as follows:

\section{Given}

k different SBU

m market share strategies for each SBU

$\mathrm{n}$ years in the study horizon

s cost of capital factor chosen by management line 1, Figure 13

$C_{j}$ after tax profit of the corporation in year $j$, Figure 10 , line 5

$E_{O}$ beginning shareholder equity from Figure 12, line 10 .

Maximize the present value of shareholder equity (F):

$$
F=E_{o}+(1+s)^{-n} L_{n}+\sum_{j=1}^{n}(1+s)^{-j}\left(C_{j}-D_{j}+E_{j}\right)
$$

\section{Where}

$I_{n}$ liquidation value of SBU at end of the final year in the study

$E_{j} \quad$ equity sales in year $j$

$D_{j}$ dividends paid in year $j$, and the SBU embodied in $C_{j}$ are the variables to be determined

Subject to the constraints discussed in the previous section.

There are two difficult problems presented by this set of equations. First, the contribution of the corporation $C_{j}$ is not only a function of SBU contribution but is also a function of the cash available for investment by

Reproduced with permission of the copyright owner. Further reproduction prohibited without permission. 
the corporation in the past time period. The second is the integer nature of the problem introduced by the fact an SBU is either included or not included in the evaluation set.

This system of equations is linear and the problem could probably be formulated as a linear integer programming problem, but the size of the problem would be too large for the interactive mode of the computer used in this research, and the amount of computer time involved even if the problem could be formulated, is probably excessive.

For the above reasons, the nature of the problem was examined and a method of finding a quasi-optimum was discovered, which seems to be satisfactory for most cases. In practical problems, any set of the SBU being considered will frequently be a feasible solution because the company is operating and totally unreasonable sets would not be considered. Thus a method was devised for ordering the set of SBU and their market share strategies into a sequence which contributes the most to the present value of the shareholder equity. The methodology for the other optimization criteria follow a similar technique and are discussed in succeeding sub sections.;

To develop a measure of success, it is necessary to determine, for each market share option for each SBU, the measure of value $(R)$ of that option to the corporation as measured by the present value of shareholder equity. This measure of value is the present value of the after tax contribution of the SBU, reduced by an appropriate share of corporate expense, 
plus the present value of the liquidation value of the option after the last year of the planning horizon. In formula from this measure is for each SBU option:

$$
R=S+L
$$

\section{Where}

$L=$ The present value of the liquidation value in the final year

$\mathrm{S}=$ The present value, over the planning horizon, of the sum of the after tax contribution of the SBU reduced by an appropriate share of the corporate expense.

It is useful to assume that the measure of the appropriate share of the corporate expense is added in the same ratio as the present value of the SBU after tax contribution, plus liquidation value, is to the total contribution of the company. If this is done, the order of the $\mathrm{R}^{\prime} \mathrm{s}$ one to another is not changed by the addition of this factor. This is Edsily demonstrated as follows: Given an ordered set of factors

$$
\begin{aligned}
& a_{1}>a_{2}>a_{3} \ldots a_{k} \text { in which a factor equal to } \\
& c a_{i} / \Sigma a_{i}=b a_{i} \text { is added to each } a_{i} .
\end{aligned}
$$

The set becomes

$$
a_{1}+a_{1} b ; a_{2}+a_{2} b ; \ldots
$$

Which can be restated as

$$
a_{1}(1+b) ; a_{2}(1+b) ; \ldots
$$

This is equivalent to multiplying the original inequality formula by $(1+b)$; the order is unchanged by the addition of the factor in question, and as far as ordering is concerned, the corporate income (expense) may be ignored.

Reproduced with permission of the copyright owner. Further reproduction prohibited without permission. 
This assumption seems to be a valid way of assuming how corporate expenses should be allocated. It is also intuitively pleasing that the importance of each SBU to the corporation is independent of the corporate expenses incurred. This, of course, may not be true, but it is assumed to be true in this work, and it should be noted that it can be made to be true by assigning all of the expenses appropriate to an SBU to that SBU in the input data.

Once the order of importance $\mathrm{R}$ is computed, the method of finding the set of SBU, and their market share options which maximize the present value of shareholder equity, proceeds as follows. The algorithm starts by evaluating the set of SBU options which have the largest $\mathrm{R}$ factor, and if it is found this set violates the constraints, then a new set to be evaluated is found which varies from the first by the smallest amount the data allows. The new set is composed of the options which reduce the sum of the $R^{\prime} s$ in the evaluation set by the least amount. Thus:

1. Compute $\mathrm{R}$ for each SBU market share option in the entire set of possible combinations. If there are $\mathrm{k} S \mathrm{SBU}$ and $\mathrm{m}$ market share options then there will be $\mathrm{k}$ times $\mathrm{m}$ ratios.

2. Sort the R's into descending order for each SBU.

3. For each $S B U, k$, compute the positive differences $D_{k}$ of the largest $R_{k_{1}}$, minus the next largest $R_{k_{2}}$ until all $\mathrm{m}$ differences are found. For the smallest $R_{k_{m}}$ the difference is simply $R_{k_{m}}$ - zero $=R_{k_{\overline{41}}}$.

Reproduced with permission of the copyright owner. Further reproduction prohibited without permission. 
4. Use the model to evaluate the set of SBU market share options having the largest R. (Recall only one market share option for each SBU)

5. If the restraints are not violated, this set of SBU options is optimal and the algorithm is finished.

6. If the restraints are violated, remove the market share option having the smallest difference $D_{k}$ in the set just evaluated, and replace it with the market share option whose $R$ is the next smallest for that same SBU. It may be that the option with the smallest $R$ in any SBU may be removed. This means the SBU is to be liquidated. After the first iteration, it is necessary to find which market share option or options to remove by eliminating that set which has the next largest sum of $D_{k^{\prime} s}$ exceeding the sum of $D_{k^{\prime} s}$ removed at the preceding step. Only those $D_{k^{\prime} s}$ which have been previously eliminated, or are next lowest in rank in the SBU line to those which have been eliminated at some time, are eligble for consideration for elimination. But within an SBU, before a $D_{k}$ is eligible for elimination, all prior $D_{k}$ in that row must be included in the sum being computed.

7. Repeat Step 4 - the algorithm is complete when the first feasible set is found a t Step 5 .

This algorithm is not the same as a complete evaluation of all possible

Reproduced with permission of the copyright owner. Further reproduction prohibited without permission. 
SBU options, because it stops as soon as the largest feasible solution is found. If the maximum set is very near to being a feasible set, the algorithm is quite efficient. If not, it is still accurate, but it is less efficient. Although the algorithm is judged to be accurate, it was determined a quasi-optimal procedure would be used at step 6 for two reasons. The first is a significant amount of computer time is required to find the entering set of market share options, and the second is the mechanical optimum does not necessarily suit the needs of the decision-maker using the model. Therefore, it was decided to let the decision-maker choose which SBU option to change in an interactive mode with the computer and by using his own skill to reach a satisfactory or quasi-optimum solution.

As an aid to help accomplish the decision-maker's task, the computer was programmed to provide the amount the unrestrained optimum solution requires in new equity to meet the restraints. In addition, the amount the elimination of each SBU option decreases the magnitude of the optimization criterion is also computed. Thus, the decision-maker has some mechanical data at his disposal, as well as his knowledge about special situations in each SBU, to help him reach a "satisficing" optimum.

\section{Case II - Growth in Earnings Per Share}

The next objective function for which an algorithm must be found is growth in earnings per share. There are several ways to define growth, but quite arbitrarily and for the convenience and ease of programming, it was chosen to define growth as the after tax earnings in the last year of

Reproduced with permission of the copyright owner. Further reproduction prohibited without permission. 
the planning period minus those in the first year. This method has recognized shortcomings, but changing to other methods introduces operational rather than conceptual complexities into the program, and since the merits of any one method may be debated against another, this method was chosen. The objective function to be maximized is given as:

$$
\mathrm{F}=\mathrm{P}_{\mathrm{n}}-\mathrm{P}_{1}
$$

Where $P_{n}$ equals the after tax profit of the corporation in the last year of the planning horizon, and $\mathrm{P}_{1}$ equals the after tax profit of the corporation in the first year of the planning horizon. The formula is subject to the same balance sheet restrictions as used in Case 1. The variables to be determined are the SBU market share options which are contained in the profit variables. It is further assumed the criterion is the growth in earnings per share on the beginning number of shares. This assumption allows the objective function to contain only profit and not the profit per share.

The solution to this problem is of the same nature as discussed for the present value of shareholder equity and can proceed in a nearly parallel manner.

It is assumed any SBU option present at the end of the planning horizon was also present at the beginning of the planning period (no matter how small) and vice versa. This is an operational requirement and not a restriction on liquidating or acquiring SBU, but it does require that such actions are planned. The model does not automatically make these decisions.

Reproduced with permission of the copyright owner. Further reproduction prohibited without permission. 
The solution parallels Case I as follows: After a suitable assumption about corporate expense or profit to make the ranking of the decision variables independent of this factor, define a measure of value for each SBU option as $R=S_{n}-S_{1}$. Where $S_{n}$ is the after tax profit, of the SBU option in question for the last year of the planning horizon, found by applying the corporate tax rate to the calculated, fully taxed equivalent of the SBU's pretax income available from line 8 and line 9 of Figure 9. In a like manner, $S_{1}$ is the corresponding value for the first year of the planning horizon. Once the $\mathrm{R}$ factors have been computed, the solution to the optimization problem uses the same algorithm as Case I.

\section{Case III - Growth in Total Assets}

The next case to be discussed is growth in total assets. As with the other cases, the approach is to find how much an SBU market share option contributes to the objective function and to use the maximization algorithm in exactly the same way as before. The same point to point definition of growth is used as in Case II--namely, that the total assets at the end of the planning period minus the corresponding value at the beginning is a maximum. Thus, maximize. $F=B_{n}-B_{0}$; where $B_{n}$ is the total assets of the corporation at the end of the last year of the planning period, $\mathrm{B}_{\mathrm{O}}$ is the corresponding value at the beginning of the planning period, and subject to the same balance sheet constraints as the previous cases. The variables to be determined are also the same as the previous cases, but this case is somewhat more invoived than the previous one because the SBU assets 
and liabilities sheet, Figure 11 does not carry a cash account. Only the corporate balance sheet, Figure 12, and the simulation output derived as the evaluation proceeds, contains cash and investments. For the purpose of the discussion here, cash and investments can be considered to be the same without loss of generality.

It is necessary to determine the contribution of the SBU option to the corporation's total assets before it is possible to calculate an $\mathrm{R}$ factor and proceed with the solution by the algorithm of Case I. To do this, consider that all balance sheet asset accounts, except cash and investments, are simply the sum of the corresponding SBU accounts. Cash and investments are the consequence of balancing the liabilities side of the ledger, but the only contribution SBU make to liabilities is after tax profits and payables. Thus total asset growth will be largest when the corporation is composed of those SBU options which have the largest net assets plus payables growth combined with total contribution over all years of the planning period.

Before defining the $\mathrm{R}$ function, a choice must be made as to whether total assets should be defined as before or after depreciation, and it was arbitrarily determined assets after depreciation would be used. This figure corresponds to the total asset line on the balance sheet; however, gross assets (that is, neglecting depreciation) could be chosen just as easily with probably somewhat different results. It is a problem because depreciation is frequently computed for tax purposes and, for this and perhaps other reasons, net assets may or may not reflect the true value of

Reproduced with permission of the copyright owner. Further reproduction prohibited without permission. 
the fixed assets involved.

The measure of value $R$ of each SBU is given by:

$$
\mathrm{R}=\mathrm{A}_{\mathrm{n}}-\mathrm{A}_{1}+\mathrm{p}_{\mathrm{n}}-\mathrm{p}_{1}+\sum_{j=1}^{n} \mathrm{~S}_{j}
$$

where $A_{n}-A_{1}$ is the difference between ending and beginning net assets for the SBU option, $p_{n}-p_{1}$ is the difference between ending and beginning payables for the SBU option, and $\sum_{j=1}^{n} \quad S_{j}$ is the after tax profit of the SBU option over all years of the planning period.

Other factors can affect total assets; . these are ignored as being outside the influence of the SBU options which are the decision variables. Such things as dividend policy and debt to equity ratio policy can greatly change the size of the total assets, but they are strategic decisions and cannot be controlled by the managers of the SBU. Once the $\mathrm{R}$ factors have been computed, the solution of the maximization problem utilizes the algorithm of Case I in the same manner.

\section{Case IV - Total Assets}

This case is very similar in structure to that of the growth of total assets (Case III). The $R$ factor simply ignores the beginning value of the balance sheet $A_{1}$ and $p_{1}$. Thus for this case:

$$
R=A_{n}+p_{n}+\sum_{j=1}^{n} s_{j}
$$

where the variables have the same definition as in Case III, and the solution proceeds in the same manner.

Reproduced with permission of the copyright owner. Further reproduction prohibited without permission. 


\section{Case V-Growth in Sales}

The last case to be considered is for growth in sales. This ls conceptually the easiest case and the problem is simply stated as maximize:

$$
\mathrm{F}=\mathrm{T}_{\mathrm{n}}-\mathrm{T}_{1}
$$

where $T_{n}$ and $T_{1}$ are total corporation sales in the last year and first year of the planning horizon respectively. The $R$ factor is $R=t_{n}-t_{1}$ where $t_{n}-t_{1}$ is the growth in sales for each SBU option as the difference between last and first year sales. These are computed from the input given on line 1 of Figure 9 and the algorithm of Case $I$ is used in the same way as in the previous cases.

Reproduced with permission of the copyright owner. Further reproduction prohibited without permission. 
APPENDIX B

COMPUTER PROGRAMS

\section{LIST OF PROGRAMS FOUND IN APPENDIX B}

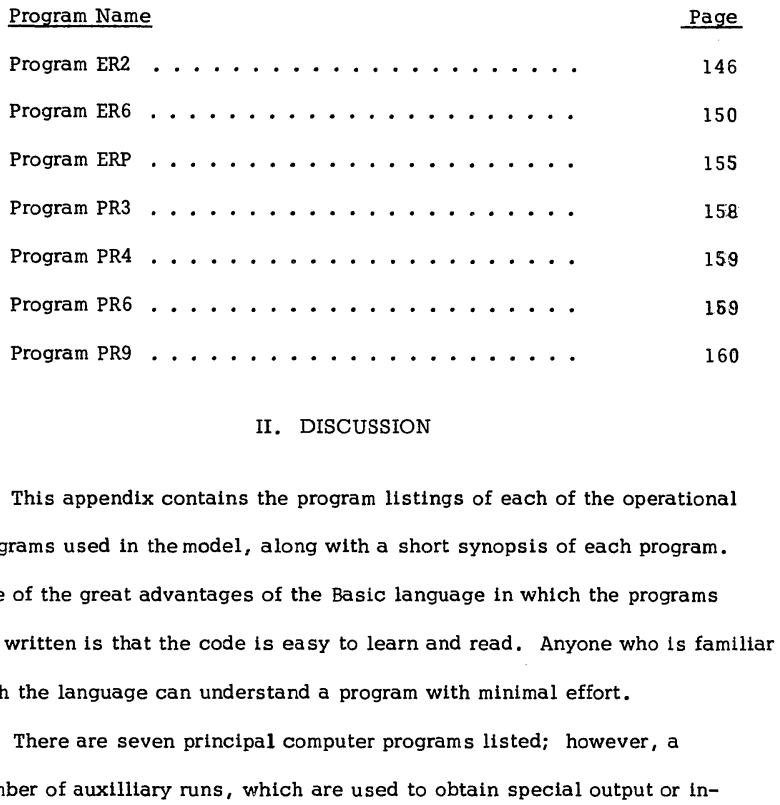

number of auxilliary runs, which are used to obtain special output or in-

Reproduced with permission of the copyright owner. Further reproduction prohibited without permission. 
frequently required results along with standard file handling rontines, are not shown.

\section{Program ER2}

Program ER2 is the first of two major programs in the model and is used to intialize files and compute intermediate results. If an optimum solution is to be obtained, the program computes the amount which each SBU market share option contributes to the measure being optimized; sorts the SBU market share options into decreasing order of contribution to the measure; stores the results as intermediate files; and selects the S BU market share options which give the unrestricted optimum. On the other hand, if only an evaluation of a set of SBU market share options is to be obtained, rather than an optimal set computed, the program summarizes the input data files to obtain SBU profit and loss and asset and liability values as intermediate results for the next program.

Each of the five measurement criteria discussed in Appendix A can be programmed for inclusion in Program ER2; although the case shown in the listing of this appendix is the present value of shareholder equity. The other measures require minor changes to the program where the contribution to the measurement criterion is computed for each SBU market share option. See Figure 4 for flow chart of Program ER2.

\section{Program ER6}

Refer to Figure 5 for flow chart of program ER6 which is the second 
major program in the model. This program uses the intermediate results stored by Program ER2 to compute the final outputs of the model. If the model is performing an evaluation of a given set of SBU market s hare options, the program uses the initial values of the corporate balance sheet Figure 12 and applies the restrictions imposed by the program. In which case it is assumed that the ultimate restrictions, on the amount of new equity which can be raised, can be met. If the restrictions cannot be met, the computer continues af ter reporting the fact.

If the program is computing an optimum, and the restrictions are not violated, the program continues as above. If the restrictions cannot be met, the program requests the operator to selectively change the SBU market share options, and the program will try again. This cyclic sequence will be continued until the restrictions are met and the program can compute all of the desired output. For a typical interactive sequence of this type, see computer output J12 (second) of Appendix C where the computer found at the end of year 1 (CPL Comp 1) that $\$ 479.4258$ more new equity was needed than could be raised. The computer requested the operator to input a new $\mathrm{K}$ and $\mathrm{V}(\mathrm{K})$. (SBU number and market share option respectively.) SBU 16 was liquidated $(\mathrm{V}(16)=0)$, and the program printed out the total equity required was $\$ 5,122.398$ ( 479.4258 more than could be raised). It then completed the first year and found with the new set there was $\$ 253.3672$ still needed in equity beyond what the restrictions would allow. The interactive sequence is seen to continue until the final year is satisfactorily completed (the fifth year in the case shown - CPL Comp 5). 


\section{Program ERP}

Program ERP uses the output of Program ER2 to obtain the probability results indicated in computer output $\mathrm{Pl}$ through $\mathrm{P} 4$ found in Appendix C. Twenty arbitrary probability distributions are found in the DATA section of the program and can be quite easily changed at the discretion of the operator. The format of the computer output also is found in Appendix C and consists of the mean and variance of the distribution of each asset account being considered, the payable value, the after tax profit value; and where appropriate the liquidation value of SBU being liquidated.

\section{Program PR3}

Program PR3 is one of a series of four programs used to print results from the model and is used to list the balance sheet for each year of the planning horizon from an output file created by Program ER6. As explained in Chapter II the model is so large the programs cannot all be in working memory at the same time with the particular subset of the Basic language which was used, and therefore it was necessary to segment the model. The format for reading the balance sheet printout (for example the first page of Computer run $\mathrm{AO}$ ) is given by Figure 14 of Appendix C.

The program also prints a number of self explanatory statistics (for example see the second page of computer run $\mathrm{AO}$ ) some of which are single values referring to the entire planning period while others are for each year of the planning horizon.

Reproduced with permission of the copyright owner. Further reproduction prohibited without permission. 


\section{Program PR4}

Program PR4 is the second in the series of output programs of the model and is used to print the profit and loss statement of the company for each year of the planning horizon. It also prints the equity sales, if any are required, and the set of SBU market share options used in the case which was run.

\section{Program PR6}

Program PR6 is the third program in the series used to obtain output of the model and is used with the SBU profit and loss data file Table XXIII, and the set of SBU market share options, to obtain the sales by year and the growth in sales for the entire period. Because the program must process the entire file to obtain the desired values, it requires approximately twenty minutes of terminal connect time and is expensive to operate.

\section{Program PR9}

Program PR9 is used to obtain computer run W1 for use with the interactive sequence of Program ER6 to find the restricted optimum. Program PR9 uses the intermediate results of Program ER2 to obtain the sum of the amount each SBU contributes to the measurement criteria in question; however, PR9 may require reprogramming if other measurement criteria are used. 
PLEASE NOTE:

The appendices contain very light and broken print. Filmed as received, best copy available.

UNIVERSITY MICROFILMS

Reproduced with permission of the copyright owner. Further reproduction prohibited without permission. 


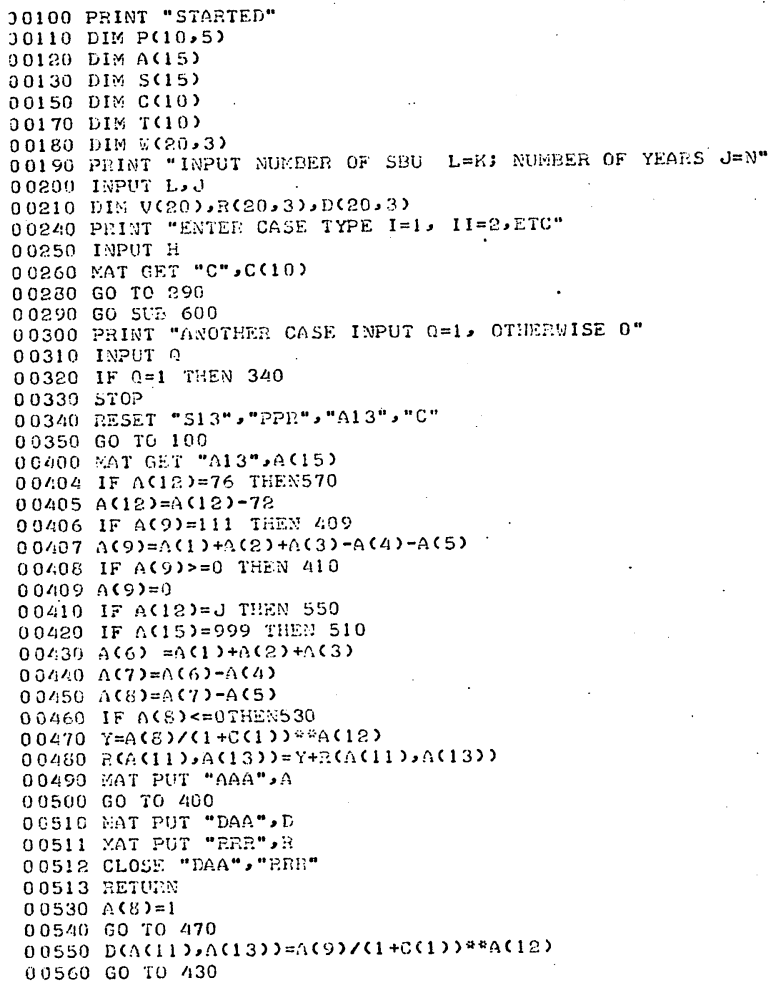

Reproduced with permission of the copyright owner. Further reproduction prohibited without permission. 


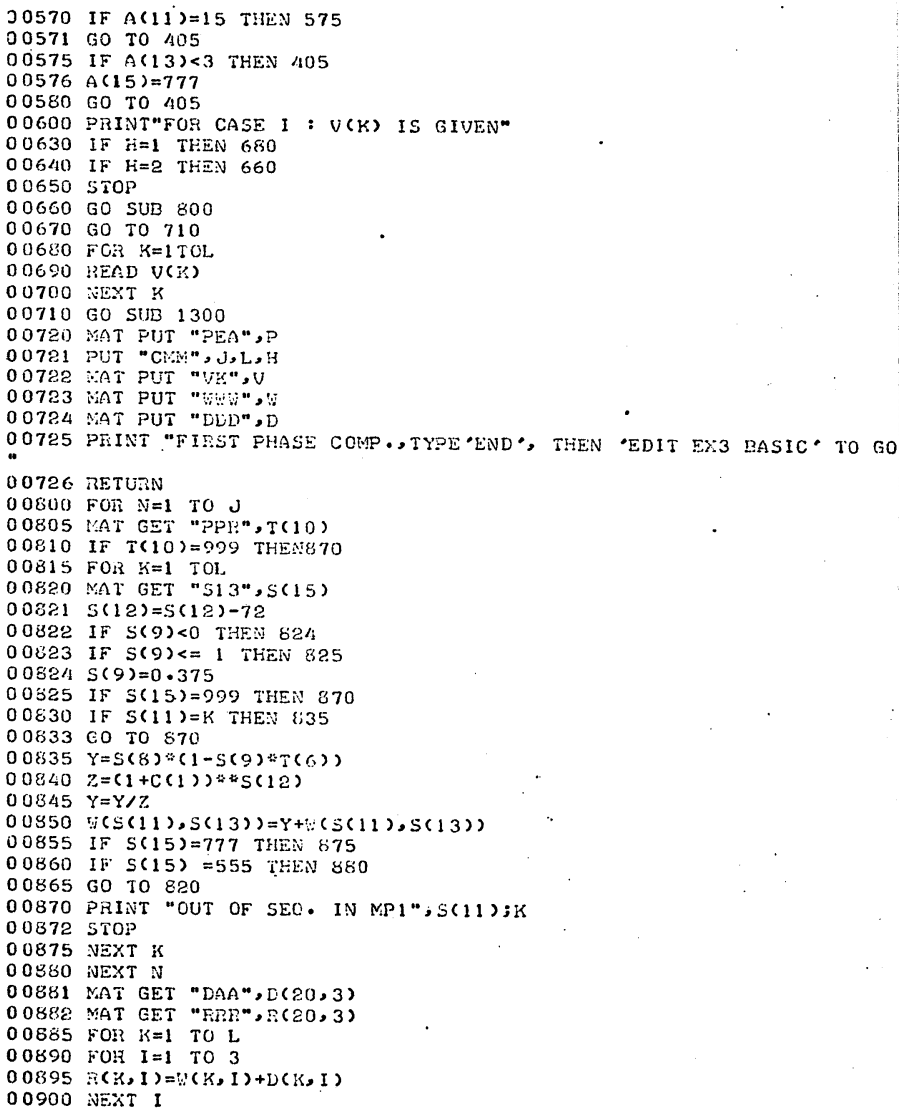

Reproduced with permission of the copyright owner. Further reproduction prohibited without permission. 


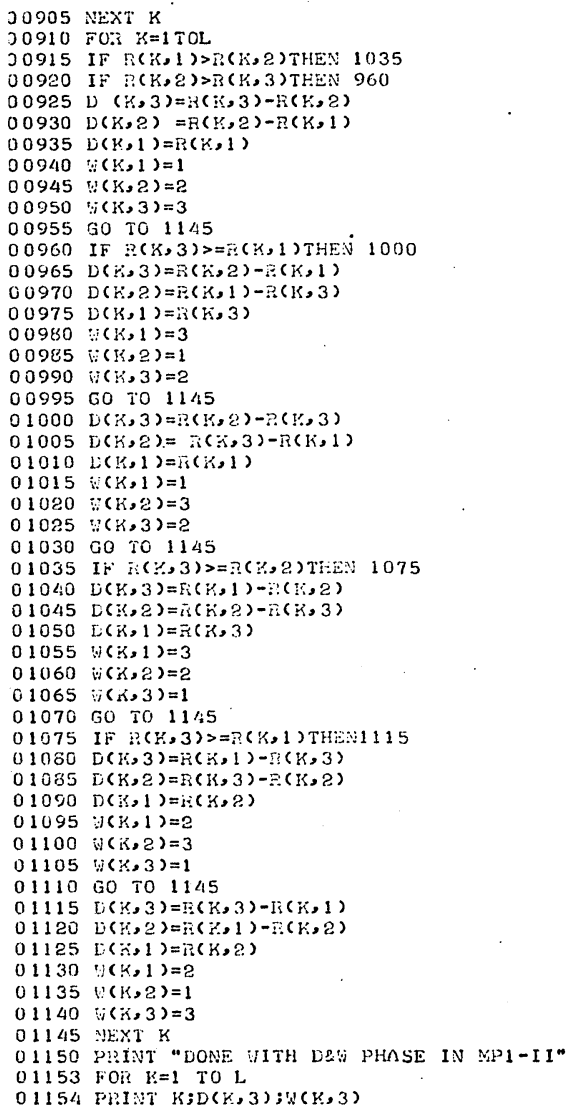

Reproduced with permission of the copyright owner. Further reproduction prohibited without permission. 


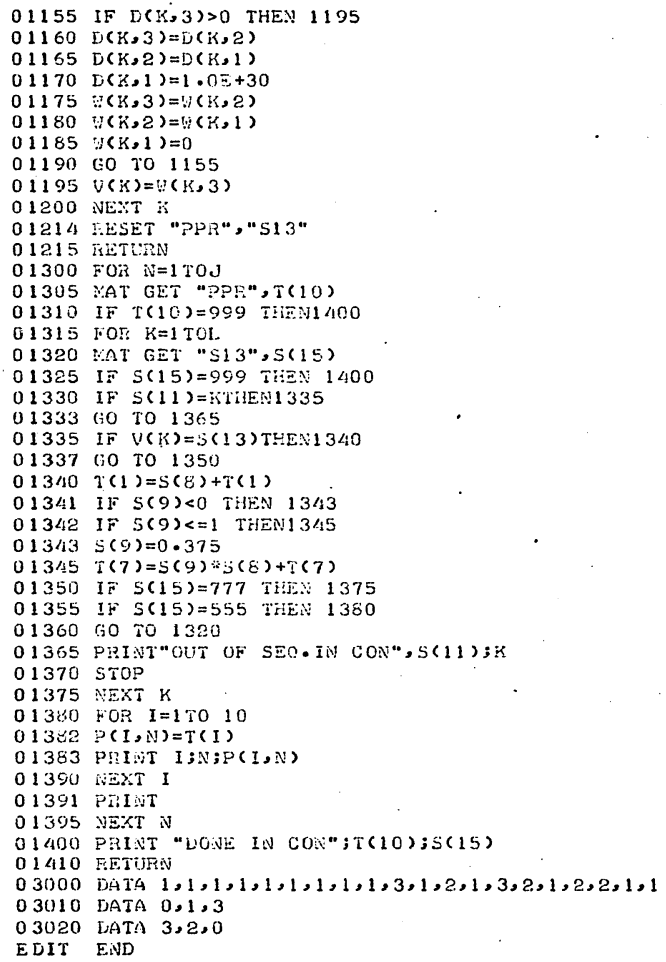

Reproduced with permission of the copyright owner. Further reproduction prohibited without permission. 
PROGRAM ER6

SECTION II OF THE MODEL

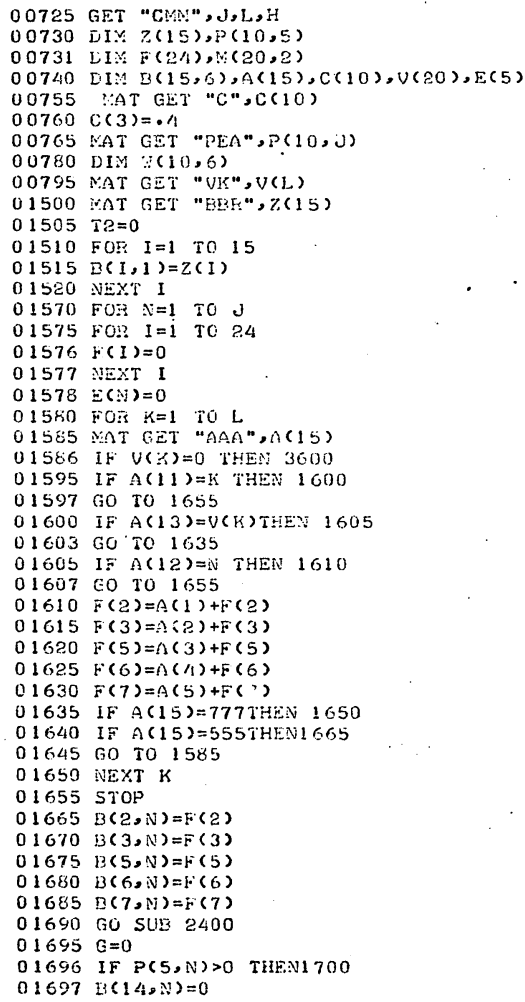

Reproduced with permission of the copyright owner. Further reproduction prohibited without permission. 
01698 GO TO 1705

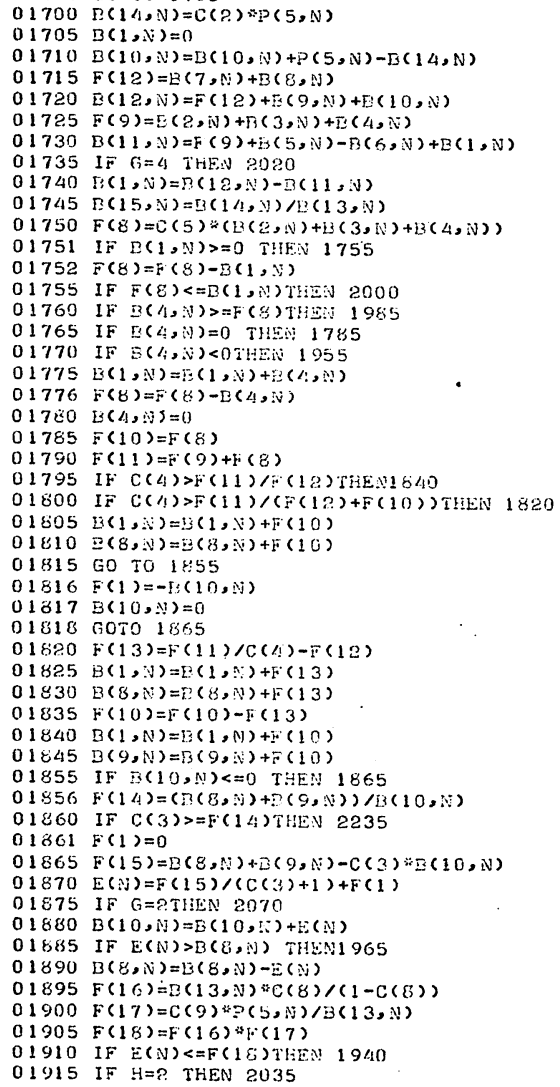

Reproduced with permission of the copyright owner. Further reproduction prohibited without permission. 


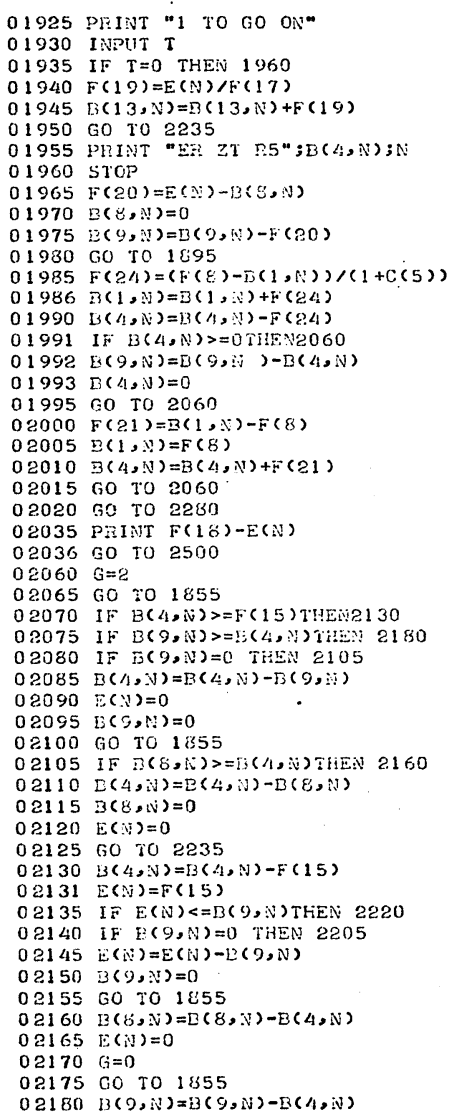

Reproduced with permission of the copyright owner. Further reproduction prohibited without permission. 


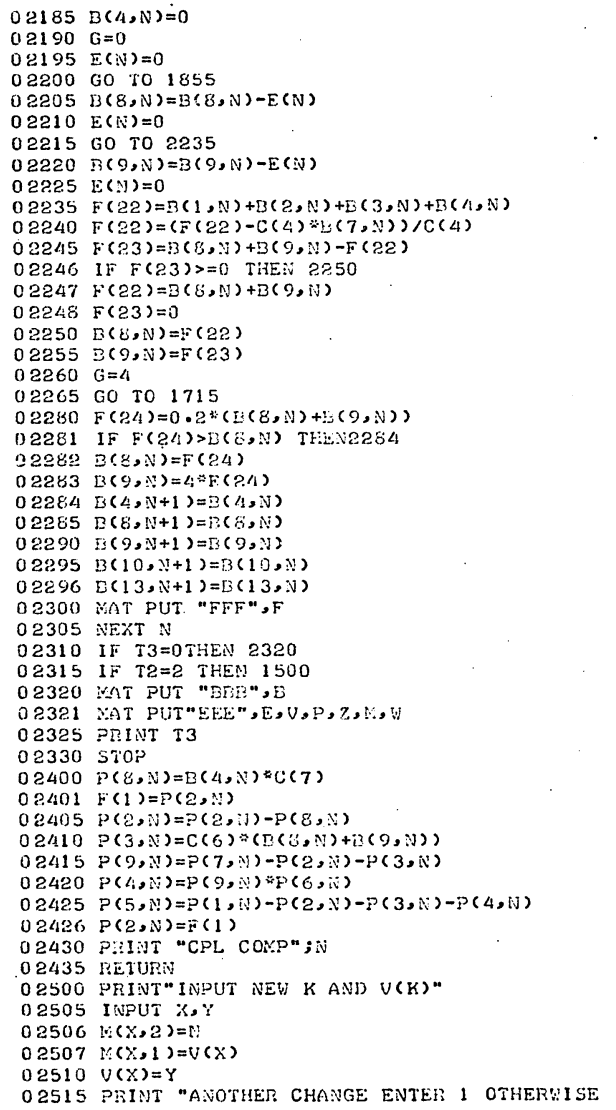

Reproduced with permission of the copyright owner. Further reproduction prohibited without permission. 


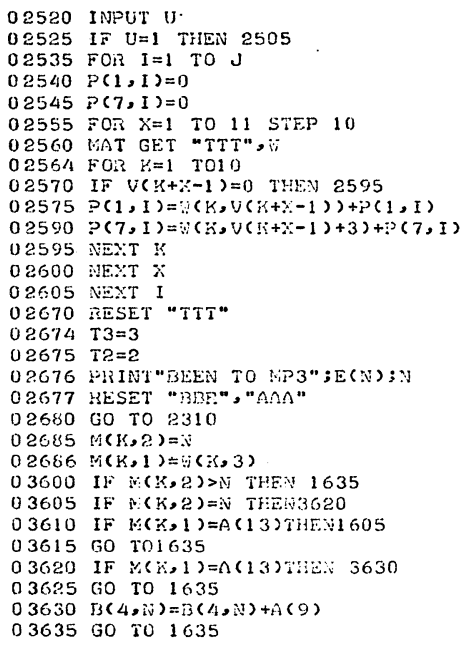

Reproduced with permission of the copyright owner. Further reproduction prohibited without permission. 


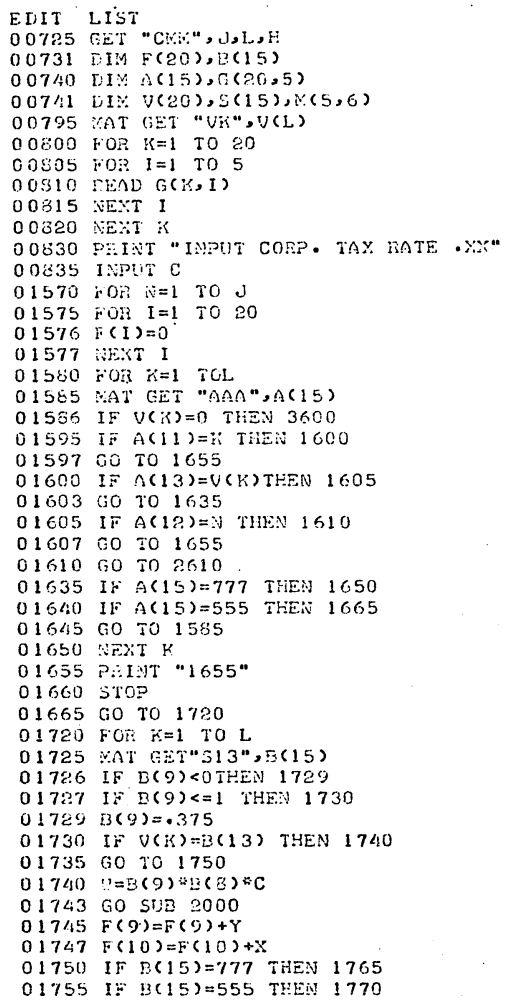

Reproduced with permission of the copyright owner. Further reproduction prohibited without permission. 


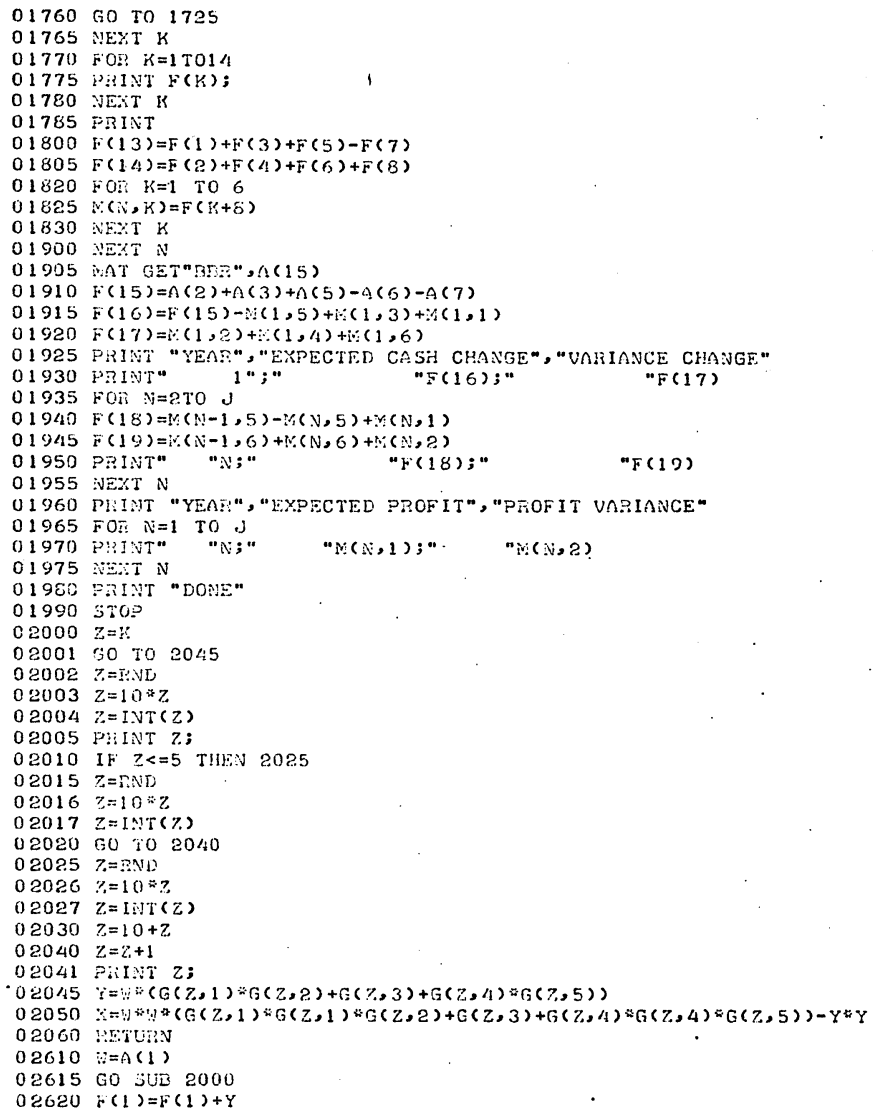

Reproduced with permission of the copyright owner. Further reproduction prohibited without permission. 
$02625 F(2)=F(2)+X$

$02640 \quad i=A(2)$

02645 GO SUB 2000

$02650 F(3)=F(3)+Y$

$02655 \quad F(/ i)=F(4)+X$

$02670 \quad i=A(3)-A(4)$

02675 GO SUB 2000

$02680 \mathrm{~F}(5)=\mathrm{F}(5)+\dddot{\mathrm{Y}}$

$02685 \quad F(6)=F(6)+Y$

$02700 \quad y=n(5)$

02705 GO SUT 2000

$02710 \quad F(7)=F(7)+Y$

$02715 \quad F(B)=F(B)+X$

02740 SO TO 1635

03600 IF N>1 THEN 1635

03605 PHINT"SFij"K; "ILIQUIDATED, INPUT OPTION $" * 0,1,2,3 "$

03610 INDUT T

03620 IF $T=\cap(13)$ THEN 3630

03625 GO TO 1635

$03630 \quad \because=A(\Omega)$

$03635 \mathrm{GO} \mathrm{SUH}$ ?000

$03640 \quad F(11)=\bar{F}(11)+Y$

$03645 \mathrm{~F}(12)=F(12)+X$

03650 GO TO 1635

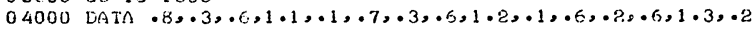

04010 DATA $.8, .41, .4,1 \cdot 2, .2$

04015 LATA $8, \ldots 4,44,1,1, \ldots 2, .8, .4, .5,1,2,1$

04020 DATA $7, .2, .7,1.1, .1, .7, .4, .4,1,1, .2, .7, .5, .4,1,1, .1$

04025 DATA $.7, .1, .8,1.1, .1,7, \cdot 1, .8,1 \cdot 2, .1, \cdot 6, .3, .5,1 \cdot 2, \cdot 2$

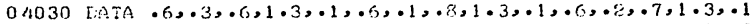

04035 LnTh $.8, .3, .5,1 \cdot 1, .2, .8, \cdot 2, .5,1 \cdot 1, .3, .8, .2, \cdot 6,1 \cdot 1, .2$

04040 DATA $\cdot 7, .3, \cdot 5,1 \cdot 1, .2, .6, .4, .5,1 \cdot 2, .1$

EDIT EXD

Reproduced with permission of the copyright owner. Further reproduction prohibited without permission. 


\section{TO PRINT OUT BAIANCE SHEET AND STATISTICS}

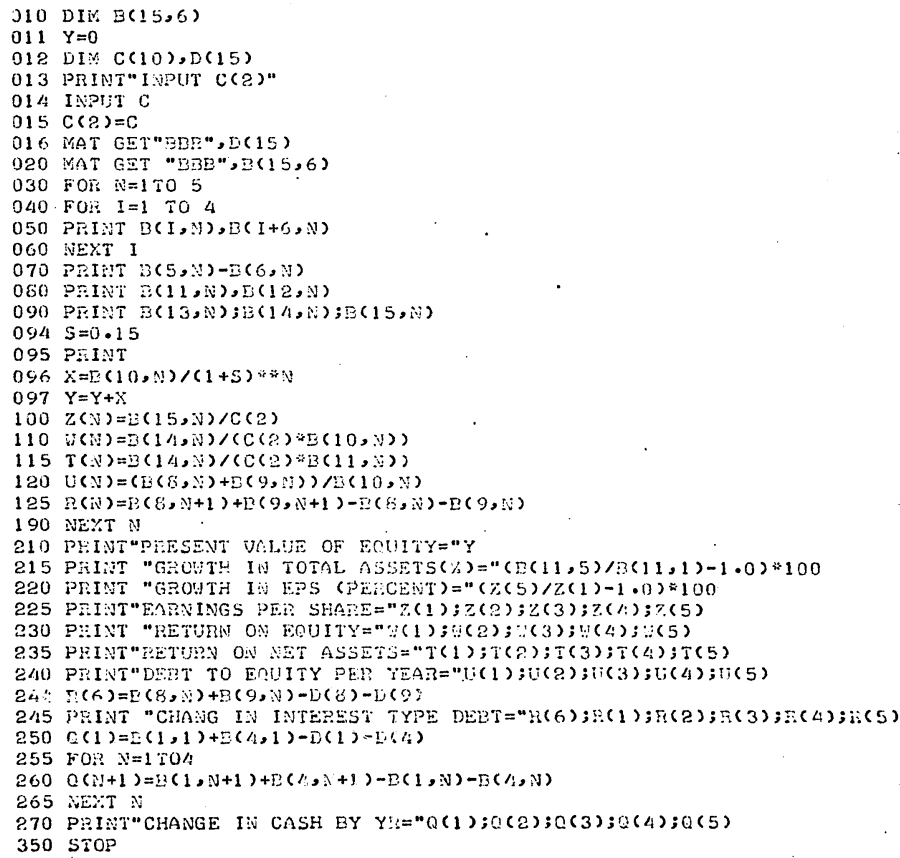

Reproduced with permission of the copyright owner. Further reproduction prohibited without permission. 
PROGRAM PR 4

TO PRINT OUT PROFIT AND IOSS STATEMENT

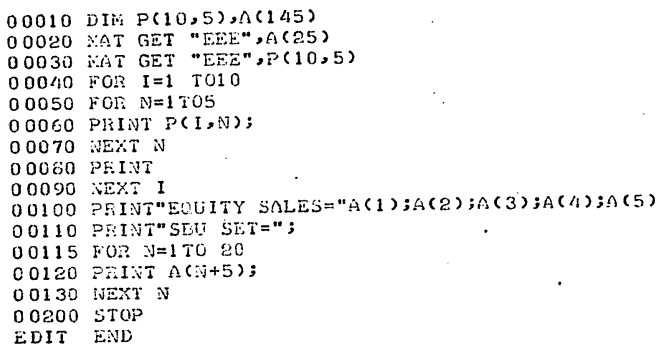

PROGRAM PR6

TO PRINT OUT GROWTH IN SAIES

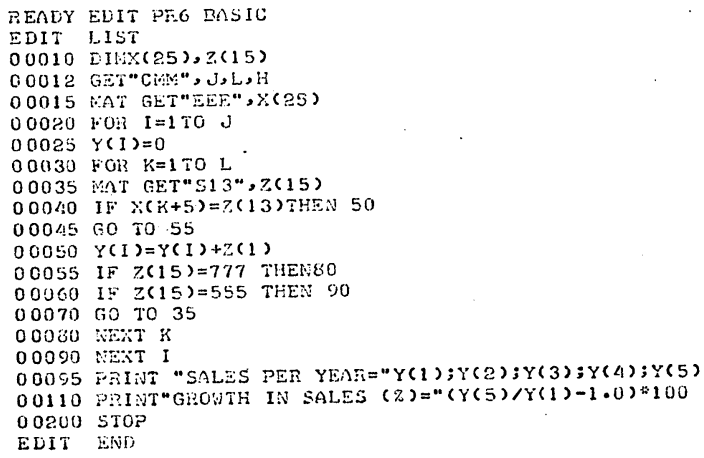

Reproduced with permission of the copyright owner. Further reproduction prohibited without permission. 


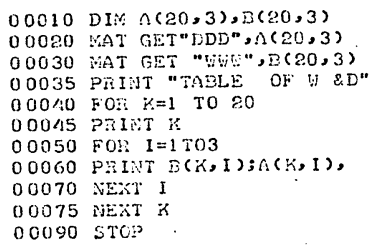




\section{APPENDIX C}

\section{COLIECTION OF SPECIFIC RUN RESULTS}

I. LIST OF COMPUTER RUNS FOUND IN APPENDIX C

\section{Computer Run}

Page

$\mathrm{AO}$

Al

173

A2-1

175

A2-2

177

A3-1

179

A3-2

181

A4

183

A5-1

A5-2

A6

189

A7-1

191

A7-2

193.

A7-3

195

B1

B2-1 
Computer Run

Page

B2-2 $\ldots \ldots \ldots \ldots \ldots \ldots \ldots \ldots \ldots \ldots \ldots \ldots \ldots \ldots \ldots \ldots \ldots \ldots \ldots \ldots \ldots$

B $-1 \quad \ldots \ldots \ldots \ldots \ldots \ldots \ldots \ldots \ldots \ldots \ldots \ldots \ldots \ldots \ldots \ldots \ldots \ldots \ldots . \ldots 203$

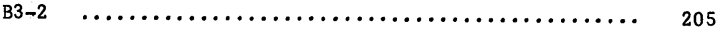

E1 $\quad \ldots \ldots \ldots \ldots \ldots \ldots \ldots \ldots \ldots \ldots \ldots \ldots \ldots \ldots \ldots \ldots \ldots \ldots \ldots \ldots 207$

$\mathrm{E} 2-1 \quad \ldots \ldots \ldots \ldots \ldots \ldots \ldots \ldots \ldots \ldots \ldots \ldots \ldots \ldots \ldots \ldots \ldots \ldots \ldots \ldots$

$E 2-2 \quad \ldots \ldots \ldots \ldots \ldots \ldots \ldots \ldots \ldots \ldots \ldots \ldots \ldots \ldots \ldots \ldots \ldots \ldots \ldots \ldots \ldots 211$

$E 3-1 \quad \ldots \ldots \ldots \ldots \ldots \ldots \ldots \ldots \ldots \ldots \ldots \ldots \ldots \ldots \ldots \ldots \ldots \ldots \ldots \ldots 213$

E $3-2 \quad \ldots \ldots \ldots \ldots \ldots \ldots \ldots \ldots \ldots \ldots \ldots \ldots \ldots \ldots \ldots \ldots \ldots \ldots \ldots \ldots \ldots$

Fl $\quad \ldots \ldots \ldots \ldots \ldots \ldots \ldots \ldots \ldots \ldots \ldots \ldots \ldots \ldots \ldots \ldots \ldots \ldots \ldots \ldots \ldots, 217$

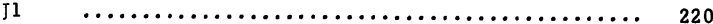

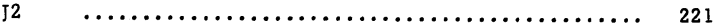

J3 $\quad \ldots \ldots \ldots \ldots \ldots \ldots \ldots \ldots \ldots \ldots \ldots \ldots \ldots \ldots \ldots \ldots \ldots \ldots \ldots \ldots 22$

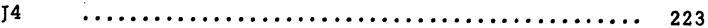

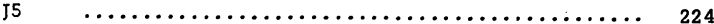

J6 $\quad \ldots \ldots \ldots \ldots \ldots \ldots \ldots \ldots \ldots \ldots \ldots \ldots \ldots \ldots \ldots \ldots \ldots \ldots \ldots 225$

J7 $\quad \ldots \ldots \ldots \ldots \ldots \ldots \ldots \ldots \ldots \ldots \ldots \ldots \ldots \ldots \ldots \ldots \ldots \ldots \ldots 26$

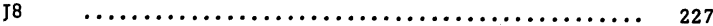

J9 $\quad \ldots \ldots \ldots \ldots \ldots \ldots \ldots \ldots \ldots \ldots \ldots \ldots \ldots \ldots \ldots \ldots \ldots \ldots \ldots \ldots$

J10 $\quad \ldots \ldots \ldots \ldots \ldots \ldots \ldots \ldots \ldots \ldots \ldots \ldots \ldots \ldots \ldots \ldots \ldots \ldots \ldots .230$

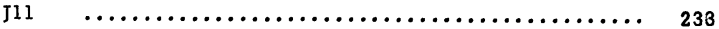

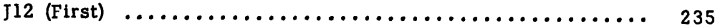

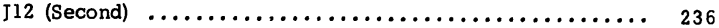

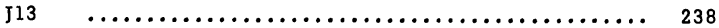

Reproduced with permission of the copyright owner. Further reproduction prohibited without permission. 
Computer Run

Page

Pl

P2

P3

242

P4

243

Wl

\section{OVERVIEW}

This appendix contains a collection of the specific run results, along with a chart which gives a definition of each line in the computer printout of the balance sheet to aid in identifying those lines which are not labeled. A final section gives the SBU market share options used in each run.

\section{DISCUSSION}

Each of the major runs of the model are found in this appendix, and Tables XVIII through XX serve as a partial index to the runs. Programming labels in the Basic language, although posstble, is not convenient and definitely takes up valuable computer time and space, and therefore labels were not printed by the computer.

See Figure 14 for the layout of the balance sheet which is printed by computer run ER6. Line one refers to the first line of each block of numbers printed. Refer to Page 1 of Computer Run A0 and note that line 


\section{SUMMARY OF COMPUTER RUNS}

\begin{tabular}{|c|c|c|c|c|c|}
\hline $\begin{array}{l}\text { Computer } \\
\text { Run }\end{array}$ & $\begin{array}{l}\text { Policy }^{1} \\
\text { Case }\end{array}$ & $\begin{array}{l}\text { Measure-1 } \\
\text { ment Case }\end{array}$ & $\begin{array}{l}\text { Debt to } \\
\text { Equity } \\
\text { Ratio }\end{array}$ & $\begin{array}{l}\text { Div. } \\
\text { Rate }\end{array}$ & Title \\
\hline AO & - & - & .6 & .2 & $\begin{array}{l}\text { Company management } \\
\text { case }\end{array}$ \\
\hline $\mathrm{Al}$ & - & I & .6 & .2 & $\begin{array}{l}\text { Present value of share- } \\
\text { holder equity }\end{array}$ \\
\hline A2-1 & I & I & .6 & $\cdot \boldsymbol{x}$ & $"$ \\
\hline A2 -2 & & & .6 & .3 & $"$ \\
\hline A3-1 & II & I & .45 & .2 & $"$ \\
\hline A3-2 & & & .5 & .2 & $"$ \\
\hline A4 & III & I & .6 & .2 & $\begin{array}{l}\text { The SBU which give } \\
\text { maximum market share }\end{array}$ \\
\hline A5-1 & IV & I & .6 & .2 & $\begin{array}{l}\text { The SBU which give } \\
\text { minimum market share }\end{array}$ \\
\hline A5-2 & & & .6 & .2 & $\begin{array}{l}\text { The SBU which give } \\
\text { medium market share }\end{array}$ \\
\hline A6 & $\mathrm{V}$ & I & .6 & .2 & $\begin{array}{l}\text { With oniy SBU \#18 } \\
\text { Option } 1\end{array}$ \\
\hline A7-1 & VI & I & .6 & .2 & With SBU except \#18 \\
\hline A7-2 & VI & I & .6 & .2 & With SBU \#18 Option \#2 \\
\hline A7-3 & VI & I & .6 & .2 & With SBU \#18 Option \#3 \\
\hline $\mathrm{Bl}$ & - & II & .6 & .2 & $\begin{array}{l}\text { For growth in earnings } \\
\text { per share }\end{array}$ \\
\hline
\end{tabular}

Reproduced with permission of the copyright owner. Further reproduction prohibited without permission. 
TABLE XIX

CONTINUATION OF TABLE XVIII

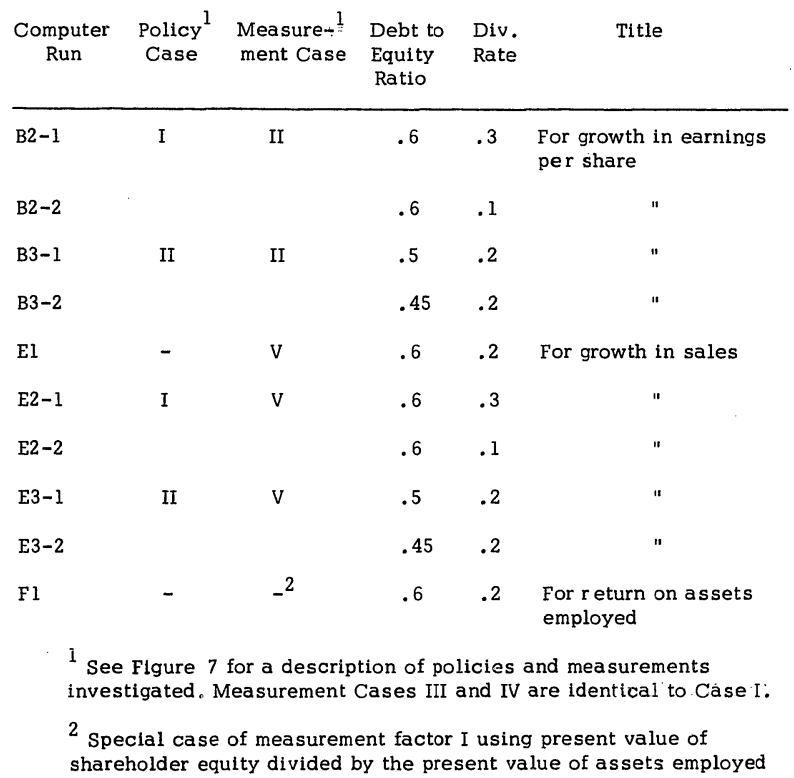

Reproduced with permission of the copyright owner. Further reproduction prohibited without permission. 
TABLE XX

SUMMARY OF COMPUTER RUNS IN JOINT EFFECTS STUDY

Computer Run

$\mathrm{Jl}$

J2

J3

J4

J5

J6

J7

J8

J9

J10

JlI

$\mathrm{J} 12$

J13

Al

A2-1

A2-2

A3-1

A3-2

\section{Dividend}

Rate

.3

.3

.3

.2

.1

.1

.1

.1

.1

.3

.3

.2

.2

.2

.1

.3

.2

.2
Debt to Equity Ratio

.5

.45

.7

.7

.7

.45

.5

.4

.3

.4

.3

.4

.3

.6

.6

.6

.45

.50

Reproduced with permission of the copyright owner. Further reproduction prohibited without permission. 


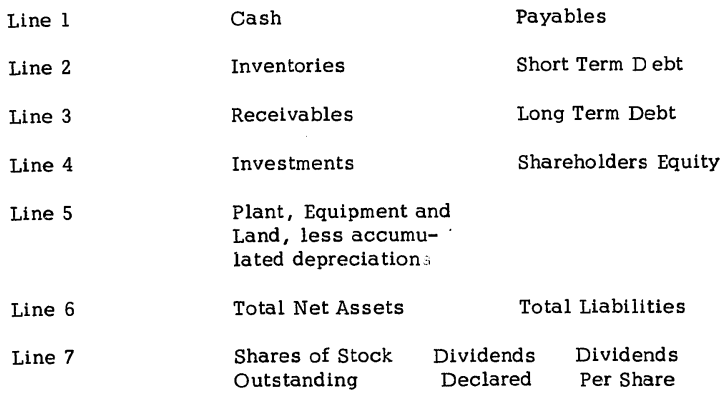

Figure 14. Guide to layout of balance sheet printouts. 
one contains the number 4602.297 , and the succeeding first lines are $3761.860 ; 4536.457 ; 5278.277 ;$ and 6129.609 .

See Figure 10 of Appendix A for the layout of the profit and loss portions of the output as printed by Program PR4, but note that each column represents one year in the planning horizon. Thus from the second page of Computor Run AO, the total SBU contribution for year three of the study is 16664 and the net profit after tax in year five is 12192.70 .

The right-hand side of the second page of some of the computer runs, is difficult to read because the computer output terminal may execute a carriage return in the middle of a number, and if it does, the remainder of the number is found at the start of the next line.

Table XXI lists the SBU market share options which were used in the computer runs listed in this appendix.

Figure 15 is a guide to the layout of the probability run printout labeled Computer Run Pl through P4. The format of the three lines shown are repeated for each year in the planning horizon. The last two sections of the printout contain the mean cash flow and variance for the year listed, and the last lines contain the mean profit and variance.

Reproduced with permission of the copyright owner. Further reproduction prohibited without permission. 


\begin{tabular}{|c|c|c|c|c|c|c|}
\hline Line 1 & $\begin{array}{l}\text { Mean of } \\
\text { Inventory }\end{array}$ & $\begin{array}{l}\text { Variance } \\
\text { of } \\
\text { Inventory }\end{array}$ & $\begin{array}{c}\text { Mean of } \\
\text { Receivables }\end{array}$ & $\begin{array}{c}\text { Variance } \\
\text { of } \\
\text { Receivables }\end{array}$ & $\begin{array}{l}\text { Mean Net } \\
\text { Plant and } \\
\text { Equipment }\end{array}$ & $\begin{array}{c}\text { Variance Net } \\
\text { of Plant and } \\
\text { Equipment }\end{array}$ \\
\hline Line 2 & $\begin{array}{l}\text { Mean of } \\
\text { Payables }\end{array}$ & $\begin{array}{c}\text { Variance } \\
\text { of } \\
\text { Payables }\end{array}$ & $\begin{array}{l}\text { Mean of } \\
\text { Profit }\end{array}$ & $\begin{array}{l}\text { Variance } \\
\text { of } \\
\text { Profit }\end{array}$ & & \\
\hline Line 3 & $\begin{array}{l}\text { Mean of } \\
\text { Liquidation } \\
\text { Value }\end{array}$ & $\begin{array}{c}\text { Variance } \\
\text { of } \\
\text { Liçuidation } \\
\text { Value }\end{array}$ & Zero & Zero & & \\
\hline
\end{tabular}

Figure 15. Guide to layout of probability run printouts. 
TABLE XXI

THE MARKET SHARE OPTIONS WHTCH ARE IN THE OPTDMUM SET YOR EACH CASE

\begin{tabular}{|c|c|c|c|c|c|c|c|c|c|c|c|c|c|c|c|c|c|c|c|c|}
\hline $\begin{array}{l}\text { Computer } \\
\text { Bun } \\
\end{array}$ & 1 & 2 & 3 & 4 & 5 & 6 & 7 & 8 & 9 & $\frac{\text { SBU M }}{10}$ & $\frac{\text { unber }}{11}$ & 12 & 13 & 14 & 15 & 16 & 17 & 18 & 19 & 20 \\
\hline AO & 1 & 2 & 1 & 2 & 1 & 2 & 1 & 1 & 1 & 3 & 1 & 2 & 1 & 3 & 2 & 1 & 2 & 2 & 1 & 1 \\
\hline Al & 1 & 1 & 1 & 1 & 1 & 1 & 1 & 1 & 1 & 2 & 1 & 1 & 1 & 3 & 2 & 1 & 1 & 1 & 1 & 2 \\
\hline$A^{2}$ & 1 & 1 & 1 & 1 & 1 & 1 & 1 & 1 & 1 & 1 & 1 & 1 & 2 & 3 & 2 & 1 & 1 & 1 & 2 & 1 \\
\hline A3 & 1 & 1 & 1 & 1 & 1 & 1 & 1 & $i$ & 1 & 2 & 2 & 1 & 1 & 3 & 2 & 1 & 1 & 1 & 1 & 1 \\
\hline $\mathbf{N}^{4}$ & 1 & 1 & 1 & 1 & 1 & 1 & 1 & 1 & 1 & 1 & 1 & 1 & 1 & 2 & $1^{\circ}$ & 1 & 1 & 1 & 1 & 1 \\
\hline A5-2 2 & 2 & 2 & 2 & 2 & 2 & 2 & 2 & 2 & 2 & 2 & a & 2 & 2 & 3 & 2 & 2 & 2 & 2 & 2 & 2 \\
\hline 16 & 0 & 0 & 0 & 0 & 0 & 0 & 0 & 0 & 0 & 0 & 0 & 0 & 0 & 0 & 0 & 0 & 0 & 1 & 0 & 0 \\
\hline A7-1 & 1 & 1 & 1 & 1 & 1 & 1 & 1 & 1 & 1 & 1 & 1 & 1 & 1 & 3 & 2 & 1 & 2 & 0 & 1 & 2 \\
\hline $17-2$ & 1 & 2 & 1 & 1 & 1 & 1 & 1 & 1 & 1 & 1 & 1 & 1 & 1 & 3 & 2 & 1 & 1 & 2 & 1 & 1 \\
\hline$A 7-3$ & 1 & 1 & 1 & 1 & 1 & 2 & 1 & 1 & 1 & 1 & 1 & 1 & 1 & 3 & 2 & 2 & 1 & 3 & 1 & 1 \\
\hline B & 1 & 2 & 1 & 1 & 1 & 1 & 1 & 1 & 1 & 3 & 1 & 2 & 1 & 2 & 2 & 2 & 1 & 2 & 1 & 1 \\
\hline B & 1 & 1 & 1 & 1 & 1 & 1 & 1 & 1 & 1 & 1 & 1 & 1 & 1 & 1 & 2 & 1 & 1 & 1 & 1 & 2 \\
\hline $\mathbf{n}$ & 1 & 3. & 1 & 1 & 2 & 2 & 1 & 2 & 2 & 1 & 1 & 1 & $I$ & 2 & 2 & 1 & 1 & 2 & 2 & 3 \\
\hline J. & 2 & 1 & 1 & 2 & 2 & 1 & 1 & 1 & 1 & 1 & 1 & 1 & 1 & 3 & 2 & 1 & 2 & 1 & 1 & 1 \\
\hline$\sqrt{2}$ & 1 & 1 & 1 & 2 & 1 & 1 & 1 & 1 & 1 & 1 & 1 & 1 & 1 & 3 & 2 & 1 & 1 & 2 & 2 & 2 \\
\hline$\sqrt{3}$ & 1 & 1 & 1 & 2 & 1 & 1 & $\cdot 1$ & 2 & 1 & 1 & 1 & 1 & 1 & 3 & 2 & 1 & 1 & 2 & 1 & 1 \\
\hline 54 & 1 & 1 & 1 & 2 & 1 & 1 & 1 & 1 & 2 & 1 & 1 & 1 & 1 & 3 & 2 & 1 & 1 & 1 & 1 & 1 \\
\hline$\sqrt{5}$ & 1 & 1 & 1 & 2 & 1 & 1 & 1 & 1 & 1 & 2 & 1 & 2 & 1 & 3 & 2 & 1 & 1 & 2 & 1 & 1 \\
\hline 56 & 1 & 1 & 1 & 1 & 1 & 2 & 2 & 1 & 2 & 1 & 1 & 1 & 1 & 3 & 2 & 1 & 2 & 1 & 1 & 1 \\
\hline$\pi 7$ & 1 & 1 & 1 & 1 & 1 & 1 & 1 & 1 & 1 & 2 & 1 & 1 & 1 & 3 & 2 & 1 & 1 & 2 & 1 & 1 \\
\hline 58 & 1 & 2 & 1 & 2 & 1 & 1 & 1 & 1 & 1 & 1 & 1 & 1 & 1 & 3 & 2 & 1 & 2 & 1 & 1 & 1 \\
\hline J9 & 0 & 1 & 2 & 2 & 2 & 1 & 2 & 1 & 1 & 1 & 1 & 1 & 1 & 3 & 2 & 1 & 1 & 1 & 1 & 2 \\
\hline 520 & 1 & 2 & 0 & 2 & 2 & 2 & 2 & 0 & 2 & 0 & 2 & $i$ & 2 & 0 & 2 & 0 & 2 & 2 & 2 & 0 \\
\hline נג & 1 & 1 & 1 & 2 & 1 & 0 & 1 & 1 & 1 & 1 & 1 & 1 & 1 & 3 & 0 & 1 & 2 & 1 & 1 & 1 \\
\hline ת122 & 1 & 1 & 3 & 1 & 1 & 1 & 2 & 1 & 0 & 1 & 2 & 2 & 1 & 3 & 2 & 2 & 1 & 1 & 1 & 1 \\
\hline$\sqrt{23}$ & 1 & 2 & 1 & 1 & 0 & 1 & 1 & 1 & 1 & 1 & 2, & 0 & 1 & 3 & 2 & 1 & 1 & 1. & 1 & 1 \\
\hline P1 & 2 & 1 & 1 & 1 & 1 & 1 & 1 & 1 & 1 & 1 & 1 & 1 & 1 & 3 & 2 & 1 & 1 & 1 & 1 & 1 \\
\hline PR & 1 & 2 & 1 & 1 & 1 & 2 & 1 & 2 & 1 & 1 & 2 & 1 & 1 & 3 & 2 & 1 & 1 & 2 & 1 & 1 \\
\hline P3 & 1 & 1 & 1 & 1 & 2 & 1 & 1 & 2 & 1 & 1 & 1 & 1 & 1 & 3 & 2 & 1 & 1 & 0 & 1 & 2 \\
\hline $\mathrm{P}_{4}$ & 1 & 2 & 1 & 1 & 2 & 1 & 1 & 1 & 1 & 2 & 1 & 1 & 1 & 3 & 2 & 2 & 1 & 1 & 1 & 1 \\
\hline $\mathbf{m}$ & 1 & 1 & 2 & 2 & 1 & 1 & 1 & 1 & 1 & 1 & 1 & 1 & 1 & 3 & 2 & 3 & 2 & 1 & 1 & 1 \\
\hline
\end{tabular}

Reproduced with permission of the copyright owner. Further reproduction prohibited without permission. 
COMPUTER RUN AO

COMPANY MANAGEMENT CASE

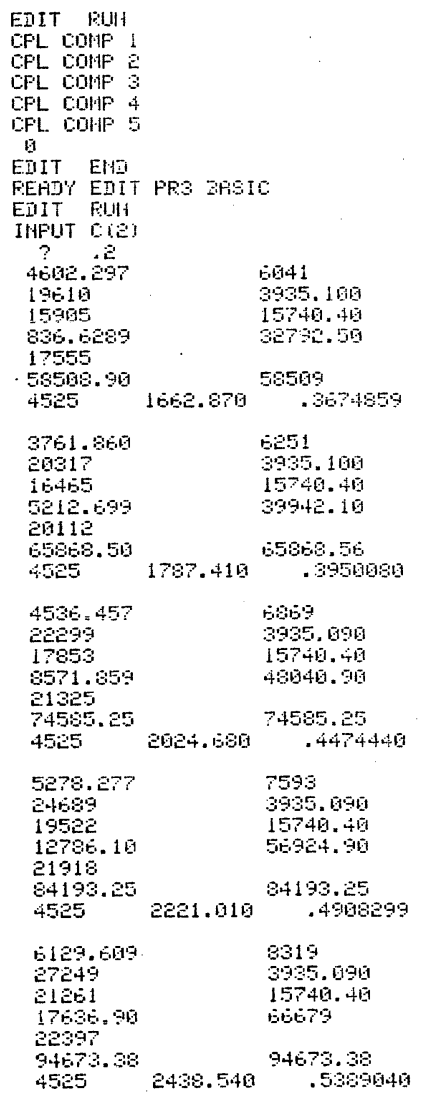

Reproduced with permission of the copyright owner. Further reproduction prohibited without permission. 


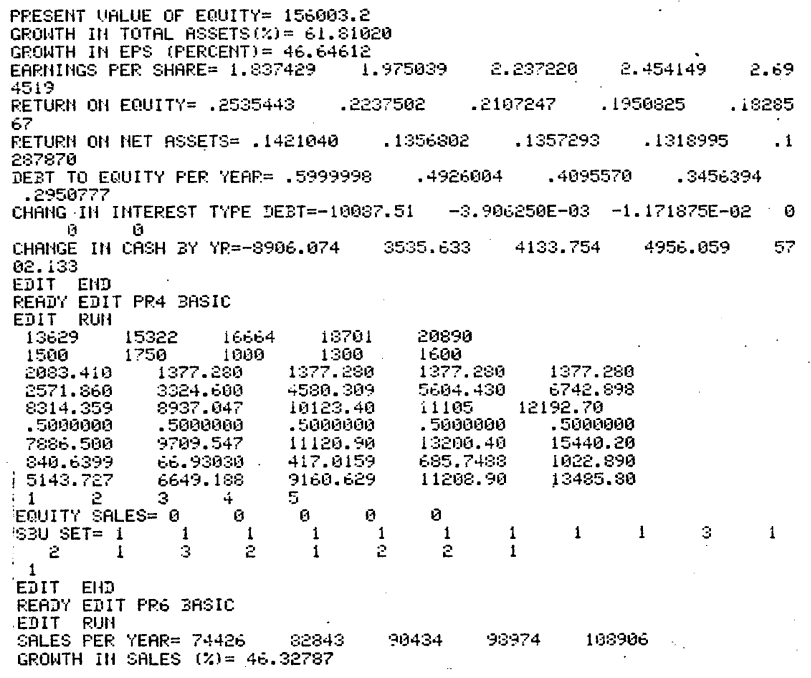

Reproduced with permission of the copyright owner. Further reproduction prohibited without permission. 
COMPUTER RUN AI

PRESENT VALUE OF SHAREHOTDERS

EQUIIY

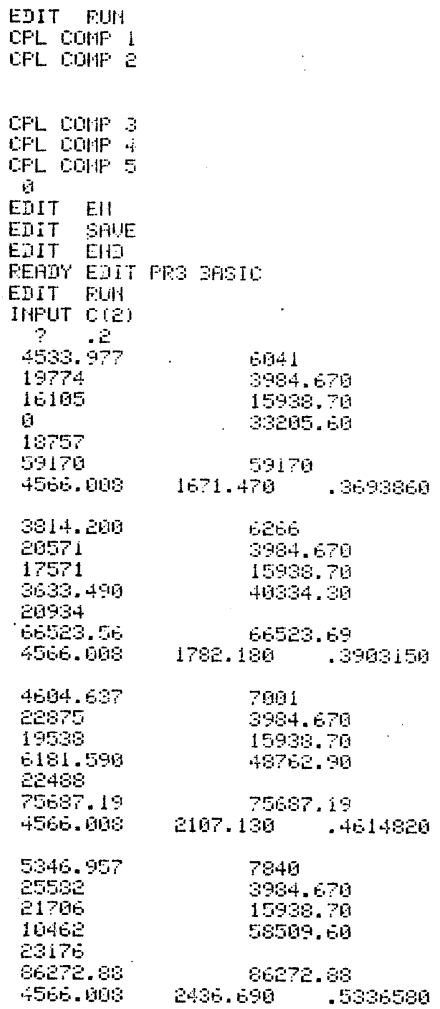

Reproduced with permission of the copyright owner. Further reproduction prohibited without permission. 


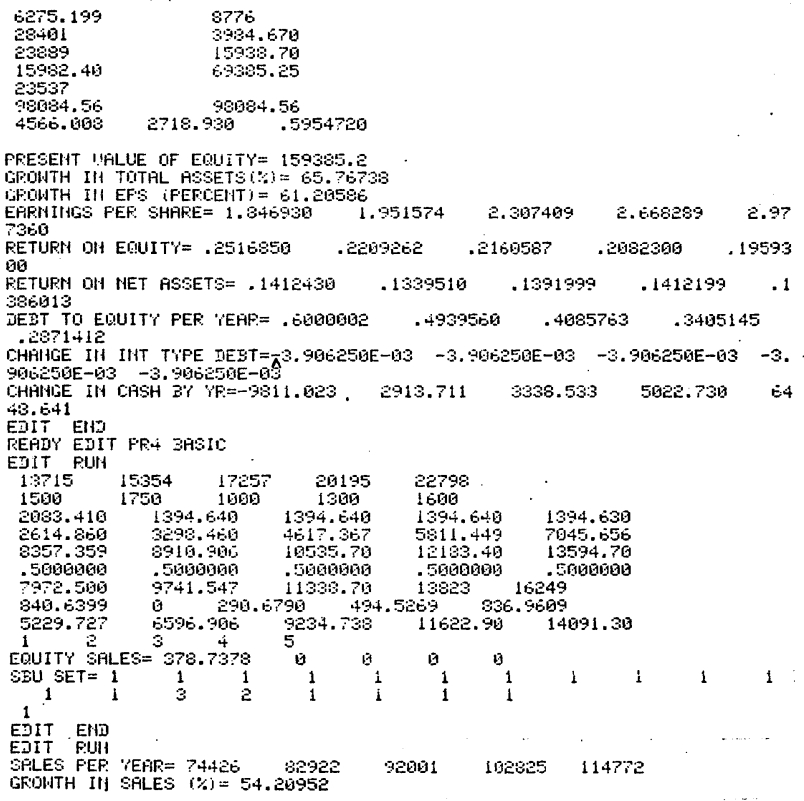

Reproduced with permission of the copyright owner. Further reproduction prohibited without permission. 


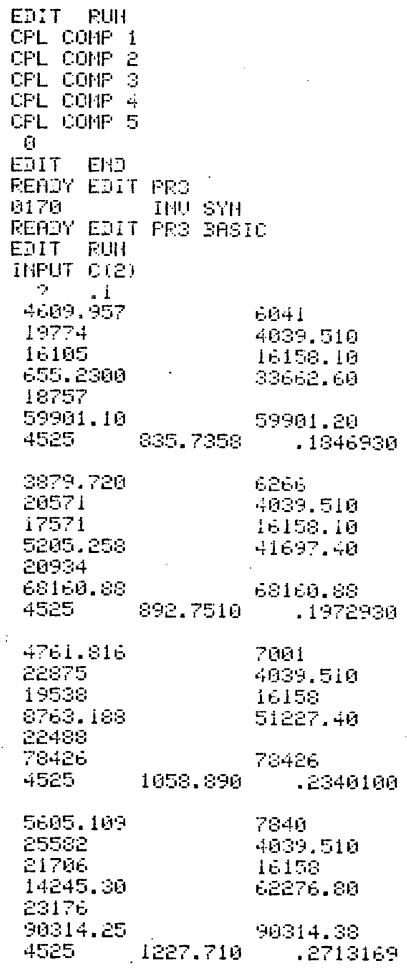

Reproduced with permission of the copyright owner. Further reproduction prohibited without permission. 


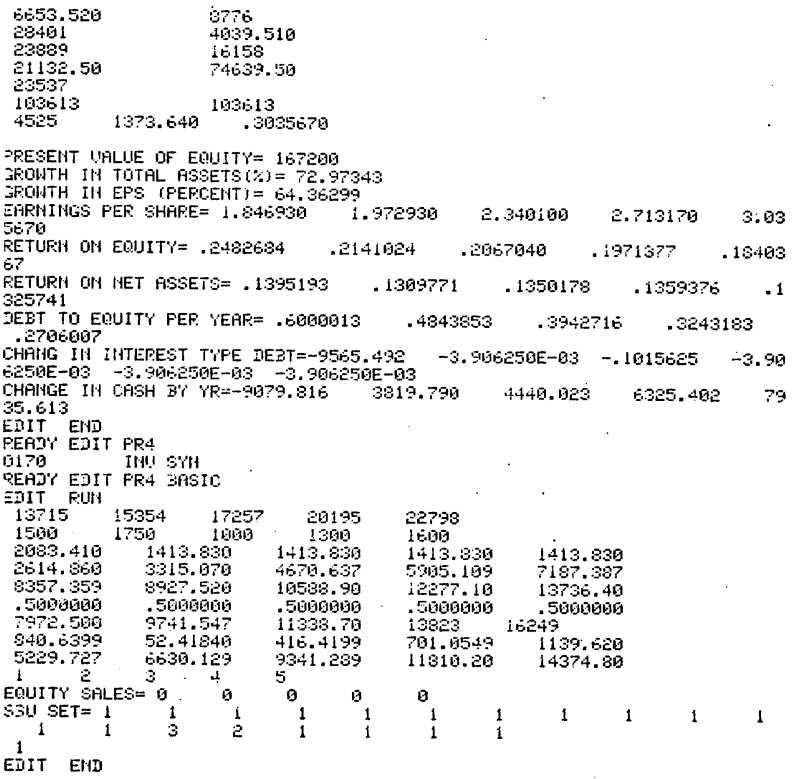

Reproduced with permission of the copyright owner. Further reproduction prohibited without permission. 


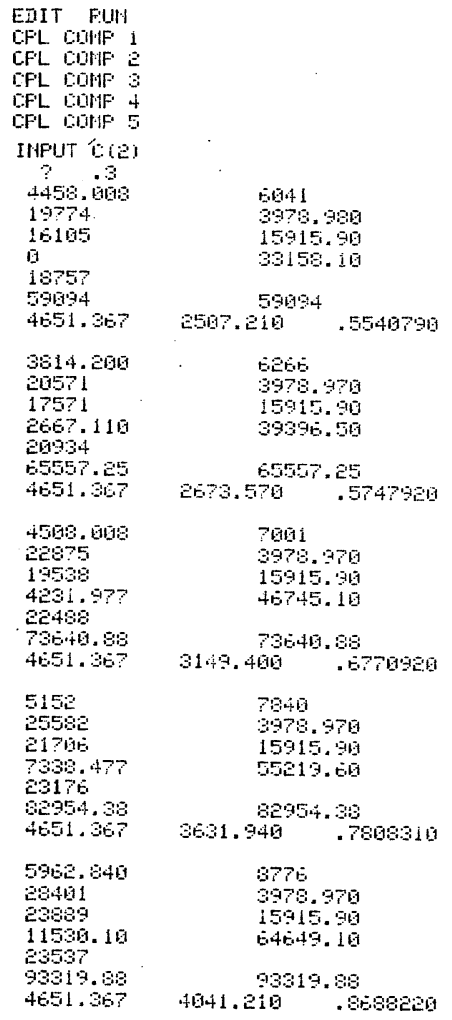

Reproduced with permission of the copyright owner. Further reproduction prohibited without permission. 
FRESEHT YALUE OF EDUITY $=153072.3$

GFOWTH IN TOTAL ASSETS $(\because)=57.91759$

GROWTH IN EFS (PERCENT) $=56.80 .475$

EFPIIIHGS PER SHARE $=1.846939 \quad 1.915973$

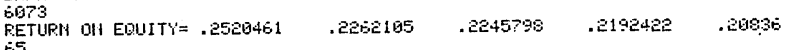

E.5

FETURN OH HET RSSETS $=.1414250 \quad .1359407 .1425567 \quad .1459413 \quad .1$

443498

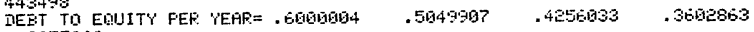

.9077362

CHFHG IN IHTEREST TYFE DEBT $=-9868.133$ - $1.171875 E-192-3.910250 E-03-3$

$.906256 \mathrm{E}-03-3.965250 \mathrm{E}-93-3.906250 \mathrm{E}-03$

CHFHGE IH $\mathrm{CASH}$ 3Y YR=-9865.992 2023.301

घ2.461

EDIT END

PEADY EDIT PF.4

G170 INU SYH

FEADY EDIT PR4 SASIC

EDIT FIIH

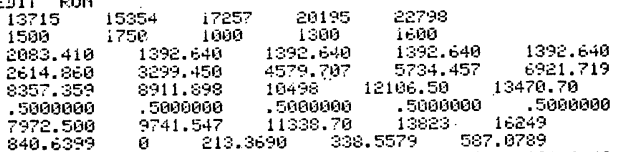

$5229.727 \quad 6598.396 \quad 9159.430 \quad 11468.90 \quad 13843.49$

12 . 34

EQUITY SHLES $=116$ ?

SEU SET $=1$ 1

1

FIT FHT

Reproduced with permission of the copyright owner. Further reproduction prohibited without permission. 


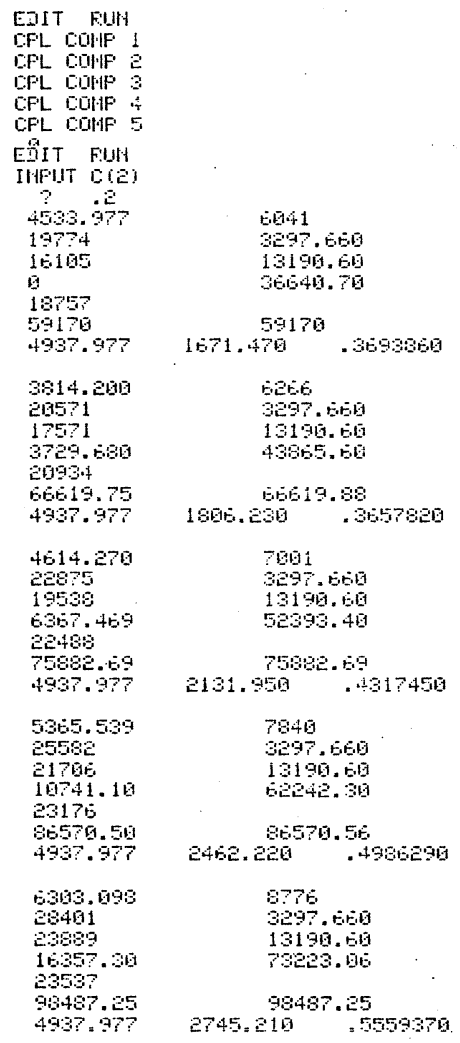

Reproduced with permission of the copyright owner. Further reproduction prohibited without permission. 


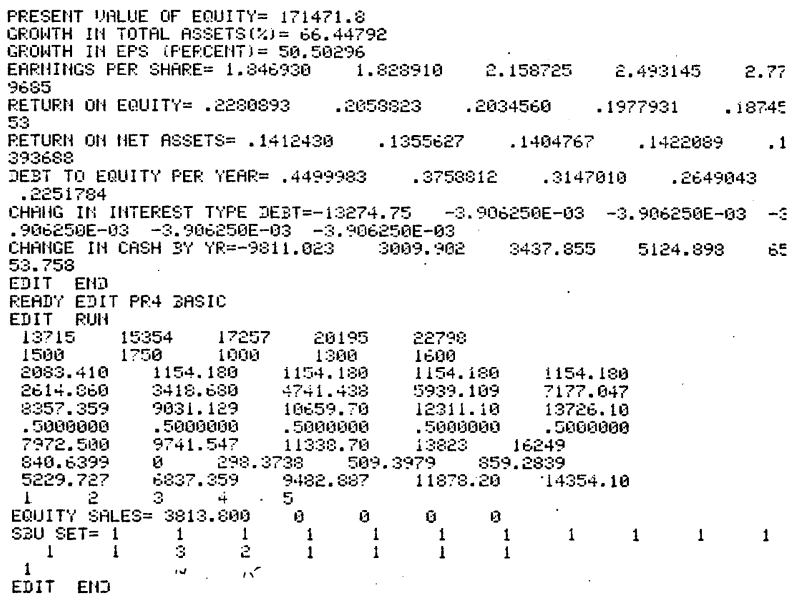

Reproduced with permission of the copyright owner. Further reproduction prohibited without permission. 


\section{PRESENT VAUUE OF SHAREHOIDERS EQUITY}

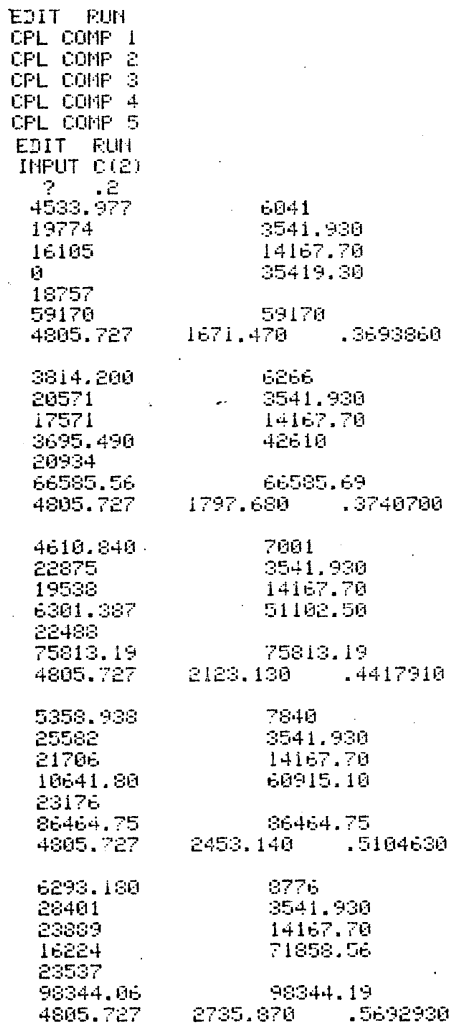

Reproduced with permission of the copyright owner. Further reproduction prohibited without permission. 


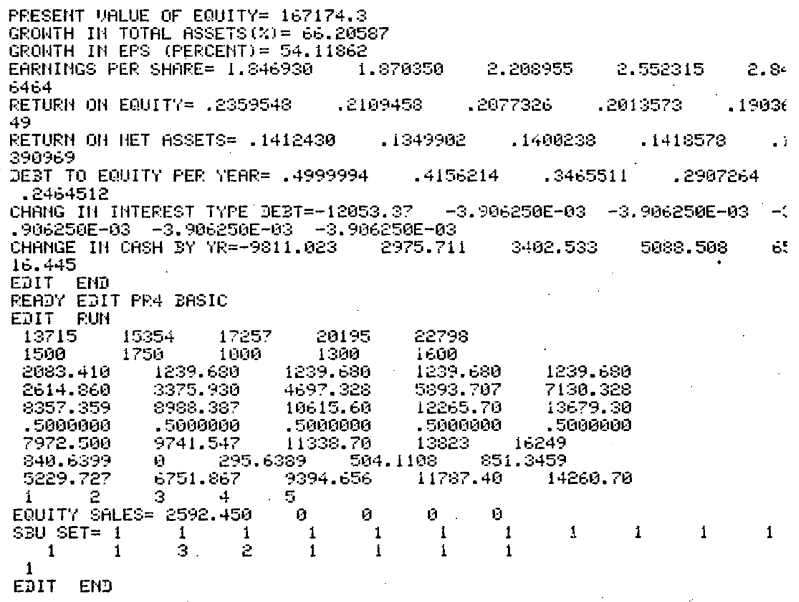

Reproduced with permission of the copyright owner. Further reproduction prohibited without permission. 


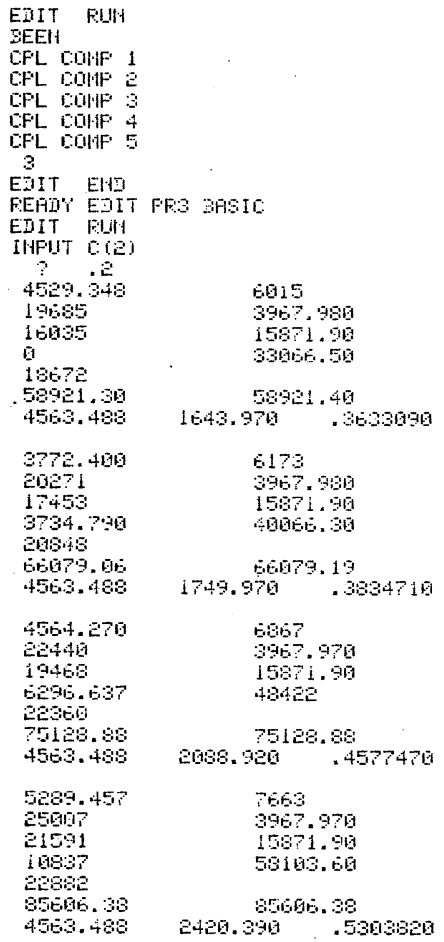




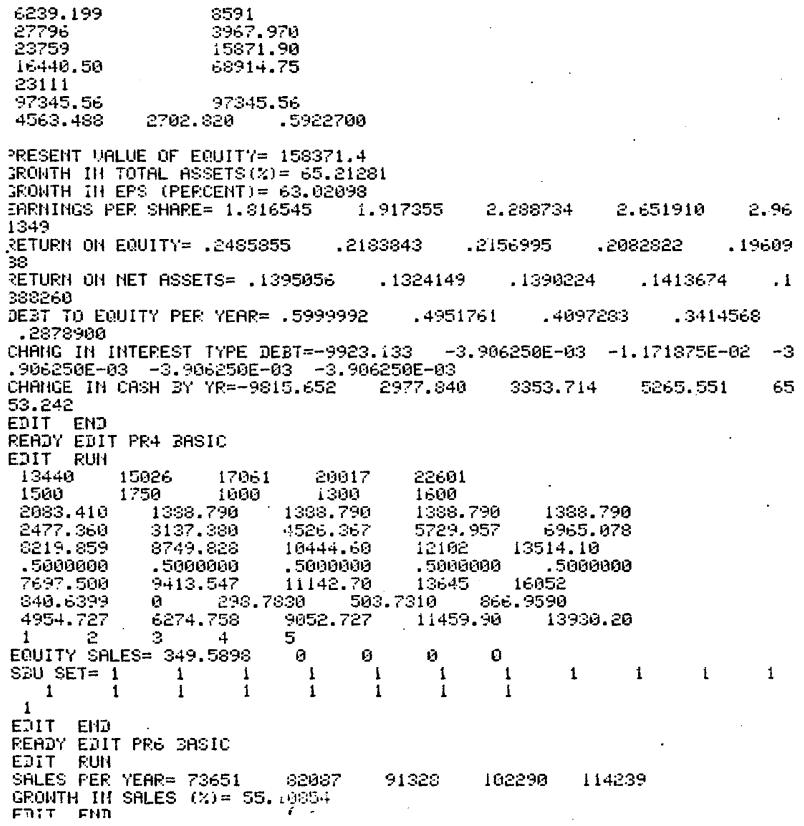

Reproduced with permission of the copyright owner. Further reproduction prohibited without permission. 


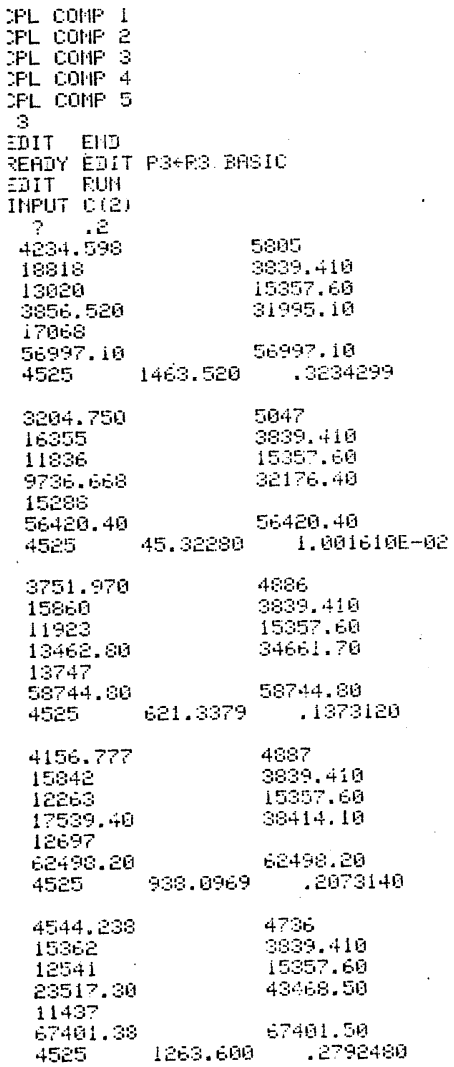

Reproduced with permission of the copyright owner. Further reproduction prohibited without permission. 


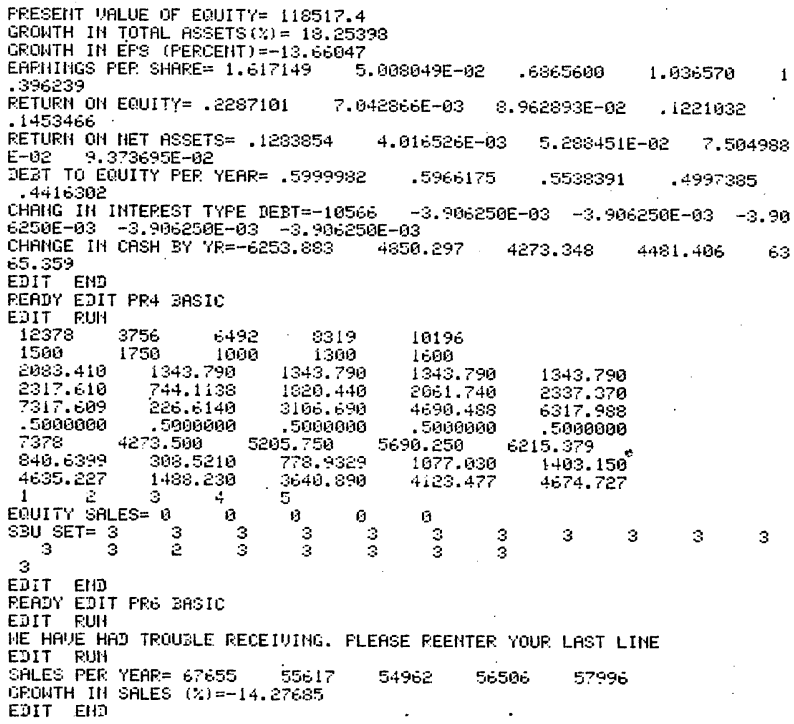

Reproduced with permission of the copyright owner. Further reproduction prohibited without permission. 


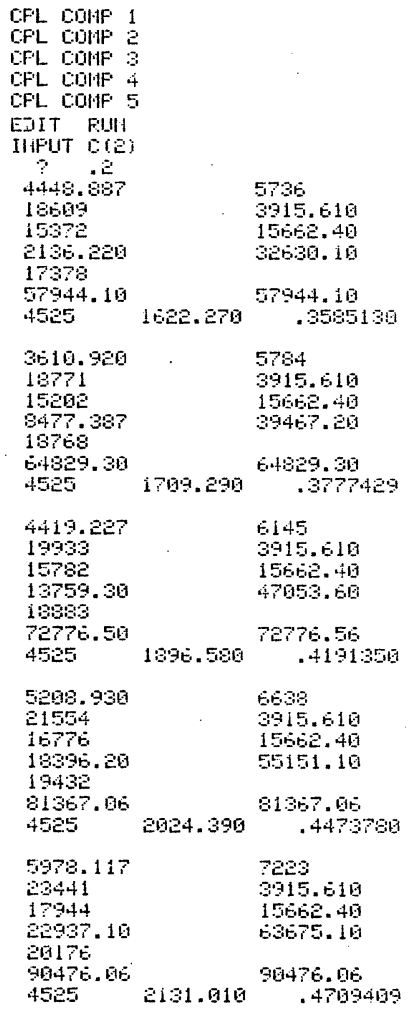

Reproduced with permission of the copyright owner. Further reproduction prohibited without permission. 
DFESEHT LALUE OF EQUITY $=152346$

IFOWTH IH TOTAL ASSETS $(\%)=55.14365$

SFOWTH IN EF'S (PERCENT) $=31.35945$

ERRHIHGS FEF. SHARE $=1.792564 \quad 1.888715 \quad 2.095675 \quad 2.236890 \quad 2.35$ 4705

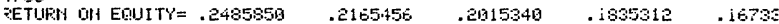
47

BETURN OHA HET A6SETS= $.1399858 \quad .1318399 \quad .1393017 \quad .1243936 \quad .1$

177565

DEET TO EOUIT' PER YERF $=.5999984 \quad .4960577 \quad .4150789 \quad .3549835$ .3674672

SHAHG IH INTEREST TYFE DEZT=-10184.99 -3.996250E-03 $-3.906250 E-03-3$

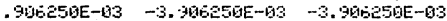

SHAHGE II CASH BY YK $=-7.759 .895$ 5503.195

10.986

EDIT END

REAIT EDIT PRA SHSIC

EDIT FUN

13223

1500

14430

15115

16313

13913

2083.410

2368.560 1759

1600

$\begin{array}{ll}1370.409 & 1370.460 \\ 2933.990 & 3939.890\end{array}$

3111.359

5546.436 9462.935

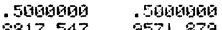

-56日ด

58.547

$170.8970 \quad 679.1909$

8.40 .6399

4737.727

$5867.97 ?$

7879.598

6090.215

5426.605

5

ECUITY SHLES=

2

$2^{\text {SET }=} \frac{?}{2}$

$\begin{array}{ll}2 & 2 \\ 3 & 2\end{array}$

可

190

17.59

16010

$1370.465 \quad 1370.469$

$4521.359 \quad 5205.199$

16121.9410055

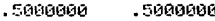

$10812.40 \quad 11909.20$

$1100.759 \quad 1471.700$

$9242.707 \quad 10410.40$

EDIT END

READY EDIT EЧPRD ERSIC

EDIT FUIII

SHLES FER YEHF:= 71730, 7.291 79567 84670 90461

GFONTH IN SHLES $(\%)=26,1: 213$

E.IT FIII

Reproduced with permission of the copyright owner. Further reproduction prohibited without permission. 


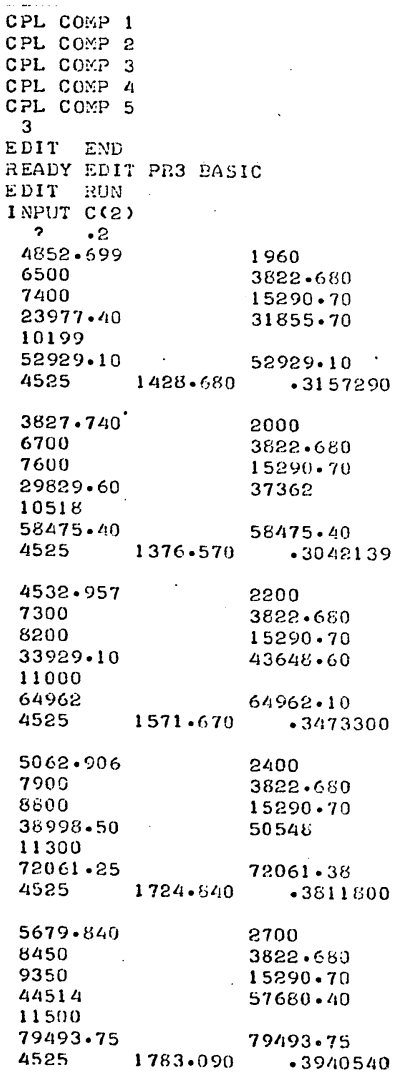

Reproduced with permission of the copyright owner. Further reproduction prohibited without permission. 
PRESENT UNLUE OF EQUITY $=142229.7$

GROWTH IN TOTAL ASSETS $(\not 2)=50.18910$

G:ROUTH IN EPS (PERCENT) $=24 \cdot 80754$

EAININGS PER SHARE $=1.578645 \quad 1.521070 \quad 1.736650 \quad 1.905900 \quad 1.97$ 0269

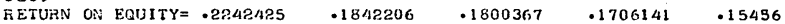

63

RETURN ON NET ASSETS $=.1349617 \quad .1177050$
121528

DELIT TO EQUITY PER YEAL: $.5999987 \quad .5115727 \quad .4378921 \quad .3781233$ .3313670

CHANG IN INTEREST TYPE DEBT $=-10649.62 \quad-3.906250 E-03 \quad-3.906250 \mathrm{E}-03 \quad-3$

- $906250 E-03 \quad-3.906250 E-03 \quad-3.906250 E-03$

CHANCE IN CASH. BY YR= $14485.10 \quad 4827.238 \quad 4804.715 \quad 5599.352 \quad 61$

32.434

EDIT END

READY EUIT PRA BASIC

EDIT LIST 20

00020 MAT GET "EEE", A(2.5)

ED1T 20 NAT GETWEEE*, A (145)

EIIT RUN

$\begin{array}{lllll}9188 & 9323 & 9750 & 10800 & 11100\end{array}$

$\begin{array}{lllll}1500 & 1750 & 1000 & 1300 & 1600\end{array}$

$2083.410 \quad 1337.940 \quad 1337.940$

$1400.840 \quad 1270.400 \quad 1940.090$

$7143.379 \quad 6882.840 \quad 7858.340$

$.5000000 \quad .5000000 \quad .5000000$

$3445.500 \quad 3710.550 \cdot 3831.750$

$2939.680 \quad 1918.190 .2386 .370$

1600

$2.52 \cdot 190$

$8624 \cdot 188$

.5000000

4428

2714.330

$2801.770 \quad 2540.810$

$3880 \cdot 180$

$4504 \cdot 379$

$1337 \cdot 940$

$2366 \cdot 470$

$8915 \cdot 469$ 4551

EOUITY SALES $=0$

SEU SET $=0$

00

$\begin{array}{lll}0 & 0 & 0\end{array}$

0

EDIT RUIT

SFILES PEF. 'IEAF: 3 अव 1

IFONTH IH SALES $\% 1:$ CH,

EIIT EHJ

Reproduced with permission of the copyright owner. Further reproduction prohibited without permission. 
COMPUTER RUN A7-1

WITH AII SBU EXCEPT NO. 18

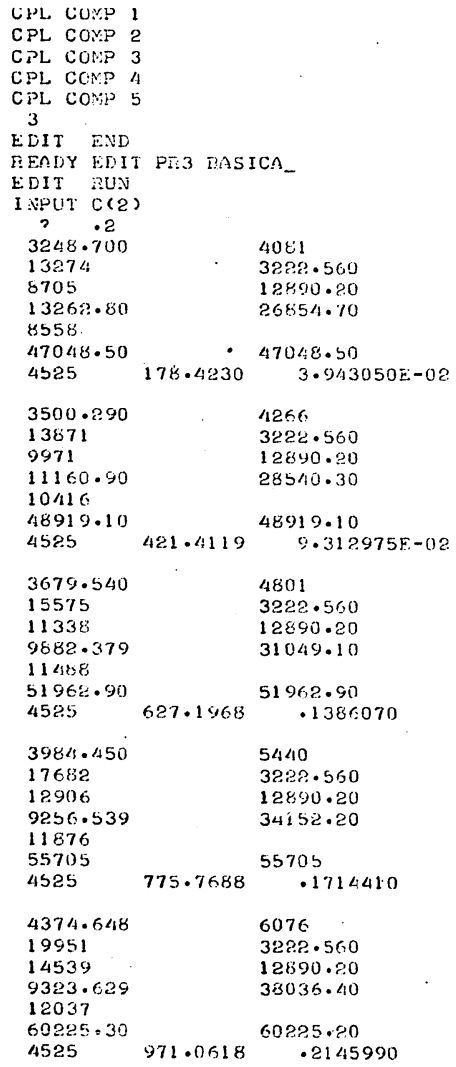

Reproduced with permission of the copyright owner. Further reproduction prohibited without permission. 
PIBESENT UNLUE OF EOUITY $=103785.3$

GiNOWT IN TOTAL NSSETS $(\%)=28.00674$

GIOOTH IN EPS (PERCENT) $=444.2456$

$\begin{array}{lllll}\text { EAININGS PER SHARE }=.1971525 & .4656488 & .6930348 & .8572048 & 1.07 \\ 2994 & & & & \end{array}$

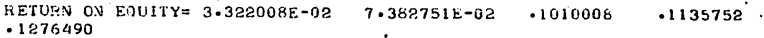

RETUKN ON NET ASSETS $=1.896160 E-02 \quad 4.307234 \mathrm{E}-02 \quad 6.035045 E-02 \quad 6.963$

$187 \mathrm{E}-02 \quad 8.061910 \mathrm{E}-02$

LERT TO EQUITY PER YEAR $=.5999977 \quad .5645617 \quad .5189444 \quad 04717926$ .4235141

CHANG IN INTEREST TYPE DEET $=-13650.24 \quad-3.906250 \mathrm{~F}-03 \quad-3.906250 E-03-5$

- SOG2SOE-03 -3.506250E-03 -3.906250E-03

CHANGE IN CASH BY YR= $2166.496 \quad-1850.313 \quad-1099.273 \quad-320.9336 \quad 4 E$

7.2852

EDIT ENL

ELIT RUN

4527

1500

2.083 .410

$892 \cdot 1150$

6031

1000

$892 \cdot 1150$

.5000000

4527

840.6399

$1784 \cdot 230$

1127.900

2107.060

2107.060

.5000000

$603 i^{2} 7507$

1061.020

4214.129

29

1 2 3

EDUITY SALES $=0$

SISU SET $=1$

1

$$
1
$$

1

EDIT FUN

SALES PEF: YEAF: $44135 \quad 51519$

GFUHTH IH SFLES $(\%)=73.4 \%$

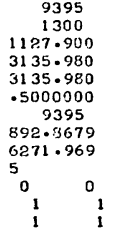

11698

1600

1127.900

$3878 \cdot 850$

3878.850

.5000000

11698

790.5898

$7757 \cdot 688$

1127.900

$4855 \cdot 309$

$4855 \cdot 309$

.5000000

$7 / 10.5229$

$9710 \cdot 617$

0

$$
1
$$

$\begin{array}{ll}1 & 1 \\ 0 & 1\end{array}$

1

1

1

1

Reproduced with permission of the copyright owner. Further reproduction prohibited without permission. 


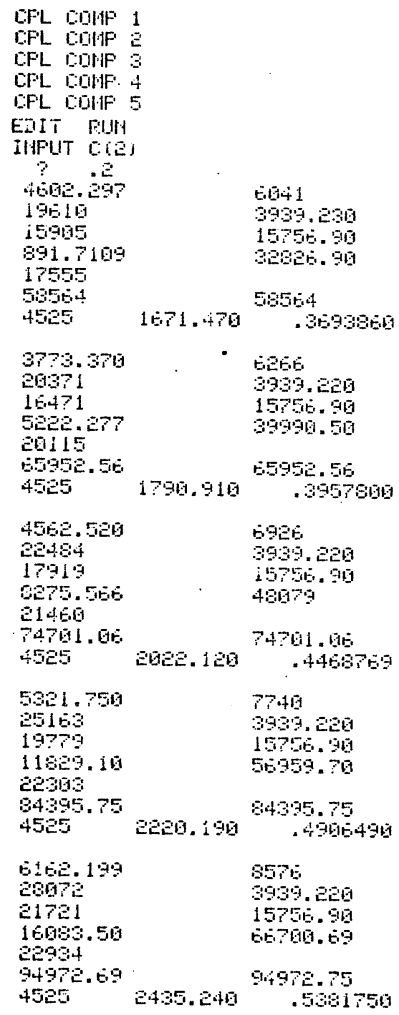

Reproduced with permission of the copyright owner. Further reproduction prohibited without permission. 
PEESENT UALUE DF EOUIT' $=155125.4$

GROWTH IH TOTAL HSSETS $(\%)=62.16398$

GFOWTH IH EPS (PEPCENT) $=45.69444$

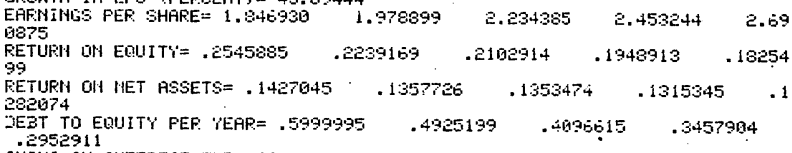

CHAHIG IN IHTEREST T'PPE DEET=-10066.60 $-1.171875 E-02-3.906250 E-03-3$

$.966250 \mathrm{E}-03 \mathrm{3}-3.90625 \mathrm{EE}-03 \quad-3.910 \mathrm{~B} 250 \mathrm{E}-03$

CHAMGE IN CHSH EY $Y K=-8850.992 \quad 351.63 ? \quad 3842.438 \quad 4312.762 \quad 50$

94.852

EDIT END

FEADY EDIT FF:4 BASIC

EDIT RUN

$13715 \quad 15354 \quad 16639 \quad 18718 \quad 20935$

$15001750 \quad 1000 \quad 1300 \quad 1500$

$2083.410 \quad 1378.739 \quad 1379.739 \quad 137 \%$

$2614.860 \quad 3342.090 \quad 4507.457 \quad 5600.36$

$6357.359 \quad 6954.527 \quad 10110.001109 .90$

.58 g. 5 .

$7972.5130 \quad 9741.547 \quad 11995.90$

.590019090 .5039809

$13217.40 \quad 15.455 .20$

$840.1399 \quad 71.33690 \quad 417.7920 \quad 662.94+9 \quad 946.3250$

5229.727 $5084.150 \quad 9134.930 \quad 11209.79 \quad 13452.80$

$\begin{array}{llll}1 & 2 & 3 & 5 \\ \text { ENUITY SALES } & 0 & 0 & 0 \\ \text { SPUT }=1 & 1 & 1 & 1\end{array}$

READY EDIT FPS ZASIC

EDIT FUH

GFLES PEF YEHF:- 74426 92922 $99330 \quad 190474 \quad 111526$

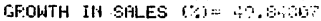

EDIT EHI

Reproduced with permission of the copyright owner. Further reproduction prohibited without permission. 


\section{WITH SBU NO. 18 OPTION 3}

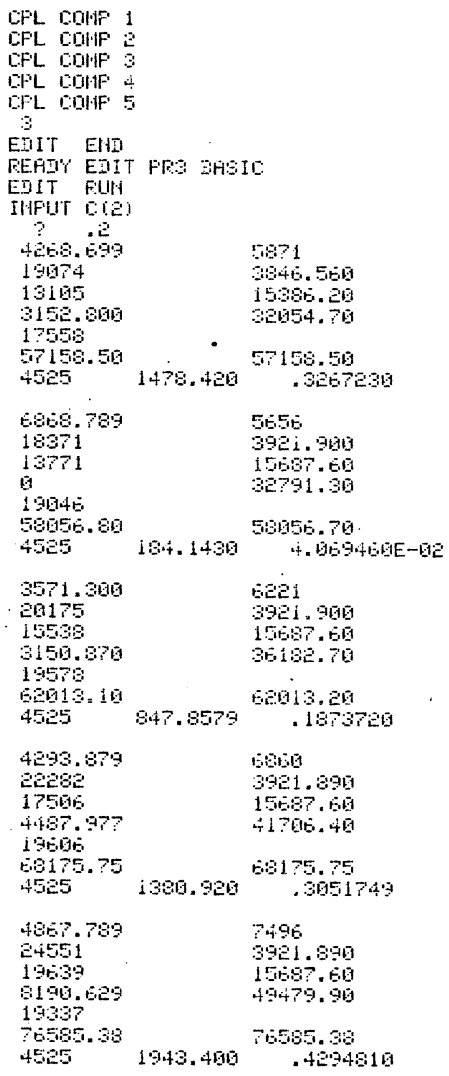

Reproduced with permission of the copyright owner. Further reproduction prohibited without permission. 
FRESEHT UALUE OF EOUITY $=124905.3$

CFONTH IH TOTAL HESETS $(\%)=33.98770$

GRONTH IN EFS (PEFCENT $=31.45193$

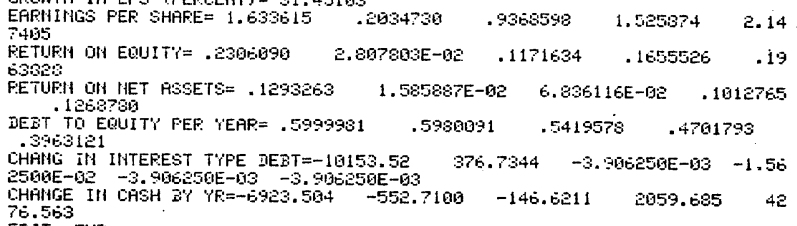

EDIT EHI

FEADY EIIT PR.4 3ASIC

EIIT RIJH

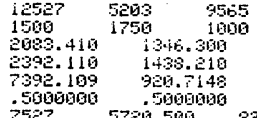

$7527 \quad 5700.500$

845. 6399 252.224a

$4784.2 e 7$ 2876.430

1 i 3

EOUUT'T SALES $=0$

SEU $S E T=\frac{1}{1} \quad \frac{1}{3} \quad 1$

1

EIIT END

REHDY EDIT FRE BASIC

EDIT PUII

SALES FEF: YEAR: $=6953$

GFOUTH IH GRLES CI= AOESO

$13 \sin 1$

$1372.13000001372 .680 \quad 1372.500$

2953.0419 4275.316 5736.367

+239.289 694.578 9717

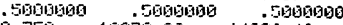

8276. 750 19972.30 14066.48

$0 \quad 252.0690 \quad 59.0338$

590.090 8501.5+8 $11+72.70$

5

$\begin{array}{llllllllll}1 & 0 & 9 & 0 & & & & & & \\ 2 & 1 & 1 & 1 & 1 & 1 & 1 & 1 & 1\end{array}$

EDIT EHD

Reproduced with permission of the copyright owner. Further reproduction prohibited without permission. 


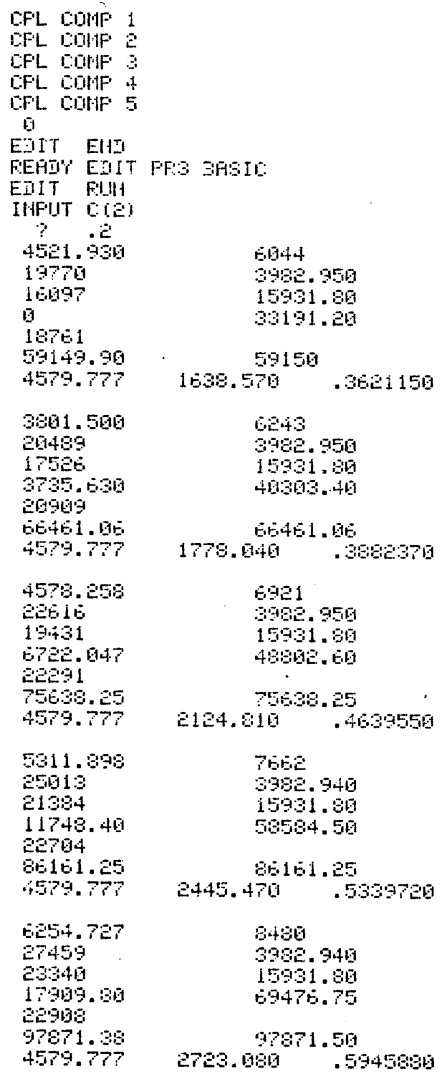

Reproduced with permission of the copyright owner. Further reproduction prohibited without permission. 
FRESEIT UALUE OF EQUITY $=159463.8$

LFOWTH III TOTHL ASSETS $(\%)=05.46320$

LROWTH II EF'S (PERCEIT) $=04.19858$

EAPHIHIS FER SHARE= $1.810575 \quad 1.941185$

2. 069860 2. 97

2:339

RETUFH ONA EQUITY $=.2468380$ . 2อ65819 .2175944 21387131 .19597

GE.

PETURH 에 HET ASSETS= $=1365999$

391152

IEET TO EQUITY PEF: YEAF = .50ḦLDG8

.1337655

.1494586

$.1419124 \quad .1$

. $2866.38 \% 3$

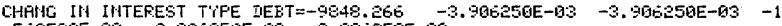

$.562501 \mathrm{E}-92 \quad-3.906250 \mathrm{E}-103-3.965250 \mathrm{E}-0.3$

CHANGE IN $\mathrm{CASH} 3 \mathrm{Y} Y \mathrm{~V}=-9323.979$ 3615.199

04.227

EDIT EDIT

EDIT EHD

F:ERDY EIIT FR4 SHSIC

EDIT RUI

$\begin{array}{lll}13336 & 15312 & 17425 \\ 1590 & 1758 & 16013\end{array}$

2083. 410

2450. 300

1394.030

3277.719

8192.859

3590.207

- 5 abegaba

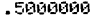

7043.500

9699.547

219239

1310

139.4 .1930

4705.758

10624.10

. 50 190165

340.8399

1

11505.70

22736

16019

$1394.035 \quad 1394.030$

$5655.359 \quad 7066.418$

$12227.41 \quad 13515.40$

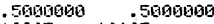

$49015.72 ?$

386? 18187

1325

EQUITY SALES $=495.3419$

SPU SET $=1$ i 1

EIIT EHII

FEADY EDIT PFG EASIC

EDIT FUII

SFILES PER YEAR $=74691$

GROWTH IH SHLES $(\because)=50.1>747$ 


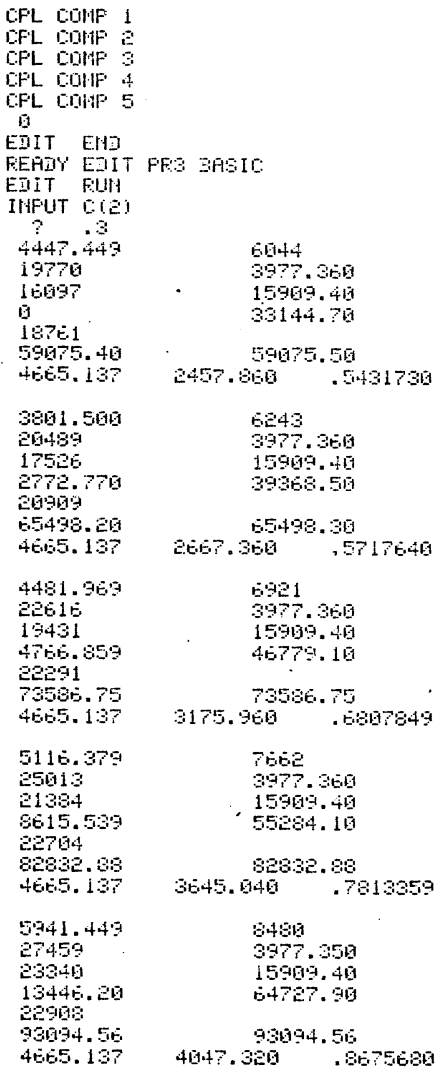

Reproduced with permission of the copyright owner. Further reproduction prohibited without permission. 
FFESEHT JALUE OF EQUITY $=153137.9$

GROWTH IH TOTAL ASOETS $(\%)=57.58600$

GROWTH IN EFS (FERCENT) $=59.72 \mathrm{Z2} 3$

EAFNIHGS FEF: SHHRE = 1.816576. 1.965681

1893

RETUKN ON EQUITY $=.2471849$

.2258456

2.269263

2. 5104453

Q.

P.t

RETURH OH HET ASSETS= .1396849

449178

DEET TO EOUITY FER YEAR= .5999981

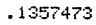

Reproduced with permission of the copyright owner. Further reproduction prohibited without permission. 


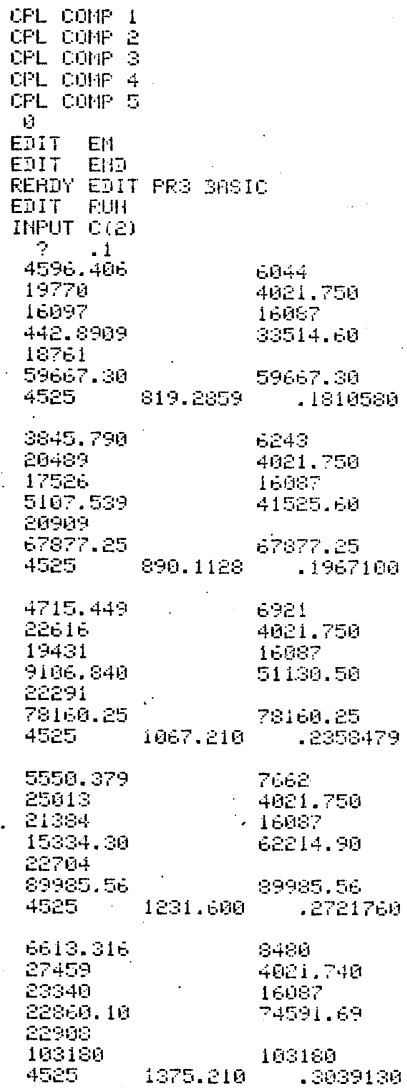

Reproduced with permission of the copyright owner. Further reproduction prohibited without permission. 
PFESEHT UALUE OF EQUITY $=166818.6$

GFOWTH IN TOTAL HSSETS(\%)= 72.92546

GFONTH IN EFS (FEFCENT $=6.0 .65393$

EARNIHGS FER SHARE $=1.810589 \quad 1.967100 \quad$ 2.358479 2.721760 3.03

RETURH OH EQUITY= .2444565 .2143539 .20872e9 $\quad .1979591 \quad .18436$

RETURH DH NET RSSETS= . $1373091 \quad .1311358 \quad .1365413 \quad .1368665 \quad .1$

39286

DEST TO EQUITY PEF VEAR: . .599994? . 2695041

CHFHG IH INTEFEST TYFE IEZT=-9654.262 0 0 b $-1.171375 E-02$

$-3.901250 \mathrm{E}-63$

CHAIIIE IN CASH $2 Y$ YR $=-9395.795$

88.738

$\begin{array}{llll}3914.031 & 4868.957 & 7062.387 & 85\end{array}$

EIIT ENJ

FEADT EDIT FR4 ZATSIL

EDIT FINH

13380 15312 $17+25$

2083.41017501407 .5100

2450.359

3208.680

3192.859

$5 \% 01.129$

.5006000

. 5 14.

7643.550

9699.547

$6+15.6399$

35.43120

49010.727

0577.359

i ${ }^{2} \quad 3$

EQUIT' SALES $=0$

SSU SET $=1$ c

8 1

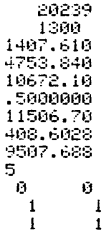

22736

1600

$1407.510 \quad 1407.610$

$5943.957 \quad 7203.059$

12315 1375e.19

$.5090095 \quad .5806000$

13867 1E18?

728.5469 .1226 .745

$11697.90 \quad 1.446 .10$

a 40.5

2

1

1

1

31

Reproduced with permission of the copyright owner. Further reproduction prohibited without permission. 


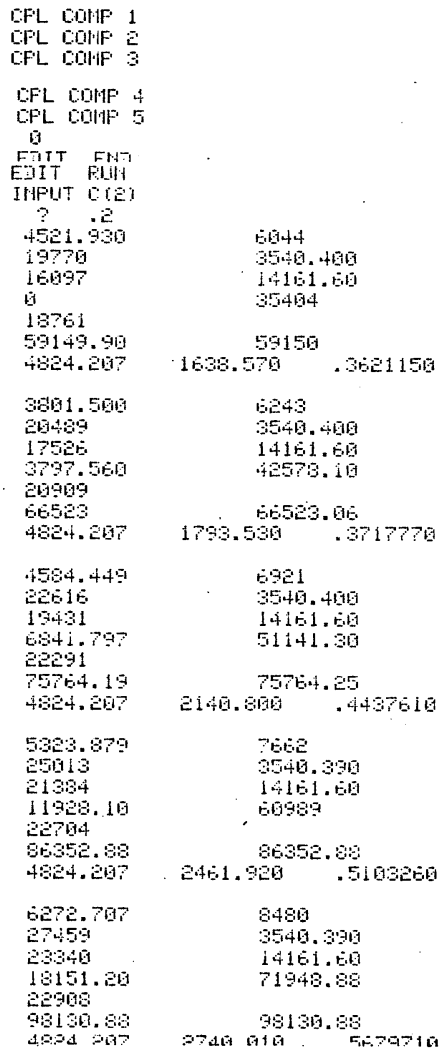


PFESENT UALIJE OF EOUITY = $167249 . \dot{0}$

FONTH IN TUTAL ASSETS $(2)=65.90195$

JFOWTH IH EFS (FERCENT) $=55.34814$

$\begin{array}{lllll}\text { EHFHIHGS FEF SHARE }=1.810575 & 1.858935 & 2.218004 & 2.551629 & 0.83\end{array}$

ZETUFIN DN EQUITY $=.2314193 \quad .2106165 \quad .2093025 \quad .2018331 \quad .19941$

37 ETUFH ON HET RESETS= .1385099 .1348053 .1412804 $.1485500 \quad .1$

390100

DEET TO EQIUIT'Y PER 'CEAR' $=.4999999$

$.4157535 \quad .3461390 \quad .2902488$

- 240.0356

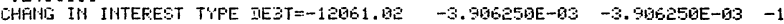

$.56250 \mathrm{EE}-62-3.90 \mathrm{E} 25 \mathrm{EE}-03-3.96025 \mathrm{E}-03$

CHAHGE IH $\mathrm{CHSH}$ S\% $Y F=-9623.970$ 3677.129 $3827.136 \quad 5825.730 \quad 71$

71.939

EIIT EIT

PEAT' EDIT FF:4 3 ASIC

EDIT FUN

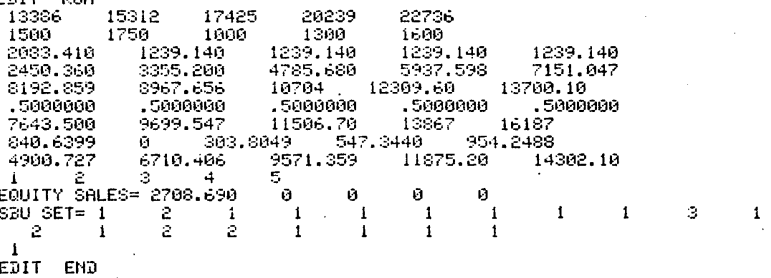

Reproduced with permission of the copyright owner. Further reproduction prohibited without permission. 
COMPUTER RUN B3-2

FOR GROWTH IN EARNINGS PER SHARE

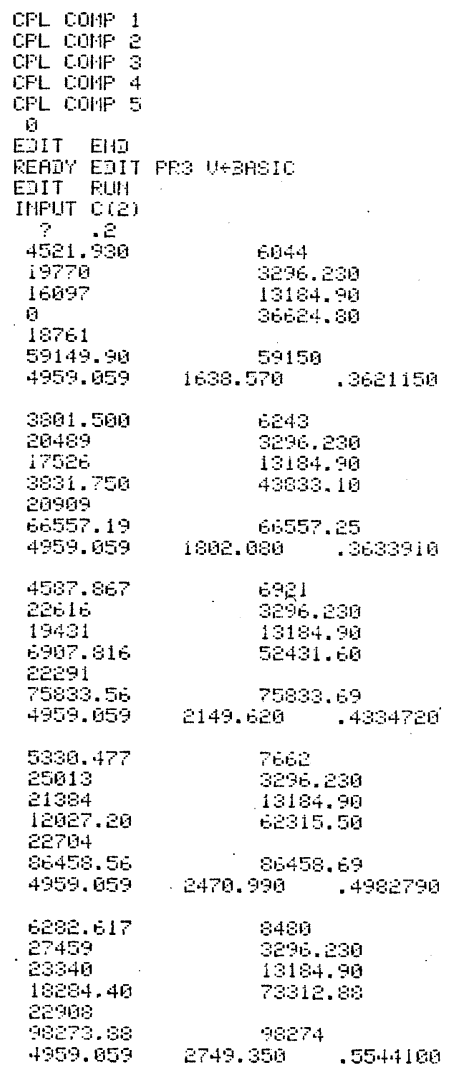

Reproduced with permission of the copyright owner. Further reproduction prohibited without permission. 
FRESEHT IIALUE DF EOUITY $=171545.1$

GFOWTH IH TOTAL ASSETS $(\%)=60.14369$

CROWTH IN EFS (PEFIEEHT) = 53.10326

$\begin{array}{llllll}\text { EAPIIIHS FEF: SHARE= } 1.810575 & 1.816955 & 2.167359 & 2.491395 & 2.77\end{array}$ 2050

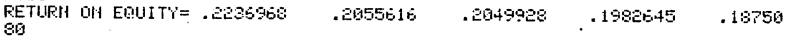

KETUEN DH HET ASSETS= . 13650999

1353783

$.1417328 \quad .142900 \mathrm{ge} \quad .1$

JEZT TD EQUITY FEF: YEAR: $=.4499390$

. 28480503

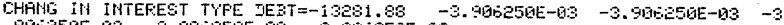

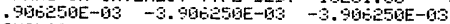

CHAIIE IN CASH 84 YR $=-9623.970 \quad 3111.320$

B9. 340

$3862.434 \quad 5861.992 \quad 72$

EDIT EHD

FEADY EDIT FR4 SASIC

EDIT FIIH

$13366 \quad 15312 \quad 17425 \quad 26239$ 22736

1596 1750 1960 1910

2053.419 1153.680 1153.689 1153.680 1153.689

2450.360

8192.859

3397.730

+989.777

598.969 . 7197.750

.5861日aa

7045.500

3. 373

10748.16

. 5 ag9o6a

.5000000

12355

13745.89

840.6399

$9699.54 ?$

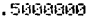

138671613

1 1 $20795.859 \quad 9659.547 .11965 .901493 .50$

EOUITY SALES= 3929.509

SEU SET $=1 \quad \frac{2}{2} 1$ 1 2

D

is

Reproduced with permission of the copyright owner. Further reproduction prohibited without permission. 


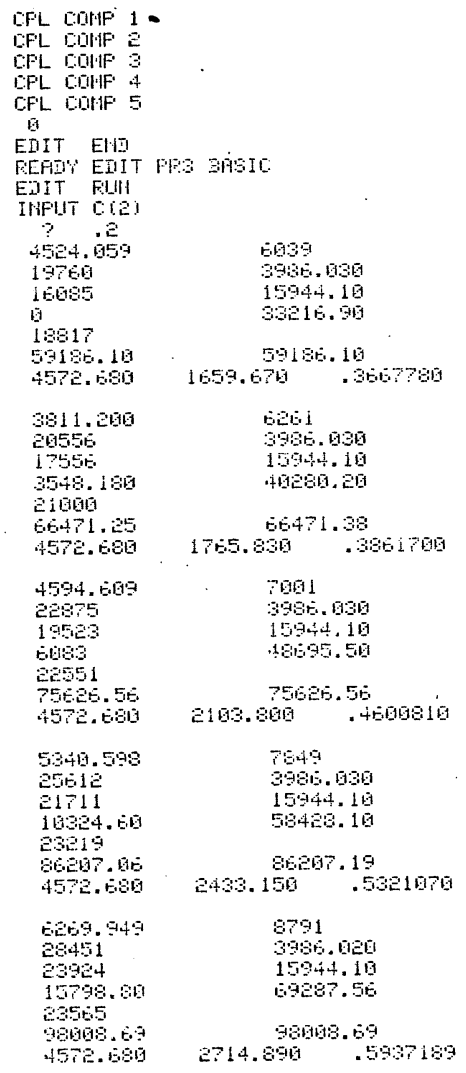


PRESENT YALUE OF EQUITY:- 159214.?

GRONTH IH TOTAL HSSETS $\%)=65.59410$

IGFOWTH III EF'S (FEFICENT) $=61.87419$

EARHIMLS FER SHARE $=1.6359891 .930849$

3595

2. $3919495 \quad 2.669535$

2.96

FETURH OH EQUIT'i= .249823e .2191933 .2169159 . .2082174 . 49591

RETUFIH OHA HET RSSETS= .14G2077

.1323265

$.1395913 \quad .1411224 \quad .1$

385025

DEET TO EQUITY FER YEAR $=.5999995$ .2876435

$.4947871 \quad .4992806$

.3411051

CHFHG IH IHTEREST TYFE DEQT $=-9832.983$

$.906250 \mathrm{E}-03-1.171375 \mathrm{E}-0 \mathrm{E}-3.906 \mathrm{E} 5 \mathrm{E}-03$

CHAIHEE IN CASH $5 Y$ Y $=-9920.941$ 2635. 320

03.551

EDIT EHD

READY EDIT PRG BASIC

EDIT FUH

$\begin{array}{lllll}13597 & 15191 & 17231 & 201 \mathrm{es} & \text { 2e769 } \\ 1509 & 1750 & 1009 & 1309 & 1600\end{array}$

$2005.410 \quad 1395.110 \quad 1395.110 \quad 1395.110 \quad 1395.110$

- 2555.86 3e16.720 8298.359

.5813010

8629.168

46019.719

10519

599.758

7854.596

.560日aำ

9578.547

12165.80

70.25 .430

$\$ 40.5399$

.5060090 .5060190

5111.727

5 11312.76

13574.40

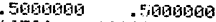

EOUIT $i \stackrel{2}{S}$ FILES $=432.20 \%$ $5433.439 .3538,486.639$

3795 $16 \mathrm{Ee}$

SEIJ $\mathrm{SET}=1$ 1 1 1 1 9201.435

1925.968

1

EDIT EHD

PEAT' EDIT FEE IASIC

EIIT RUII

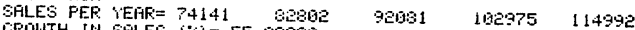

GRONTH IN SFLES $(\%)=55.099000$

$\begin{array}{rrrrrrrr}0 & 1 & 0 & 1 & & & & \\ 1 & 1 & 1 & 1 & 1 & 1 & 1 & 1\end{array}$

Reproduced with permission of the copyright owner. Further reproduction prohibited without permission. 
COMPUTER RUN E2-I

FOR GROWTH IN SAIES

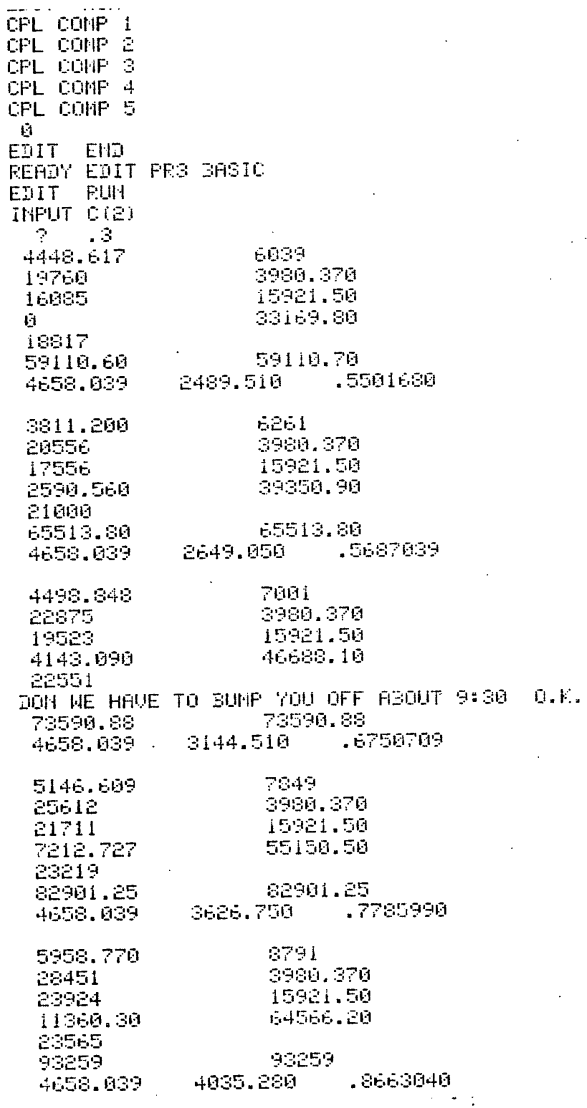

Reproduced with permission of the copyright owner. Further reproduction prohibited without permission. 


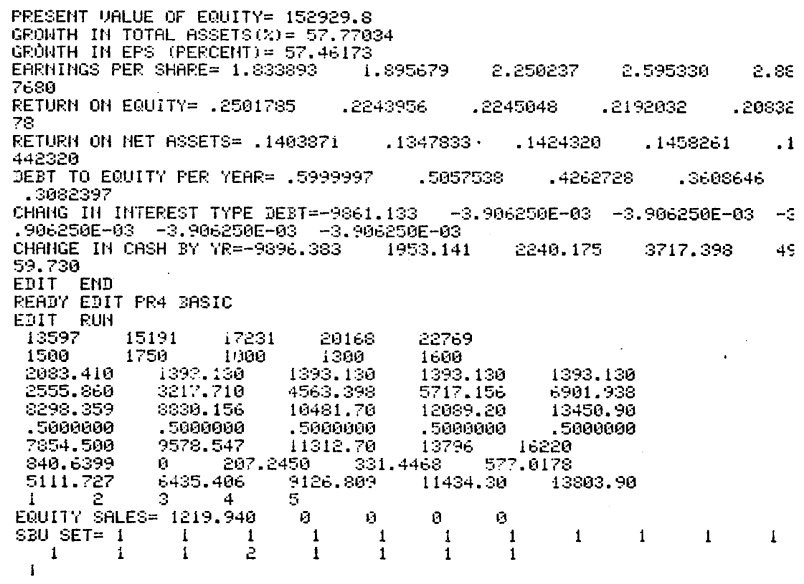




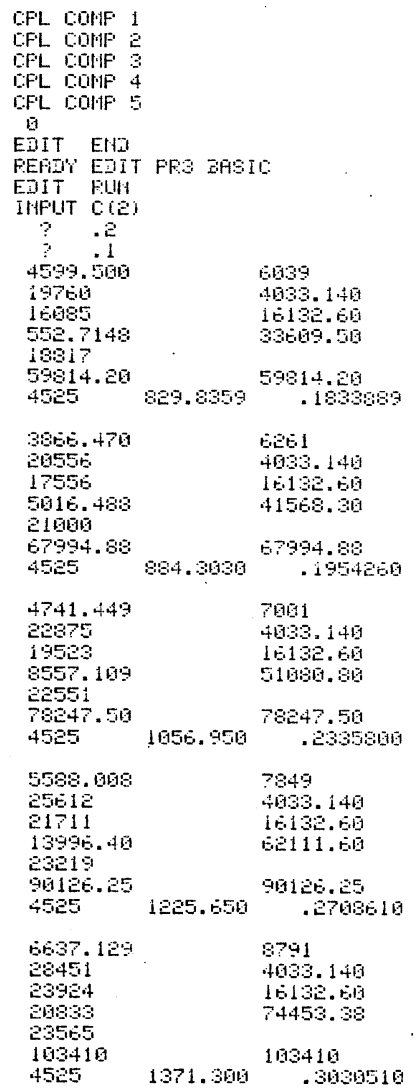


PFESEIT UILLLE OF EQUIT'Y= IESTPE.9

GFOUTH IH TDTAL HSSETS $(\%)=72.86531$

GFOUTH IN EPS (PEFCEIT) $=0.5 .25041$

EAFHIHGS PEF SHAFE= 1.83599131 .9542619

15511

2.3358015 2.798611 3.193

FETUPH DH EQIITY= .245965e $\quad .2127350 \quad .2069175 \quad .1973344 \quad .18418$

25

RETUPH OH HET ASSETS= $=1387357 \quad .13015544 \quad .1350778 \quad .1359926 \quad .1$

Sébisi

JEST TO EDIUIT'Y PER YEAR = . EGGGOIG $.4851229 \quad .3947811 \quad .3246894$ .2708505

EHATH IN INTEFEST TYFE DEET $=-9597.266 \quad-3.906250 \mathrm{E}-103 \quad-3.965250 \mathrm{~B}-103 \quad-3$

$.90625 \mathrm{E}-0 \mathrm{3}-3.960250 \mathrm{E}-0 \mathrm{3}-3.906250 \mathrm{E}-03$

CHAIIGE IN CHSH $9 \%$ IF $=-9192.795 \quad 3739.742$

85.723

$4415.598 \quad 6285.848 \quad 78$

EDIT EHI

FEATIY EIIT PR4 IASIC

EIIT FUH

\begin{tabular}{|c|c|c|}
\hline 13597 & 15191 & 17231 \\
\hline $\begin{array}{l}1500 \\
2003.417\end{array}$ & 1750 & 101010 \\
\hline 2633.411 & 1411.6019 & 3230.584 \\
\hline 6290.354 & \multirow{2}{*}{\multicolumn{2}{|c|}{$\begin{array}{l}3843.127 \\
.51001001\end{array}$}} \\
\hline 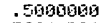 & & \\
\hline 354.5613 & \multicolumn{2}{|c|}{9573.547} \\
\hline 8419.6399 & \multirow{2}{*}{\multicolumn{2}{|c|}{44.21719}} \\
\hline 5111.727 & & \\
\hline 2 & \\
\hline JIT' SAL & \multirow{2}{*}{\multicolumn{2}{|c|}{$8=$}} \\
\hline$E T=1$ & & \\
\hline 1 & & 2 \\
\hline
\end{tabular}

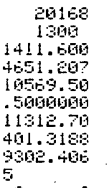

2ล769

1600

$1411.506 \quad 1411.603$

$5884.477 \quad 7164.047$

$12256.59 \quad 13713.10$

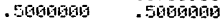

1379516220

$684.5688 \quad 1119.710$

$11769 \quad 14328.10$

1

G

$\begin{array}{llllllll}1 & 1 & 1 & 1 & 1 & 1\end{array}$

Reproduced with permission of the copyright owner. Further reproduction prohibited without permission. 


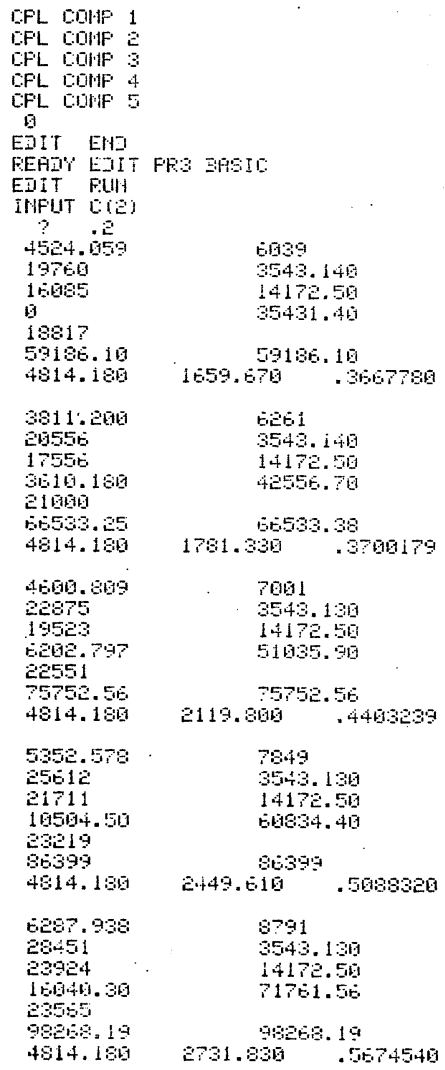


PRESENT UALUE OF EOUITY $=167906.4$

GROWTH IN TOTHL HESETS $\%$ \% $=66.03250$

GROMTH IH EFS (PEFCENT) $=5.7 .71324$

EAFNINLS PER SHARE $=1.833699 \quad 1.850089 \quad 2.201619 \quad 2.544160 \quad 2.83$

PETURN OH EQUIT' $i=.2342089 \quad .2092891 \quad .2076 ? 74 \quad .2013342 \quad .19634$

D.8

$\begin{array}{llllll}\text { FETUPN ON HET HSSETS }=.1400077 & .1339676 & .1399161 & .1417615 & .1\end{array}$

DEZT TO EQUITY PEF YEFF: .4999982 .4152831 .3471299 .2912107 . 2400579

CHAIt IH IHTEFEST TYFE DEST=-12047.37 -3.966250E-03 -1.171875E-62 -3

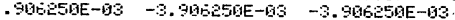

CHANGE II CASH BY YR=-9620.941 $2897.320 \quad 3362.222 \quad 5953.473 \quad 04$

$71.155^{\circ}$

EDIT EHI

READ'Y EDIT FR.4 3HSIL

EDIT RUN

$\begin{array}{lllll}13597 & 15191 & 17231 & 20168 & 2876\end{array}$

$1500 \quad 1750 \quad 1961350 \quad 16010$

2083.410 1249.15日 1246.100 1240.100 1240.100

$2555.050 \quad 3294.220 \quad 4680.757$ 5876.159 7110.129

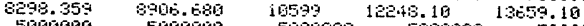

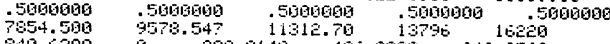

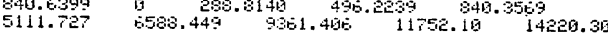

\begin{tabular}{|c|c|c|c|c|c|c|c|c|}
\hline 1 & 3.4 & 5 & & 111 & 13 & 142 & & \\
\hline EDUITY SALES= & $=25.51 .591$ & 0 & 0 & 0 & 0 & & & \\
\hline GBU $\mathrm{SET}=1$ & $1 \quad 1$ & 1 & 1 & 1 & 1 & 1 & 1 & 1 \\
\hline EDIT ${ }^{1} \frac{1}{1}$ & $e$ & 1 & i & 1 & 1 & & & \\
\hline
\end{tabular}

Reproduced with permission of the copyright owner. Further reproduction prohibited without permission. 


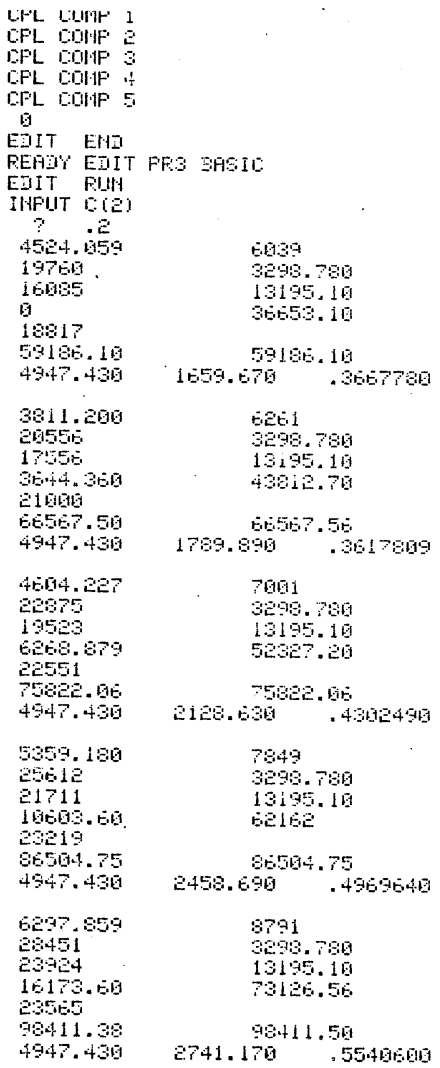




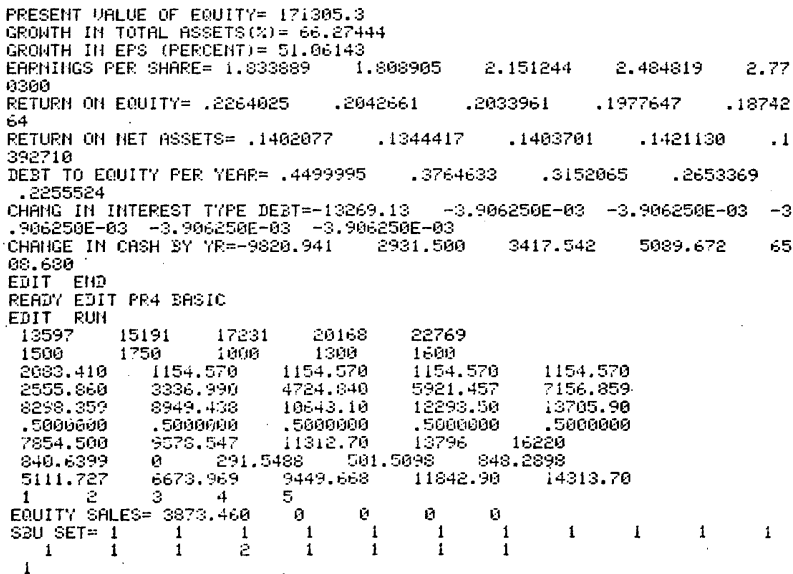




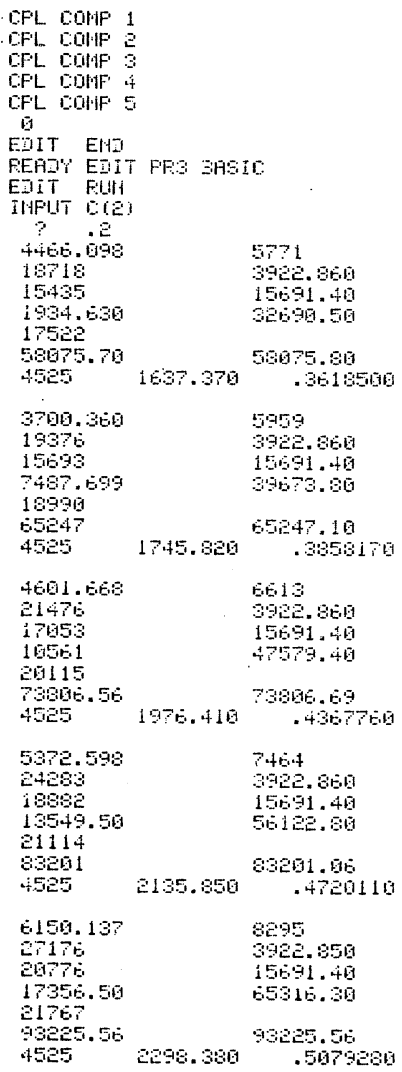


决SEHT UALUE OF EQUITY $=154 \mathrm{EPC} .1$

JFOHTH IH T!THL ASSETS $\% 1=60.52417$

SFOWTH IN EFS (FEFCENT) $=40.36967$

EHFIIIMGS FER SHARE= 1.809250 1.989085

98.39

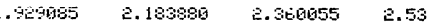

RETURH OH EOUITY= .2564352 .2200218 .2075900 .1962836 .17594

23

FETURH DHA HET ASSETS= .1499686 $.1337554 \quad .1333312 \quad .1283548 \quad .1$

232598

DEBT TO EQIITY FEF VEHR= .5999987

. 30102053

CHAIIG IH IHTEREST TYFE DEET $=-10148.75 \quad-3.906250 \mathrm{E}-03 \quad-3.906250 \mathrm{E}-93 \quad-3$

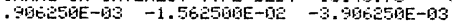

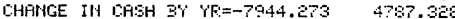

64.539

3974.605

3759.439

EDIT ENI

FERDY EDIT PRA ERSIC

EDIT FUN

$\begin{array}{lllll}13974 & 14614 & 15995 & 17685 & 19423\end{array}$

150101750 1009 1300

2083.410

244.4 .3619

1373

3116.606

1373

1373

sist. 859

8729. 109

.5064150

. 5096060

4398.957

9802.059

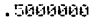

$901.547 \quad 10451.90$

T031.515

154.7706

599.159

8077.956

033.315

4863.727 3

1

EUUITY SHLES $=0$

SSU $\triangle E T=I$

4

3 .

ह 1
5

2. $\quad 11.11$

517873

5178.637

16679.29

.5606010

12185.413

344.8818

15357.30

5042.078

11491.90

. 5 1990日0

13973.20

1083.9619

12084.20

ELIT RUN

SALES PEII YEAI:= $71773 \quad 78501$

GEOWTH IN SALES $(\%)=46.77934$

a

$\begin{array}{llllll}9 & 1 & 2 & 1 & 1 & 1 \\ 2 & 2 & & & \end{array}$

EDIT END 
COMPUTER RUNS FOR THE INVESTIGATION OF JOINT EFFECTS

Reproduced with permission of the copyright owner. Further reproduction prohibited without permission. 


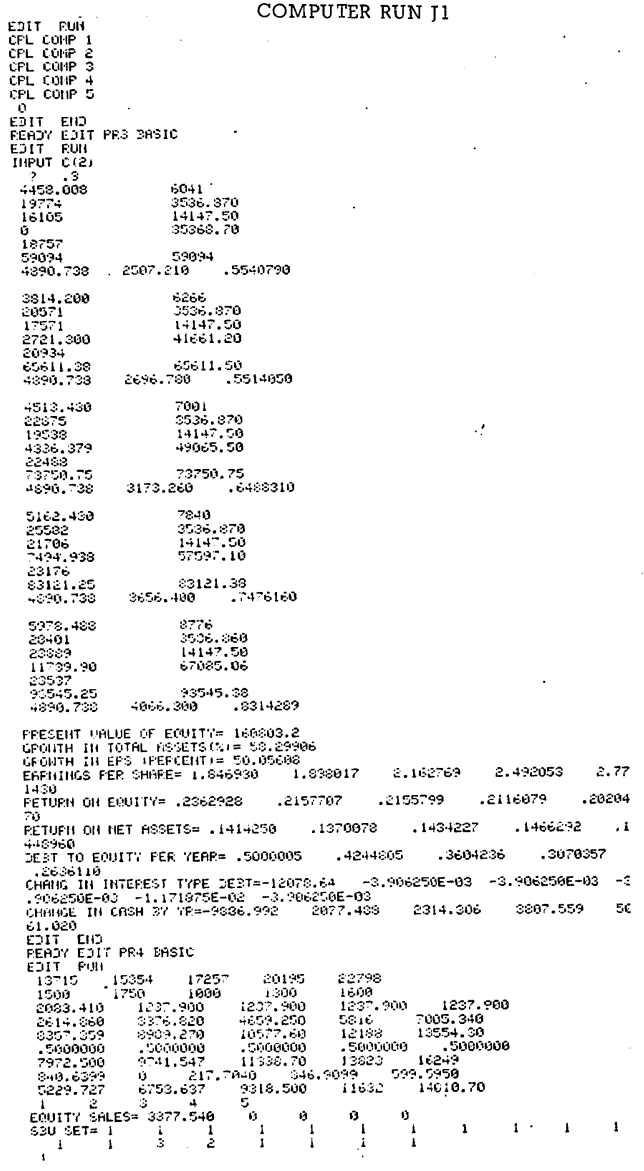




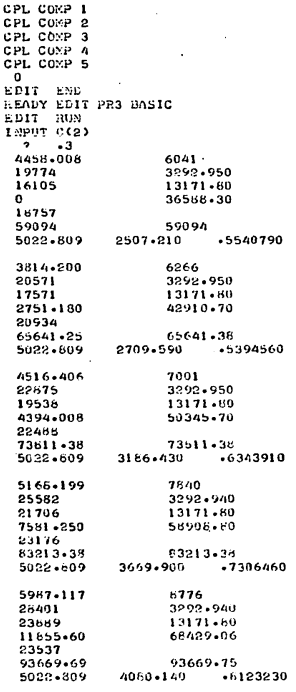

PrESENT VALUE OF EOUITY 165068.4

GHOSTH IN TUT:AL ASSET $3(\lambda)=5 \% .50963$

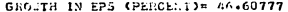

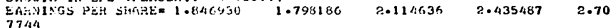

7744

iLTLEN ON ENUITY= .2844164 .210482E .2109700 .2076600 .19875

REEURY ON NET ASSETS= +1414250 .1375959 •143E997 .1A700\% 451,60

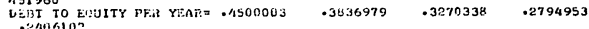

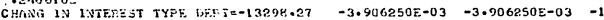

- $562500 \mathrm{E}-02 \quad-3.0063 \mathrm{~S}=03-3.906250 \mathrm{H}-03$

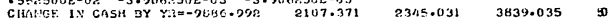

93 .?:6

EDIT END

REIUY EUIT PKA UASIC

ETIT HU:

$13715^{15354} \quad 17257 \quad 80195 \quad 20798$

$1500 \quad-1750 \quad 1000 \quad 1300 \quad 1600$

$2083.410 \quad 1152.530 \quad 1152.530 \quad 1152.530 \quad 1152.530$

2611.860 3/419.510 4703.12, SH61.98R 7051.477

$8357.359 \quad 9031.95 \% \quad 10621.413 \quad 12933 \quad 13600.50$

$.5000000 \quad .5000000 \quad .5000000 \quad .5000000 \quad .5000900$

$7172.500 \quad 9741.517$ 11336.70 $13123 \quad 16249$

640.639900629 .0940 351.5210 606.5000

$\begin{array}{lllll}5229.727 & 6839.020 & 9406.258 & 11722 & 14103\end{array}$

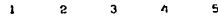

ECUITY SNLESS $=4597 \cdot 148$

$\mathrm{SIJU}$ SET $=\begin{array}{lll}1 & 1 & 1 \\ 1 & 3 & 2\end{array}$

1

5.

0000

0

11.11

Reproduced with permission of the copyright owner. Further reproduction prohibited without permission. 


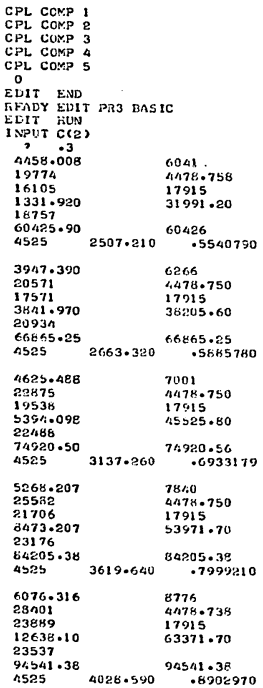

PFE.SERT YALLE OF EOUITY= 149006.8

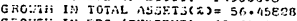

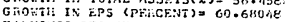

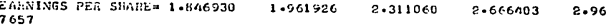

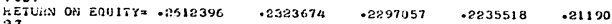

IEETUIN ON NET ASSETS $=.1383077 \quad .1327705 \quad .1395817 \quad .1432562 \quad .1$ IEELT TO EDUITY IPER YEAR * .699997A -5B61379 .4918914
$.35337 ! 3$

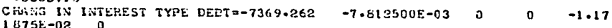

CIMNGE IN CNSH iY YH=-8555.074 $1999.432 \quad 2230.225 \quad 3721.828 \quad 49$

ELIT END

FEALY EDIT PIKA LASIC

ELIT RUN

$\begin{array}{lllll}13715 & 1535 h & 17257 & 20125 & 2279 H\end{array}$

$\begin{array}{lllll}1500 & 1750 & 17257 & 27125 & 2279 \\ 1500 & 1.300 & 1600\end{array}$

$\begin{array}{llllll}2.033 .410 & 1567.560 & 1567.569 & 1567.560 & 1567.560\end{array}$

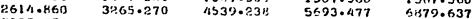

$\begin{array}{lllll}8357.359 & 1477.719 & 11457.50 & 12065.50 & 13426.60\end{array}$

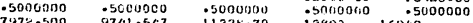

$737 \% .500 \quad 9741.547 \quad 11336.79 \quad 13823 \quad 162 / 19$

$440.6399 \quad 106.5540 \quad 307.3569 \quad 431.5276 \quad 677.8560$

$\begin{array}{lllll}5249.727 & 6530.527 & 9072.468 & 11387 & 13759.30\end{array}$

1 2 $3{ }^{3} \quad 4 \quad 5$

SBU SET $=1 \quad 1$

5

$\mathbf{1}$

Reproduced with permission of the copyright owner. Further reproduction prohibited without permission. 


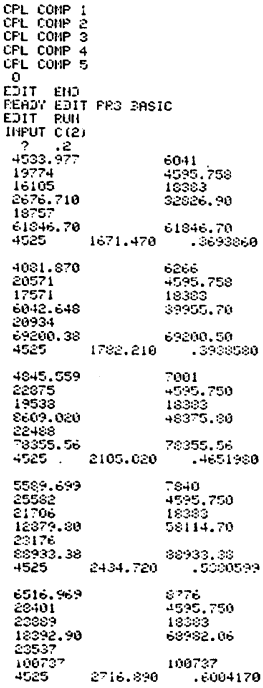

PFESEITT UALUE DF EOUITY $=1580 \% 8.9$

GFCLITH III TOTHL ASSETS $(:)=0.68174$

CFOWTH IH EFS (FEFCENT) $=52.5 .453$

EFFUIHCS PEF SHAFE= 1.246430 1.969290 2.325990 2.870099 3.00

2065

$230233 \quad .2175696 \quad .2044754 \quad .49692$

72

HFIt OH EQUIT: $=.25 ; 5085$

FETUPTI OH TIET RSSETS $=.1351301$

$346500^{\circ}$

$.1237717 \quad .1343240 \quad \ldots 135845 \quad .1$

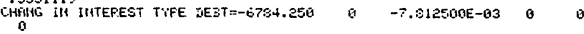

CHPAGE II CHSH ZI IF:-7134.316 2313.829 3330.05? 5014.918 64

A9.371

EDIT END

EEADT EJIT FF.4 BASIC

E.IT PUI

\begin{tabular}{|c|c|c|c|c|}
\hline $\begin{array}{l}13715 \\
1500 \\
2083.410 \\
514.080 \\
6357.359 \\
50013000 \\
7972.500 \\
640.099 \\
529.727\end{array}$ & 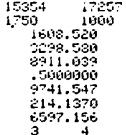 & 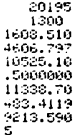 & 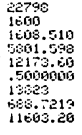 & $\begin{array}{r}1008.510 \\
7035 .+30 \\
13564.40 \\
.5000000 \\
164+4 \\
1030.360 \\
14070.90\end{array}$ \\
\hline
\end{tabular}

1 ECUIT:

SBU SET $=\frac{1}{1}$

$\frac{1}{2}$

5

0

a

(1)

Reproduced with permission of the copyright owner. Further reproduction prohibited without permission. 


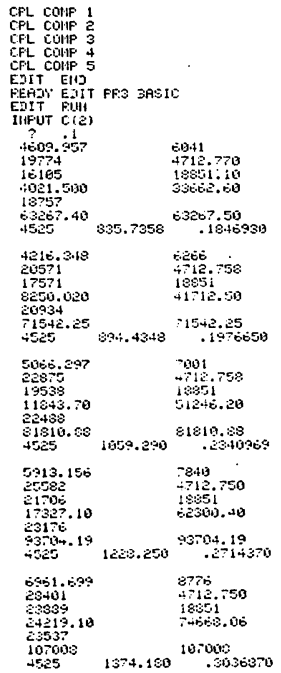

FFESEIT UHLUE OF EOUIT\%= 16:COS1.4

GFOWTH III TOTFL RESETE $1 ., 1=0.13$ EUS

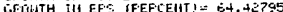

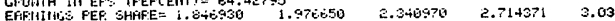

FETUPH on EOUIT

So

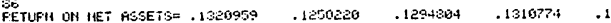

DEST TO EQUITY FEF: 'REAR= .7000014 .5\$49087 .4598147 .3752279

CHAII" II IIITEPEST T'IFE JEET=-6199.250 -.1093750 0 -7.812EDOE-403

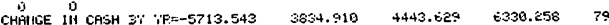

CHAiliGE
40.543

Reproduced with permission of the copyright owner. Further reproduction prohibited without permission. 


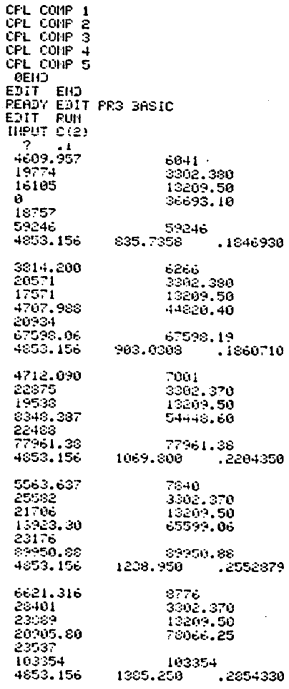

FFESEHT IMLUE OF EOUITY= $17 P 917$.?

GFOI:TH III TOTAL FSSETS $(\%)=74.4 .4087$

CFOITH IN EFS IFEFIEIIT $=54.54+54$

EHFHillios PEF SHAFE $=1.040330 \quad 1.800710 \quad \varepsilon .204350 \quad 2.552060 \quad 2.35$

4330

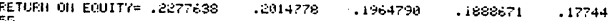

RETUFH OH IHET ASSETS= . 1410629 .1355863 .13?2213 .1377363 .

34 औง?

DE2T TO EOUIT' PEF IEAR= .4499995 .3E84099 .3932000 .2517089

CI:FAli III IHTEFEST TIFE JEPT $=-13251.13 \quad-3.906250 E-03-1.552500 E-92-3$

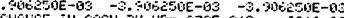

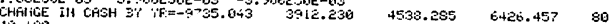

$40 . \pm 60$

EDIT EIT

FEADI EDIT FP.4 SASIC

E.JIT FUII

$1 \geqslant 15$

1500

$15354 \quad 1725 ? \quad 20195 \quad 22798$

$2063 .+19$

2014.800

$2501000 \quad 1300$

$1155.330 \quad 1155.830$. 1155.830

$3+17.800 \quad 4779.750$ +. 15.530

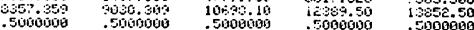

ic. 17.520

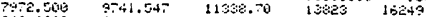

$840.399 \quad 0 \quad 37.650 \%$ is . 3708 1113.360 529.727 5830.707 9559.500 12035 14007.

1 ENUTH SHLES $=3630.469$

SEU SET $=1$

(1)

$\begin{array}{lllllll}0 & 0 & & & & \\ 1 & 1 & 1 & 1 & 1 & 1\end{array}$

Reproduced with permission of the copyright owner. Further reproduction prohibited without permission. 


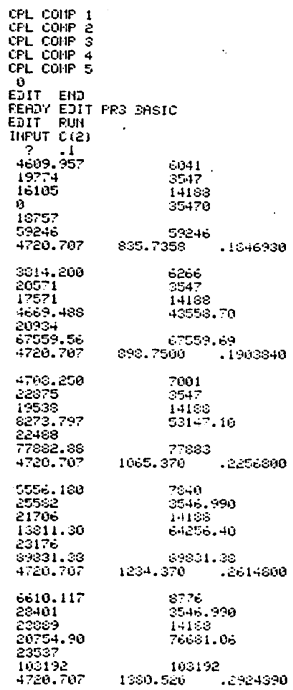

FPESEHT I:ALUE OF EOUITY $=173 \mathrm{c} .33 .2$

GFOHTH III TOTFL FISETS $: 0,=-17545$

CFONTH IN EF' IFEFCENT $1=5,3783$

ERFIIIICS PEF SHAFE $=1.846950$ 1.903849 $2.256901 \quad 2.614800 \quad 2.92$

FETUFII OH EQUITY: .2358178 .2583309 .2004509 .1921008 .18003

it

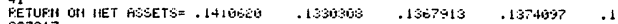
337217

DEBT TO ENUIT' FEF VEFF: . .50019000 . .

. 2312025

CHAHG III IHTEPEST THPE IEET $=-12028.01$ a 0 o $-1.121675 E-02 \quad-3.99$

EESUE-93 -3.900:50E-03

CHAHCF III CASH B' 'TR=-9735. $943 \quad 3373.739$ 4498.355 $6385.430 \quad 79$

97.539

EDIT EHS

FEADT ETIT FRA 3FSTO

EDIT PUIT

13715

1509

2003.410 $1555+17257$

$50 \quad 1906$ 20195 22798

$12+1 .+50$

355?. $35 \%$

Foboung

$1=4.139$

2457.5010 10552.70

5000

5000000

F

7972.500 $9741.5+7$ i 1338.70

8.413 .6393 0 3.3.55

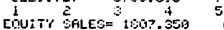
01.90381194 .900 SEU SET $=1$ 4.470 .80911943 .50 14512.48

i

$\begin{array}{llllllll}5 & 0 & 0 & 0 & 1 & & \\ 1 & 1 & 1 & 1 & 1 & 1 & 1 & 1 \\ 1 & 1 & 1 & 1 & & & 1\end{array}$

Reproduced with permission of the copyright owner. Further reproduction prohibited without permission. 


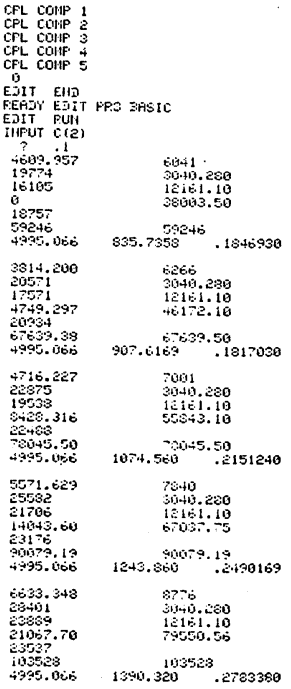

FFESEIT LIALUE DF EOUIT' $i=1$ SESS5.8

ISFOWIH III TOTFL HSSETS $:, 1=74.74251$

CFOHTH III EFS IFEFCEIIT, $=5,13$, ?0305

$\begin{array}{llllll}\text { EHFIIIIG: FEF SHAFE }=1.248+30 & 1.817030 & 2.151259 & 2.490170 & 2.78\end{array}$

FETURH OH EQUIT $i=.2152153 \quad .1965 ? 27 \quad .1324250 \quad .1855463 \quad .17477$

FETIJPI OH HET ASSETS= .141062日 $.13+1643 \quad .137638 \quad .1380852 \quad .1$

HETH TO EOHITY FEP VEFF. .3999993 .32\%2329 .2722158 .2267584

1910907

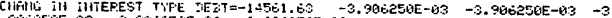

$906250 \mathrm{E}-03-3.90525 \mathrm{Jj}-03-3.906250 \mathrm{E}-193$

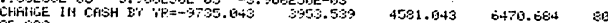

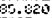

EDIT EHD

FEADT EDIT PF:A EASIC

EDIT FiHt

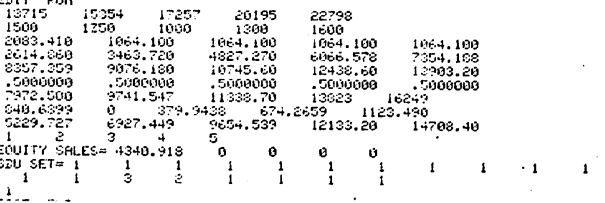

Reproduced with permission of the copyright owner. Further reproduction prohibited without permission. 


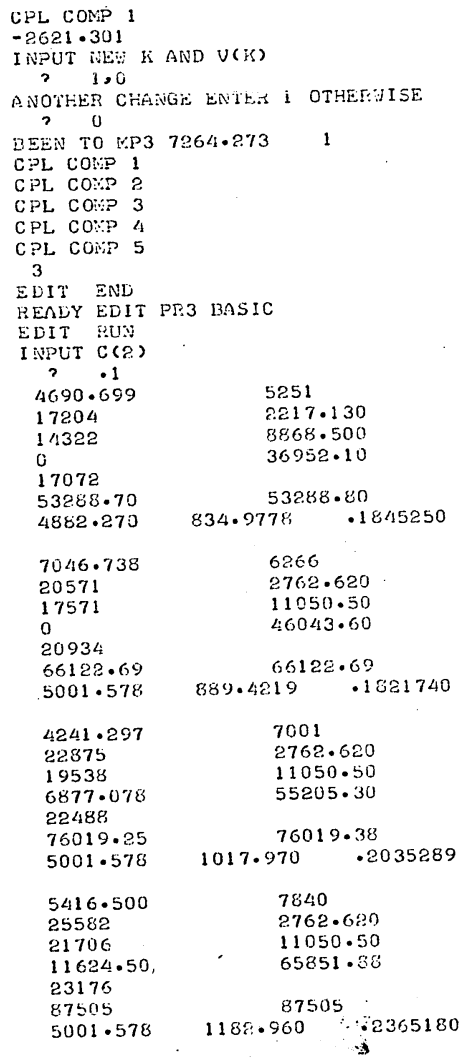

Reproduced with permission of the copyright owner. Further reproduction prohibited without permission. 


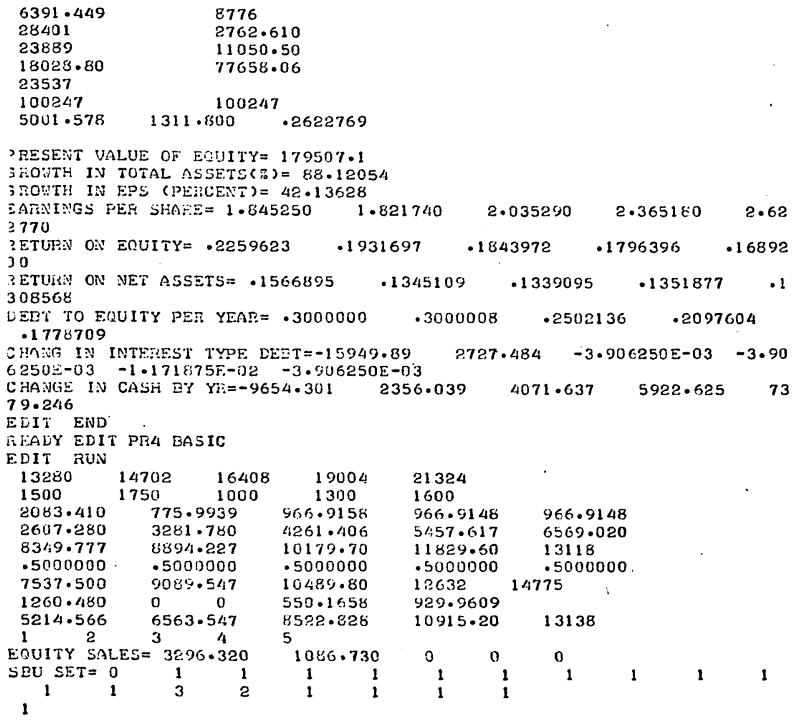

Reproduced with permission of the copyright owner. Further reproduction prohibited without permission. 


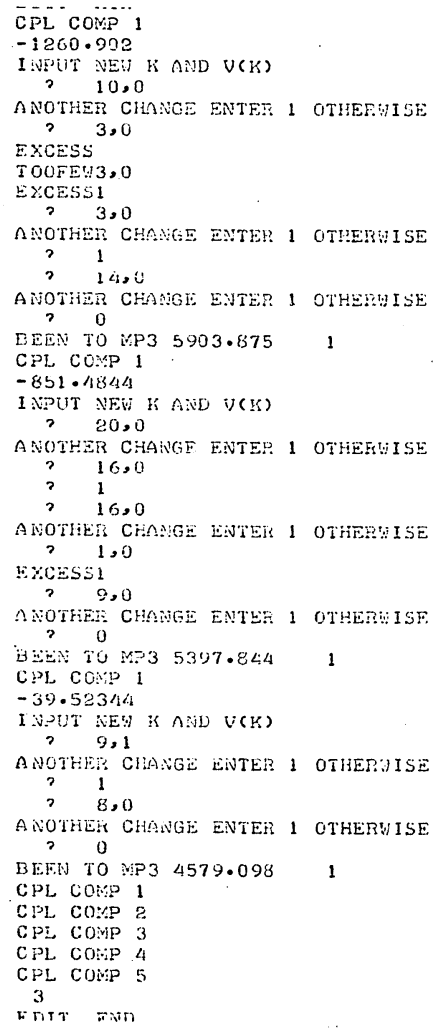

A NOTHER CHASGE WUTEI 1 OTHEATISE $? 1,0$ 


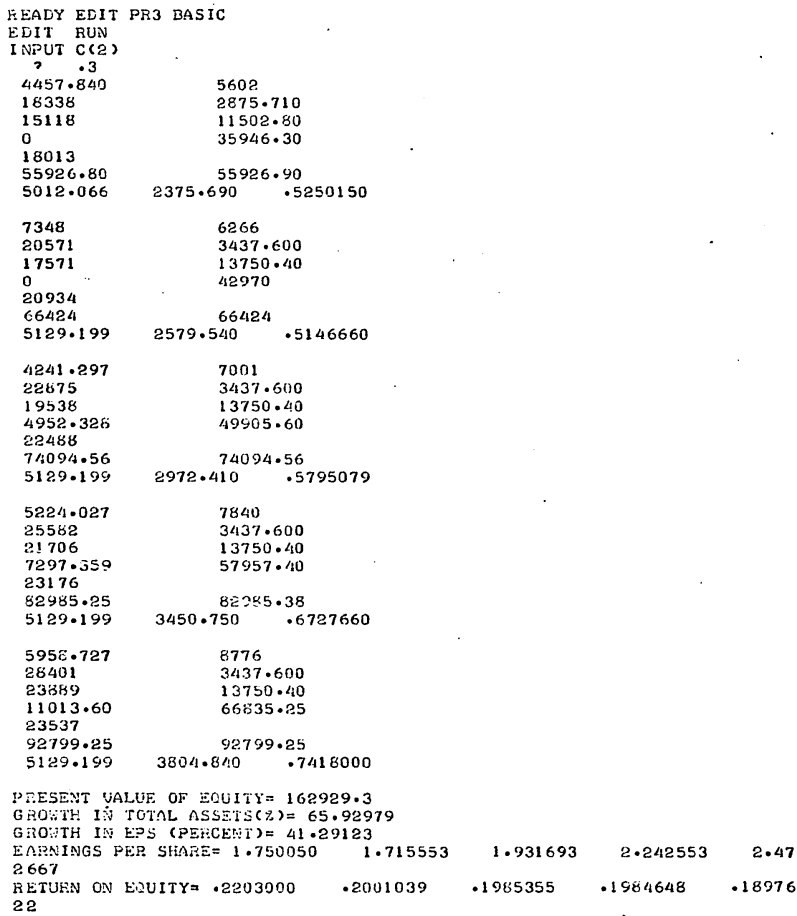

Reproduced with permission of the copyright owner. Further reproduction prohibited without permission. 


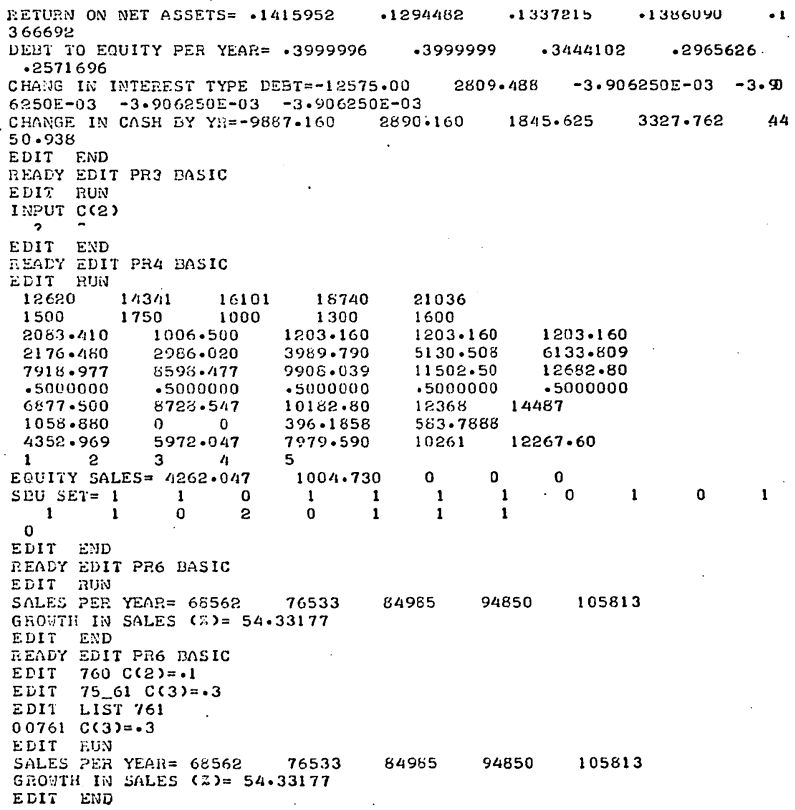

Reproduced with permission of the copyright owner. Further reproduction prohibited without permission. 


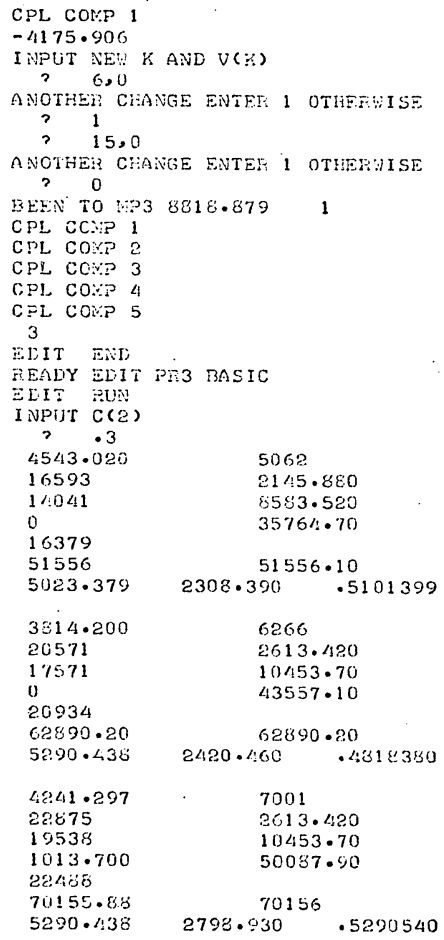

Reproduced with permission of the copyright owner. Further reproduction prohibited without permission. 


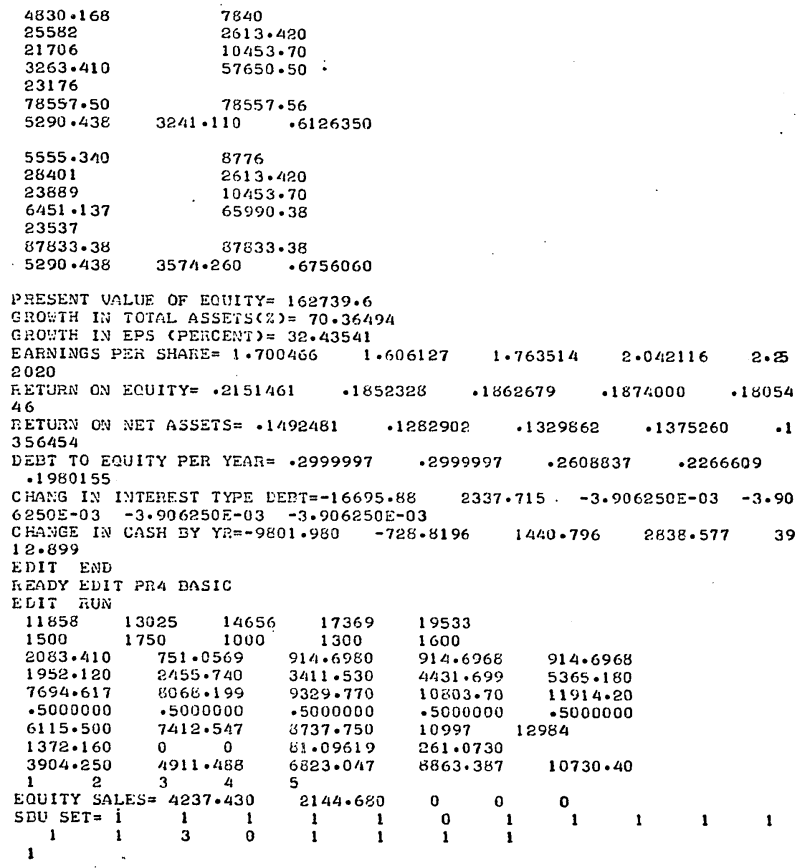

Reproduced with permission of the copyright owner. Further reproduction prohibited without permission. 
CPL COHP 1

IIFUT IIEN $2:$ AHS UR(N)

AIUUTHEP CHAIGE EITEF 1 OTHERHISE

$? 0$

PEEI TO HIS T122.398

CFL COMP 1

CFL CONP 2

CFL COHP 3

CFL COHP 5

3

ETIT EIT

FERD ET EDIT PR3 3ASIC

EDiT FUH

IIIFUT C(2)

$?$
$+54+4.0400$

19351

$15050^{\circ}$

b

$185+3$

$5829 \%$. 10

5010.430

$301+.200$

20571

30. +9.930

20934

0.040 .00

5010.430

$45+16.289$

$20 \% 5$

19536

5.7 .699

$2 \mathrm{e}+48$

75214.88

$5010 .+36$

3305.560

2502

2170

10191.20

$231>0$

6581.38

5016.430

เं239. 180

केषit!

3069

15029.30

2.3537

07695.38

9016.430

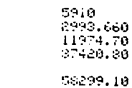

1679.790 .3712200

Bctis:

$2 \sin$

i. 474.80

..? - 05.510

$1321.054+100$

1321.270 .003000

$-701$

2.93 .5619

1. $9-4.60$

$53+5.60$

75814.58

2134.490 .4255910

$\operatorname{Tin} 3$

293

1140.00

$\tan 3.10$

$55 \% 21.38$

360.489560

BTA

200.60

$119+4.010$

3395.19

97595.35

$2722 \cdot 0+4 \cdot 0.5420250$

PFESEIT MPLUE OF EOUIT'H= 17417?.2

GFOUTH IN TOTAL ASETS $\$(\%)=0 ? .57611$

GFOUITH III EF'S IFEFCEIIT, = 40.1733 ?

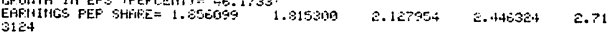

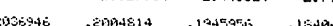

30

2004814

0.16404

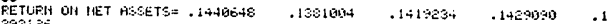

343120

DEZT TD EOUIT' FEF :EAF= .4000009 .3340160 .2811172 .2373540

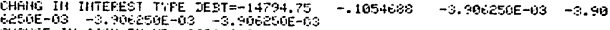

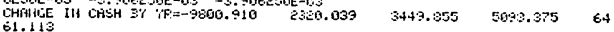

EDIT EITJ

FEFIT EDIT FPA ZARIC

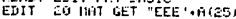

EDIT PUII

13733 15399 1:235 20058 22511

$1500 \quad 1750$ i

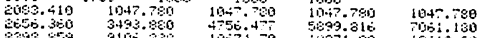

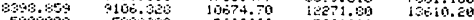

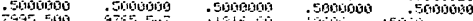

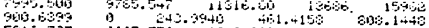

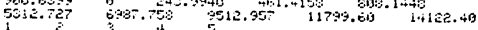

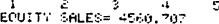

EOU $C E T=1$ T 19

1

Reproduced with permission of the copyright owner. Further reproduction prohibited without permission. 


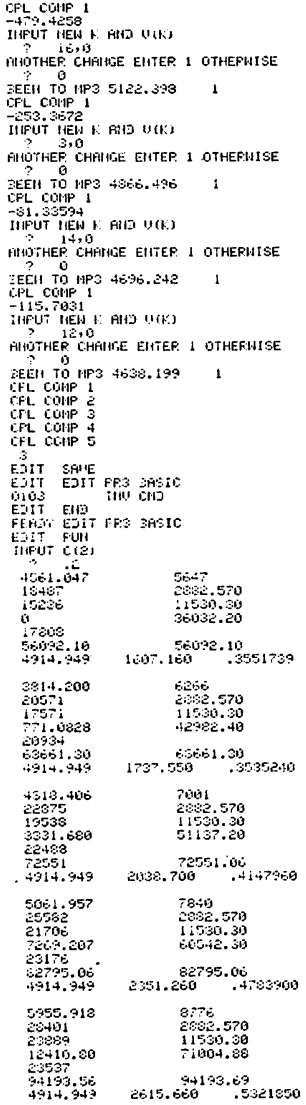


FRESENT UALUE OF EQUITY $=167374.1$

GFOUTH IN TOTAL ASSETS $(\%)=67.92659$

GROHTH IN EF'S (FERCENT) $=49.83777$

ERFNIHGS FER SHAFE $=1.775669 \quad 1.767619 \quad 2.073979 \quad 2.391950 \quad 2.60$ 0925

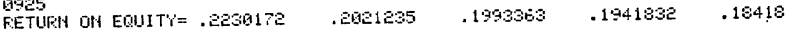

RETUFIH OH INET ASSETS= .1432605 $\quad .1364863 \quad .1405012 \quad .1419927 \quad .1$

393449

IEET TO EQUIT' FEF YEAR $=.3999995$

$.3353801 \quad .2818469 \quad .2368627$

.2029841

CHAIIG IN IHTEFEST TYPE IEET $=-15850.144-3$.

CHAIIE II CASH DY YR=-9783.953 24.2343

35.551

EIIT EITI

FEADY EDIT PFA EABIC

EDIT HFT GET "EEE", ACLS)

DiBa IHU CHD

EDIT 20 MAT LET "EEE", H(25)

EIIT SFUE

EIT FUH

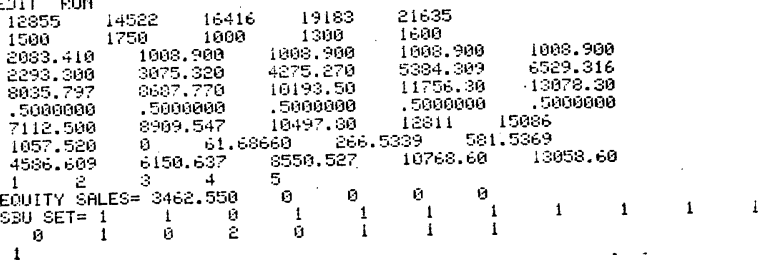

Reproduced with permission of the copyright owner. Further reproduction prohibited without permission. 
COMPUTER RUN J13

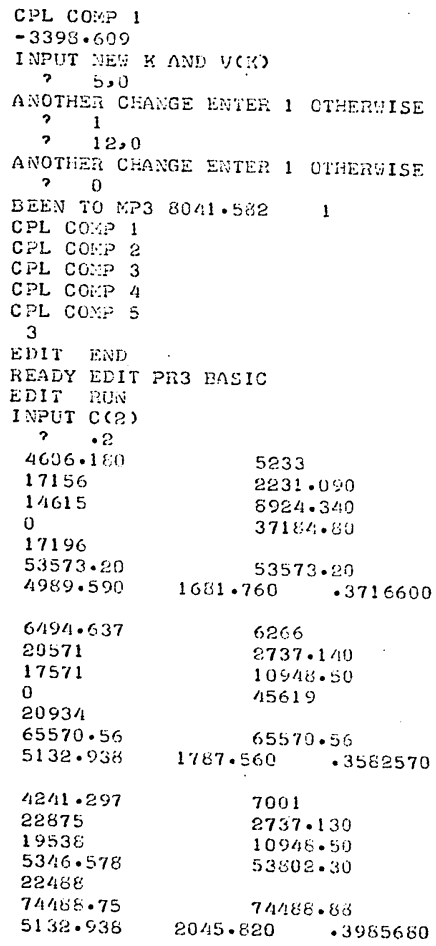

Reproduced with permission of the copyright owner. Further reproduction prohibited without permission. 


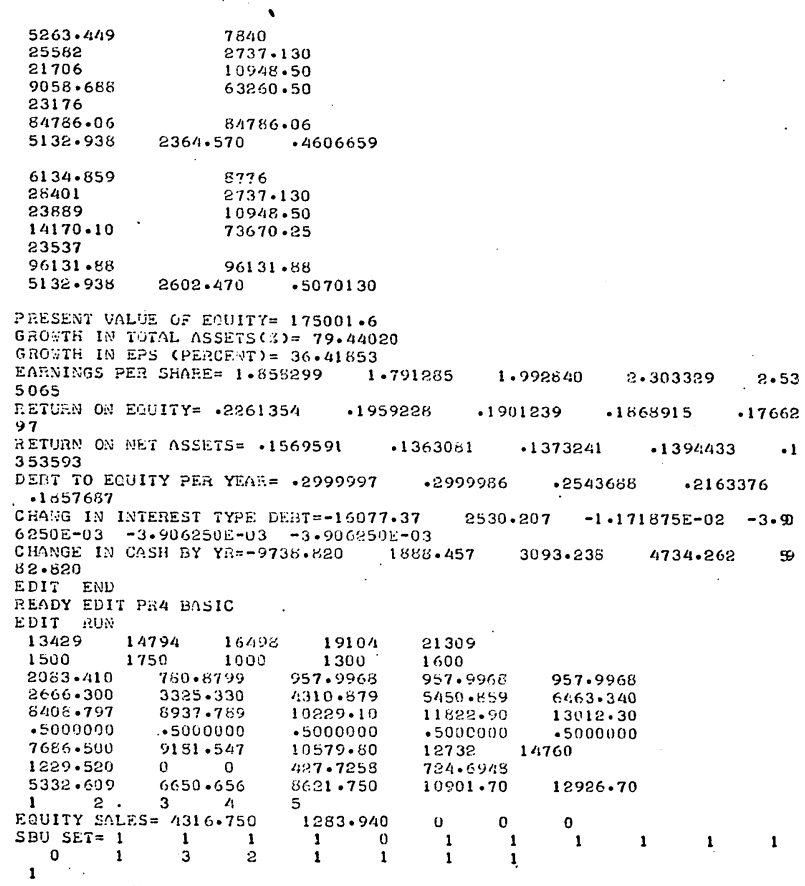

Reproduced with permission of the copyright owner. Further reproduction prohibited without permission. 
COMPUTER RUNS FOR PROBABILITY

INVESTIGATION

Reproduced with permission of the copyright owner. Further reproduction prohibited without permission. 


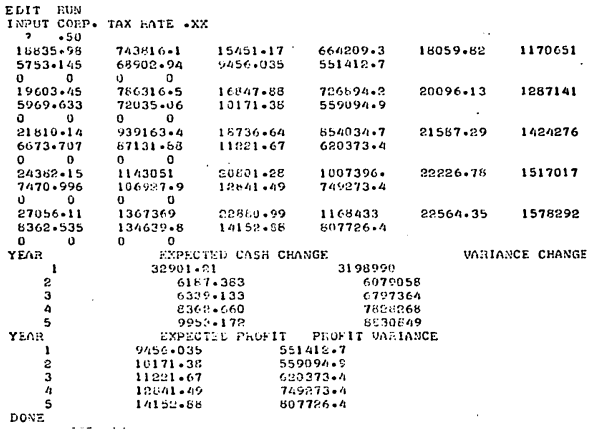

COMPUTER RUN P2

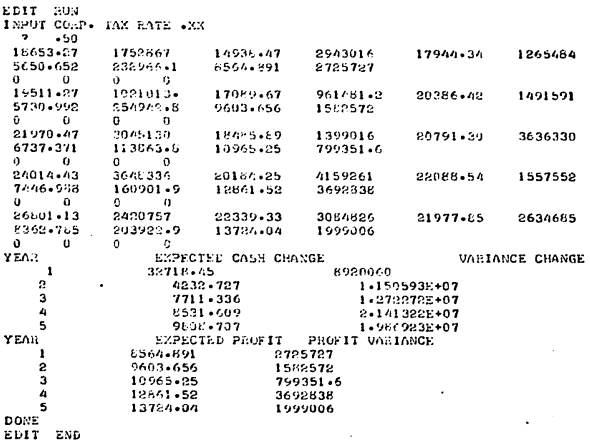

Reproduced with permission of the copyright owner. Further reproduction prohibited without permission. 


\section{COMPUTER RUN P3}

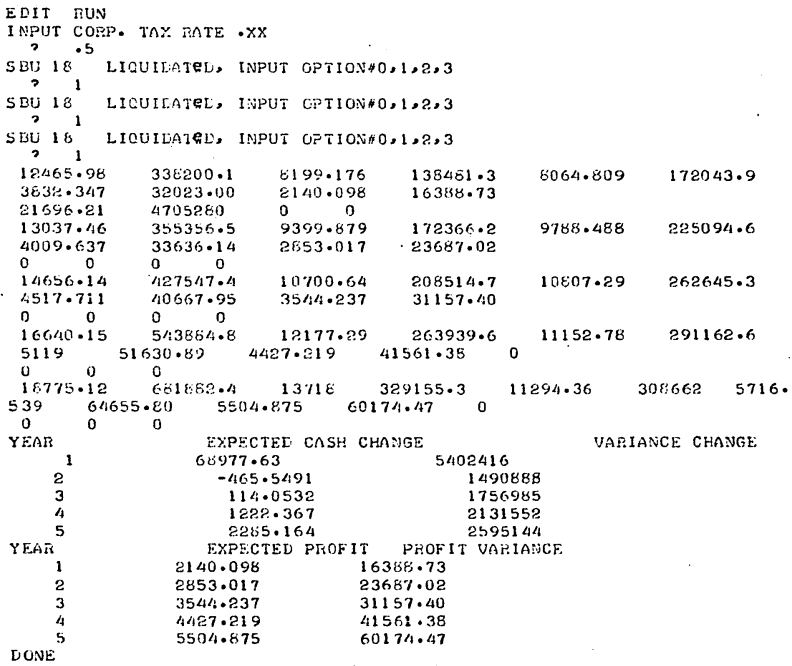

Reproduced with permission of the copyright owner. Further reproduction prohibited without permission. 
COMPUTER RUN P4

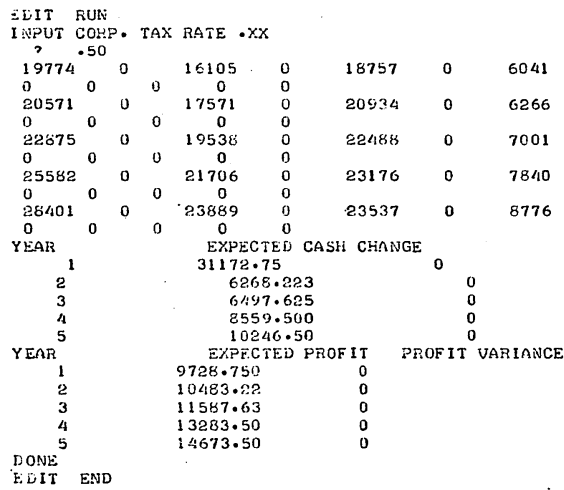

Reproduced with permission of the copyright owner. Further reproduction prohibited without permission. 
COMPUTER RUN

FOR

RESTRICTED OPTIMA

Reproduced with permission of the copyright owner. Further reproduction prohibited without permission. 
GUIDE TABIE FOR USE WHEN FINDING RESTRICTED OPTIMA

$\begin{array}{ll}\text { EDIT } & \text { RUN } \\ \text { TAELE } & \text { OF \&D } \\ 1 & 4431.066 \\ 2 & 1323.174 \\ 3 & 449.0989 \\ 4 & 1127.954 \\ 5 & 3163.758 \\ 6 & 5299.578 \\ 7 & 763.4993 \\ 8 & 1656.089 \\ 9 & 866.7048 \\ 10 & 386.4563 \\ 11 & 2931.063 \\ 12 & 2166.819 \\ 13 & 931.3831 \\ 14 & 566.1404 \\ 15 & 2903.552 \\ 16 & 666.7217 \\ 17 & 575.2192 \\ 18 & 39810.52 \\ 19 & 1598.464 \\ 20 & 614.8166\end{array}$

Reproduced with permission of the copyright owner. Further reproduction prohibited without permission. 


\section{APPENDIX D}

INPUT DATA

I. LIST OF TẢBLES FOUND IN APPENDIX D

Page

Table XXII Corporate Balance Sheet Data ............ 247

Table XXIII SBU Profit and Loss Data ............. 248

Table XXIV SBU Assets and Liabilities Data ........... 254

Table XXV Corporate Profit a nd Loss Data ........... 260

Table XXVI Corporate Specifications Data ........... 261

Table XXVII Arbitrarily Assigned Three-Point Probability

Distribution Used with the Probabilistic

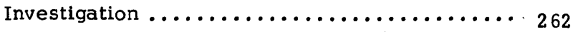

\section{DISCUSSION}

This appendix contains the input data files used in the research along with the arbitrarily assigned three-point probability distributions used in the probability investigation. The format of Table XXIII is identical to the one in Figure 9. For example, for the first record (Line \#10), the SBU contribution is given in data position \#8 and is equal to 435 .

The format of Table XXIV is simtlar to that of Table XXIII and is

Reproduced with permission of the copyright owner. Further reproduction prohibited without permission. 
identical to Figure 11. The format of Table XXV is found in Figure 10 of Appendix A. All lines of Table XXV, except: 2,6 and.10, are calculated by the computer and-hence have zero entries initially.

\section{TABLE XXII}

CORPORATE BALANCE SHEET DATA 1

(Thousands of dollars)

\section{Beginning of Year One}

\section{Line \#}

1 Cash

2 Inventories

3 Receivables

4 Investments

5 Plant, Equipment and Land

6 Accumulated Depreciation

11 Total Assets

\begin{abstract}
$\underline{\text { Assets }}$
\end{abstract}

3837

17559

12500

10508

$\underline{25000}$

8000
Line \#

7 Payables

8 Short Term Debt

9 Long Term Debt

10 Shareholder Equity
Liabilities 5500

22707

$\underline{26141}$

13 Shares of common stock outstanding

12 Total Liabilities $\underline{61404}$

14 Dividend declared on beginning number of shares (total \$)

\section{Computer Supplied}

15 Dividends per Share

Computer Supplied

${ }^{1}$ A balance sheet which had a value of net assets after payables equal to $\$ 70039$ (neglecting cash and investments) was used for the probability investigation instead of the \$4i559 shown here which was used for all other investigations.

Reproduced with permission of the copyright owner. Further reproduction prohibited without permission. 


\section{SBU PROFIT AND LOSS DATA}

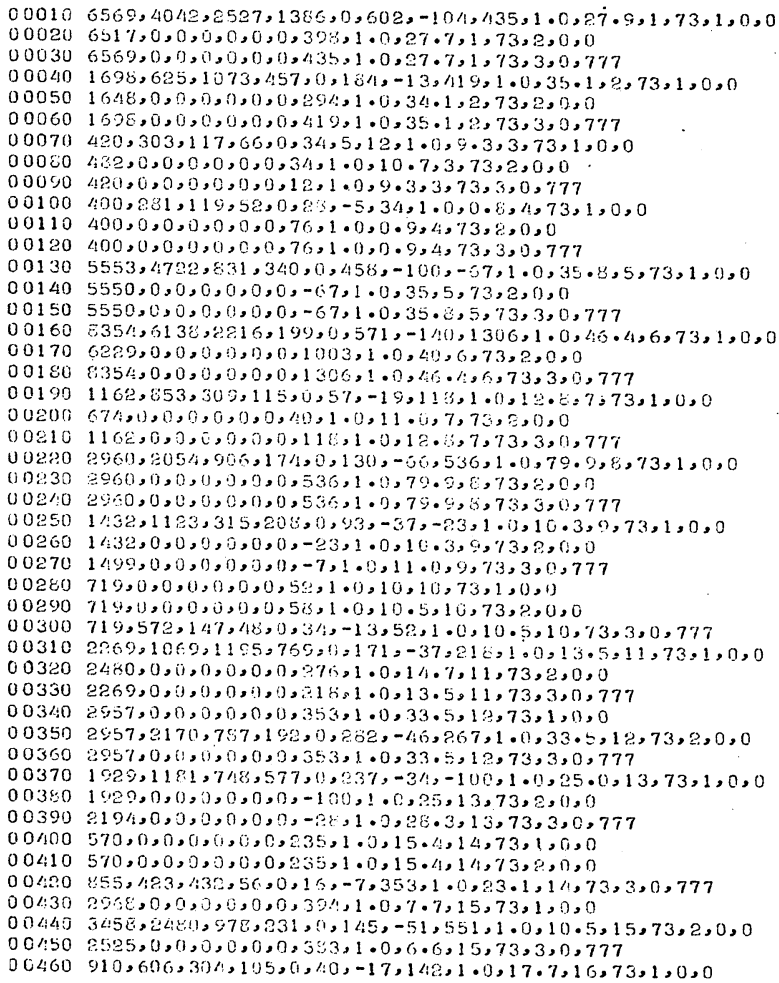

Reproduced with permission of the copyright owner. Further reproduction prohibited without permission. 
$00470805,0,0,0,0,0,0,115,1,0,15,7,16,73,2,0,0$

$00480910,0,0,1,0,0,0,1 / 12,1 \cdot 0,15 \cdot 7,16,73,3,0,777$

$004901121,0,0,0,0,0,0,148,1 \cdot 0,48 \cdot 7,17,73,1,0,0$

$005011121,790,331,99,0,60,-24,1 / 18,1,0,42,1,17,73,2,0,0$

$005101063,0,0,0,0,0,0,155,1.0,41 \cdot 3,17,73,3,0,777$

$0052030291,0,0,0,0,0,0,9158,0375,51,0,16,73,1,0,0$

$0053030291,14023,16268,40,1,0,5310,-679,9188,0375,61,0,16,73,2,0,0$

$005400 \quad 044,47,0,0,0,0,0,0,6000,0375,40,0,18,73,3,0,777$

$005501369,126,0,141,51,0,36,-12,40,1,0, ? ?, 1,19,73,1,0,0$

$005601126,0,0,0,0,0,0,180,1.0,18,6,15,73,2,0,0$

$005701369,0,0,1,0,0,0,40,1,0,82 \cdot 1,19,73,3,0,777$

$005800,0,0,0,0,0,0,0,1,0,0,20,73,1,0,0$

$0059097,0,0,0,0,0,0,-4,1,1, i), 3 \cdot 0,20,73,2,0,0$.

$006000,0,0,0,0,0,0,0,1,0,0,20,73,3,0,555$

$006107320,4491,2 \times 29,1409,0,649,-119,653,1,0,201,2,1,74,1,0,0$

$006207200,0,0,0,0,0,0,1489,1,0,27,7,1,74,2,0,0$

$005306750,0,0,0,0,0,0,155,1,0,25,0,1,74,3,0,777$

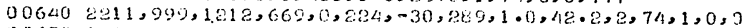

$006501709,0,0,0,0,0,0,310,1.0,32 \cdot 6,2,74,2,0,0$

$066601620,0,0,0,0,0,0,1,0,1,0,31 \cdot 0,2,74,3,0,777$

$00670624,417,207,145,0,1,2,5,15,1,0,12,7,3,74,1,0,0$

$006810511,0,0,0,0,0,0,65,1 \cdot 0,10,4,3,74,2,0,0$

$00690480,0,0,0,0,0,0,15,1 \cdot 0,8 \cdot 5,3,74,3,0,777$

$007001006,679,329,169,0,57,-3,95,1,0,1,9,1,74,1,0,0$

$00710400,0,0,0,0,0,0,76,1.0,0,9,4,74,2,0,0$

$00720200,0,0,0,0,0,0,0,1,0,0,4,4,71,3,0,777$

$007306761,5620,1161,300,0,149,-115,170,1 \cdot 0,36,6,5,74,1,0,0$

$007406400,0,0,0,0,0,0,141,1.0,35,5,71,2,0,0$

$007505550,0,0,0,0,0,0,-6,7,1,0,30,5,74,3,0,777$

$007609105,6593,2512,205,0,462,-12,3,1662,1 \cdot 0,14,1,6,7 / 1,1,0,0$

$007706169,0,0,0,0,0,1,1143,1.0,40,6,74,2,0,0$

$007808100,0,0,0,0,0,0,1300,1,0,42,0,5,74,3,0,777$

$007901393,1013,360,130,0,8,-22,1 \angle 5,1.0,15,8,7,74,1,0,0$

$00300715,0,0,0,0,0,0,60,1,0,11,1,7,74,2,0,0$

$0081011110,0,0,0,0,0,0,100,1.0,11,0,7,74,3,0,777$

$008208954,2029,925,174,0,136,-73,552,1 \cdot 0,38,5,8,74,1,0,0$

$008302680,0,0,0,0,0,0,475,1.0,79.9,5,74,2,0,0$

$008402600,0,0,0,0,0,0,1472,1,0,79,8,74,3,0,777$

$006501583,1260,324,220,0,109,-39,-44,1,0,11,7,9,74,1,0,0$

$006601350,0,0,0,0,0,0,-25,1,0,10 \cdot 0,2,74,2,0,0$

$00870163,0,0,0,0,0,0,34,1,0,1,3,9,74,3,0,777$

$00880730,0,0,0,0,0,0,52,1.0,12,10,74,1,0,0$

$00890640,0,0,0,0,0,0,52,1,0,10 \cdot 5,10,74,2,0,0$

$00500564,439,125,48,0,49,-10,38,1,0,9,3,10,74,3,0,777$

$009103357,1606,1779,1057,0,204,-46,472,1,0,17,8,11,74,1,0,0$

$009202628,0,0,0,0,0,0,396,1 \cdot 0,14 \cdot 7,11,7 \mathrm{H}, 2,0,0$

$009302 \varepsilon 30,0,0,0,0,0,0,220,1 \cdot 0,12 \cdot 0,11,74,3,0,777$

$009403420,0,0,0,0,0,0,390,1,0,34 \cdot 5,12,74,1,0,0$

$009503549,2631,918,211,0,993,-45,369,1,0,36,1,12,74,2,0,0$

$002603030,0,0,0,0,0,0,546,1,0,30,3,12,74,3,0,777$

$009702143,1237,906,534,0,242,-30,0,1,0,25,0,13,74,1,0,0$

$009602150,0,0,0,0,0,0,0,1,0,25,13,7 / i, 2,0,0$

Reproduced with permission of the copyright owner. Further reproduction prohibited without permission. 
$009902323,0,0,0,0,0,0,141,1,0,27 \cdot 2,13,74,3,0,777$

$01000695,0,0,0,0,0,0,10 /, 1,0,16,5,1 / 4,7 / 1,1,0,0$

$01010580,0,0,0,0,0,0,250,1 \cdot 0,13 \cdot 6,14,74,2,0,0$

$01020 \$ 15,446,369,78,0,16,-8,267,1,0,19,4,14,74,3,0,777$

$010303323,0,0,0,0,0,0,132,1,0,8,1,15,74,1,0,0$

$010404038,2959,1079,235,0,145,-52,647,1,0,10,7,15,74,2,0,0$

$010502546,0,0,0,0,0,0,359,1,0,6,2,15,74,3,0,777$

$010601000,673,327,108,0,10,-19,160,1,9,16 \cdot 5,16,74,1,0,0$

$01070850,0,0,0,0,0,0,130,1 \cdot 0,16 \cdot 3,16,74,2,0,0$

$01080755,0,0,0,0,0,0,108,1,0,14,0,16,74,3,0,777$

$010901220,0,0,0,0,0,0,164,1,0,44,0,1 \%, 74,1,0,0$

$011001170,330,34,101,0,60,-24,163,1,0,42,7,17,74,2,0,0$

$011101102,0,0,0,0,0,0,139,1,0,40 \cdot 1), 17,74,3,0,777$

$0112031303,0,0,0,0,0,0,0323, .398,63 \cdot 0,13,71,1,0,0$

$0113031303,14500,16713,1: 275,0,4480,-635,9323, .398,63.0,18,74,2,0,0$

$0114014609,0,0,0,0,0,0,-6,0375,95,4,18,7 i, 3,0,777$

$011501650,1140,310,60,0,50,-37,363,1,0,24,5,19,74,1,0,0$

$011601231,0,0,0,0,0,0,312,1,0,16,5,19,74,2,0,0$

01170 i $320,0,0,0,0,0,0,40,1,0,20,0,19,74,3,0,777$

01160 ?66,250,16,22,0,25,-2,-33,1,0,16.0,20,74,1,0,0

$01190812,0,0,0,0,0,0,0,1 \cdot 0,14 \cdot 7,20,74,2,0,0$

$012000,0,0,0,0,0,0,0,1,0,0,20,74,3,0,555$

$012108160,4904,3254,1559,0,718,-130,849,1 \cdot 0,30,3,1,75,1,0,0$

$01220-7949,0,0,0,0,0,0,733,1 \cdot 0,27 \cdot 7,1,75,2,0,0$

$012306850,0,0,0,0,0,0,465,1,0,24,0,1,75,3,0,777$

01240

01250

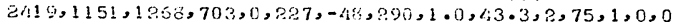

01260

$1426,0,0,0,0,0,0,336,1,0,3 \%, 7,0,75,2,0,0$

012.70

$1510,0,0,0,0,1,0,425,1 \cdot 0,27,0,2,75,3,0,777$

01230

$780,461,319,162,0,43,7,102,1,0,14,6,3,75,1,0,0$

01290

$548,0,0,11,0,0,0,70,1 \cdot 0,10,1,3,75, \varepsilon, 0,1)$

$01306,15,0,0,0,0,0,0,17,1 \cdot 0,7 \cdot 7,3,75,3,0,777$

01310

2000, $1260,740,330,0,111,-12,237,1,0,3,3,4,75,1,0,0$

01320

$400,0,0,0,0,0,0,76,1,0,0,9,4,75,2, j, 0$

01330

01340

$0,0,0,0,0,3,0,0,1,0,0,4,75,3,0,777$

01350

$7334,5984,1395,410,9,525,-123,339,1,0,413,6,5,75,1,0,0$

01360

$6350,0,0,0,0,0,0,155,1,0,35,5,75,2,0,1$ :

01370

$4880,0,0,0,0,0,0,-6,1,0,27,5,75,3,0.777$

01380

$9391,6653, ? 735,215,0,484,-143,1396,1,0,48 \cdot 7,6,75,1,0,0$

$6078,0,0,0,0,0,0,1471,1,0,1 ! 0,6,75,2,0,0$

01390

$7340,0,0,0,0,0,0,1250,1 \cdot 0,35 \cdot 0,6,75,3,0,777$

014150

$1586,1130,453,145,0,94,-24,195,1 \cdot 0,17,7,7,75,1,0,0$

01410

$776,0,0,0,0,0,0,6,1,0,11 \cdot 5,7,75,2,0,0$

$01421)$

$960,0,0,0,0,0,0,95,1 \cdot 0,10 \cdot 8,7,75,3,0,777$

$014: 319$

$2971,2016,255,155,0,143,-62,595,1 \cdot 0,85 \cdot 8,8,75,1,0,0$

01440

? $760,0,0,0,1), 0,0,500,1,0,79,9,8,75,2,0,0$

$01450 \div 959,1532,127,230,0,133,-42,25,1,0,14,8,9,75,1,0,0$

$014601305,0,0,0,0,0,0,-25,1,0,10,0,0,75,2,0,0$

$01470148,0,0,0,0,0,0,32,1 \cdot 0,1 \cdot 1,9,75,3,0,777$

$01480625,0,0,0,0,0,0,52,1,0,13,10,75,1,0,0$

$0111906668,0,0,0,0,0,0,54,1,0,10,5,10,75,2,0,0$

$01500501,380,131,40,0,24,-3,49,1,0,7,9,10,75,3,0,777$

Reproduced with permission of the copyright owner. Further reproduction prohibited without permission. 
$015105135,2611,2514,1443,0,355,-69,647,1 \cdot 0,24,4,11,75,1,0,0$

01520

$2913,0,0,0,0,0,0,506,1,0,13,8,11,75,2,0,0$

01530

2?00,0,0,0,0,0,0,200,1,0,10,5,11,75,3,0,777

01540

$3000,0,0,0,0,0,1,120,1,0,35,5,12,75,1,0,0$

01550

$3723,2754,969,174,0,275,-45,1171,1 \cdot 0,34,5,12,75,2,0,0$

01560

$2816,0,0,0,0,0,0,439,1,0,26.3,12,75,3,0,777$

01570

$2432,1471,061,659,0,250,-35,17,1,0,24 \cdot \%, 13,75,1,0,0$

01580

$2430,0,0,0,0,0,0,17,1,0,25,13,75,2,0,0$

01590

$2233,0,0,0,0,0,0,133,1,0,22,5,13,75,3,0 ; 777$

01600

$830,0,0,0,0,0,0,125,1 \cdot 0,17 \cdot 7,14,75,1,0,0$

01610

$590,0,0,0,0,0,0,225,1,0,12.5,11,75,2,0,0$

01620

$750, b 01,142,56,0,16,-9,151,1,0,15 \cdot 9,11,75,3,0,777$

01630

$359,0,0,0,0,0,0,535,1 \cdot 0,8.1,15,75,1,0,0$

01640

01650

$4345,315 /, 1151,067,0,165,-5 /, 705,1,0,10,5,15,75,2,0,0$

01660

$2550,0,0,0,0,0,0,1: 1,1,0,5,0,15,73,3,0,777$

01670

$1100,746,354,141,0,44,-51,164,1 \cdot 0,19.4,10,75,1,0,0$

01680

$930,0,0,0,0,0,0,140,1,0,16,3,16,75,2,0,0)$

01690

$735,0,0,0,0,0,0,105,1,0,13 \cdot 0,16,75,3,0,777$

01700

$1330,0,0,0,0,0,0,000,1,0,2,0,0,17,75,1,0,0$

01710

$1235,070,365,103,0,60,-25,177,1 \cdot 0,42 \cdot 7,17,75,2,0,0$

$017 \varepsilon 0$

$1126,0,0,0,1), 0,0,166,1,0,36,0,17,75,3,0,777$

01730

$33100,0,0,0,0,0,0,9750,035,3,55 \cdot 0,16,75,0,0$

01740

$32029,15849,16780,4350,0,2632,-6 t, 1,9132, .393$

01750

$16499,0,0,0,0,0,0,2058, .375,32,16,75,5,0,777$

01750

$1942,1566,676,55,0,50,-37,534,1,0,27 \cdot 4,19,75,1,0,0$

01770

$1366,0,0,0,0,0,0,250,1,0,190,19,75,2,0,0$

01780

$1270,0,0,0,0,0,0,4 i), 1 \cdot 0,18.0,19,75,3,0,777$

01750

$590,445,1<15,38,0,17,-2,38,1,0,28,6,20,75,1,0,0$

01800

$350,0,0,0,0,0,0,70,1,0,16,8,20,75,2,0,0$

01810

$0,0,0,0,0,0,0,0,1 \cdot 0,0,20,75,3,0,555$

01820

$5090,537 c, 371 \ddot{0}, 1655,0,736,-136,1191,1,0,33,5,1,76,1 ; 0,0$

01830

$8775,0,0,0,0,0,0,977,1,0,27 \cdot 7,1,76,2,0,0$

01320

$7200,0,0,0,0,0,0,500,1 \cdot 0,22,0,1,76,3,0,777$

01850

$2716,127:, 1434,759,0,267,-53,359,1 \cdot 0,1: 4 \cdot 1,2,75,1,0,0$

01560

$2020,0,0,0,0,0,0,361,1,0,32,0,2,76,2,0,0$

01370

$1450,0,0,0,0,0,0,430,1,0,0,3,5,0,76,3,0,777$

$018: 0$

$1414,6 n 0,414,195,0,52, \$, 146,1 \cdot 0,17 \cdot 5,3,76,1,0,0$

01890

$574,0,0,0,0,2,0,64,1 \cdot 0,9,5,3,76,2,0,0$

01909

$395,0,9,9,0,0,0,20,1.0,0,8,3,76,3,0,777$

01910

$2500,1559,941,445,0,135,-14,347,1,0,3,5,4,76,1,0,0$

01920

$400,0,0,0,0,0,0,7 \epsilon, 1,0,0,9,4,76,2,0,0$

01930

$0,0,0,0,1,0,0,0,1 \cdot 0,0,4,76,3,0,777$

$0194 i$

$91153,7250,1803,1550,0,589,-143,3,621,1,6,41,8,5,76,1,0,0$

ij 1950

$7600,10,0,0,0,0,0,35,1 \cdot 0,35,5,76,2,0,0$

01561

$5100,0,0,0,0,0,0,-70,1 \cdot 0,03,5,5,76,3,0,777$

$01 \% 70$

$0053,6710,2913,227,0,486,-141,2059,1 \cdot 0,50 \cdot 3,6,76,1,0,0$

01960

$7337,0,0,0,0,0,0,1604,1,0,40,6,76,8,6,0$

01021

$6500,0,0,0,0,0,0,1150,1,0,34,0,6,76,3,0,777$

02000

$1750,122,572,150,0,93,-25,254,1 \cdot 0,19 \cdot 7,7,76,1,0,0$

(3) to 10

स35,0,0,0,0,0,0,20, $1 \cdot 0,10,9,7,76,2,0,0$

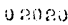

$\$ 70,0,0,0,0,0,0,0 j, 1 \cdot 0,9 \cdot 5,7,76,3,0,777$

$2000,1390,900,140,0,126,-60,634,1 \cdot 0,48,8,8,76,1,0,0$

Reproduced with permission of the copyright owner. Further reproduction prohibited without permission. 
$020302840,0,0,0,0,0,1), 575,1 \cdot 0,79,9,8,76,2,0,0$

$020102350,0,0,0,0,0,0,410,1,0,6,3,8,76,3,0,777$

$020502617,2033,581,231,0,170,-47,137,1.0,15.7,9,76,1,0,0$

$0 ? 0601327,0,0,0,0,0,0,-35,1 \cdot 0,10,0,9,76,2,0,0$

$0207098,0,1,0,0,0,0,1,1,0,0.7,9,76,3,0,777$

$02080985,0,0,0,0,0,1,52,1 \cdot 0,15,10,76,1,0,0$

$02090690,0,0,0,0,0,0,56,1 \cdot 0,10 \cdot 5,10,76,2,0,0$

UE100 417,310,107,30,0, $20,-6,49,1,0,6,4,10,76,3,0,777$

$021106905,3464,2541,1635,0,443,-83,780,1.0,26,2,11,76,1,0,0$

$021702986,0,0,0,0,0,0,593,1 \cdot 0,12 \cdot 6,11,75,2,0,0$

$021302130,0,0,0,0,0,0,220,1 \cdot 0,9 \cdot 0,11,76,3,0,777$

$021401.250,0,0,0,0,0,6,470,1 \cdot 0,36,5,1,, 76,1,0,0)$

$021503497,2605,892,147,0,222,-43,460,1.0,29 \cdot 1,12,76,2,0,0$

$021602612,0,0,0,0,0,0,316,1 \cdot 0,21 \cdot 6,1 \%, 76,3,0,777$

$021702906,1607,1101,690,0,275,-140,94,1.0,27.1,13,76,1,0,0$

$021[06030,0,0,0,0,0,0,73,1.0,25,13,76,2,0,0$

$021002146,0,0,0,0,0,0,87,1,9,20.0,13,76,3,0,777$

$02200585,0,0,0,0,0,0,145,1 \cdot 0,16.9,14,76,1,0,0$

0 0.210 $590,0,0,0,0,0,0,210,1 \cdot 0,11 \cdot 4,14,76,2,0,0$

$05 ? 50$

02530

$\{35,555,250,79,6,16,-10,175,1 \cdot 0,16 \cdot 0,14,76,3,0,777$

0.240

0 2.250

$3661,0,0,0,0,0,0,516,1.0,6.5,15,76,1,0,0$

0 दृero

$4546,3273,1273,265,0,165,-55,767,1 \cdot 0,10.6,15,76,2,0,0$

02.270

दil E, 0, 0, 0, 0,0,0, $406,1 \cdot 0,5.5,15,76,3,0,777$

1) $32 \leq 0$

i290, $673,417,130, i, 43,-23,201,1 \cdot 0,21.7,16,70,1,0,0$

0 segn

$580,0,0,0,0,0,0,150,1.0,16,4,16,75,0,0,0$

$715,0,0,0,0,0,0,10 \%, 1 \cdot 0,12 \cdot 0,16,76,3,0,777$

0 10 230

$1460,0,0,0,0,0,0,215,1 \cdot 9,40 \cdot 0,17,76,1,0,0$

02310

$1301,620,361,105,0,60,-25,1 \mathrm{c} 1,1 \cdot 0,14,8,17,76,2,0,0$

0.320

$1149,0,0,0,0,0,0,174,1 \cdot 0,37 \cdot 6,17,76,3,9,777$

02330

02310

$35500,0,0,0,0,0,0,10800, \ldots 10,57 \cdot 5,13,76,1,0,0$

$0: 2350$

$33449,16920,17209,4400,0,2794,-699,938, .410,53.0,18,76,2,0,0$

$023501579,0,0,0,0,0,0,262,1 \cdot 0,110,19,76,2,0,0$

$1675,0,0,0,0,0,0,4206,031=35,3,16,76,3,0,777$

$02: 3701210,0,0,0,0,0,0,40,1 \cdot 0,10 \cdot 0,19,76,3,0,777$

$0<300901,615,255,40,0,17,-2,227,1 \cdot 9,31.7,20,76,1,0,0$

$02340119,0,0,0,0,0,0,119,1 \cdot 0,1 \% \cdot 7,20,76,2,0,0$

$02400206,0,0,0,0,0,0,-33,1 \cdot 0,0.4,20,76,3,0,555$

$0 ? 410$

02420

$101 ; 05,5355,4210,1607,0,796,-131,1474,1.0,36.0,1,77,1,0,555$

02430 $9 / 4: 3,0,0,0,0,0,0,1152,1 \cdot 1,2,7 \cdot 7,1,77,2,0,555$

02410 $71100,0,0,0,0,0,0,4,30,1 \cdot 1,0,1,0,1,77,3,0,555$

02450 $3102,1440,1652,864,0,250,-56,490,1 \cdot 0,44 \cdot 0,2,77,1,0,555$

024,0 $2306,0,0,0,0,0,0,452,1 \cdot 0,32 \cdot 7,2,77,2,0,555$

02470
$02400,77,500$
$008,0,0,0,0,0,0,90,1.0,9.7,3,77,2,0,555$

$0.2490375,0,0,0,0,0,0,20,1 \cdot 0,6,0,3,77,3,0,555$

0 2500 3000,$1 ; 72,1128,5 \% 5,0,159,-17,427,1.0,3.8,4,77,1,0,555$

$02510400,0,0,0,0,0,0,76,1 \cdot 0,0 \cdot 9,4,77,2,0,555$.

$025200,0,0,0,0,0,0,0,1 \cdot 0,0,1,77,3,0,555$

$0253010660,4443,2243,460,0,634,-160,969,1.0,42,3,5,77,1,0,555$

$02540 \mathrm{i} 950,0,0,0,0,0,0,615,1 \cdot 0,35,5,77,2,0,555$

Reproduced with permission of the copyright owner. Further reproduction prohibited without permission. 


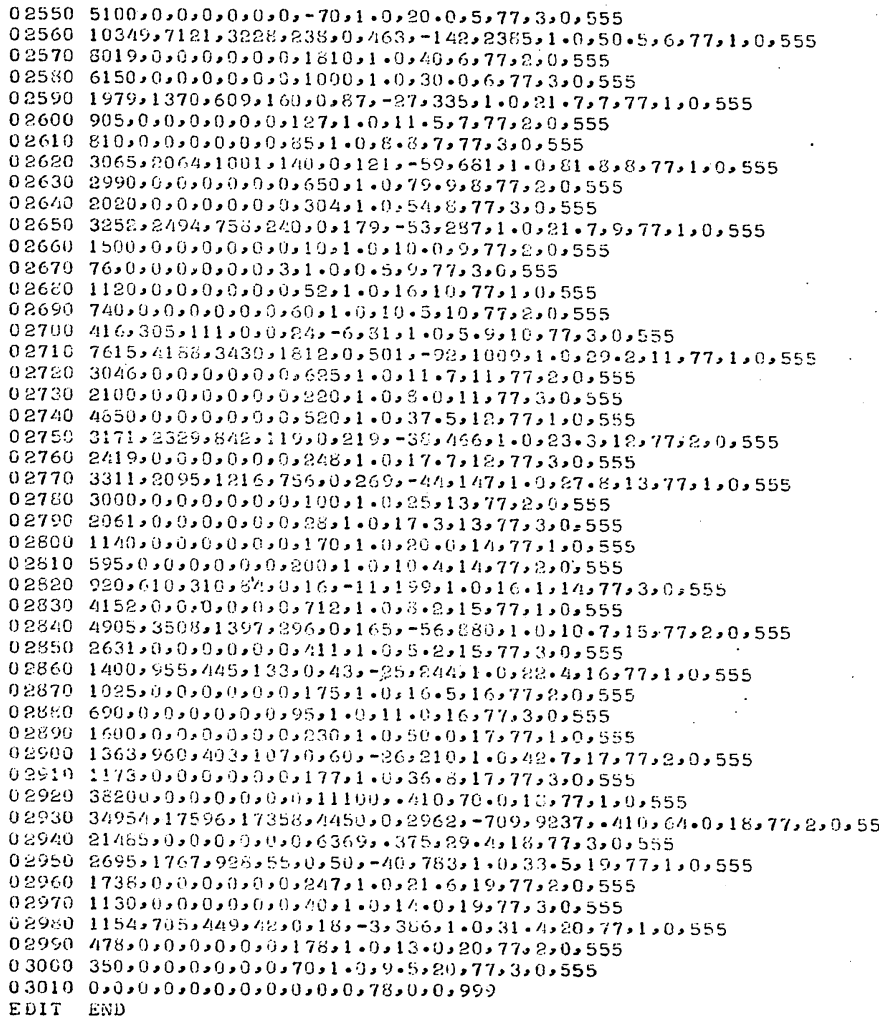

$025505100,0,0,0,0,0,0,-70,1 \cdot 0,20 \cdot 0,5,77,3,0,555$

$0256010349,7121,3228,235,0,463,-142,2365,1 \cdot 0,50.5,6,77,1,0,555$

$025708019,0,0,0,0,0,0,1610,1 \cdot 0,40,6,77,2,0,555$

$0253306150,0,0,0,0,0,0,1000,1 \cdot 0,30 \cdot 0,6,77,3,0,555$

$025901979,1370,609,160,0,87,-27,335,1 \cdot 0,21.7,7,77,1,0,555$

$02600905,0,0,0,0,0,0,127,1 \cdot 0,11 \cdot 5,7,77,2,0,555$

$810,0,0,0,0,0,0,05,1 \cdot 0,8 \cdot 3,7,77,3,0,555$

0263

$026 \% 10$

02650

02660

02670

प $26 \mathrm{C} 0$

02.690

02700

02710

02.720

02730

0275

) 2770

02780

02790

02800

02810

02520

() 2840

02450

02860

0) 2870

0 2.8:0

0 2890

(1) 250

0 ?2:1

02030

02940

$0: 350$

02060

02970

نे

02950

0.3010

EDIT END

Reproduced with permission of the copyright owner. Further reproduction prohibited without permission. 


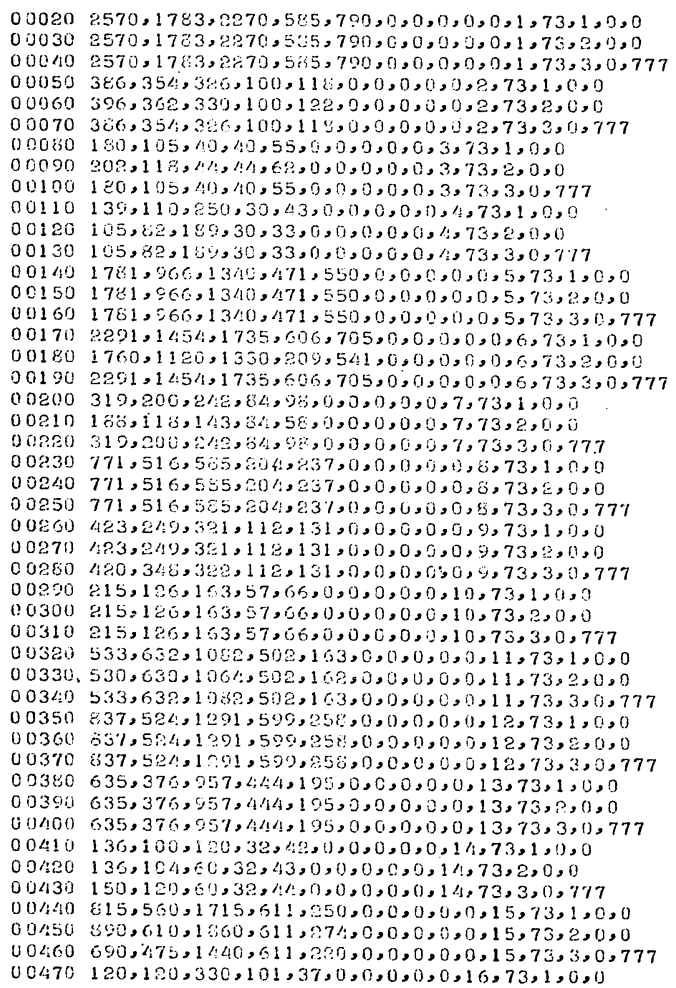

Reproduced with permission of the copyright owner. Further reproduction prohibited without permission. 
$00480115,115,320,101,35,0,0,0,0,0,16,73,0,0,0$

$00490120,120,330,101,37,0,0,0,0,0,16,73,3,0,777$

$005001.70,160,300,99,52,0,0,0,0,0,17,73,1,0,0$

$00510170,160,300,09,50,0,0,0,0,0,17,73,2,0,0$

$00520165,155,290,99,51,0,0,0,0,0,17,73,3,0,777$

$005306500,7400,17235,7036,1960,0,0,0,0,0,18,73,1,0,0$

$005<06336,7200,16033,7035,1960,0,0,0,0,0,16,73,2,0,0$

$005505800,4400,16300,7300,1790,0,0,0,0,0,18,73,3,0,777$

$00560864,300,250,167,265,0,0,0,0,0,10,73,1,0,0$

$00570517,1,9,153,45,160,0,0,0,0,0,19,73,2,0,0$

$00580364,300,950,167,565,0,0,0,0,0,19,73,3,0,777$

$005500,0,0,0,0,0,0,0=0,0,20,73, i, 0,0$.

$0000016,17,45,5,(1,0,0,0,1), 0,80,73,0,0,0$

$006100,0,0,0,0,0,0,0,0,0,20,73,3,0,555$

$006202165,1006,2574,745,665,0,0,0,19,0,1,74,1,0,0$

00030 e!40, 1500, $2615,67,066,0,0,0,0,0,1,74,9,0,0$

$006402610,1 \times 30, ? 345,745,005,0,0,0,0,0,1,71,3,0,777$

$00650421,475,350,112,130,0,0,0,0,0,2,74,1,0,0$

$00660420,364,553,107,120,0,0,0,0,0,0,74,2,0,0)$

$006703 \%, 340,335,113,113,0,0,0,0,0,2,74,3,0,777$

$0068020 \%, 155,54,37,52,0,0,0,0,0,3,74,1,0,0$

$00600805,1<1,49,45,64,0,0,0,0,0,3,74,8,0,0$

$00700180,100,40,40,55,0,0,0,0,0,3,74,3,0,777$

$00710315,850,250,45,95,0,0,0,0,0,4,74,1,0,0$

$00720105,82,189,4: 0,33,0,0,0,0,0,4,74,2,0,0$

$007300,0,0,0,0,0,0,0,0,0,4,7 i, 3,0,777$

007401 1396, $1154,1,51,643,5,4,0,0,0,0,0,0,5,74,1,1), 0$

$007501050,1080,1540,605,570,0,0,0,0,0,5,74,2,0,0$

$007601781,966,1340,605,550,0,0,0,0,0,5,71,3,0,777$

$007702212,1551,0273,740,685,0,0,0,0,0,6,74,1,0,0$

$007311830,1162,1350,406,565,0,0,0,0,0,6,74,2,0,0$

$00 \% 002150,1400,1750,7 / 0,650,0,0,9,0,0,6,7 / 9,3,0,777$

$00800342,236,352,116,106,0,0,0,0,0,7,74,1,0,0$

$00610801,156,154,26,62,0,0,0,0,0,7,74,2,0,0$

$00320300,130,935,110,96,0,0,0,0,0,7,74,3,0,777$

$0043007 \%, 593,58,230,603,0,0,0,0,0,0,74,1,0,0$

$0081: 0615,450,550,230,190,0,3,0,0,0,-7,74,0,0,0$

$00653005,450,1,55,530,1 \% 7,0,0,0,0,0,5,74,3,0,777$

00850 123,271,i,34,143,131,0,0,0,0,0,4,74,1,0,0

DoE? 360, $230,360,140,115,0,0,0,0,0,9,74,7,0,0$

$0050040,33,36,36,12,0,0,0,0,0,5,74,3,6,777$

$00690220+126,200,73,65,0,0,0,0,0,10,74,1,0,0$

$00900190,113,163,67,5 \%, 1,0,0,0,0,10,71:, 0,0,0$

0i) $91014 i, 95,156,50,45,0,0,0,0,1,10,7 i, 3,0,777$

00920 619,658, $556,744,85 \%, 0,0,0,0,0,11,74,1,0,0$

$00930563,675,1155,187,172,0,0,0,0,0,11,71, ?, 0,0$

$00040530,635,1082,700,153,0,0,0,0,0,11,74,3,0,777$

$00950970,605,1500,730,695,0,0,0,0,0,12,74,1,0,0$

$00960988,637,1516,7 \varepsilon 2,354,0,0,0,0,0,12,74,2,0,0$

$00979810,502,125,6 \times, 250,0,0,0,0,0,1: 74,3,0,777$

$0095070,409,1052,5 i) 4,218,0,0,0,0,0,13,74,1,0,0$

$00990706,420,1052,501,2,1 \%, 0,0,0,0,0,13,74,2,0,0$

Reproduced with permission of the copyright owner. Further reproduction prohibited without permission. 


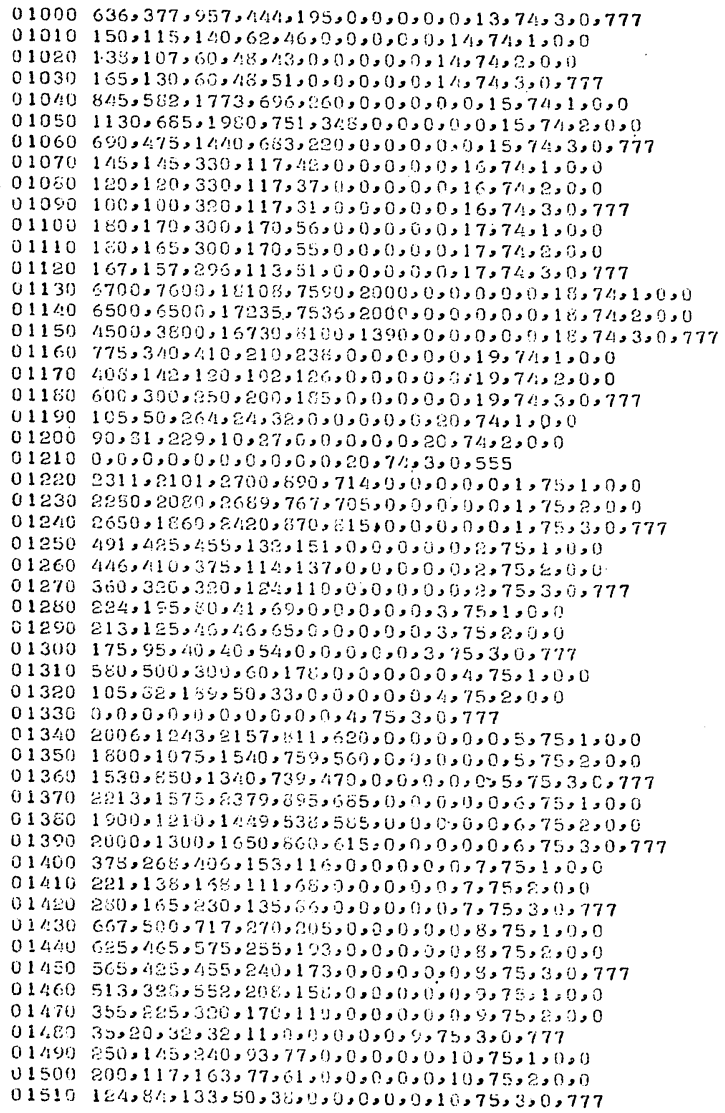

Reproduced with permission of the copyright owner. Further reproduction prohibited without permission. 
$01520117:, 1211,2310,1118,360,0,0,0,0,0,11,75,1,0,0$

$01530596,710,1210,244,164,0,0,0,0,0,11,75,2,0,0$

$01540520,625,1022,900,160,0,0,0,0,0,11,75,3,0,777$

$015501070,675,1800,680,330,0,0,0,0,0,12,75,1,0,0$

$015601021,660,1643,794,315,0,0,0,0,0,12,75,2,0,0$

$01570775,450,1177,727,235,0,0,0,0,0,1=, 75,3,0,777$

$01580755,467,1131,571,230,0,0,0,0,0,13,75,1,0,0$

$01590755,467,1075,571,232,0,0,0,0,0,13,75,2,0,0$

$01600621,370,033,152,192,0,0,0,0,0,13,75,3,0,777$

$01610150,130,160,97,55,0,0,0,0,0,14,75,1,0,0$

$01620141,109,60,60,43,0,0,0,0,0,14,75,2,0,0$

$01630180,145,60,60,55,0,0,0,0,0,1 / 1,75,3,0,777$

$01640910,625,1905,7: 54,280,0,0,0,0,0,15,75,1,0,0$

$016501345,620,256,96,3,414,0,0,0,0,0,15,75,2,0,0$

$01660600,145,1440,755,220,0,0,0,0,0,15,75,3,0,777$

$01670175,175,430,143,54,0,0,0,0,0,16,75,1,0,0$

$01680124,124,342,140,36,0,0,0,0,0,16,75,2,0,0$

$0169095,05,310,143,09,0,0,0,0,0,16,75,3,0,777$

$01700200,185,300,141,52,0,0,0,0,0,17,75,1,0,0$

$01710190,175,300,141,50,0,0,0,0,0,17,75,2,0,0$

$01720170,160,300,126,52,0,0,0,0,0,17,75,3,0,777$

$017307300,3200,15500,8500,220 \%, 0,0,0,0,0,15,75,1,0,0$

01740 6909,5581, $18103,6136,4123,0,0,0,0,0,16,75,2,0,0$

$017504600,4200,16900,6900,11420,0,0,0,0,0,18,75,3,0,777$

$01760910,399,560,265,280,0,6,0,0,0,19,75,1,0,0$

$0177056,0,195,165,103,175,0,0,0,0,0,19,75,2,0,0$

$01730530,600,250,29:, 165,0,0,0,0,0,10,75,3,0,777$

$01790133,121,334,51,41,0,0,0,0,0,20,75,1,0,0$

$01300106,06,274,33,33,0,0,0,0,0,20,75,2,0,0$

$018100,0,0,0,0,0,0,0,0,0,20,75,3,0,555$

018500 254:5, $337,2921,1035,755,0,0,0,0,0,1,76,1,0,0$

$018302440,2730,2671,861,755,0,0,0,0,0,1,75,2,0,0$

$012402750,1550,2490,1000,653,0,0,0,0,0,1,76,3,0,777$

$0165 i] 545,1176,552,155,169,0,0,0,0,0,2,75,1,0,0$

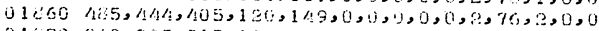

$01670340,305,315,136,105,0,0,0,0,0,9,76,3,0,777$

$0 ! 590200,053,95,47,0,0,0,0,0,0,0,3,76,1,0,0$

$01590217,120,50,47,5,6,0,0,0,0,0,3,76,0,0,0$

$01000170,00,40,1: 0,50,6,0,0,0,0,3,76,3,0,777$

$01910721,625,321,75,503,0,0,0,6,0,4,76,1,0,0$

$01920105,02,169,60,33,0,0,0,0,0,4,76,6,0,0$

$010300,0,0,0,0,0,0,0,0,0,1,76,3,0,777$

$010402443,1508,2472,1076,755,0,0,0,0,0,5,76,1,0,0$

$01550 \varepsilon 0410,1050,1740,913,6,30,0,0,0,0,0,5,76,2,0,0$

$019601640,835,1340,673,505,0,0,0,0,0,5,76,3,0,777$

$019702247,1010,2273,585,700,0,0,0,0,0,6,76,1,0,0$

$010802040,1205,1550,000,627,0,0,0,0,0,6,76,2,0,0$

$010901000,1200,1600,950,525,0,0,0,0,0,6,75,3,0,777$

$02000413,291,416,1: 1,127,0,0,0,0,0,7,76,1,0,0$

$02010241,151,141,130,74,0,0,0,0,0,7,7,0,0,0$

$02020060,150,255,100,80,0,0,0,0,0,7,76,3,0,777$

$02030662,19 \%, 659,200,200,0,0,0,0,0,8,76,1,0,0$

Reproduced with permission of the copyright owner. Further reproduction prohibited without permission. 
$02040640,485,570,280,198,0,0,0,0,0,8,76,2,0,0$

$02050505,383,425,250,155,0,0,0,0,0,8,76,3,0,777$

$02060681,437,684,299,210,0,0,0,0,0,0,70,1,0,0$

$02070355,225,320,200,110,0,0,0,0,0,9,75,2,0,0$

$0208024,13,21,21,7,1,0,0,0,0,9,76,3,0,777$

$02090295,172,280,117,01,0,0,0,0,0,10,76,1,0,0$

$02100205,121,163,67,63,0,0,0,0,0,10,76,2,0,0$

$02110105,71,106,14,32,0,0,0,0,0,10,76,3,0,777$

$021201322,1406,2477,1341,1: 14,0,0,0,0,0,11,76,1,0,0$

$02130631,750,1281,30 /, 194,0,0,0,0,0,11,76,2,0,0$

$0214050,620,1052,1062,155,0,0,0,0,0,11,76,3,1,777$

$021501200,760,2100,1060,370,0=0,0,0=0,12,76,1,0,0$

$021609 / 11,619,1563,733,250,0,0,0,0,0,12,76,2,0,0$

$02170735,460,1133,755,220,0,0,0,0,0,12,75,3,0,777$

$02180860,541,1575,071,065,0,0,0,0,0,13,76,1,0,0$

$02190820,495,1125,650,253,0,0,0,0,0,13,75,2,0,0$

$02200617,367,908,536,190,0,0,0,0,0,13,76,3,0,777$

$\mathrm{C} 2210=30,165,1 \mathrm{50}, 137,71,0,0,0,0,0,14,76,1,0,0$

$02220143,112,60,60,43,0,0,0,0,0,14,76,2,0,0$

$02230200,100,60,60,62,0,0,0,0,0,1 / 1,76,3,0,777$

1)2240 945,650,1595,\$79,290,0,0,0,0,0,15,76,1,0,0

$022501550,770,8650,1197,476,0,0,0,0,0,15,76,2,0,0$

02260 6.90, $475,14140,627,220,0,0,0,0,0,1:, 76,3,0,777$

$02270210,210,430,160,64,0,0,0,0,0,16,76,1,0,0$

$02280130,130,360,163,40,0,0,0,0,0,16,76,2,0,0$

$0229000,90,300,170,27,0,5,0,0,0,16,76,3,0,777$

$02300225,200,330,170,69,0,0,0,0,0,17,76,1,0,0$

$02310000,165,300,160,61,0,0,0,0,0,1 \%, 76,2,0,0$

$02320173,162,303,143,53,0,0,0,0,0,17,76,3,0,777$

$023307000,8300,20530,9200,2400,0,0,0,0,0,18,76,1,0,0$

$023407461,6073,10163,8736,3310,0,0,0,0,0,18,76,2,0,0$

$023504600,4600,17: 30,9700,1 / 20,0,0,0,0,0,16,76,3,0,777$

$023601069,400,660,330,326,0,0,0,0,0,19,76,1,0,0$

02370 720,250,210,116,2ez,0,0,0,0,0,19,76,2,0,0

$02380465,200,250,250,145,0,0,0,0,0,19,76,3,0,777$

$02300142,185,554,84,44,0,0,1,0,0,20,75,1,0,0$

$02400115,105,220,00,35,0,0,0,0,0,20,70,2,0,0$

U2410 $105,5,0,064,34,35,0,0,0,0,0,20,76,3,0,555$

U2420 $2601,2404,3103,1255,800,0,0,0,6,0,1,77,1,0,555$

$024302550,2350,3054,061,790,0,0,0,0,0,1,77,2,0,555$

$024402700,1900,2550,1 \leq 00,830,0,0,0,0,0,1,77,3,0,555$

$02450619,540,612,187,190,0,0,0,0,0,6,77,1,0,555$

$0.246054 \mathrm{~J}, 404,452,124,160,0,0,0,0,6,2,77,2,0,555$

$0247033 j, 695,300,1 / 6,100,0,9,0,0,0,2,7 \%, 3,0,555$

0 $2460360,325,110,51,111,1), 0,0,0,0,3,77,1,0,555$

02490 2द3.130,50,47,53,0,0,0,0,0,3,7, $, 2,0,555$

$02500165,05,<0,40,5 i, 0,0,0,0,0,3,77,3,0,555$

$02510849,750,355,90,25,0,0,0,0,0,0,4,77,1,0,555$

$02520106,62,160,70,33,0,0,0,0,0,4,77,2,0,555$

$005300,0,0,0,0,0,0,0,0,0,1,77,3,0,555$

i) 2540 2. $64,1775,2767,1315,805,0,0,0,0,0,5,77,1,0,555$

$02550240,1500,1940,1007,740,0,0,0,0,0,5,77,0,0,555$

Reproduced with permission of the copyright owner. Further reproduction prohibited without permission. 
$0256010410,805,1340,1007,505,0,0,0,0,0,5,77,3,0,555$

$025702421,1727,2312,110 ! 3,750,0,0,0,0,0,6,77,1,0,555$

$025302350,14190,1309,530,724,0,0,0,0,0,6,77,2,0,555$

$025901 \% 10,1100,15 b 0,1050,525,(i, 0,0,0,0,6,77,3,0,555$

$04000469,327,4: 48,2,1 /, 145,0,0,0,0,0,7,77,1,0,555$

$02610 \therefore 75,173,208,147,05,0,0,0,0,0,7,77,2,0,555$

$02620340,141,200,185,74,0,0,0,0,0,7,77,3,0,555$

$0 \leq 630700,510,608,31 \mathrm{~g}, 815, \mathrm{i}, 0,0,0,0,0,77,1,0,555$

$02640 \quad 675,505,565,305,005,0,0,0,0,0,5,77,2,0,555$

$02650455,343,406,25\}, 140,0,4,0,0,0,0,77,3,0,555$

02660 ¿57,536, $15,390,25,9,0,0,0,0,0,0,77,1,0,555$

$0067040,25,300,34,123,0,0,0,0,0,0,77,2,0,555$

$0.2650 \quad 20,11,17,17,6,0,0,1,0,0,9,77,3,0,555$

$02600335,200,329,1,5,101,0,0,0,0,1 i, 10,77,1,0,555$

$00700 \quad 290,130,153,27,5,0,0,0,0,0,0,10,77,0,0,555$

$02710104,69,100,47,4,0,0,0,0,0,10,7 \%, ?, 0,555$

$027201727,1666,2690,1,616,530,0,0,0,0,0,11,77,1,0,555$

02730 600,763,1345,368,63,0,0,0,0,0,11,77,2,0,555

$05740490,615,1060,100,150,0,0,0,0,0,11,77,3,0,555$

$027501370,555,2400,1070,460,0,0,0,0,0,12,77,1,0,555$

$09760 \quad\{13,561,1454,746,350,0,0,0,0,0,16,77, \%, 0,555$

$02770703,440,1071,312,216,0,0,0,0,0,12,77,3,0,555$

027,50 , $7,611,108,946,300,0,0,0,0,0,13,77,1,0,555$

$02790900,555,1600,720,278,0,0,0,6,0,13,77,2,0,555$

$02000605,361,020,584,187,0,0,0,0,0,13,77,2,0,555$

$02010270,210,200,172,33,0,0,0,0,0,14,77,1,0,555$

$02320115,115,69,50,43,0,0,0,0,0,1 /, 77,2,0,555$

$02351,00,175,60,50,0,0,0,0,0,0,14,77,3,0,555$

$04840585,675,2070,960,315,0,0,0,0,0,15,77,1,0,555$

$026501640,840,3020,1476,503,5,0,0,7,0,15,77,2,0,555$

$0286,690,175,1 / 240,559,200,0,0,0,0,0,15,77,3,0,555$

$0287 i j$.50, $550,430,195,0,0,0,0,0,0,16,77,1,0,555$

$02630131,130,390,181,40,0,0,0,0,0,16,77,2,0,555$

$0284085,65,250,200,75,0,0,0, i), 0,16,77,3,0,555$

$02000,415,215,350,200,7 j, 19,0,0,0,0,17,77,1,0,555$

0\%910 $210,150,300,143,65,0,0,0,0,0,17,77,6,0,555$

$02020175,151,306,155,52,0,0,0,0,0,17,77,3,0,555$

02930 8.150,0350,?1500,10000,270,0,0,0,0,0,1:,77,1,0,555

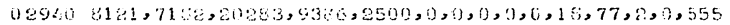

$025344600,5100,17500,16500,1 / 20,0,0,0,6,0,15,77,3,0,555$

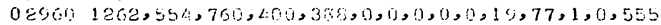

$05970375,303,252,126,270,0,0,0,0,0,14,77,6,0,555$

$02960400,265,350,350,125,0,0,0,0,0,14,77,3,0,555$

$02990164,237,54:, 114,51,0,0,0,0,0,0,77,1,0,555$

$03060 \mathrm{0} 124,113,313,35,3,0,0,0,0,0,61,77,2,0,555$

$03010115,90,27 i, 51,35,0,0,0,0,0,20,77,3,0,555$

$030200,0,0,0,0,0,0,0,0,0,0,76,0,0,409$

Reproduced with permission of the copyright owner. Further reproduction prohibited without permission. 
TABLE XXV

CORPORATE PROFIT AND LOSS DATA

$\begin{array}{cccccc}\text { Line \# } & \text { Year 1 } & \text { Year 2 } & \text { Year 3 } & \text { Year 4 } & \text { Year 5 } \\ 1 & 0 & 0 & 0 & 0 & 0 \\ 2 & 1500 & 1750 & 1000 & 1300 & 1600 \\ 3 & 0 & 0 & 0 & 0 & 0 \\ 4 & 0 & 0 & 0 & 0 & 0 \\ 5 & 0 & 0 & 0 & 0 & 0 \\ 6 & 0.5 & 0.5 & 0.5 & 0.5 & 0.5 \\ 7 & 0 & 0 & 0 & 0 & 0 \\ 8 & 0 & 0 & 0 & 0 & 0 \\ 9 & 0 & 0 & 0 & 0 & 0 \\ 10 & 1 & 2 & 3 & 4 & 5\end{array}$

Reproduced with permission of the copyright owner. Further reproduction prohibited without permission. 
TABLE XXVI

CORPORATE SPECIFICATIONS DATA

Line \# Description

1 Discount factor $s$

(Management established value

equal to the pre-tax cost of

capital to the firm)

$\underline{0.15}$

2 Dividends as a fraction of net

profit after tax

$\underline{0.20}$

3

Maximum debt to equity ratio

0.60

4 Minimum current ratio (must be greater than 1)

1.50

5

Minimum cash as a fraction of other

beginning current assets

$\underline{0.10}$

6

Effective interest rate pre-tax on long and short term debt

7

Return on corporate investments pre-tax

$\underline{0.08}$

8

Maximum acceptable dilution from equity sales (as a fraction of the current year's earnings/share)

Number of times old earnings/share for which new equity can be raised

Blank 
TABLE XXVII

\section{ARBITRARILY ASSIGNED THREE-POINT PROBABILITY \\ DISTRIBUTIONS USED WITH THE \\ PROBABILISTIC INVESTIGATIONS}

\begin{tabular}{|c|c|c|c|c|c|}
\hline Number & $\begin{array}{l}\text { Lower }{ }^{1} \\
\text { Point }\end{array}$ & $\begin{array}{c}\text { Probabllity } \\
\text { of Lower Polnt }\end{array}$ & $\begin{array}{c}\text { Probability } \\
\text { of Given Point }\end{array}$ & $\begin{array}{l}\text { Upper } \\
\text { Point }\end{array}$ & $\begin{array}{c}\text { Probabillty } \\
\text { of Upper Polnt }\end{array}$ \\
\hline 1 & .8 & .3 & .6 & 1.1 & .1 \\
\hline 2 & .7 & .3 & .6 & 1.2 & .1 \\
\hline 3 & .6 & .2 & .6 & 1.3 & .2 \\
\hline 4 & .8 & .4 & .4 & 1.2 & .2 \\
\hline 5 & .8 & .4 & .4 & 1.1 & .2 \\
\hline 6 & .8 & .4 & .5 & 1.2 & .1 \\
\hline 7 & .7 & .2 & .7 & 1.1 & .1 \\
\hline R & $:^{7}$ & .4 & .4 & 1.1 & .2 \\
\hline 9 & .7 & .5 & .4 & 1.1 & .1 \\
\hline 10 & .7 & .1 & .8 & 1.1 & .1 \\
\hline 11 & .7 & .1 & .8 & 1.2 & .1 \\
\hline 12 & .6 & .3 & .5 & 1.2 & .2 \\
\hline 13 & .6 & .3 & .6 & 1.3 & .1 \\
\hline 14 & .6 & .1 & .8 & 1.3 & .1 \\
\hline 15 & .6 & .2 & .7 & 1.5 & .1 \\
\hline 16 & .8 & .3 & .5 & 1.1 & .2 \\
\hline 17 & .8 & .2 & .5 & 1.1 & .3 \\
\hline 18 & .8 & .2 & .6 & 1.1 & .2 \\
\hline 19 & .7 & .3 & .5 & 1.1 & .2 \\
\hline 20 & .6 & .4 & .5 & 1.2 & .1 \\
\hline
\end{tabular}

Average of the means of all distributions $=\mathbf{0 . 9 4 3 5}$

Average of the variances of all distributions $=0.025$

${ }^{1}$ As a fraction of the given point which is the value used in the deterministic input.

Reproduced with permission of the copyright owner. Further reproduction prohibited without permission. 